Florida International University

FIU Digital Commons

$11-4-2013$

\title{
Novel Analytical Methodologies for the Monitoring of Traditional and Non-traditional Pollutants in different Environmental Compartments of South Florida
}

Cesar E. Ramirez

Florida International University, crami023@fiu.edu

DOI: $10.25148 /$ etd.FI13120203

Follow this and additional works at: https://digitalcommons.fiu.edu/etd

\section{Recommended Citation}

Ramirez, Cesar E., "Novel Analytical Methodologies for the Monitoring of Traditional and Non-traditional Pollutants in different Environmental Compartments of South Florida" (2013). FIU Electronic Theses and Dissertations. 962.

https://digitalcommons.fiu.edu/etd/962 


\title{
FLORIDA INTERNATIONAL UNIVERSITY
}

Miami, Florida

\section{NOVEL ANALYTICAL METHODOLOGIES FOR THE MONITORING OF TRADITIONAL AND NON-TRADITIONAL POLLUTANTS IN DIFFERENT ENVIRONMENTAL \\ COMPARTMENTS OF SOUTH FLORIDA}

\author{
A dissertation submitted in partial fulfillment of the \\ requirements for the degree of \\ DOCTOR OF PHILOSOPHY \\ in \\ CHEMISTRY \\ by \\ Cesar E. Ramirez
}


To: Dean Kenneth G. Furton

College of Arts and Sciences

This dissertation, written by Cesar E. Ramirez, and entitled Novel Analytical Methodologies for the Monitoring of Traditional and Non-traditional Pollutants in different Environmental Compartments of South Florida, having been approved in respect to style and intellectual content, is referred to you for judgment.

We have read this dissertation and recommend that it be approved.

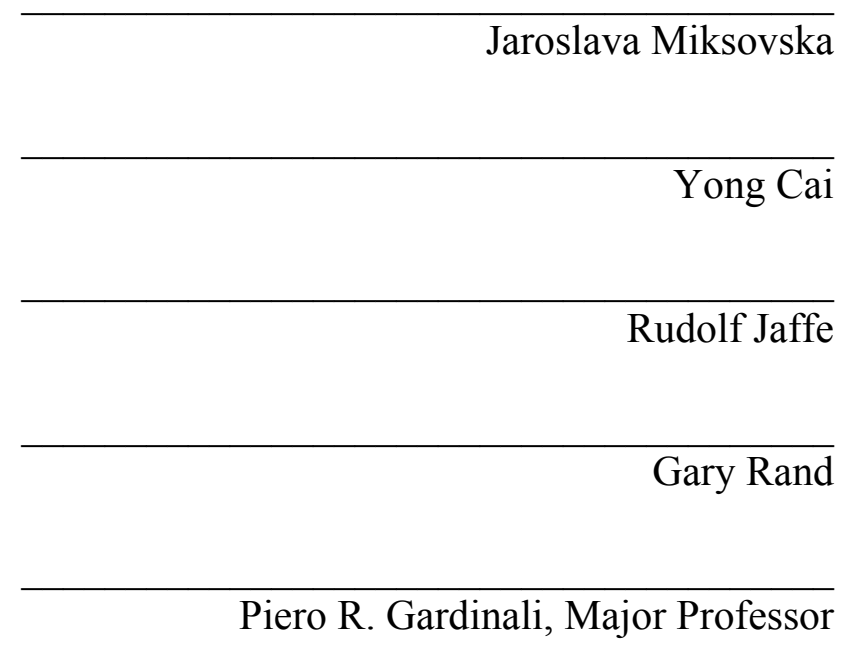

Date of Defense: November 4, 2013

The dissertation of Cesar E. Ramirez is approved.

Dean Kenneth G. Furton

College of Arts and Sciences

Dean Lakshmi N. Reddi

University Graduate School

Florida International University, 2013 
(C) Copyright 2013 by Cesar E. Ramirez

All rights reserved. 


\section{DEDICATION}

I dedicate this work to the women of my life. My grandmother Clarisa, my mother Zoilamar, my wife Luisana and my daughter Diana Carolina are my infinite sources of love and inspiration. 


\section{ACKNOWLEDGMENTS}

I thank God Almighty and Mother Mary for all their blessings, and for allowing me to complete this major life goal. I also wish to express my sincere gratitude to my Major Professor, Dr. Piero R. Gardinali, who gave me the opportunity to join his group and provided me with so much helpful criticism, which without any doubt made me a better scientist and a better person. He also had plenty of patience while I learned from my mistakes. The experience I gained under his guidance is priceless.

I would also like to thank my committee members Dr. Jaroslava Miksovska, Dr. Yong Cai, Dr. Rudolf Jaffe and Dr. Gary Rand, for taking the time to provide me with helpful comments and ideas to improve my research.

Thanks to Dr. Luis Arroyo-Mora for all his training during the early years of my graduate studies. Many thanks to Dr. Tatiana Trejos from the International Forensic Research Institute (FIU-IFRI), Dr. Luisa Rojas de Astudillo from Universidad de Oriente, Venezuela, and Dr. Douglas Seba from the Academy of Marine Sciences at Fort Lauderdale, for their contributions to the atmospheric particulate matter research.

I would like also to give thanks to those in my family that supported me financially, logistically and/or emotionally during this period of my life: my grandmother Clarisa, my parents Zoilamar, Jesus, Cesar and Evelyn, my in-laws Luisa and Santana,

my sisters Vanessa and Maria Alejandra, my brothers Eduardo, Ernesto, Jesus and Marco, my sister-in law Maria Rosario, my uncles Ramon and Edurne who always have been there for me, my aunt Zahira for all her love, my dear uncles Angel and Olga Marcano, who kindly sheltered me in Caracas while I was preparing to travel to the U.S., my cousins in the U.S. Arturo Ramirez and Maria Julia Fermin, and all other that in any 
way helped me to reach this goal. Also, thank you Abuelo J.R. (1925-2013) for all the love you gave me. I hope we meet again in heaven, you are there for sure.

To my special Venezuelan friends Maria Eugenia, Aquiles, Ignacio, Wily, Erich, and others that gave me full emotional support during this period. They are living proof that distance and/or time do not destroy true friendships. Thanks guys.

I am very thankful to my friends and coworkers from FIU-EARL: Ingrid, Adolfo, Luis, Natalia, Nubia, Eli, Gabriela, Jian, Sudha, Venkat, Mark, Alina, Patricia, Margarita, Kathia, Chengtao, Elsa, Allan and all others. The cafecito and party times were as essential to this work as the mass spectrometers.

I thank the Department of Chemistry and Biochemistry at FIU for giving me the honor of joining their graduate program, and for their financial support. I also acknowledge the financial support provided by the Southeast Environmental Research Center at FIU (FIU-SERC) through the Cristina Menendez Fellowship.

Also, special thanks to my wife Luisana. I am certain that this endeavor would not have come to a successful end without her infinite support, motivation and sacrifice. Last but not least, thanks to my little daughter Diana Carolina for her understanding that her father was a graduate student and therefore was always "doing homework". I hope I can make it up to you with many years of joy. 
ABSTRACT OF THE DISSERTATION

\section{NOVEL ANALYTICAL METHODOLOGIES FOR THE MONITORING OF \\ TRADITIONAL AND NON-TRADITIONAL POLLUTANTS IN DIFFERENT \\ ENVIRONMENTAL COMPARTMENTS OF SOUTH FLORIDA}

by

Cesar E. Ramirez

Florida International University, 2013

Miami, Florida

Professor Piero R. Gardinali, Major Professor

Routine monitoring of environmental pollution demands simplicity and speed without sacrificing sensitivity or accuracy. The development and application of sensitive, fast and easy to implement analytical methodologies for detecting emerging and traditional water and airborne contaminants in South Florida is presented. A novel method was developed for quantification of the herbicide glyphosate based on lyophilization followed by derivatization and simultaneous detection by fluorescence and mass spectrometry. Samples were analyzed from water canals that will hydrate estuarine wetlands of Biscayne National Park, detecting inputs of glyphosate from both aquatic usage and agricultural runoff from farms. A second study describes a set of fast, automated LC-MS/MS protocols for the analysis of dioctyl sulfosuccinate (DOSS) and 2butoxyethanol, two components of Corexit ${ }^{\circledR}$. Around 1.8 million gallons of those dispersant formulations were used in the response efforts for the Gulf of Mexico oil spill in 2010. The methods presented here allow the trace-level detection of these compounds in seawater, crude oil and commercial dispersants formulations. 
In addition, two methodologies were developed for the analysis of well-known pollutants, namely Polycyclic Aromatic Hydrocarbons (PAHs) and airborne particulate matter (APM). PAHs are ubiquitous environmental contaminants and some are potent carcinogens. Traditional GC-MS analysis is labor-intensive and consumes large amounts of toxic solvents. My study provides an alternative automated SPE-LC-APPI-MS/MS analysis with minimal sample preparation and a lower solvent consumption. The system can inject, extract, clean, separate and detect $28 \mathrm{PAHs}$ and 15 families of alkylated PAHs in 28 minutes. The methodology was tested with environmental samples from Miami. Airborne Particulate Matter is a mixture of particles of chemical and biological origin. Assessment of its elemental composition is critical for the protection of sensitive ecosystems and public health. The APM collected from Port Everglades between 2005 and 2010 was analyzed by ICP-MS after acid digestion of filters. The most abundant elements were $\mathrm{Fe}$ and $\mathrm{Al}$, followed by $\mathrm{Cu}, \mathrm{V}$ and $\mathrm{Zn}$. Enrichment factors show that hazardous elements $(\mathrm{Cd}, \mathrm{Pb}, \mathrm{As}, \mathrm{Co}, \mathrm{Ni}$ and $\mathrm{Cr})$ are introduced by anthropogenic activities. Data suggest that the major sources of APM were an electricity plant, road dust, industrial emissions and marine vessels. 


\section{TABLE OF CONTENTS}

CHAPTER

PAGE

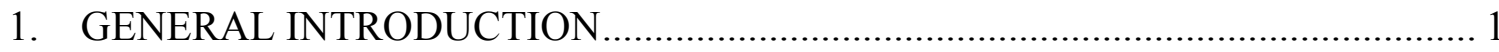

2. OCCURRENCE OF THE HERBICIDE GLYPHOSATE AND ITS MAIN METABOLITE IN CANALS WITH INFLUENCE ON PROTECTED AREAS OF

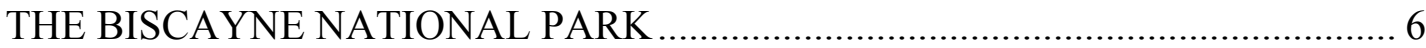

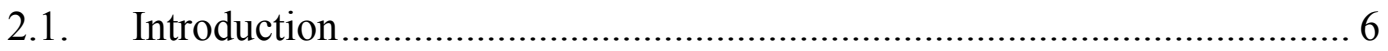

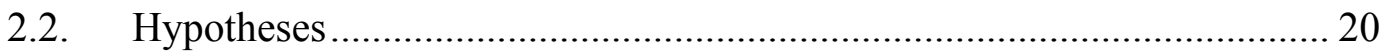

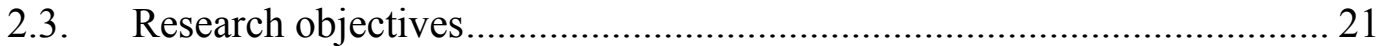

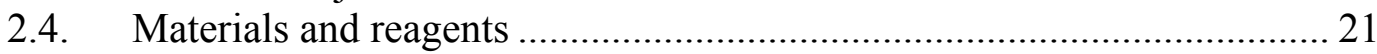

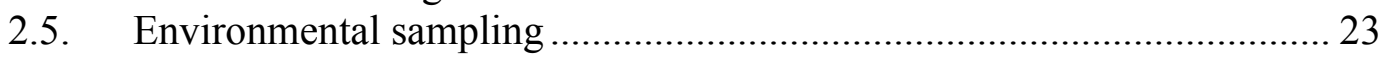

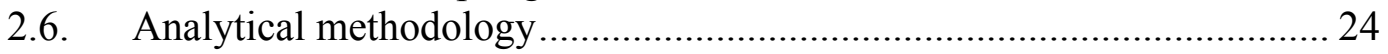

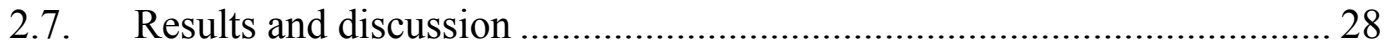

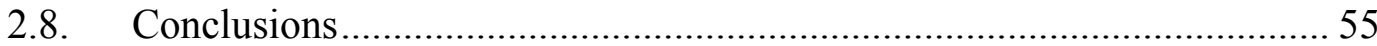

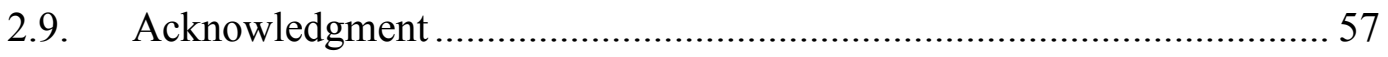

3. ANALYTICAL METHODS FOR THE ANALYSIS OF COREXIT $^{\circledR}$ DISPERSANTS IN DIFFERENT STAGES OF AN OIL SPILL MONITORING

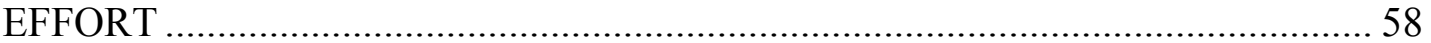

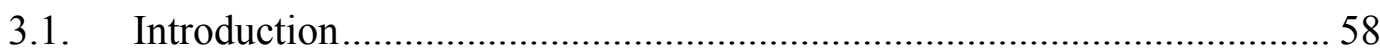

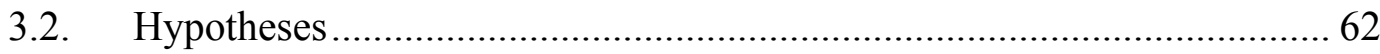

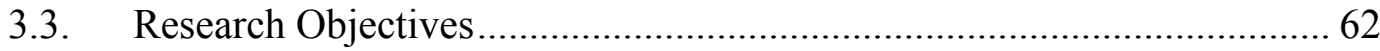

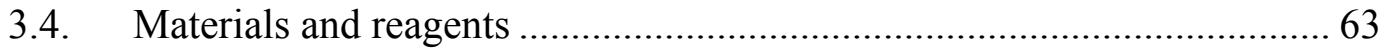

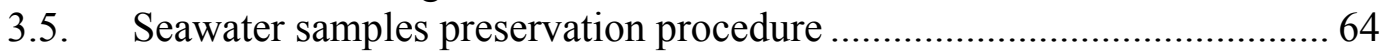

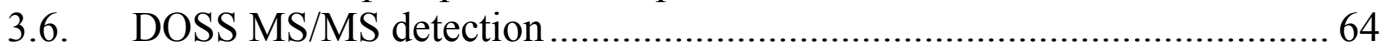

3.7. Trace level determination of DOSS seawater by online SPE-LC-MS/MS65

3.8. Fast determination of DOSS in seawater by direct injection LC-MS/MS 68

3.9. Simultaneous analysis of DOSS and 2-butoxyethanol in dispersant formulations and crude oil .................................................................... 70

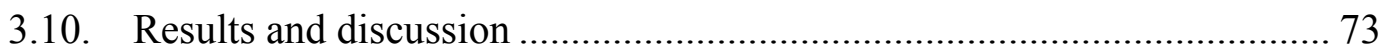

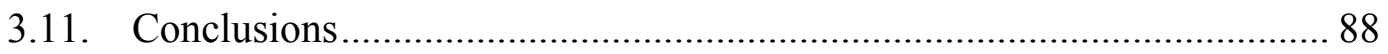

4. FULLY AUTOMATED TRACE LEVEL DETERMINATION OF POLYCYCLIC AROMATIC HYDROCARBONS IN ENVIRONMENTAL WATERS BY ONLINE

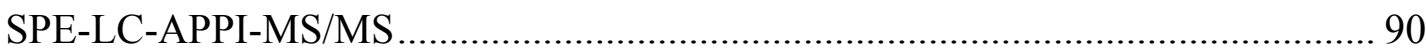

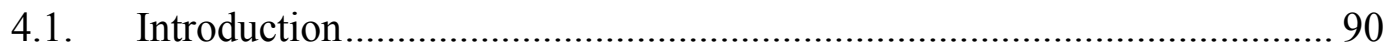

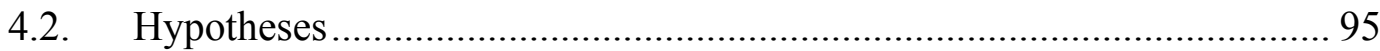

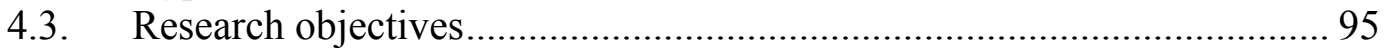

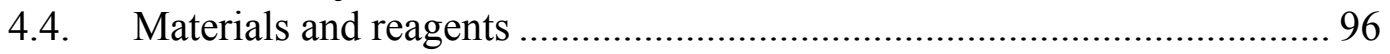

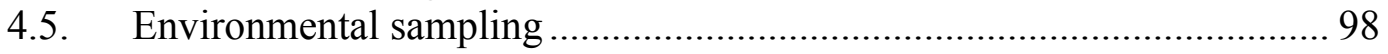

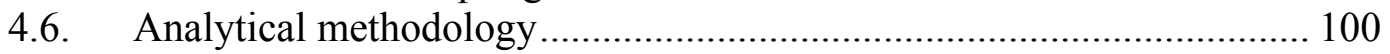

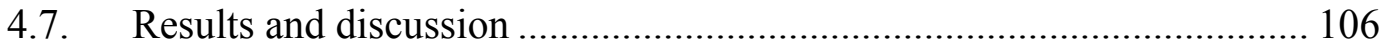


4.8. Optimization of chromatographic separation...................................... 110

4.9. Optimization of the online SPE procedure ....................................... 113

4.10. Method validation ........................................................................... 116

4.11. Environmental applications: Analysis of PAHs in environmentally relevant samples in the Miami-Dade County..................................... 120

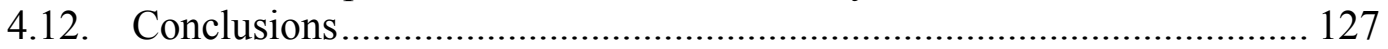

5. IDENTIFICATION OF SOURCES OF AIRBORNE PARTICULATE MATTER COLLECTED AT A COASTAL SITE OF THE MIAMI METROPOLITAN AREA

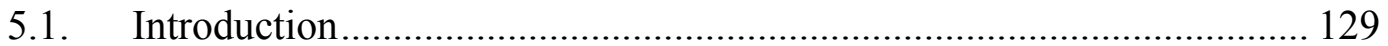

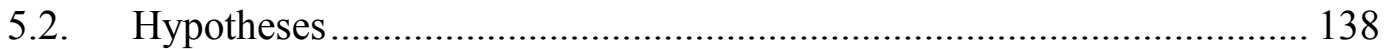

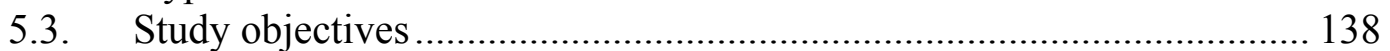

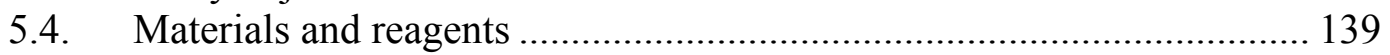

5.5. Sample collection........................................................................... 141

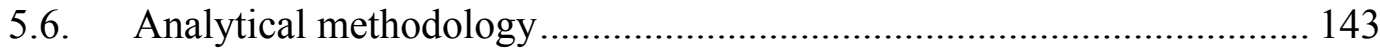

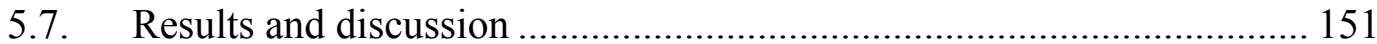

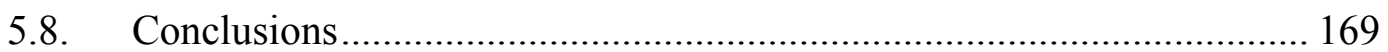

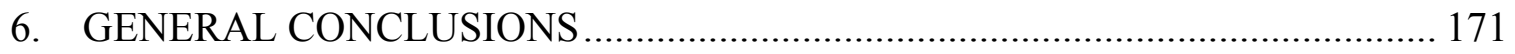

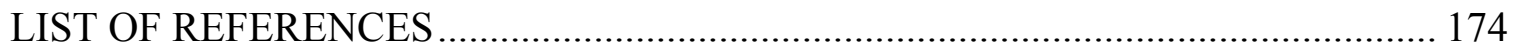

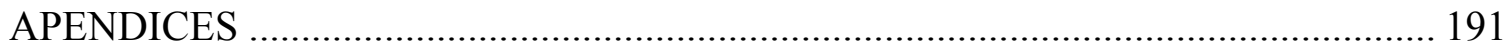

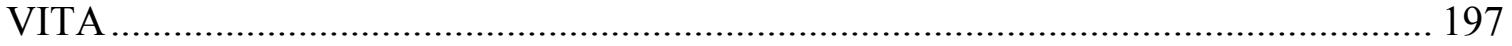




\section{LIST OF TABLES}

TABLE

PAGE

Table 2.1 Summary of liquid chromatography methodologies available in the literature for the analysis of glyphosate and AMPA in waters 16

Table 2.2 Washing program used to avoid carryover for the determination of glyphosate and AMPA in canal water by LC-FLD+MS/MS. 26

Table 2.3 Mobile phase delivery program for the determination of glyphosate and AMPA in canal water by LC-FLD+MS/MS. The rotary valve of the LCQ Mass Spectrometer was used to direct the column eluent. 26

Table 2.4 Product ion scan MS/MS detection parameters for detection of glyphosateFMOC and AMPA-FMOC using the ion trap mass spectrometer after electrospray ionization. 27

Table 2.5 Measured concentrations and quality controls from samples collected during a glyphosate spraying event at the vicinity of the BNP in February 2008. (TOP) samples collected on February $5^{\text {th }}, 2008$. (BOTTOM) Samples collected on February $06^{\text {th }}, 2008$. Samples were collected between $2 \mathrm{pm}$ and $4 \mathrm{pm}$ in both dates. $^{\text {a }}$

Table 2.6 Hydrological data from gate structures for the February, 2008 sample collection. Data obtained from DBHYDRO (SFWMD, 2013)..... 43

Table 2.7 Hydrological data from gate structures for the October 22, 2009 sample collection. Data obtained from DBHYDRO (SFWMD, 2013)... 48

Table 2.8 Measured conductivities, measurements and QCs of glyphosate and AMPA in samples collected on October 22, 2009 from all canals in the area of interest. ${ }^{\text {a }}$

Table 2.9 Hydrological data from gate structures for the April 28, 2010 sample collection. Data obtained from DBHYDRO (SFWMD, 2013). 51

Table 2.10 Measured conductivities and concentrations of glyphosate and AMPA in samples collected on April 27, 2010 from canals C-1, Goulds, C-103 and North Canal. ${ }^{\mathrm{a}}$.....

Table 3.1 Mobile phase delivery programs for pumps during the online SPE determination of DOSS in seawater. ${ }^{\mathrm{a}}$ 66

Table 3.2 Washing program used to avoid carryover during the online SPE determination of DOSS in seawater. ${ }^{\text {a }}$ 66 
Table 3.3 Mobile phase delivery program for the fast determination of DOSS in seawater by LC-MS/MS. Column eluent is diverted to waste during the first $3 \mathrm{~min}$ and again from $5.5 \mathrm{~min}$ to the end of the analytical run.

Table 3.4 Washing program used to avoid carryover for the fast determination of DOSS in seawater by direct injection LC-MS/MS. ${ }^{\text {a }}$

Table 3.5 Mobile phase delivery program for the simultaneous analysis of DOSS and 2butoxyethanol in dispersant formulations and crude oil by LC-MS/MS. ${ }^{\text {a }} . . . . .72$

Table 3.6 Results for the carryover evaluation experiment using the direct injection LCMS/MS method for DOSS in seawater. 83

Table 4.1 Polycyclic aromatic hydrocarbons listed as priority pollutants by the United States Environmental Protection Agency. 91

Table 4.2 Solvent delivery programs for all pumps used in the online SPE-LC-MS/MS analysis of PAHs. ${ }^{\text {a }}$...... 103

Table 4.3 Summary of SRM scan events for PAHs tested with this method (Bold: 16 USEPA priority PAHs; italic: isotopic labeled PAHs used as internal standards).

Table 4.4 Comparison of the first ionization energies of relevant chemical species present in the APPI source and selected PAHs with the energy of the VUV radiation produced by the krypton APPI lamp. ${ }^{\text {a }}$ 107

Table 4.5 Pooled measurements of serially diluted Standard Reference Materials 2260a and 1491a in seawater. Total dilution factors used were 1/55000 for SRM 2260a and 1/18333 for 1491a. Three measurements were performed on different analysis days 117

Table 4.6 Comparisons of MDL values obtained by SPE-LC-MS/MS and by LLE+GCMS. Fortification level were $50 \mathrm{ng} / \mathrm{L}$ in both experiments. (Concentrations are in $\mathrm{ng} / \mathrm{L})$...... 119

Table 4.7 Results from the determination of PAHs in seawater from Northern Biscayne Bay by Online SPE-LC-MS/MS ${ }^{\text {a }}$ (in bold, USEPA priority PAHs). 121

Table 4.8 Results from analysis of PAHs in rainwater and rainwater runoff from parking lots at the FIU Biscayne Bay Campus and a nearby apartment complex. (in bold, USEPA priority PAHs). 124

Table 4.9 Results from analysis of PAHs in reclaimed water obtained from the MiamiDade North District Wastewater Treatment plant. ${ }^{\text {a }}$ (in bold, USEPA priority PAHs) 126 
Table 5.1 Combined estimates of APM emissions $\left(\mathrm{PM}_{10}\right)$ from Miami-Dade, Broward and Palm Beach counties, according to the 2008 National Emissions Inventory (USEPA, 2013a). 132

Table 5.2 Elements, interferences, correction equations, calibration ranges and instrument detection limits for the determination of elemental composition of APM by ICP-MS. 147

Table 5.3 Filter data and determination of APM load (see section 5.6.1). 152

Table 5.4 Analyte concentrations measured in the Versapor filter media and estimated method detection limits. (All concentrations in $\mathrm{mg} / \mathrm{Kg}$ ). 154

Table 5.5 Summary statistics on the measured elemental concentrations ${ }^{\mathrm{a}}$ of APM collected at Port Everglades, FL, between 2005 and $2010(n=42)$. 158

Table 5.6 Comparison of factor loadings obtained using PCA and source contributions (\%) obtained using UNMIX. Similarities between both models are highlighted using colors. (Loadings $>0.5$ are bolded and $<0.2$ are faded. For UNMIX: $>50 \%$ contributions are bolded, $<10 \%$ faded). 162

Table 5.7 Broward County emissions of airborne metals and percent contributions from different sources, according to USEPA National Emissions Inventory, 2008 (USEPA, 2013a). 167 


\section{LIST OF FIGURES}

FIGURE

PAGE

Figure 2.1 Structures of glyphosate and its main metabolite, aminomethylphosphonic acid (AMPA). 6

Figure 2.2 Location of the coastal canals in the vicinity of BNP, managed by the SFWMD in southern Miami-Dade County. 11

Figure 2.3 Projected construction works during Phase 1 of the $\mathrm{BBCW}$ project to allow the use of freshwater to hydrate coastal wetlands in the Biscayne Bay. (LEFT) Hydration of wetlands between C-102 and North Canal. 1, 2, 5, 6, 7: Pump stations; 3: inverted siphon to isolate L-31E from the Military canal; 4: Flap gated culverts. (RIGHT) Projected spreader canal to hydrate wetlands in the vicinity of the South District WWTP. 1: Pump station; 2: new conveyance canal from C-1 to spreader canal; 3: box culvert at L-31E; 4: new spreader canal (13,160 linear feet); 5: Remnant mosquito ditches that will be plugged. Image modified from Apple and Shaffer (2010). 13

Figure 2.4 Structures of the different protonation states of glyphosate and AMPA and $\mathrm{pK}_{\mathrm{a}}$ values. (Ramstedt et al, 2004; You \& Koropchak, 2003)............................ 15

Figure 2.5 Derivatization with 9-fluorenylmethylchloroformate. ................................ 17

Figure 2.6 Sample preparation process for the analysis of glyphosate and AMPA by LCFLD+MS/MS. Lyophilization time relates to 72 samples, calibrations and QCs, the maximum capacity of the $12 \mathrm{~L}$ tray lyophylizer. 25

Figure 2.7 Diagram of the FLD+MS/MS detection system for the analysis of glyphosate and AMPA in canal waters 27

Figure 2.8 Structure of aspartic acid and $\mathrm{pK}_{\mathrm{a}}$ values (Bastug et al., 2011). 30

Figure 2.9 Signal intensities obtained from derivatization of fortified, lyophilized canal waters of different conductivities against the concentration of EDTA, showing similar trends between the analytes and aspartic acid used as internal standard. Fortification levels were $4 \mu \mathrm{g} / \mathrm{L}$ of glyphosate and AMPA and $40 \mu \mathrm{g} / \mathrm{L}$ of ASP. 32

Figure 2.10 Recoveries of laboratory fortified matrices (LFM) experiments performed on canal waters of different conductivity when using $120 \mathrm{mM}$ of EDTA in both the samples and calibration solutions. Fortification level was $4.0 \mu \mathrm{g} / \mathrm{L}$. A $20 \%$ deviation from $100 \%$ recovery is represented by dashed lines. 33

Figure 2.11 Kinetic experiment on the derivatization of glyphosate and AMPA under the conditions described in the developed methodology. Derivatization is complete after $20 \mathrm{~min}$ at room temperature and products were stable up to 480 
min ( 8 hours). Concentrations were $400 \mu \mathrm{g} / \mathrm{L}$ for both analytes in the derivatization mixture (equivalent to $20 \mu \mathrm{g} / \mathrm{L}$ before lyophilization) $(\mathrm{n}=2)$. . 34

Figure 2.12 Chromatograms obtained from lyophilized canal water (sample site 1, C-1 canal, April 2010 collection) with and without analyte fortification. Fortification levels were $12.5 \mu \mathrm{g} / \mathrm{L}$ for glyphosate (green) and AMPA (blue), and $40 \mu \mathrm{g} / \mathrm{L}$ for the ASP internal standard (black). 37

Figure 2.13 Sampling sites and results for collections in February 2008 at C-103 and North Canal. (RL: $0.174 \mu \mathrm{g} / \mathrm{L}$ for GLYP; $0.324 \mu \mathrm{g} / \mathrm{L}$ for AMPA). 42

Figure 2.14 Terrestrial vegetation observed on the shoreline of North Canal at sampling site 1 , the most contaminated site with glyphosate in this study. (Picture taken at the moment of sample collection on February $6^{\text {th }}, 2008,2: 15$ PM) .......... 44

Figure 2.15 Two-day average concentrations measured in North Canal against distance from site 1, the point of highest concentrations of glyphosate detected, showing a fast decrease in concentration. 45

Figure 2.16 Sampling sites and results from the October $22^{\text {nd }}, 2009$ sample collection. Concentration color scale was reduced one order of magnitude from the 2008 sampling trips. (RL: $0.174 \mu \mathrm{g} / \mathrm{L}$ for glyphosate; $0.324 \mu \mathrm{g} / \mathrm{L}$ for AMPA)...... 49

Figure 2.17 Sampling sites and results for the April 27, 2010 sample collection after a heavy rain event, from canals C-1, Goulds, C-103 and North Canal. (RL: $0.174 \mu \mathrm{g} / \mathrm{L}$ for glyphosate; $0.324 \mu \mathrm{g} / \mathrm{L}$ for AMPA)................................. 54

Figure 3.1 Structure of the dioctyl sulfosuccinate (DOSS) anion. ................................. 59

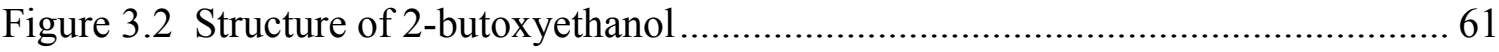

Figure 3.3 Online SPE system for the determination of DOSS in seawater. (TOP, loading position) $5 \mathrm{~mL}$ of sample are passed through the loading column followed with a washing program to remove inorganic species. (BOTTOM, analysis position) Analyte is backflushed into the analytical column for detection..... 67

Figure 3.4 Product ion scan spectrum of DOSS obtained using negative mode electrospray ionization, showing the main and secondary collision-induced dissociation products and their probable structure. (Q1: m/z 421.2; Q3: 75-500 $\mathrm{m} / \mathrm{z}$, CID: $25 \mathrm{eV}$, scan time: $120 \mathrm{~ms}$ ) 74

Figure 3.5 DOSS chromatographic signals are greater when acetonitrile is used as diluting solvent instead of deionized water at a fixed dilution factor..... 75

Figure 3.6 Determination of the optimum dilution factor using a seawater sample fortified with $5 \mu \mathrm{g} / \mathrm{L}$ DOSS. DOSS peak area increased until a 1.3 dilution factor was obtained $(20 \% \mathrm{v} / \mathrm{v}$ acetonitrile $)$, and then decreased with further dilution..... 76 
Figure 3.7 Effect of the sample preservation procedure observed in seawater samples fortified with $5 \mu \mathrm{g} / \mathrm{L}$ DOSS and stored in glass, polytetrafluoroethylene (PTFE), and polyethylene (PE) containers, measured in analyte recovery. ... 78

Figure 3.8 Validation of DOSS storage conditions. An artificial seawater sample was repeatedly analyzed for 250 days (fortification level $4.67 \mu \mathrm{g} / \mathrm{L}$, mean 5.17 $\mu \mathrm{g} / \mathrm{L})$. 79

Figure 3.9 Evolution of the acetonitrile concentration in the SPE column during the SPELC-MS/MS analysis of DOSS in seawater showing the different analysis steps. 80

Figure 3.10 Typical DOSS chromatograms obtained by online SPE-LC-MS/MS (left) and direct injection (right) methods to quantify DOSS in seawater. From top to bottom: DOSS quantitative signal, DOSS qualitative signal, and DOSS- ${ }^{13} \mathrm{C}_{4}$ internal standard. The concentrations for online SPE were: $237 \mathrm{ng} / \mathrm{L}$ DOSS and $400 \mathrm{ng} / \mathrm{L}$ DOSS- ${ }^{13} \mathrm{C}_{4}$. The concentrations for direct injection were as follows: $2,729 \mathrm{ng} / \mathrm{L}$ DOSS and 20,000 ng/L DOSS- ${ }^{13} \mathrm{C}_{4}$ 84

Figure 3.11 Chromatograms obtained using the direct injection LC-MS/MS method for serially diluted commercial formulations (dilution factor: $10^{7}$ ) and crude oil after liquid-liquid extraction. The ESI source operated in positive mode from 0 to $4 \mathrm{~min}$, and then switched to negative mode. The main SRM transition is shown for each compound, and chromatograms of both Corexit formulations are normalized to the same scale for comparison purposes. 87

Figure 4.1 Rainwater and runoff sampling during tropical storm "Andrea". A: Glassware used for collection of reference rainwater. B: Sampling site at the drain of a parking lot at Florida International University, Biscayne Bay Campus. C: Sampling site at a flooded parking lot at a nearby apartment complex.... 99

Figure 4.2 Online SPE system and automated analysis steps. Active flows are shown by arrows and thicker lines. Red: sample and PAHs. Blue: mobile phases....... 102

Figure 4.3 (Top) Graphical representation of the Photomate APPI source with the gasphase dopant delivery system used in this study (Modified from Ehrenhauser et al, 2010). (Bottom) Detail on the dopant sprayer device built from commercially available parts (Modification of the dopant introduction design from Robb et al., 2000). 109

Figure 4.4 Comparison of peaks of PAHs contained in the Standard Reference Material 1491a, obtained by GC-MS analysis (1/10 dilution in hexane, top) and by SPE-LC-MS/MS analysis (1/27500 serial dilution in seawater, bottom). A list of compounds contained in 1491a can be observed in table 4.5. 112

Figure 4.5 Effect of methanol on online SPE recovery of PAHs. (Left) Effect of the percentage of methanol dissolved in the sample. (Right) Effect of the percentage of methanol in the mobile phase used to wash the SPE column. 115 
Figure 4.6 Effect of sample loading flow rate upon online SPE recovery of labeled PAHs. 116

Figure 4.7 Chromatograms obtained upon analysis of a rainwater runoff sample from a residential parking lot showing the resolution obtained for priority PAHs. Blue trace: main (quantitative) SRM transition in runoff sample; green trace: secondary (confirmation) SRM transition in runoff sample; red trace: main SRM transition from injection of reference rainwater. The three traces of each chromatogram are normalized to the same scale. 125

Figure 5.1 Seasonal averages of the Total Ozone Mapping Spectrometer absorbing Aerosol Index (TOMS AI) satellite product, between 1980 and 1992, showing the global movement of mineral dust in November-January (top) and MayJuly (bottom) (Engelstaedter et al., 2006). 134

Figure 5.2 (Top) Location of airborne particulate matter collector at Port Everglades, Florida $\left(26.092542^{\circ} \mathrm{N}, 80.108415^{\circ} \mathrm{W}\right)$. (Bottom left) View of the trailer housing the air sampler and the omnidirectional air collection PVC pipe. (Bottom right) View of the air sampler machine with a new filter being loaded.... 142

Figure 5.3 Output from the photographic procedure to determine areas of weighed filter pieces. (LEFT) Unexposed filter material. (RIGHT) Exposed filter subsample. This particular sample had an area density of $9.35 \mathrm{mg} / \mathrm{cm}^{2}$, equivalent to $18.6 \% \mathrm{w} / \mathrm{w}$ of APM and a concentration of APM in the filtered air of 34 $\mu \mathrm{g} / \mathrm{m}^{3}$ 144

Figure 5.4 Equilibration time required for the weighting of a whole exposed filter (Final recorder weight: $32611.4 \mathrm{mg}$, dotted line).....

Figure 5.5 Enrichment factors used to identify elements of anthropogenic origin using aluminum as crustal reference. 156

Figure 5.6 Box-plot diagrams of elements measured in the APM collected at Port Everglades, FL, ordered by decreasing mean concentrations.

Figure 5.7 Digital microscope images of Versapor $^{\circledR}$ filters before and after APM collection at Port Everglades, FL 160

Figure 5.8 Contributions to individual elements in the APM collected at Port Everglades by each of the sources identified by the UNMIX statistical model. 163

Figure 5.9 Concentrations of tracers of geological material measured in APM samples collected in 2006. African Dust events are highlighted with shaded areas. (Sm and $\mathrm{La}$ were excluded from the REEs as they present anthropogenic enrichment in the EF analysis, section 5.7.3). 164 
Figure 5.10 Location of the air sampler (yellow arrow) relative to the three docks of Port Everglades, FLL and the Port Everglades Power Station (red icon). ........... 166 


\section{LIST OF ABREVIATIONS AND ACRONYMS}

\begin{tabular}{|c|c|}
\hline ABBREVIATION & FULL NAME \\
\hline APM & Airborne Particulate Matter \\
\hline APPI & Atmospheric Pressure Photoionization \\
\hline BNP & Biscayne National Park \\
\hline $\mathrm{CCV}$ & Continuous Calibration Verification \\
\hline $\mathrm{CE}$ & Collision Energy \\
\hline CERP & Comprehensive Everglades Restoration Plan \\
\hline CID & Collision Induced Dissociation \\
\hline DOSS & Dioctyl sulfosuccinate \\
\hline $\mathrm{EF}$ & Enrichment Factor \\
\hline GC-MS & Gas Chromatography-Mass Spectrometry \\
\hline HESI & Heated Electrospray Ionization \\
\hline ICP-MS & Inductively Coupled Plasma Mass \\
\hline & Spectrometry \\
\hline ICVS & Initial Calibration Verification Standard \\
\hline LC-MS/MS & $\begin{array}{l}\text { Liquid chromatography-tandem mass } \\
\text { spectrometry }\end{array}$ \\
\hline LFM & Laboratory Fortified Matrix \\
\hline LLE & Liquid-Liquid Extraction \\
\hline LRB & Laboratory Reagent Blank \\
\hline MDL & Method Detection Limits \\
\hline NAAQS & National Ambient Air Quality Standard \\
\hline
\end{tabular}


NEI

NOEC

PAHs

PCA

REE

RL

RW

SFWMD

SPE

SRM

SW

TSP

$\mathrm{UCC}$

USDOC

USDOT

USEPA

USGS

WWTPs
National Emissions Inventory

No effect environmental concentration

Polycyclic Aromatic Hydrocarbons

Principal Component Analysis

Rare Earth Elements

Reporting Limits

Rainwater

South Florida Water Management District

Solid Phase Extraction

Selected Reaction Monitoring

Seawater

Total Suspended Particles

Upper Crustal Concentrations

United States Department of Commerce

United States Department of Transportation

United States Environmental Protection Agency

United States Geological Survey

Wastewater Treatment Plants 


\section{GENERAL INTRODUCTION}

South Florida is a globally recognized tourist destination and also a preferred retirement location for senior citizens of the United States. Thus, protection of the local environment to preserve the health of residents and to protect enjoyable natural resources that are part of the local attractions is of utmost economic importance. It is also a unique geographical unit in which an ever-growing urban population, large port and airport facilities, mining industries and agricultural areas are competing for natural resources such as water with two large national parks and several other protected lands. These ecosystems are in constant threat from pollution generated by the aforementioned local anthropogenic activities. On a more regional scale, the Gulf of Mexico coast also offers touristic destinations and seafood resources that are in constant threat from large scale oil extraction activities. These anthropogenic disturbances are responsible for the introduction of waterborne pollutants that can affect coastal ecosystems. Lastly, global scale phenomena also affect the environmental quality of South Florida. The region is a recipient of transatlantic transport of mineral dust from Northern Africa, volcanic ashes from the Caribbean Islands and mineral material from other regions of the United States such as loess from the Mississippi River valley (Muhs et al., 2007). These factors have an impact on local air quality.

The Environmental Analysis Research Laboratory at Florida International University (EARL-FIU) is part of the Southeast Environmental Research Center (SERC), and it has been active in the development of robust, sensitive, easy to implement and cost effective analytical methodologies, to monitor the occurrence, provenance and fate of 
chemical pollutants by analyzing different compartments of the local environment such as soil, water and biological tissue. In that scope, the dissertation presents the results of four different research projects that contributed new sensitive and easy to implement analytical methodologies, which targeted both traditional and emerging environmental problems.

The herbicide glyphosate is used for different maintenance activities in canals managed by the South Florida Water Management District. The construction of new infrastructure to divert these waters to hydrate coastal wetlands of Biscayne National Park is already under way. Large amounts of the herbicide could potentially be introduced in that delicate ecosystem. Thus, a novel methodology was developed to assess the occurrence and fate of the herbicide and its main metabolite in waters from these canals in South Miami-Dade County.

On April 20th, 2010, the Deepwater Horizon Platform accident triggered a massive response effort in the Gulf of Mexico. Concerns about the environmental impact of both the accident and the remediation effort were widespread in the population of the Gulf States. An unprecedented quantity of oil dispersants was employed, specifically a formulation called Corexit ${ }^{\circledR}$, and at the time there were no analytical methodologies available for the detection of its main components, which was a necessity to evaluate the fate of these compounds. The analytical challenge was addressed, which resulted in three protocols for the trace level determination of two compounds contained in Corexit ${ }^{\circledR}$, namely dioctyl sulfosuccinate (DOSS) and 2-butoxyethanol, in different samples relevant for the monitoring of an oil spill monitoring effort. These results were published in 
Analytical and Bioanalytical Chemistry, and although two other research groups were able to submit their methodologies before EARL-FIU, the contribution included in this work was the most sensitive, easy to implement, with the fastest sample throughput, and also addressed the problems related with DOSS sample stability. The developed analytical protocols are currently being used to analyze samples from collaborating laboratories and private clients, and also by group collaborators trying to understand the fate of DOSS in the environment.

Another analytical challenge triggered by the Gulf Oil Spill was the analysis of polycyclic aromatic hydrocarbons (PAHs) in surface waters. These analytes are ubiquitous in urban environments and many of them are well-known carcinogens, and can also find their way into surface waters from accidental releases of crude oil and derivates. Analysis of PAHs is usually performed after labor-intensive sample preparation techniques, which consume large quantities of toxic solvents and severely hinders the ability of laboratories to produce fast results. My work resulted in the development of a technique that challenges traditional approaches in terms of speed, environmental friendliness and operation costs. The developed methodology allows the determination of PAHs in surface waters in virtually real time, and is also being employed by EARL-FIU collaborators trying to understand the behavior of PAHs in seawater.

Lastly, EARL-FIU is performing efforts to try to understand the amount of toxic elements in particulate matter suspended in the local air, its provenance and the contributions of far-traveled mineral dust to the local airborne pollution, producing a 
record of filtered airborne particulate collections from a local coastal facility since 2005 . During my investigation, the analysis of a large number of elements in those samples was performed, to establish provenance of airborne pollution using statistical analysis and also to identify periods of high concentrations of airborne particulate related to longrange transport of African dust.

In summary, my dissertation research attempted to answer the following questions:

1. Is the herbicide glyphosate present in the canals that will be used to hydrate protected wetlands of the Biscayne National Park? If so, is it a threat to these ecosystems?

2. Is it possible to perform ultra-trace, fast automated analysis of markers of the Corexit ${ }^{\circledR}$ dispersant formulations heavily used for the remediation efforts of the Gulf of Mexico Oil Spill? Can the analysis be performed on different samples relevant for an oil spill monitoring effort, such as seawater, crude oil, and also commercial formulations? What are the implications regarding sample handling and analyte stability?

3. Is it possible to develop a fully automated methodology for fast analysis of PAHs in surface waters, producing results in almost in real time? How would such a methodology compare with the traditional technique in terms of speed and sensitivity? Can it be applied to samples relevant for the South Florida environment? 
4. What are the sources of airborne particulate matter in a coastal site of the Miami Metropolitan area? What are the air concentrations of toxic metals? Is it possible to identify periods of high contributions of far-traveled dust?

The dissertation is structured in four independent chapters, each of them with an introduction presenting a background on the analytical challenge and the relevance of the research. Materials, reagents, the instrumentation employed and the developed analytical protocols are also presented. A discussion on method development and analysis performance on the basis of figures of merit is given along with the practical applications to assess pollution levels on the local environment. Emphasis was made on analytical simplicity and robustness, with heavy use of automated or unattended preconcentration techniques. 


\section{OCCURRENCE OF THE HERBICIDE GLYPHOSATE AND ITS MAIN METABOLITE IN CANALS WITH INFLUENCE ON PROTECTED AREAS OF THE BISCAYNE NATIONAL PARK}

\subsection{Introduction}

\subsubsection{General background on glyphosate and its main metabolite}

Glyphosate (N-(phosphonomethyl)glycine, CAS number 1071-83-6, figure 2.1) is a broad-spectrum herbicide patented in 1974 under the brand "Roundup ${ }^{\circledR}$ " by the Monsanto Corporation in the United States. The development of genetically modified, glyphosate-resistant crops (GRCs) such as soybean, canola, cotton, maize and alfalfa made glyphosate the most used herbicide globally in agricultural activities (Duke \& Powles, 2008). An approximate 83 million hectares worldwide are planted with GRCs and 42 million of them are in the United States (Gianessi, 2008). The ever-increasing consumption of glyphosate for agricultural purposes in the U.S. reached $8 \times 10^{7} \mathrm{~kg}$ of the herbicide in 2007 (active ingredient mass) (Coupe et al., 2012).

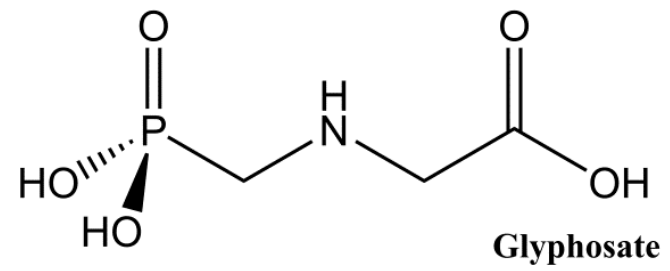<smiles>NCP(=O)(O)O</smiles>

Figure 2.1 Structures of glyphosate and its main metabolite, aminomethylphosphonic acid (AMPA). 
Glyphosate interrupts the enzyme-catalyzed conversion of shikimic acid into aromatic amino acids (phenylalanine, tyrosine and tryptophan) in plant chloroplasts, a process known as the shikimate pathway. As a result, vegetation dies quickly after the herbicide application (Steinrucken \& Amrhein, 1980). However, how the plant dies from the interruption of this process is still a matter of scientific debate (Duke \& Powles, 2008; Pollegioni et al., 2011).

Glyphosate absorption by plants is only effective when sprayed on foliage as the compound is quickly immobilized in soils thus it cannot reach plant roots (Glass, 1987; Rueppel et al., 1977). Once in soils, glyphosate is quickly biodegraded. The factors affecting degradation rates have been summarized in an extensive review (Borggaard \& Gimsing, 2008). Briefly, two possible pathways of degradation have been identified: one produces sarcosine and glycine, while the other produces aminomethylphosphonic acid (AMPA, CAS number 1066-51-9, figure 2.1). Because AMPA is usually detected in soils and waters where glyphosate has been applied, the AMPA pathway is usually accepted as the main degradation process of glyphosate. Degradation rates are highly dependent on localized soil composition and bacterial activity. The metabolite is also degraded and mineralized by bacterial activity, although field tests demonstrated that biodegradation rates are much slower than the parent herbicide (Giesy et al., 2000; Rueppel et al., 1977). The extent of the contribution of the sarcosine pathway to the environmental degradation of glyphosate is a matter of ongoing scientific debate and the contribution of other processes such as photodegradation, volatilization and hydrolysis are considered insignificant (Giesy et al., 2000). 
In recent publications, researchers have shown that the strong adsorption of glyphosate to soils and its fast biodegradation does not entirely prevent the occurrence of the herbicide and its metabolite in agricultural runoff and their introduction into surface waters, especially when glyphosate is applied in porous soils and application is followed by heavy rain events (Borggaard \& Gimsing, 2008; Imfeld et al., 2013). Coupe detected glyphosate and AMPA in almost 100\% of samples in basins located in large agricultural areas of the United States and France, known to be planted with GRCs, concluding that around $1 \%$ of all glyphosate applied to GRCs fields reach surface waters, amount that varies depending on the local hydrology (Coupe et al., 2012).

Glyphosate is also used to eradicate undesired terrestrial vegetation in the margins of waterways and also emerging aquatic plants in wetlands and estuaries. Thus, in areas where such activities are performed glyphosate can enter surface waters directly which results in much higher surface water concentrations that would result from agricultural runoff alone (Giesy et al., 2000; Solomon \& Thompson, 2003). A special formulation of glyphosate called Rodeo ${ }^{\circledR}$ (now called Aquamaster ${ }^{\circledR}$ ) was introduced for use over and/or near aquatic environments. Rodeo is free of the surfactants that are present in regular formulations and are intended to increase glyphosate absorption by reducing the surface tension between the sprayed droplets and the plant leaves. This is important as toxicities of surfactants in regular glyphosate formulations (such as polyethoxylated tallow amine, POEA, the surfactant contained in Roundup ${ }^{\circledR}$ ) are known to be much higher to aquatic organism than glyphosate itself (Giesy et al., 2000; WHO, 1994). 
Kolpin et al. (2006) pointed out that urban activities are an alternative source of glyphosate and AMPA that enter surface waters, albeit in a lower scale than agricultural usage and vegetation control. These authors analyzed 40 samples collected from 11 wastewater treatment plants (WWTPs) discharged effluents and their influenced streams in the United States, finding glyphosate in $18 \%$ and AMPA in $67 \%$ of the collected samples with maximum concentrations of 2.2 and $3.9 \mu \mathrm{g} / \mathrm{L}$, respectively. However, other studies have shown that the presence of AMPA in effluents from WWTPs is attributed to degradation of household cleaning phosphonic detergents such as 1-hydroxyethylene-1,1diphosphonic acid, ethylendiaminetetra(methylenephosphonic acid) or diethylenetriaminepenta(methylenephosphonic acid) (HEDP, EDTMP and DTPMP) (Botta et al., 2009; Jaworska et al., 2002; Skark et al. 1998). Thus, the presence of WWTPs discharges in study areas should be considered as a possible source of AMPA not related to glyphosate usage.

Glyphosate is highly soluble in water (10-15.7 g/L) (Battaglin et al. 2005). However, water mobility is limited as the herbicide is quickly removed from surface waters by biodegradation to AMPA (Rueppel et al., 1977) and by adsorption to suspended particulate matter and sediments (WHO, 1994). On the basis of a literature review of dissipation experiments, Giesy et al. (2000) estimated an average aquatic halflife of 7-14 days for glyphosate.

The World Health Organization released an extensive report on the known environmental hazards of glyphosate and of its commercial formulations. In that report, the most sensitive aquatic organisms to aqueous glyphosate (without surfactants) were 
green algae and diatoms, with no-observed effect concentrations (NOEC) of 200 and 300 $\mu \mathrm{g} / \mathrm{L}$, respectively. Acute toxic concentrations $\left(\mathrm{EC}_{50}\right)$ were 2500 and $1300 \mu \mathrm{g} / \mathrm{L}$ for the same organisms (WHO, 1994). Toxic concentrations for other aquatic organisms considered in that report (fish, crustaceans) were in the high $\mathrm{mg} / \mathrm{L}$ levels. Aminomethylphosphonic acid is less toxic than glyphosate to aquatic organisms and is considered to pose little or no threat to ecosystems. (Giesy et al., 2000).

Given the toxicity of glyphosate to organisms that form the base of the food chain, the occurrence of the herbicide may constitute an important stressor in delicate ecosystems such as Biscayne National Park (BNP), which is under the direct influence of a large number of canals managed by the South Florida Water Management District (SFWMD) (Figure 2.2). The SFWMD canal system is over 1800 miles long and provides flood control, water supply, navigation and environmental management over 16 counties of the State of Florida. Canal maintenance activities are performed routinely throughout the year to allow maximum flow of water during storm events, and include ground, water and aerial application of glyphosate to combat the emergence of undesired vegetation. The herbicide applications also include larger water bodies of the system such as Lake Okeechobee and the Everglades Storm Treatment Areas (Ferriter et al., 2006; Galloway, 2009; James \& Zhang, 2011; SFWMD, 2010). 


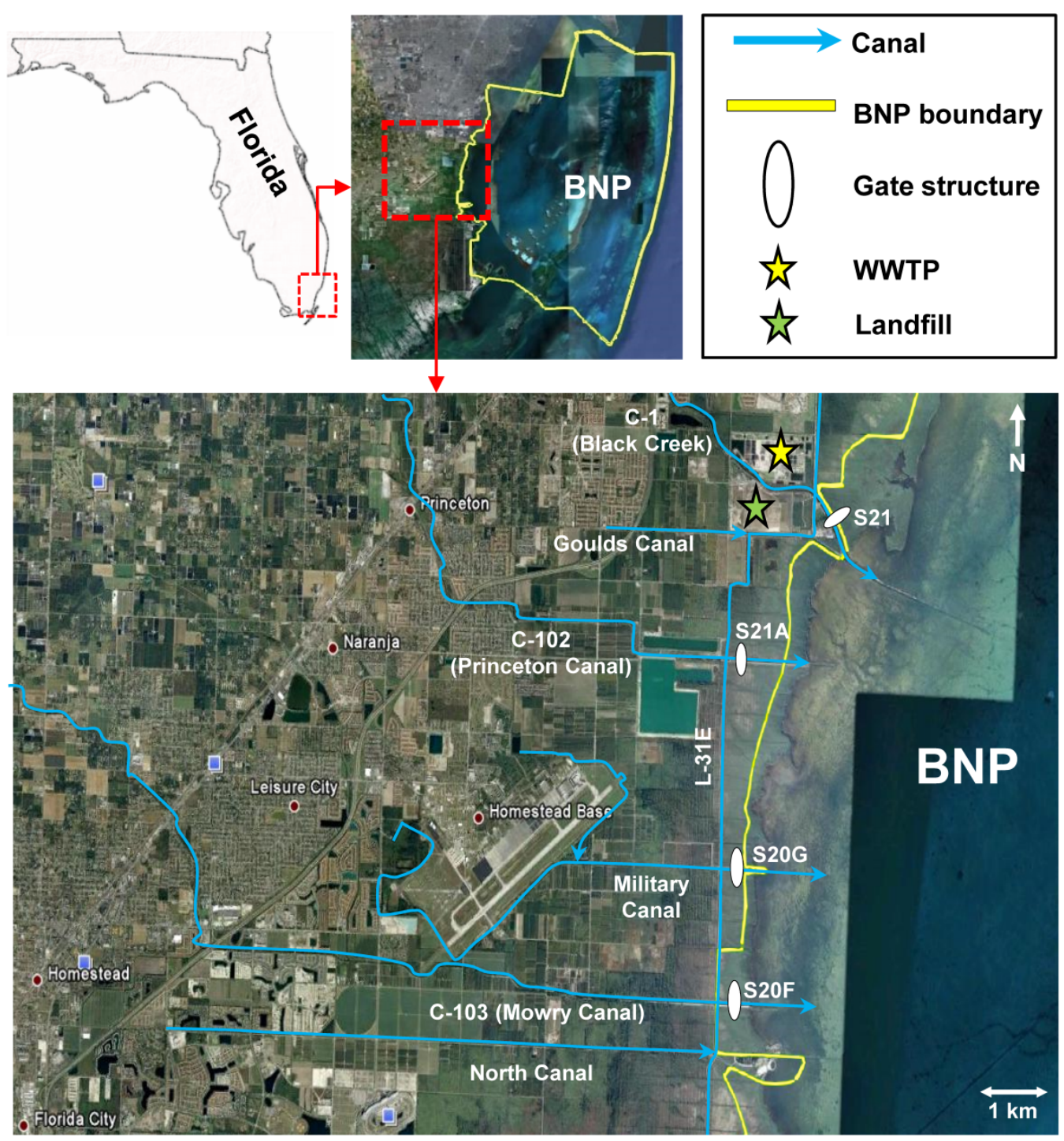

Figure 2.2 Location of the coastal canals in the vicinity of BNP, managed by the SFWMD in southern Miami-Dade County. ${ }^{1}$

In addition, these canals go through agricultural areas in southern Miami-Dade County. Agricultural use of glyphosate for weed control is also an important source of this compound into the local environment, as glyphosate was the main herbicide for

\footnotetext{
${ }^{1}$ Satellite images throughout text were prepared using Google Earth ${ }^{\circledR}$.
} 
agricultural purposes in Florida between 2007 and 2009 (FDACS, 2010), and is used in weed management by tropical fruit farms in southern Miami-Dade County (Mossler \& Nesheim, 2011).

As part of the Biscayne Bay Coastal Wetlands (BBCW) project included in the Comprehensive Everglades Restoration Plan (CERP), these canals will be employed as a source of freshwater to restore historical freshwater flow to coastal wetlands that are currently stressed by alternating low salinity and hypersaline conditions (SFWMD \& USACE, 2011). The construction of four new culverts in the L-31E canal levee was already completed in April, 2010 and freshwater discharge to wetlands north of the C-103 canal has already started (Apple \& Shaffer, 2010). Other projected works during the initial phase CERP include the construction of a canal to transfer water from the $\mathrm{C}-1$ canal into coastal wetlands east of the South District WWTP (see figure 2.3).

As proposed by Schuler and Rand, the increased supply of freshwater into protected areas affected by CERP may also represent an increased input of herbicides from agriculture and urban activities, which may pose a threat to the primary producers that are the base of the food chain (Schuler \& Rand, 2008). Given the extensive applications of glyphosate for system-wide vegetation eradication and the presence of agricultural areas in the vicinity of the canals, freshwater discharged into the protected areas of the BNP have the potential of introducing large amounts of glyphosate and its main metabolite into these fragile ecosystems. 


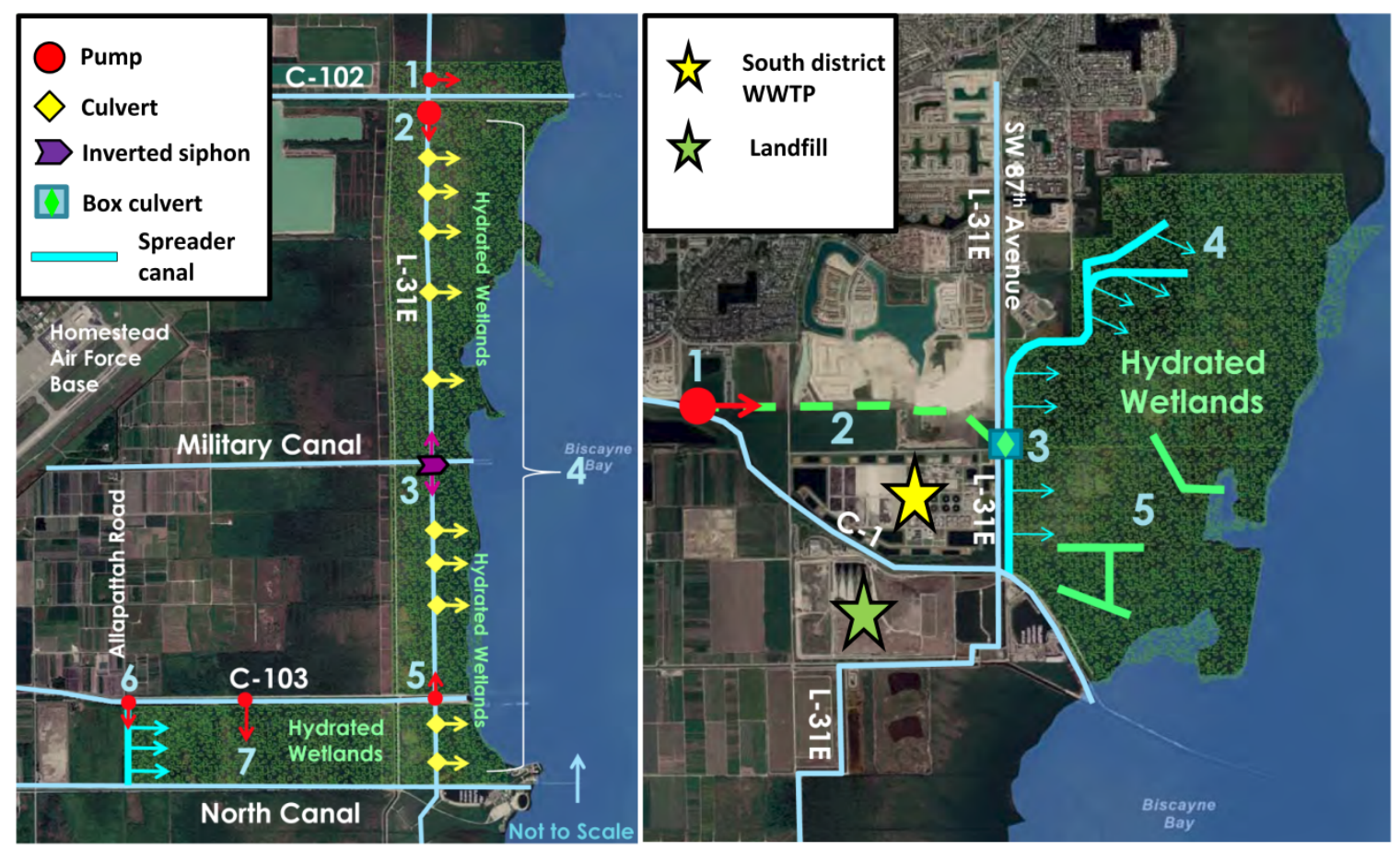

Figure 2.3 Projected construction works during Phase 1 of the BBCW project to allow the use of freshwater to hydrate coastal wetlands in the Biscayne Bay. (LEFT) Hydration of wetlands between C-102 and North Canal. 1, 2, 5, 6, 7: Pump stations; 3: inverted siphon to isolate L-31E from the Military canal; 4: Flap gated culverts. (RIGHT) Projected spreader canal to hydrate wetlands in the vicinity of the South District WWTP. 1: Pump station; 2: new conveyance canal from $\mathrm{C}$-1 to spreader canal; 3: box culvert at L-31E; 4: new spreader canal (13,160 linear feet); 5: Remnant mosquito ditches that will be plugged. Image modified from Apple and Shaffer (2010).

The SFWMD maintains a large pesticide monitoring program on these canals, and although glyphosate is the most used herbicide in Florida it is not included in that effort (Pfeuffer, 2011). Therefore, glyphosate and AMPA are potential candidates to be included in such monitoring programs, and a simple, sensitive analytical methodology would be a desirable tool to achieve this task in large regional efforts. 


\subsubsection{Background on the analysis of glyphosate and AMPA in environmental waters}

In aqueous solutions, glyphosate and AMPA are either ions or zwitterions regardless of $\mathrm{pH}$ (see figure 2.4 ). Therefore, these molecules are highly hydrophilic, nonvolatile and insoluble in most organic solvents. Nevertheless, a number of methodologies to analyze glyphosate and AMPA in environmental waters by gas chromatography (GC) after derivatization followed by liquid-liquid extraction, extract clean-up and concentration steps were developed right after the introduction of the herbicide, and reports until the end of the previous century have been summarized elsewhere (Stalikas \& Konidari, 2001). Since glyphosate and AMPA have the phosphonate moiety in their structure, the main advantage of GC methodologies is the use of the selective nitrogen/phosphorus detector (NPD). However, low sample throughput and extraction efficiencies make GC methodologies unsuitable for routine analysis of glyphosate and AMPA in environmental waters.

In contrast, liquid chromatography (LC) is compatible with aqueous injections and has been more favored in the literature for the analysis of these hydrophilic compounds. Still, the absence of fluorophore or chromophore moieties prompted the development of derivatization methodologies to enable the use of mainstream detection techniques such as fluorescence (FLD). A summary of references of previously reported methodologies to analyze glyphosate and AMPA in waters is presented in table 2.1. 


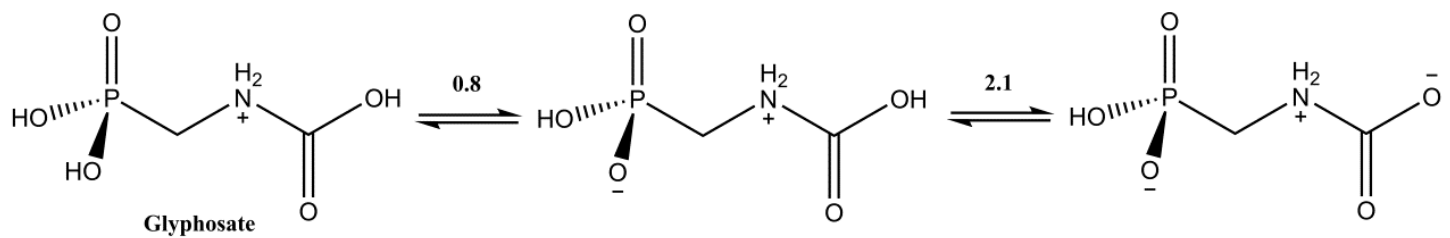

Glyphosate

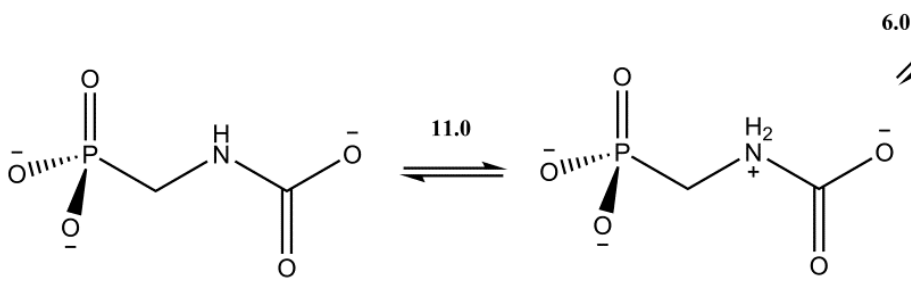

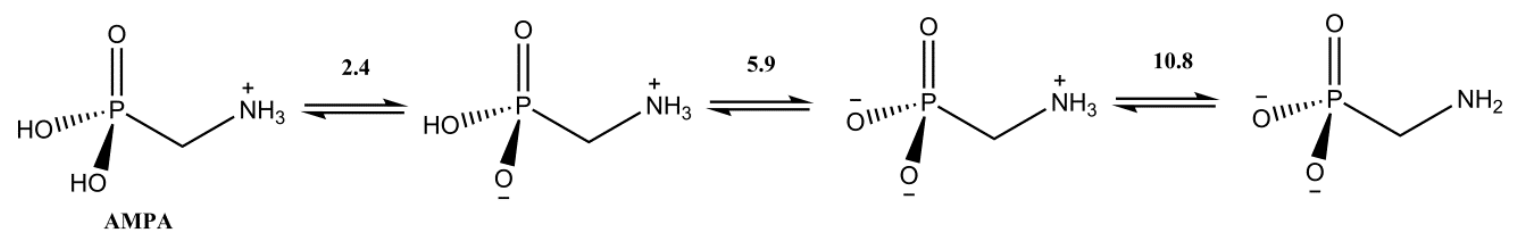

Figure 2.4 Structures of the different protonation states of glyphosate and AMPA and $\mathrm{pK}_{\mathrm{a}}$ values. (Ramstedt et al, 2004; You \& Koropchak, 2003).

An ion exchange liquid chromatography method with post column derivatization using o-phtalaldehyde-2-mercaptoethanol (OPA-ME) was introduced by Moye for the analysis of vegetable extracts (Moye et al., 1983), and derived in a USEPA method for the analysis of drinking water (USEPA, 1990). However, post-column derivatization required specialized instrumentation and was later replaced by easier to implement techniques. The same research group introduced 9-fluorenylmethylchloroformate (FMOC-Cl, figure 2.5) as a pre-column, highly fluorescent derivatizing reagent for the analysis of glyphosate and AMPA in waters by LC-FLD (Miles et al., 1986; Moye \& Boning, 1978). 
Table 2.1 Summary of liquid chromatography methodologies available in the literature for the analysis of glyphosate and AMPA in waters.

\begin{tabular}{|c|c|c|c|c|c|c|c|c|c|c|c|}
\hline Reference & $\begin{array}{l}\text { Water } \\
\text { type }^{\mathrm{a}}\end{array}$ & $\begin{array}{c}\text { Deriv. } \\
\text { reagent }\end{array}$ & $\mathbf{P C}$ & $\begin{array}{c}\text { SPE } \\
\text { mode }^{d}\end{array}$ & SPE Sorbent & $\begin{array}{c}\text { Sample } \\
\text { size } \\
(\mathrm{mL})\end{array}$ & $\begin{array}{c}\mathrm{LC} \\
\operatorname{mode}^{\mathrm{d}}\end{array}$ & $\begin{array}{l}\text { Stat. } \\
\text { phase }\end{array}$ & Det. & $\begin{array}{l}\text { GLYP } \\
\text { MDL }^{\mathrm{g}}\end{array}$ & $\begin{array}{c}\text { AMPA } \\
\text { MDL }^{\mathrm{g}}\end{array}$ \\
\hline Miles (1986) & $\mathrm{S}$ & FMOC-Cl & Rotoevap. & - & - & 100 & IE & $\mathrm{NH}_{2}$ & FLD & 10 & 10 \\
\hline USEPA (1990) & $\mathrm{D}$ & OPA-ME & None & - & - & 0.2 & IE & $\mathrm{NH}_{2}$ & FLD & 8.99 & n.a. \\
\hline Oppenhuizen (1991) & $\mathrm{S}$ & OPA-ME & Rotoevap. & - & - & 250 & IE & $\mathrm{NH}_{2}$ & FLD & 1 & 1 \\
\hline Sancho (1996) & $\mathrm{S}$ & FMOC-Cl & None & - & - & 2 & $\mathrm{RP}+\mathrm{IE}$ & $\mathrm{C} 18 / \mathrm{NH} 2$ & FLD & 1 & 1 \\
\hline Mallat (1998) & $\mathrm{S}$ & OPA-ME & SPE & IE & LiChrolut EN & 50 & IE & $\mathrm{NH}_{2}$ & FLD & 2 & 4 \\
\hline Vreeken (1998) & S, D & FMOC-Cl & Online SPE & IE & PLRP-S & 4 & $\mathrm{RP}$ & $\mathrm{C} 18$ & MS & 0.05 & 0.05 \\
\hline Le Fur (2000) & $\mathrm{S}$ & FMOC-Cl & None & - & - & 0.05 & IE & $\mathrm{NH}_{2}$ & FLD & 0.1 & 0.1 \\
\hline Patsias (2001) & $\mathrm{S}, \mathrm{G}$ & OPA-ME & Online SPE & IE & PRP-X100 & 100 & IE & Polymeric & FLD & 0.02 & 0.1 \\
\hline Grey (2001) & $\mathrm{S}, \mathrm{D}, \mathrm{G}$ & FMOC-Cl & Rotoevap. & - & - & 50 & $\mathrm{RP}$ & $\mathrm{C} 18$ & MS & 0.06 & 0.3 \\
\hline Le Bot (2002) & $\mathrm{S}$ & FMOC-Cl & None & - & - & 0.05 & IE & $\mathrm{NH}_{2}$ & FLD & 0.04 & 0.06 \\
\hline Lee (2002) & $\mathrm{S}, \mathrm{G}$ & FMOC-Cl & Online SPE & $\mathrm{RP}^{\mathrm{e}}$ & Oasis HLB & 5 & $\mathrm{RP}$ & $\mathrm{C} 18$ & MS & 0.084 & 0.078 \\
\hline You (2003) & $\mathrm{S}$ & None & None & - & - & 0.1 & IE & $\mathrm{NH}_{2}$ & $\mathrm{CNLS}^{\mathrm{h}}$ & 41 & 53 \\
\hline Hidalgo (2004) & $\mathrm{S}$ & FMOC-Cl & None & - & - & 0.30 & $\mathrm{RP}+\mathrm{IE}$ & $\mathrm{C} 18 / \mathrm{NH}_{2}$ & FLD & 0.1 & 0.1 \\
\hline Nedelkoska (2004) & $\mathrm{S}$ & FMOC-Cl & None & - & - & n.a. & IE & $\mathrm{NH}_{2}$ & FLD & 0.16 & 0.16 \\
\hline Guo (2005) & $\mathrm{D}, \mathrm{G}$ & None & None & - & - & 0.5 & IE & $\mathrm{QA}^{\mathrm{e}}$ & ICP-MS & 0.7 & 0.7 \\
\hline Ibanez (2005) & $\mathrm{S}, \mathrm{G}$ & FMOC-Cl & Online SPE & $\mathrm{RP}$ & Oasis HLB & 4 & $\mathrm{RP}$ & $\mathrm{C} 18$ & $\mathrm{MS} / \mathrm{MS}$ & 0.005 & 0.005 \\
\hline Corbera (2006) & $\mathrm{S}$ & FMOC-Cl & SPE & IE & Amberlite & 100 & $\mathrm{IE}$ & $\mathrm{NH}_{2}$ & FLD & 0.1 & 0.3 \\
\hline Coutinho (2008) & $\mathrm{S}$ & None & None & - & - & 0.02 & IE & QA & $\mathrm{EC}$ & 38 & 240 \\
\hline Hanke (2008) & $\mathrm{S}$ & FMOC-Cl & SPE & $\mathrm{RP}$ & Strata X & 80 & RP & $\mathrm{C} 18$ & MS/MS & 0.0007 & 0.0008 \\
\hline Qian (2009) & $\mathrm{S}$ & $\mathrm{CNBF}^{\mathrm{b}}$ & None & - & - & 0.02 & $\mathrm{RP}$ & $\mathrm{C} 18$ & UV-VIS & 9 & n.a. \\
\hline Kusters (2010) & $\mathrm{D}$ & FMOC-Cl & Rotoevap. & - & - & 250 & $\mathrm{RP}$ & $\mathrm{C} 18$ & FLD & 0.012 & 0.014 \\
\hline Sun (2010) & $\mathrm{S}$ & MOBS-F & Rotoevap. & - & - & 100 & $\mathrm{RP}$ & $\mathrm{C} 18$ & UV-VIS & 0.1 & 0.1 \\
\hline Hao (2011) & $\mathrm{S}, \mathrm{G}, \mathrm{D}$ & None & None & - & - & 0.07 & $\mathrm{MM}^{\mathrm{f}}$ & $\mathrm{R}-\mathrm{NH}_{2}$ & MS/MS & 1.5 & 3.9 \\
\hline
\end{tabular}

${ }^{\mathrm{a}}$ Water type: S: surface waters; D: drinking water; G: groundwater. ${ }^{\mathrm{b}} \mathrm{CNBF}$ : 4-chloro-3,5-dinitrobenzotrifluoride. ${ }^{\mathrm{c}} \mathrm{MOBS}-\mathrm{F}$ : -methoxybenzenesulfonyl fluoride. ${ }^{\mathrm{d}}$ IE: Ion-

exchange; RP: reverse phase. ${ }^{\mathrm{e}} \mathrm{QA}$ : Quaternary ammonium. ${ }^{\mathrm{f}} \mathrm{MM}$ : mixed mode (reverse phase + weak ion exchange). ${ }^{\mathrm{g}} \mathrm{Reported} \mathrm{MDL}$ or LOD in $\mu \mathrm{g} / \mathrm{L}$. ${ }^{\mathrm{h}} \mathrm{CNLS}$ : Condensation

Nucleation Light scattering. 

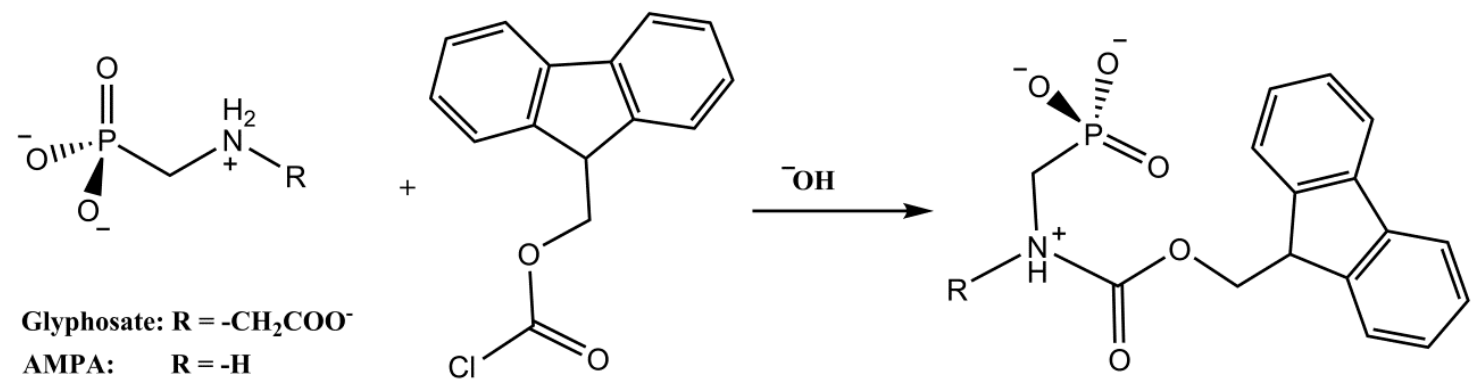

Figure 2.5 Derivatization with 9-fluorenylmethylchloroformate.

The FMOC-Cl reaction is fast, compatible with water and is performed at room temperature without any special instrumentation prior to injection in the LC system. The addition of the large size, non-polar FMOC moiety to glyphosate and AMPA makes the retention of these compounds in reverse-phase columns possible, using stationary phases such as $\mathrm{C} 8$ and $\mathrm{C} 18$. These are more resistant to hydrolysis and therefore last much longer than columns with amino moieties traditionally used in ion-exchange chromatography (Ibanez et al., 2005; Le Fur et al., 2000). These advantages have made FMOC-Cl the most frequently used reagent for derivatization of glyphosate and AMPA, despite some drawbacks such as the very favorable side reaction with water to produce a large excess of FMOC-OH. The side product needs to be either removed before injection by cleanup steps or chromatographically resolved from the analytes before detection. Another drawback is that the FMOC-Cl reagent will react with any compound in the derivatization mixture that contains a primary or secondary amine, which can potentially introduce interferences that will also need to be chromatographically resolved for fluorescence detection. To overcome this challenge, the use of tandem mass spectrometry (MS/MS) as a selective tool to detect glyphosate-FMOC and AMPA-FMOC was 
previously demonstrated (Hanke et al., 2008; Ibanez et al., 2005) and is an alternative for laboratories with such capabilities.

As shown in table 2.1, preconcentration has been previously performed by solidphase extraction (SPE) operating either in ion-exchange (IE) mode or in reverse-phase (RP) mode after FMOC-Cl derivatization. Hanke et al. (2008) obtained the highest sensitivity in all reported methods to date by performing SPE in RP mode after derivatization with FMOC-Cl with a careful optimization of all parameters of derivatization, preconcentration and MS/MS detection. Ultra-trace SPE methodologies such as the latter suffer from a low sample throughput given the multiple steps involved, and can also require well trained analysts and expensive consumable materials.

A considerable sample throughput increase can be obtained by using online-SPE methodologies. However, the instrumentation used can be expensive and difficult to operate, especially methodologies involving ion exchange online-SPE which require automated loading of disposable SPE cartridges with systems such as the Symbiosis/Prospekt ${ }^{\mathrm{TM}}$ used by Vreeken et al. (1998), Patsias et al. (2001) and Lee et al. (2002), the latter being the official U.S. Geological Survey (USGS) methodology for glyphosate and AMPA. Additionally, reported sensitivities were not as high as offline SPE methods. Some authors have also reported that retention of underivatized AMPA in ion-exchange SPE cartridges is overall much lower than glyphosate, resulting in a low sensitivity for this analyte (Corbera et al., 2006; Patsias et al., 2001).

The use of less complicated techniques with a high sample throughput and lower operation costs may be more desirable for routine monitoring of these analytes. A simple 
alternative preconcentration method previously reported is water removal by rotoevaporation, taking advantage of the very low vapor pressure of these analytes $\left(4.3 \times 10^{-10} \mathrm{mmHg}\right.$ at $25^{\circ} \mathrm{C}$ for glyphosate) (Battaglin et al., 2005). Since no special instrumentation or consumables such as SPE cartridges and organic solvents are needed, rotoevaporation is a low-cost technique, although not free of disadvantages. Sample throughput is low as the number of rotoevaporators available limits the amount of samples than can be treated simultaneously. In addition, it has been demonstrated that glyphosate has an elevated affinity for glass surfaces, and severe analyte losses will occur if the molecule is put into contact with glassware before any derivatization steps (Miles et al., 1986), making necessary the use of silanization agents to pretreat rotoevaporation glassware (Grey et al., 2001).

Lyophilization is an alternative drying technique in which water is sublimated from frozen samples by placing them under very high vacuum, taking advantage of the thermodynamic properties of water. The concept of lyophilizing surface waters to preconcentrate pesticides with low volatility was first proposed by Wells as a method to allow distribution of standard reference materials for unstable organic pesticides in surface waters, such as atrazine, parathion and carbaryl (Wells, 1998). These compounds were stable up to 12 months in the lyophilized powder, proving the concept of water removal to isolate pesticide residues that can later be reconstituted for a specific purpose. However, only one report on the use of lyophilization as a preconcentration technique for pesticides was found in the literature. Sinha et al. (2011) preconcentrated pesticide residues from $5 \mathrm{~mL}$ of drinking water, performing reliable quantitation at concentrations 
as low as $0.1 \mu \mathrm{g} / \mathrm{L}$. Pesticides included in that study were monocrotophos, imidacloprid, triazofos, ethion, atrazine, propanil, quinalphos and metribuzin, all of them containing very polar moieties such as the organothiophosphate group. Thus, this principle should also allow preconcentration of the very non-volatile glyphosate and AMPA, and this possibility has not been explored before.

The main drawback of lyophilization is the preconcentration of non-volatile matrix components, which is also the case for the previously tested rotoevaporation approach and therefore analytical performance should be similar. However lyophilization allows the use of low-cost disposable plastic containers reducing the risk of crosscontamination and avoiding the use of glassware. With the use of large volume bulk tray lyophilizers this approach could also increase sample throughput as a large number of samples that can be simultaneously dried, with the added benefit that this is an unattended operation.

\subsection{Hypotheses}

- Lyophilization can be used for the preconcentration of glyphosate and AMPA from canal water, and the non-volatile matrix effects that could affect the FMOC-Cl derivatization can be controlled in order to establish a low cost, sensitive analytical protocol.

- Glyphosate and AMPA are present in canal waters that will be used to hydrate protected wetlands from Biscayne National Park as part of the Comprehensive Everglades Restoration Plan (CERP), and could introduce the herbicide to this protected environment. 


\subsection{Research objectives}

The main objective of this work was to develop a simple analytical protocol for the routine determination of glyphosate and its main metabolite in canal waters by investigating for the first time the possibility of preconcentration of these compounds by lyophilization, in order to take advantage of the simplicity and lower cost of evaporation techniques relative to more sophisticated approaches such as SPE.

Another objective was to perform a survey of levels of glyphosate and AMPA to assess the occurrence of the herbicide and its main metabolite in canal waters that will be used to hydrate coastal wetlands of the BNP as part of the Comprehensive Everglades Restoration Program, potentially introducing the herbicide in the protected environment of a National Park.

\subsection{Materials and reagents}

Acetonitrile (LC-MS grade), ammonium acetate (HPLC grade), sodium borate (certified ACS grade), ammonium hydroxide (trace metal grade) and EDTA (disodium, dihydrate, certified ACS grade) were purchased from Fisher Scientific (Fairlawn, NJ, USA). Solid FMOC-Cl (97\% pure) was obtained from Sigma-Aldrich (St. Louis, MO, USA). A certified standard mixture of glyphosate and AMPA (100 $\mu \mathrm{g} / \mathrm{L}$ in water) was obtained from Accustandard (New Haven, CT, USA) and used for calibration. Glyphosate (Pestanal ${ }^{\circledR}$ grade), obtained from Sigma-Aldrich, and neat AMPA (99\% pure), obtained from MP Biomedicals (Santa Ana, CA, USA), were used as secondary 
source standards for initial calibration verification (ICV) purposes. Glyphosate-FMOC and AMPA-FMOC were obtained from Dr. Ehrenstorfer (Augsburg, Germany).

Canal samples were collected in $250 \mathrm{~mL}$ disposable polyethylene (PE) bottles, obtained from Fisher Scientific. Sample conductivity measurements were performed with a 556MPS Handheld Multiparameter Instrument (YSI Incorporated, Yellow Springs, OH, USA). Disposable polypropylene (PP) centrifuge tubes were used for lyophilization, also obtained from Fisher Scientific. Samples were frozen and lyophilized using a Lyph-lock 6 lyophilization system equipped with a $12 \mathrm{~L}$ stoppering tray, obtained from Labconco (Kansas City, MO, USA). Derivatized residues were filtered using $17 \mathrm{~mm}, 0.45 \mu \mathrm{m}$ polytetrafluoroethylene (PTFE) syringe filters (GE Water \& Process Technologies, Feasterville-Trevose, PA, USA). Amber borosilicate LC vials and PTFE lined caps were also obtained from Fisher Scientific. Vials were cleaned by heating to $450{ }^{\circ} \mathrm{C}$ for at least $6 \mathrm{~h}$ before use.

Chromatographic separations were performed by a Surveyor HPLC system (Thermo Scientific, Waltham, MA, USA) which integrates an autosampler with column temperature control and a quaternary HPLC pump. Injections were made using a $10 \mu \mathrm{L}$ stainless steel sample loop. Separations were performed on a Gemini ${ }^{\circledR}$ C18 column (150 $\times 4.6 \mathrm{~mm}, 5 \mu \mathrm{m})$ protected by a SecurityGuard ${ }^{\mathrm{TM}} \mathrm{Gemini}^{\circledR} \mathrm{C} 18$ guard column $(4 \times 3 \mathrm{~mm}$, $5 \mu \mathrm{m}$ ). Columns and guard columns were obtained from Phenomenex (Torrance, CA, USA). Polyetheretherketone (PEEK) tubing was used throughout the HPLC system. Detection was simultaneously performed by a Spectrasystem ${ }^{\circledR}$ FL3000 fluorescence detector and a LCQ Advantage Max ${ }^{\mathrm{TM}}$ ion trap mass spectrometer equipped with an 
electrospray ionization (ESI) source. A Quicksplit ${ }^{\mathrm{TM}}$ device obtained from ASI (Richmond, CA, USA) was used to split the column effluent and allow dual detection. Instrument control, data acquisition and data processing were performed using Xcalibur 2.0. All detectors and the processing software were obtained from Thermo Scientific. The fluorescence detector was connected to the acquisition computer by an SS420x analog-todigital converter (ADC), obtained from Agilent (Santa Clara, CA, USA).

\subsection{Environmental sampling}

The use of glassware was avoided during sample collection, storage and sample pre-treatment. All samples were collected in clean $250 \mathrm{~mL}$ PE bottles, rinsed once with sample water and then filled completely. Collected samples were placed in plastic bags and transported to the laboratory on ice. Upon arrival, conductivities were measured and samples were stored at $4^{\circ} \mathrm{C}$ if analysis was to be performed no more than 14 days later. For longer term storage, samples were frozen and kept at or below $-20^{\circ} \mathrm{C}$.

Three different field sample collections were performed from the canals managed by the SFWMD with potential direct influence on BNP, in southern Miami-Dade County (see figure 2.2). The laboratory was notified of a glyphosate spraying even for maintenance activities in North Canal on February 5, 2008 (Bellmund, 2008). Samples were collected from North Canal and C-103 on that day between 3:00 PM and 4:30 PM, and the sampling was repeated 24 hours later. A wide-area field sample collection was performed on October 22, 2009 from all canals listed in figure 2.2, in order to assess background levels throughout the coastal canal system. A third and final field collection

was performed on April 27, 2010, a day after a heavy rain event, in order to assess if 
rainwater runoff is an important source of these compounds in local conditions. In this trip, samples were collected from canals C-1, Goulds, C-103 and North Canal.

\subsection{Analytical methodology}

\subsubsection{Sample preconcentration and derivatization}

A graphical summary of the sample preparation process is presented in figure 2.6. A total of $20 \mathrm{~mL}$ of each raw canal water were added to disposable PP centrifuge tubes and fortified with aspartic acid as internal standard (fortification level: $40 \mu \mathrm{g} / \mathrm{L}$ ). Calibration and quality control (QC) solutions (in deionized water) were prepared using the same procedure, adding glyphosate and AMPA from certified standard solutions in water. Calibration range was 0.1 to $50 \mu \mathrm{g} / \mathrm{L}$. To avoid mechanical losses and crosscontamination during lyophilization, the openings of the PP tubes containing the samples, calibrations and QCs were covered with aluminum foil and four small holes were opened using a needle to allow water removal. Covered samples were frozen to $-50{ }^{\circ} \mathrm{C}$ and then dried under high vacuum. Dry residues were suspended in $450 \mu \mathrm{L}$ of $25 \mathrm{mM}$ sodium borate $(\mathrm{pH}=9)$ and $250 \mu \mathrm{L}$ of a $500 \mathrm{mM}$ EDTA basic solution $(\mathrm{pH}=9$, adjusted with sodium hydroxide). Using disposable polyethylene transfer pipettes, suspended residues were transferred to $2 \mathrm{~mL}$ amber $\mathrm{LC}$ vials containing $300 \mu \mathrm{L}$ of a $3.75 \mathrm{mM}$ FMOC-Cl solution in acetonitrile, for a total volume of $1 \mathrm{~mL}$. Vials were capped, shaken and allowed to react for at least 3 hours. Derivatization mixtures were then filtered $(0.45 \mu \mathrm{m}$, PTFE), collecting the filtrate in a new LC vial, and injected in the HPLC system without further treatment. 

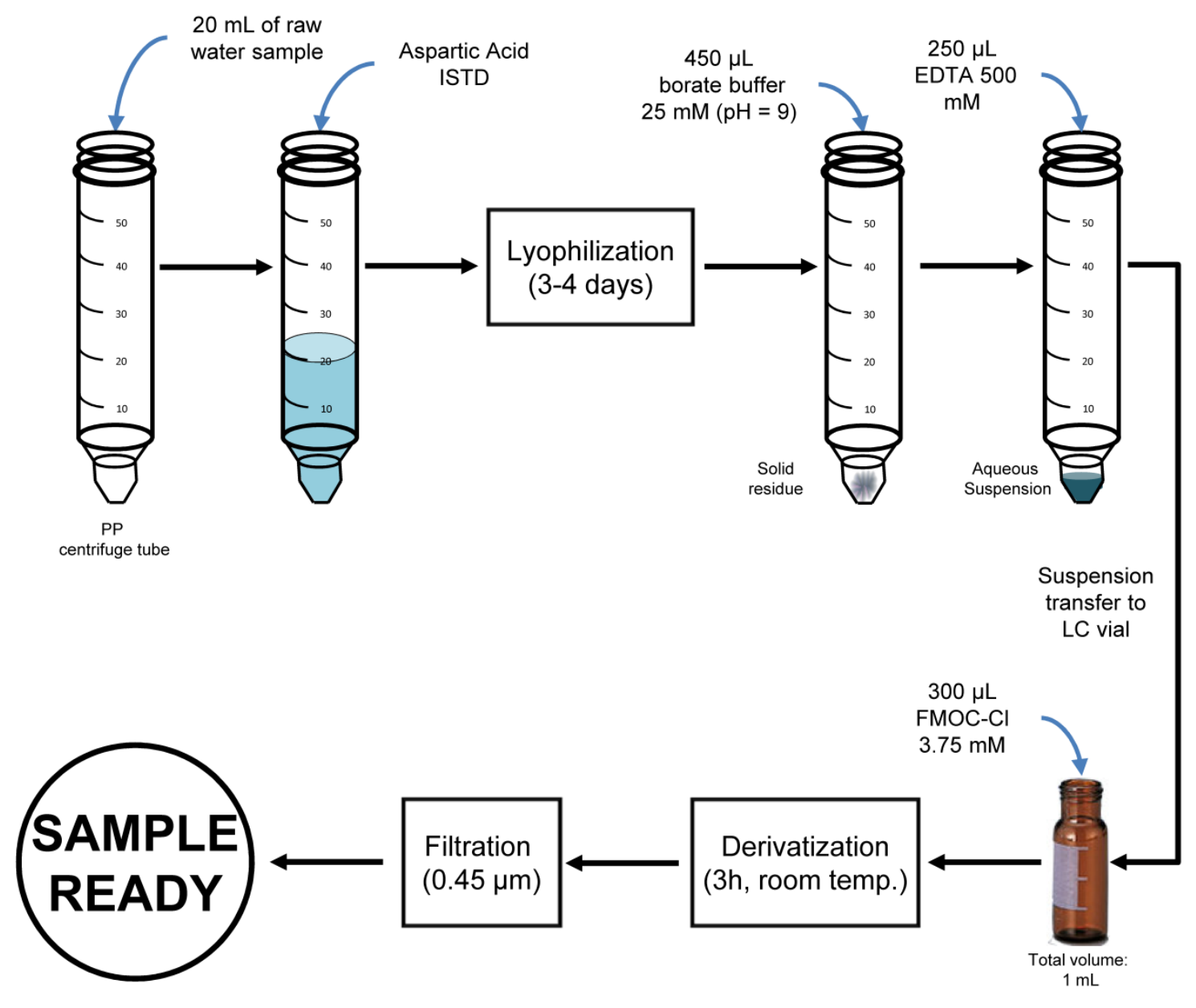

Figure 2.6 Sample preparation process for the analysis of glyphosate and AMPA by LCFLD+MS/MS. Lyophilization time relates to 72 samples, calibrations and QCs, the maximum capacity of the $12 \mathrm{~L}$ tray lyophylizer.

\subsubsection{Analysis by LC-FLD+MS/MS}

Injection volume was $10 \mu \mathrm{L}$ and the autosampler washing steps used to avoid carryover are listed in table 2.2. Separation was performed in 25 min according to the binary mobile phase gradient presented in table 2.3, using acetonitrile and an ammonium/ammonia buffer $(\mathrm{pH}=9.5)$ prepared with ammonium acetate $(1 \mathrm{mM})$ and ammonium hydroxide $(0.05 \% \mathrm{v} / \mathrm{v})$. The column was kept at $25{ }^{\circ} \mathrm{C}$. 
Table 2.2 Washing program used to avoid carryover for the determination of glyphosate and AMPA in canal water by LC-FLD+MS/MS.

\begin{tabular}{cccc}
\hline Washing step & Solvent & $\begin{array}{c}\text { Volume } \\
(\boldsymbol{\mu L})\end{array}$ & Solvent path \\
\hline 1 & Methanol & 400 & Needle rinse \\
2 & $5 \% \mathrm{NH}_{4} \mathrm{OH} \mathrm{v} / \mathrm{v}$ in water & 400 & Sample line $\rightarrow$ injector port $\rightarrow$ waste \\
3 & Methanol & 800 & Sample line $\rightarrow$ injector port $\rightarrow$ waste \\
\hline
\end{tabular}

Table 2.3 Mobile phase delivery program for the determination of glyphosate and AMPA in canal water by LC-FLD+MS/MS. The rotary valve of the LCQ Mass Spectrometer was used to direct the column eluent.

\begin{tabular}{|c|c|c|c|c|c|}
\hline $\begin{array}{l}\text { Time } \\
(\min )\end{array}$ & $\begin{array}{c}\text { Acetonitrile } \\
(\%)\end{array}$ & $\begin{array}{c}\text { Buffer } \\
(\%)\end{array}$ & $\begin{array}{l}\text { Flow rate } \\
\text { (mL/ min) }\end{array}$ & $\begin{array}{c}\text { Segment } \\
\text { description }\end{array}$ & $\begin{array}{l}\text { Eluent directed } \\
\text { towards: }\end{array}$ \\
\hline 0 & 1 & 99 & 1.0 & \multirow{3}{*}{$\begin{array}{c}\text { Removal of } \\
\text { inorganic } \\
\text { species }\end{array}$} & \multirow{3}{*}{ Waste } \\
\hline 1.00 & 1 & 99 & 1.0 & & \\
\hline 4.99 & 10.4 & 89.6 & 1.0 & & \\
\hline 5.00 & 10.4 & 89.6 & 1.0 & \multirow{4}{*}{$\begin{array}{l}\text { Detection } \\
\text { period }\end{array}$} & \multirow{4}{*}{ Detectors } \\
\hline 10.0 & 24.5 & 75.5 & 1.0 & & \\
\hline 12.0 & 99 & 1 & 1.0 & & \\
\hline 13.9 & 99 & 1 & 1.0 & & \\
\hline 14.0 & 99 & 1 & 1.0 & \multirow{2}{*}{$\begin{array}{c}\text { Removal of } \\
\text { derivatization } \\
\text { byproducts }\end{array}$} & \multirow{4}{*}{ Waste } \\
\hline 18.0 & 99 & 1 & 1.0 & & \\
\hline 20.0 & 1 & 99 & 1.0 & \multirow{2}{*}{ Column reset } & \\
\hline 25.0 & 1 & 99 & 1.0 & & \\
\hline
\end{tabular}

A flow splitting device allowed simultaneous detection by diverting $20 \%$ of the flow towards the mass spectrometer and $80 \%$ towards the fluorescence detector. A diagram of the detection system is presented in figure 2.7. 


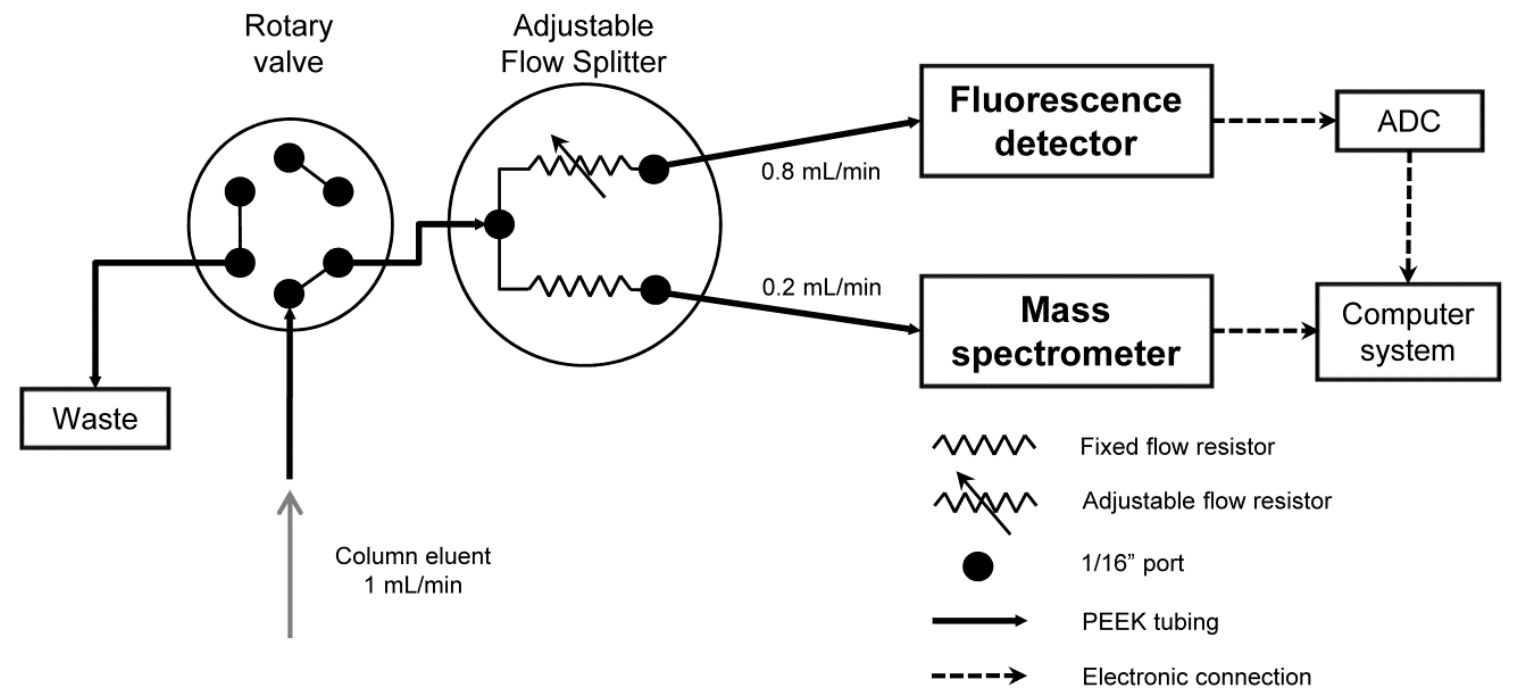

Figure 2.7 Diagram of the FLD+MS/MS detection system for the analysis of glyphosate and AMPA in canal waters

The fluorescence detector was operated at fixed wavelengths (excitation: $270 \mathrm{~nm}$, emission: $315 \mathrm{~nm}$ ) and was used for quantitative purposes, while the mass spectrometer was used only as a qualitative analysis tool. The ESI source was operated in the negative mode and the ion trap mass spectrometer was operated in the product ion scan mode, using two detection segments presented in table 2.4.

Table 2.4 Product ion scan MS/MS detection parameters for detection of glyphosateFMOC and AMPA-FMOC using the ion trap mass spectrometer after electrospray ionization.

\begin{tabular}{cccccccc}
\hline Segment & $\begin{array}{c}\text { Time } \\
(\mathbf{m i n})\end{array}$ & Compound & $\begin{array}{c}\text { Parent } \\
\text { ion } \mathbf{( m / z )}\end{array}$ & $\begin{array}{c}\text { CID }^{\mathbf{a}} \\
(\mathbf{\%})\end{array}$ & $\begin{array}{c}\text { Scan window } \\
(\mathbf{m} / \mathbf{z})\end{array}$ & $\begin{array}{c}\text { Product ion } \\
(\mathbf{m} / \mathbf{z})\end{array}$ & $\begin{array}{c}\text { RT } \\
(\mathbf{m i n})\end{array}$ \\
\hline 1 & $0-9$ & GLYP-FMOC & 390 & 25 & $145-175$ & 168 & 7.0 \\
\hline \multirow{2}{*}{2} & \multirow{2}{*}{$9-25$} & ASP-FMOC & 354 & 30 & $120-170$ & 158 & 10.2 \\
& & AMPA-FMOC & 332 & 30 & $109-111$ & 110 & 10.5 \\
\hline
\end{tabular}

${ }^{a}$ Normalized collision-induced dissociation energy. ${ }^{b}$ Product ion used for qualitative purposes, extracted from the total ion scan during data processing. 
Detection parameters used by both segments: auxiliary gas $\left(\mathrm{N}_{2}\right): 3$ arbitrary units; sheath gas $\left(\mathrm{N}_{2}\right)$ : 30 arbitrary units; capillary temperature: $350{ }^{\circ} \mathrm{C}$; source current: $80 \mu \mathrm{A}$; trap DC voltage: $10 \mathrm{~V}$; scan time: $200 \mathrm{~ms}$. Source and ion transfer parameters for glyphosate-FMOC detection (segment 1): source voltage: $4.5 \mathrm{kV}$; capillary voltage: -10 $\mathrm{V}$; tube lens offset: $-21 \mathrm{~V}$; multipole RF amplifier: $520.0 \mathrm{~V}$; multipole 1 offset: $3.4 \mathrm{~V}$; multipole 2 offset: $7.0 \mathrm{~V}$; intermultipole lens voltage: $18 \mathrm{~V}$. Source and ion transfer parameters for AMPA-FMOC and ASP-FMOC detection (segment 2): source voltage: $3.6 \mathrm{kV}$; capillary voltage: $-41 \mathrm{~V}$; tube lens offset: $16 \mathrm{~V}$; multipole RF amplifier: $550.0 \mathrm{~V}$; multipole 1 offset: $2.4 \mathrm{~V}$; multipole 2 offset: $6.5 \mathrm{~V}$; intermultipole lens voltage: $42 \mathrm{~V}$.

\subsection{Results and discussion}

\subsubsection{Optimization of the analytical methodology}

\subsubsection{Preconcentration and derivatization procedures}

The preconcentration and derivatization procedure was developed with simplicity and sample throughput as priority in order to make the methodology amenable to monitoring programs. To prove the concept of lyophilization as a preconcentration tool for glyphosate, an initial recovery experiment was performed by lyophilizing $40 \mathrm{~mL}$ of deionized water fortified at $2.5 \mu \mathrm{g} / \mathrm{L}$ of each analyte. The dried residues were derivatized and analyzed by LC-FLD, and peak signals were compared with controls prepared by introducing glyphosate and AMPA directly into the derivatization mixture. Recoveries were $(67 \pm 9) \%$ for glyphosate and $(63 \pm 4) \%$ for AMPA $(n=4)$. 
The use of $40 \mathrm{~mL}$ of water samples in this early research stage took considerable drying time (approximately 8 days for a fully loaded lyophilizer), and aluminum foil covers were perforated with multiple holes as an attempt to enhance water removal efficiency. Mechanical loss of dried powder was the most probable cause of the approximate $35 \%$ analyte signal reduction, especially after such a long lyophilization period. In order to reduce lyophilization time, sample volume was later reduced to 20 $\mathrm{mL}$. Additionally, only four small holes in the aluminum cover, opened with a needle, were found to be sufficient to allow water removal from the frozen samples, minimizing mechanical losses. These actions significantly improved the recovery of the lyophilization preconcentration, however the recovery experiment was not repeated to verify the exact extent of the improvement. Nevertheless, even a $65 \%$ recovery for both analytes represents a good compromise given the simplicity of the technique which allows unattended operation, and may be considered a middle ground between recoveries obtained by ion exchange SPE preconcentration (83\% glyphosate, 26\% AMPA) (Patsias et al., 2001) and $100 \%$ recovery of derivatized analytes by reverse phase SPE reported by Hanke et al. (2008).

Both the preconcentration and the derivatization steps have the potential to cause signal variations. In order to minimize the effects of lyophilization variables such as drying period, vacuum levels and ambient temperature, a set of calibrations and QCs were lyophilized along with every sample batch and an equal quantity of an internal standard was introduced in every lyophilized sample, calibration or QC. Aspartic acid (ASP) was selected as internal standard as this low-cost reagent has also a low vapor 
pressure $\left(2.6 \times 10^{-7} \mathrm{mmHg}\right.$ at $\left.25^{\circ} \mathrm{C}\right)(\mathrm{TOXNET}, 2007)$ and also an ionic/zwitterionic behavior in aqueous solution similar to the analytes (figure 2.8). ASP-FMOC was also sufficiently resolved from the analytes with the developed chromatographic separation.
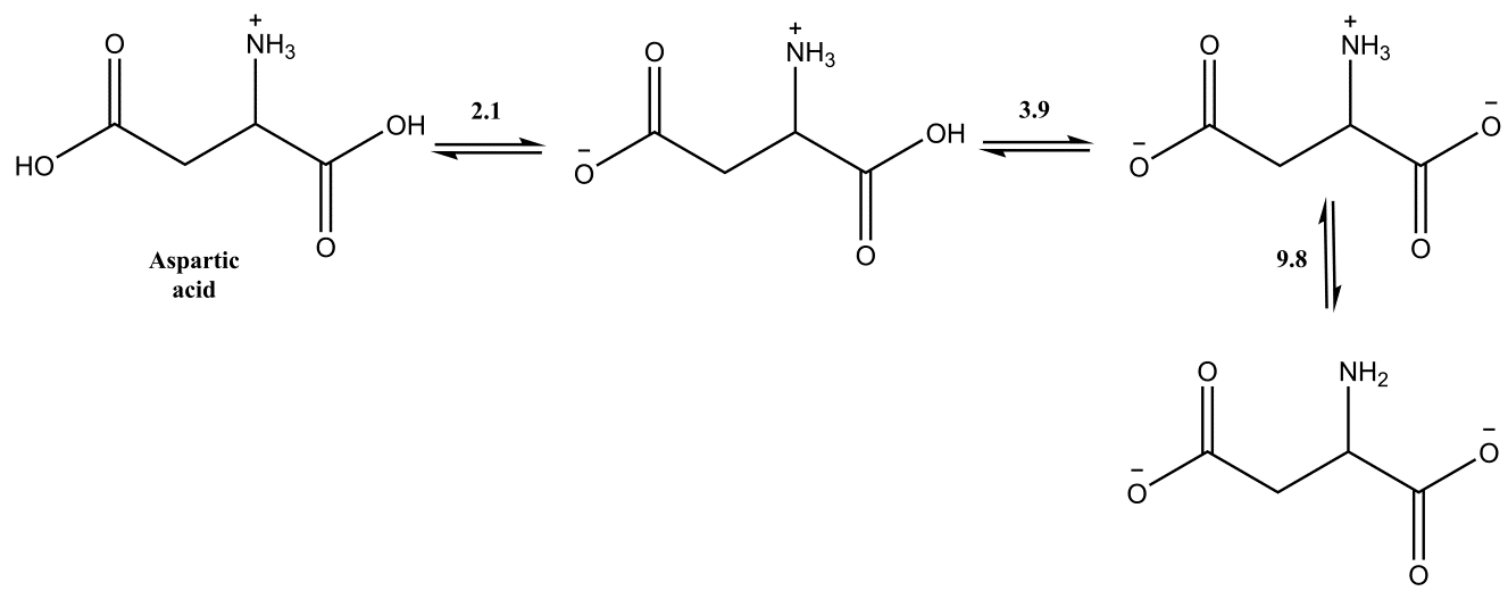

Figure 2.8 Structure of aspartic acid and $\mathrm{pK}_{\mathrm{a}}$ values (Bastug et al., 2011).

Regarding the derivatization step, both glyphosate and AMPA have strong chelating affinity for divalent cations such as $\mathrm{Ca}^{2+}, \mathrm{Fe}^{2+}, \mathrm{Cu}^{2+}$ and $\mathrm{Zn}^{2+}$, and it has been demonstrated that coordinated glyphosate and AMPA molecules do not react with FMOC-Cl and therefore severe analyte losses occur if no corrective measures are taken. The problem was first recognized by Le Fur et al. (2000), who reported significant signal degradation upon analyzing drinking waters with conductivities above $0.580 \mathrm{mS} / \mathrm{cm}$. In a round robin study, Ibanez et al. (2006) also reported that results were satisfactory except for laboratories dealing with groundwater analysis, where $15 \%$ was the best recovery reported, and attributed these results to impediment of the FMOC-Cl reaction caused by the formation of complexes with divalent cations. 
Freuze et al. (2007) released a detailed speciation study on the complexation behavior of glyphosate and AMPA in environmental waters, and on the basis of computer calculations using stability constants and expected ion concentrations, concluded that EDTA could displace glyphosate and AMPA from complexes at the basic $\mathrm{pH}$ required for FMOC-Cl derivatization. The approach was later put in practice by Hanke et al. (2008).

In the present research, lyophilized powders containing glyphosate, AMPA and ASP were suspended in EDTA solutions containing a $\mathrm{pH}=9$ borate buffer, and the FMOC-Cl reagent dissolved in acetonitrile was directly introduced without further treatment. In order to show the capacity of the internal standard to correct for both the lyophilization and derivatization steps, canal samples of different conductivity collected during October 2009 (see section 2.7.3) were fortified with $4.0 \mu \mathrm{g} / \mathrm{L}$ of each analyte, subjected to the lyophilization process, derivatized with increasing quantities of EDTA and analyzed by LC-FLD. Plots of peak areas versus EDTA concentrations, obtained after derivatization of lyophilized canal waters of different conductivities, fortified with glyphosate, ASP and AMPA are presented in figure 2.9. Glyphosate was not detected in any canal water without the addition of EDTA. These observations agree with the literature describing the impediment of the FMOC-Cl reaction by complexation and also with the use of EDTA to increase derivatization yields by releasing glyphosate from complexes.

Similar variability was observed for in signal intensities of the three compounds in deionized water, suggesting that the lyophilization process affected the three 
compounds similarly and thus ASP could be used as internal standard. In canal waters, signal intensities decreased with increasing water conductivity for both analytes and also for ASP, which suggests that the internal standard is also following a similar complex forming behavior and therefore is able to correct for the derivatization step.
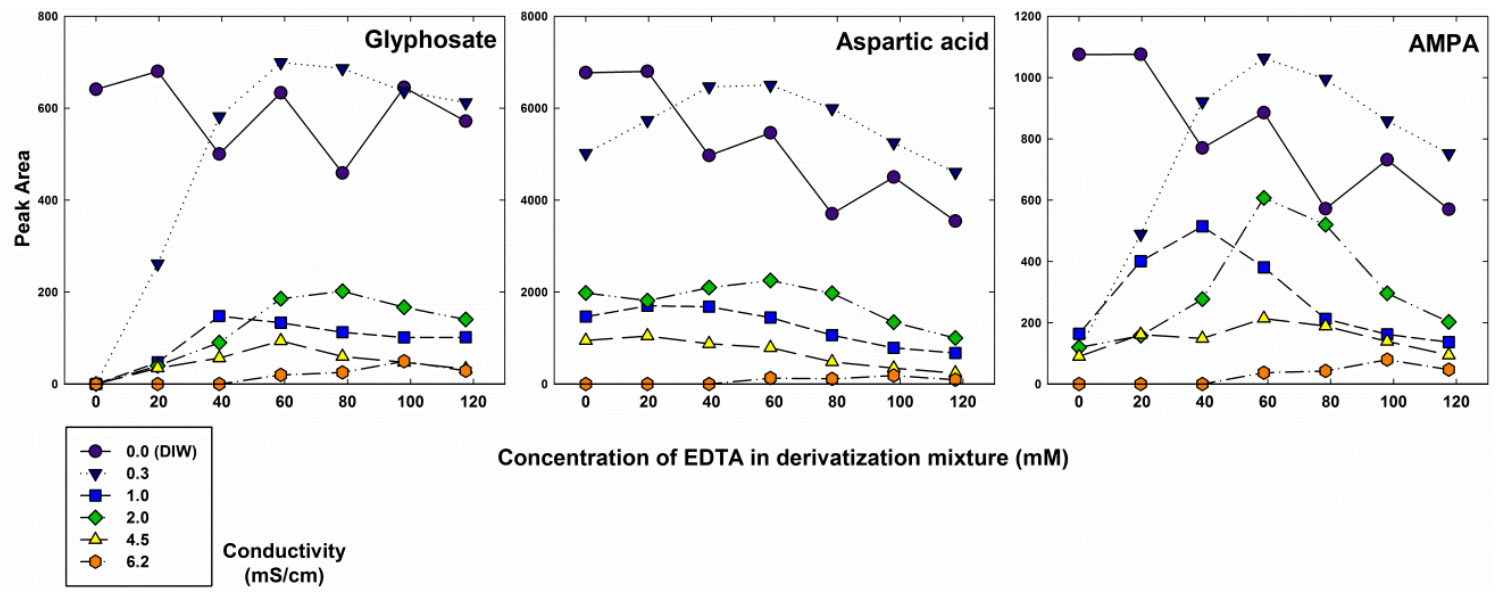

Figure 2.9 Signal intensities obtained from derivatization of fortified, lyophilized canal waters of different conductivities against the concentration of EDTA, showing similar trends between the analytes and aspartic acid used as internal standard. Fortification levels were $4 \mu \mathrm{g} / \mathrm{L}$ of glyphosate and AMPA and $40 \mu \mathrm{g} / \mathrm{L}$ of ASP.

As shown in figure 2.10, the similar behavior between the analytes and ASP translated in accurate quantitation, as good recoveries are obtained when the same amount of EDTA is used in both the fortified samples and the calibration curve. However, recoveries were biased high for the sample with highest conductivity $(6.2$ $\mathrm{mS} / \mathrm{cm}$ ), as severe signal degradation was observed at this conductivity level affecting the derivatization yield of ASP. As the EDTA solution was made basic with sodium hydroxide, attempts to further increase the concentration of EDTA from $120 \mathrm{mM}$ resulted in precipitation of the $\mathrm{FMOC}-\mathrm{Cl}$ reagent (the derivatization mixture contained $30 \%$ of 
acetonitrile to allow solubility of this compound). Therefore, the $6.2 \mathrm{mS} / \mathrm{cm}$ sample could not be quantitated correctly and a threshold of $4.5 \mathrm{mS} / \mathrm{cm}$ was set as conductivity limit for the quantitation of both analytes using $120 \mathrm{mM}$ of EDTA. As presented in section 2.7.3, this threshold affected only two of all the samples collected from the coastal canals in the area of interest.

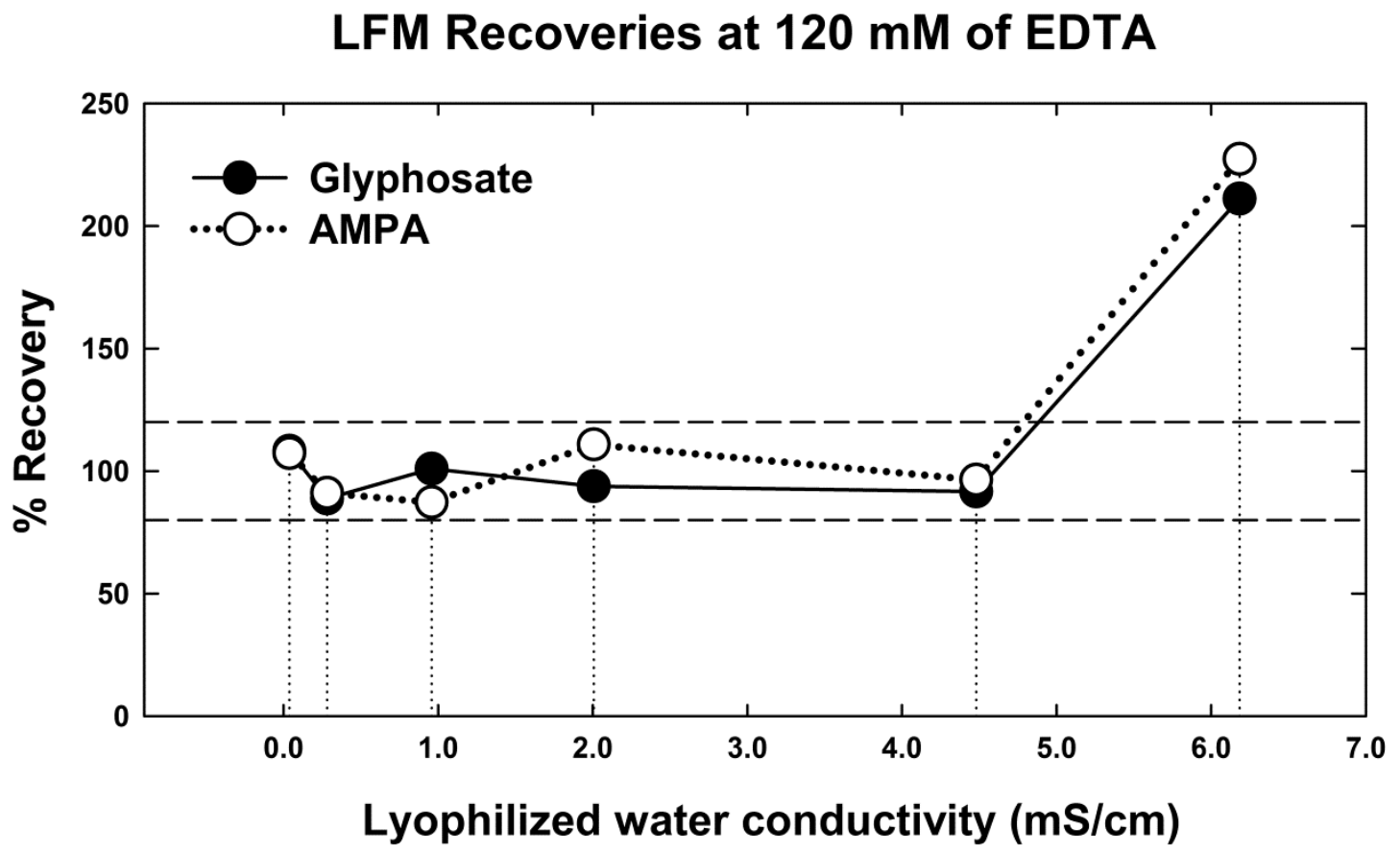

Figure 2.10 Recoveries of laboratory fortified matrices (LFM) experiments performed on canal waters of different conductivity when using $120 \mathrm{mM}$ of EDTA in both the samples and calibration solutions. Fortification level was $4.0 \mu \mathrm{g} / \mathrm{L}$. A $20 \%$ deviation from $100 \%$ recovery is represented by dashed lines.

A kinetic experiment was performed to assess the minimum reaction time and the stability of the formed FMOC derivates. As presented in figure 2.11, the reaction was completed in $30 \mathrm{~min}$ and derivates were stable up to $480 \mathrm{~min}(8 \mathrm{~h})$. These results are in agreement with observations from a previous work which found that complete 
derivatization occurred in $30 \mathrm{~min}$ and that the obtained derivates were stable for up to 2 days (Le Bot et al., 2002; Le Fur et al., 2000). Samples were injected between 2 to 4 hours after derivatization in the course of the present research.

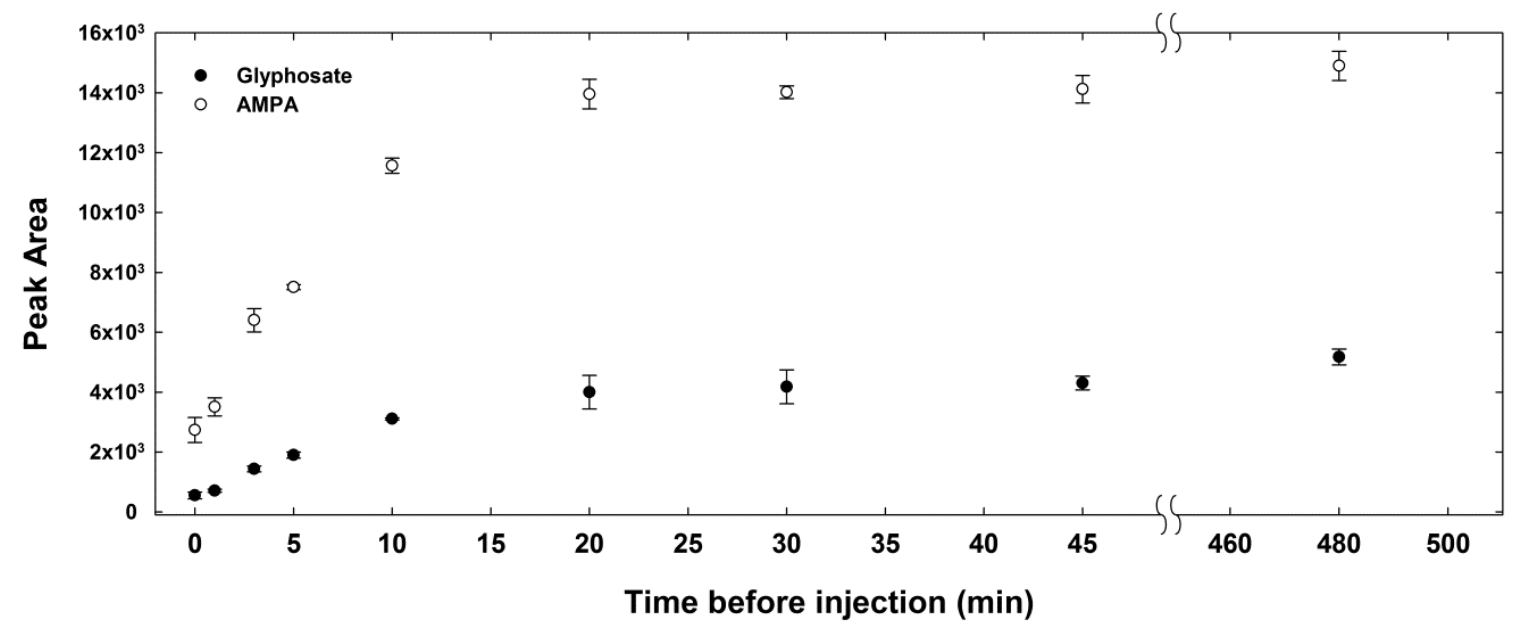

Figure 2.11 Kinetic experiment on the derivatization of glyphosate and AMPA under the conditions described in the developed methodology. Derivatization is complete after 20 $\mathrm{min}$ at room temperature and products were stable up to $480 \mathrm{~min}$ ( 8 hours). Concentrations were $400 \mu \mathrm{g} / \mathrm{L}$ for both analytes in the derivatization mixture (equivalent to $20 \mu \mathrm{g} / \mathrm{L}$ before lyophilization) $(\mathrm{n}=2)$.

\subsubsection{Chromatographic separation}

In order to perform interference-free quantitation using the fluorescence detector, proper chromatographic separation of glyphosate-FMOC and AMPA-FMOC from any possible interference must be achieved.

The use of reverse phase $\mathrm{C} 18$ columns with acetonitrile in combination with a variety of aqueous mobile phases has been preferred by previous reports for the separation of the FMOC derivates, as $\mathrm{C} 18$ columns are more durable than ion-exchange 
amino columns. However, the large quantity of the FMOC-OH reaction byproduct is retained by reverse phase columns and represents a potential source of interference for non-selective detectors such as the FLD. To resolve this challenge, some authors have used liquid-liquid extraction steps with diethyl ether to extract the byproduct before injection into the LC system (Le Bot et al., 2002; Le Fur et al., 2000). A more sophisticated approach was used by Hanke et al. (2008), who used a SPE cartridge that combines a high affinity for polar compounds and the ability to withstand cleanup steps with dichloromethane, selectively removing the non-polar FMOC-OH before eluting the derivatized analytes with methanol.

Because of its simplicity, the most widely used approach has been to chromatographically resolve the much more polar glyphosate-FMOC and AMPA-FMOC from the non-polar FMOC-OH (Grey et al., 2001; Ibanez et al., 2005; Kusters \& Gerhartz, 2010; Lee et al., 2002). This approach is preferable as it minimizes analysis steps and avoids the generation of organic solvent waste.

To maximize separation selectivity, a basic $\mathrm{pH}$ separation was selected to keep the derivatized analytes in the anionic form ensuring early elution, while causing longer retention times for neutral interferences such as FMOC-OH. As hydrolysis quickly degrades bonded stationary phases with regular, unprotected silica backbones, high $\mathrm{pH}$ separations require the use of highly endcapped stationary phases such as Phenomenex Gemini $^{\mathrm{TM}}$, which is designed to withstand $100 \%$ aqueous mobile phases and a $\mathrm{pH}$ up to 12. Using the Gemini stationary phase a gradient separation with acetonitrile and an ammonium/ammonia buffer at a $\mathrm{pH}$ of 9.5 was developed, and no peak shape degradation 
or loss of retention were observed after approximately 700 chromatographic runs during the course of my research.

A slow gradient between $1 \%$ and $25 \%$ acetonitrile in 10 minutes was used to elute the anionic glyphosate-FMOC, ASP-FMOC and AMPA-FMOC. Then, the column was quickly taken to $99 \%$ acetonitrile conditions in order to elute FMOC-OH and all other neutral interferences. A switching valve was used to divert the eluent towards waste during this step, as the highly fluorescent, highly abundant byproduct triggers the safety shutdown in the FLD used to protect the photomultiplier tube detector. To prevent the deposition of salts in the ESI source of the mass spectrometer, the switching valve must also be used during the first 5 minutes of analysis in order to flush all the non-volatile inorganic species injected along with the derivatization mixture.

Figure 2.12 shows chromatograms obtained from a lyophilized, derivatized canal water and the correspondent laboratory fortified matrix (LFM) experiment. Very clean chromatograms were obtained using the fluorescence detector, which shows selective separation of the derivatized, anionic compounds. The other major peaks between glyphosate-FMOC $(\mathrm{RT}=6.8 \mathrm{~min})$ and ASP-FMOC $(\mathrm{RT}=10.2 \mathrm{~min})$ are impurities of the EDTA and did not cause any interference as they were chromatographically resolved.

\subsubsection{Detection optimization}

The excitation and emission wavelengths ( $270 \mathrm{~nm}$ and $315 \mathrm{~nm}$, respectively) for the fluorescence of FMOC derivatives were first published by Miles in the original report that introduced the FMOC-Cl reagent (Miles et al., 1986). These wavelengths were used 
without modification. Mass spectrometry detection parameters were optimized by infusing solutions of AMPA-FMOC and glyphosate-FMOC prepared in 15\% acetonitrile/85\% ammonium/ammonia buffer $(\mathrm{pH}=9.5)$ to simulate elution conditions.

Pure FMOC derivates obtained commercially were used to prepare these optimization solutions.

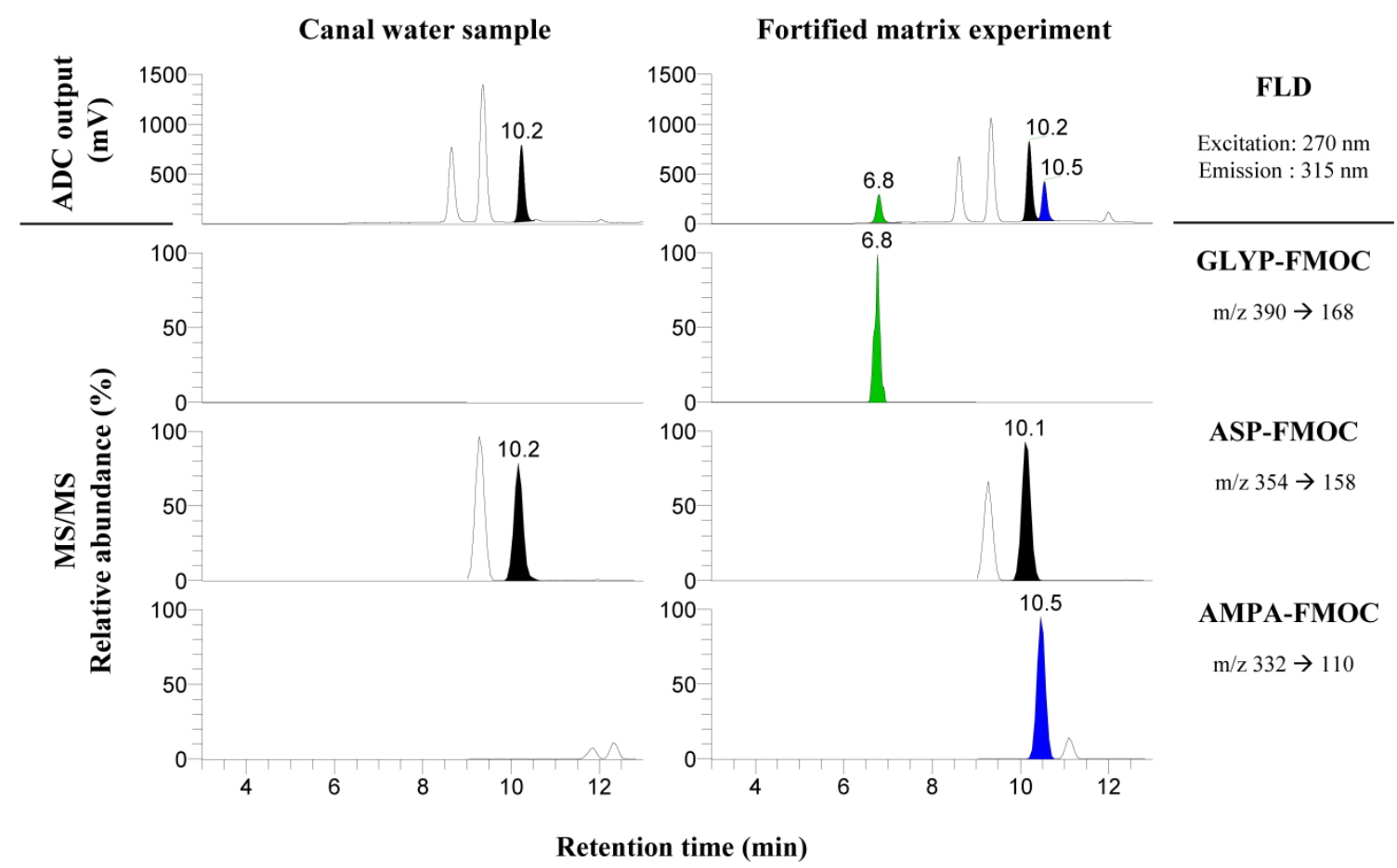

Figure 2.12 Chromatograms obtained from lyophilized canal water (sample site 1, C-1 canal, April 2010 collection) with and without analyte fortification. Fortification levels were $12.5 \mu \mathrm{g} / \mathrm{L}$ for glyphosate (green) and AMPA (blue), and $40 \mu \mathrm{g} / \mathrm{L}$ for the ASP internal standard (black). 


\subsubsection{Method validation}

\subsubsection{Calibration and quality control}

Calibration solutions were prepared in deionized water and lyophilized along with each sample batch. Curves were obtained by plotting the ratios of glyphosate-FMOC and AMPA-FMOC fluorescence peak areas to the peak area of ASP-FMOC internal standard, against the concentration in $\mu \mathrm{g} / \mathrm{L}$. Linearity was observed for both analytes in the range used $\left(\mathrm{R}^{2}>0.995 ; 0.100\right.$ to $\left.50.0 \mu \mathrm{g} / \mathrm{L}\right)$. Calibration accuracy was verified by injecting an initial calibration verification standard (ICVS, lyophilized deionized water fortified with glyphosate and AMPA to $12.5 \mu \mathrm{g} / \mathrm{L}$, using a standard purchased from a different manufacturer than the one used for calibration). Calibration stability was evaluated every 10 runs by injecting a calibration verification standard $(\mathrm{CCV}$, lyophilized deionized water fortified to $12.5 \mu \mathrm{g} / \mathrm{L}$ with the calibration standard). The measured quantity in both the $\mathrm{CCV}$ and ICVS were required to have a maximum 10\% deviation from the fortification level. A laboratory reagent blank (LRB, deionized water) and two laboratory fortified blanks (LFB, deionized water fortified to $12.5 \mu \mathrm{g} / \mathrm{L}$ ) blanks were also lyophilized with every sample batch. Additionally, a minimum of one sample duplicate and one fortified matrix experiment was always analyzed per every 10 samples. The system was continuously tested for carryover by injecting the laboratory reagent blank after every $\mathrm{CCV}$.

Compound identification was considered positive when peaks with a signal to noise ratio above 3 were present in the fluorescence chromatogram. Additionally, a signal was required to be present in the mass spectrometry chromatogram for the main product 
ion of each compound. A maximum retention time difference of 0.2 min relative to calibration standards or standard reference materials was allowed. Calculated concentrations below method detection limits (MDLs) were considered non-detections. A reporting limit (RL) of 3 times the MDLs was set in order to reduce the risk of false positives and ensure data quality.

\subsubsection{Method detection limits}

Method detection limits were calculated by multiplying the standard deviation from seven measurements by the Student $t$ value $\left(t_{(7-1,99)}=3.143\right)$, according to procedures outlined by the USEPA (2010e), using analyte-free canal water from canal C1 (site 1, April, 2010 sample collection, see section 2.7.3) fortified with glyphosate and AMPA to a concentration of $0.400 \mu \mathrm{g} / \mathrm{L}$. Method detection limits (MDL) were 0.058 $\mu \mathrm{g} / \mathrm{L}$ for glyphosate and $0.108 \mu \mathrm{g} / \mathrm{L}$ for AMPA. A reporting limit of three times the MDLs ( 0.174 and $0.324 \mu \mathrm{g} / \mathrm{L}$, respectively) was adopted to further reduce the possibility of false positives. When compared to the MDLs in the literature summarized in table 2.1, the obtained MDLs were in the same range as more complicated techniques such as the online SPE procedures reported others (Lee et al., 2002; Patsias et al., 2001; Vreeken et al., 1998). Only two techniques were found in the literature with significantly lower MDLs, the online SPE procedure described by Ibanez et al. (2005) and the offline SPE procedure described by Hanke et al. (2008), which had 10 and 80 times lower MDLs for glyphosate, respectively. Given the simplicity of this technique and the ability to preconcentrate a large number of samples in an unattended operation, the lower sensitivity may be an acceptable tradeoff for laboratories interested in monitoring 
glyphosate in surface waters. As presented in section 2.7.3, the sensitivity obtained was enough to quantify background levels of glyphosate and AMPA in the area of interest.

\subsubsection{Survey of glyphosate and AMPA in canals with direct influence on the Biscayne National Park}

\subsubsection{Glyphosate spraying event on February 2008}

Collections were made on February 5 and 6, 2008, from C-103 and North Canal, after a glyphosate application event was reported by BNP personnel. Results are presented in figure 2.13 and table 2.5. The gate structures located in these canals are constantly monitored, thus detailed records are available on conductivity, gate opening events, rainfall, head water and tail water stages during sampling periods. These records were accessed using the DBHYDRO database (SFWMD, 2013) and relevant parameters are listed in table 2.6. Although no conductivity measurements were performed in this set of samples, instant conductivity records are available from the S20F with a $3 \mathrm{~min}$ resolution. Water conductivities at the moment of sample collection at S20F (site 8) were $4.1 \mathrm{mS} / \mathrm{cm}$ on February 5, 2010 and $1.6 \mathrm{mS} / \mathrm{cm}$ during the next day, which are both below the conductivity threshold set for this methodology as discussed before, and since

conductivities in sites further away from the shoreline should be lower, the measurements were considered valid. No rainfall was recorded in the area up to 5 days before February 5 , and therefore rainwater runoff from nearby farms should not be an important source of glyphosate detected within this dataset. 
Table 2.5 Measured concentrations and quality controls from samples collected during a glyphosate spraying event at the vicinity of the BNP in February 2008. (TOP) samples collected on February $5^{\text {th }}, 2008$. (BOTTOM) Samples collected on February $06^{\text {th }}, 2008$. Samples were collected between $2 \mathrm{pm}$ and 4 pm in both dates. ${ }^{\mathrm{a}}$

\begin{tabular}{|c|c|c|c|c|c|c|c|c|c|}
\hline \multirow[b]{2}{*}{ Site } & \multirow[b]{2}{*}{ Canal name } & \multirow[b]{2}{*}{$\begin{array}{l}\text { Lat. } \\
\text { North }\end{array}$} & \multirow[b]{2}{*}{$\begin{array}{l}\text { Long. } \\
\text { West }\end{array}$} & \multicolumn{3}{|c|}{ Glyphosate } & \multicolumn{3}{|c|}{ AMPA } \\
\hline & & & & Meas. & $\begin{array}{c}\mathrm{LFM}^{\mathrm{b}} \\
\text { or } \\
\boldsymbol{D U}^{\boldsymbol{U}^{\mathbf{c}}}\end{array}$ & $\begin{array}{c}\text { \%rec } \\
\text { or } \\
\text { RPD }\end{array}$ & Meas. & $\begin{array}{c}\mathrm{LFM}^{\mathrm{b}} \\
\text { or } \\
\boldsymbol{D} \boldsymbol{U} \boldsymbol{P}^{\mathbf{c}}\end{array}$ & $\begin{array}{c}\text { \%rec } \\
\text { or } \\
\text { RPD }\end{array}$ \\
\hline 1 & North & 25.4631 & 80.3793 & 43.4 & & & 3.11 & & \\
\hline 2 & North & 25.4631 & 80.3750 & 47.2 & & & 5.86 & & \\
\hline 3 & North & 25.4631 & 80.3670 & 17.0 & 18.3 & 8 & 4.18 & 4.54 & 8 \\
\hline 4 & North & 25.4632 & 80.3592 & 12.4 & & & 5.65 & & \\
\hline 5 & North & 25.4632 & 80.3537 & 10.2 & 15.0 & 121 & 6.94 & 11.5 & 117 \\
\hline 6 & North/L-31E & 25.4632 & 80.3473 & 16.1 & & & 4.17 & & \\
\hline 7 & L-31E & 25.4667 & 80.3468 & 18.3 & & & 2.52 & & \\
\hline 8 & C-103/L-31E & 25.4700 & 80.3470 & 8.15 & & & 9.09 & & \\
\hline 9 & L31-E & 25.4722 & 80.3470 & n.a. & & & n.a. & & \\
\hline 10 & C-103 & 25.4700 & 80.3636 & 0.440 & & & 1.15 & & \\
\hline 11 & C-103 & 25.4711 & 80.3793 & - & & & - & & \\
\hline
\end{tabular}

\begin{tabular}{|c|c|c|c|c|c|c|c|c|c|}
\hline \multirow[b]{2}{*}{ Site } & \multirow[b]{2}{*}{ Canal name } & \multirow[b]{2}{*}{$\begin{array}{l}\text { Lat. } \\
\text { North }\end{array}$} & \multirow[b]{2}{*}{$\begin{array}{l}\text { Long. } \\
\text { West }\end{array}$} & \multicolumn{3}{|c|}{ Glyphosate } & \multicolumn{3}{|c|}{ AMPA } \\
\hline & & & & Meas. & $\begin{array}{c}\mathrm{LFM}^{\mathrm{b}} \\
\text { or } \\
\boldsymbol{D} \boldsymbol{U} \boldsymbol{P}^{\mathbf{c}}\end{array}$ & $\begin{array}{c}\text { \%rec } \\
\text { or } \\
\text { RPD }\end{array}$ & Meas. & $\begin{array}{c}\mathrm{LFM}^{\mathrm{b}} \\
\text { or } \\
\boldsymbol{D} \boldsymbol{U} \boldsymbol{P}^{\mathbf{c}}\end{array}$ & $\begin{array}{c}\text { \%rec } \\
\text { or } \\
\text { RPD }\end{array}$ \\
\hline 1 & North & 25.4631 & 80.3793 & 59.9 & & & 7.39 & & \\
\hline 2 & North & 25.4631 & 80.3750 & 36.9 & & & 6.04 & & \\
\hline 3 & North & 25.4631 & 80.3670 & 32.5 & & & 4.65 & & \\
\hline 4 & North & 25.4632 & 80.3592 & 14.5 & & & 6.41 & & \\
\hline 5 & North & 25.4632 & 80.3537 & 10.7 & & & 6.47 & & \\
\hline 6 & North/L-31E & 25.4632 & 80.3473 & 12.5 & 12.8 & 3 & 4.78 & 4.75 & 1 \\
\hline 7 & L-31E & 25.4667 & 80.3468 & 2.40 & & & 2.72 & & \\
\hline 8 & C-103/L-31E & 25.4700 & 80.3470 & 6.11 & 10.5 & 109 & 2.13 & 7.09 & 127 \\
\hline 9 & L31-E & 25.4722 & 80.3470 & 3.65 & & & 2.01 & & \\
\hline 10 & C-103 & 25.4700 & 80.3636 & n.a. & & & n.a. & & \\
\hline 11 & $\mathrm{C}-103$ & 25.4711 & 80.3793 & - & & & - & & \\
\hline
\end{tabular}

${ }^{a}$ All concentrations are listed in $\mu \mathrm{g} / \mathrm{L}$.; (-): Below MDL; (n.a.): data not available. ${ }^{b}$ Laboratory Fortified Matrix experiment, results presented in percent recovery. Fortification level was $4.0 \mu \mathrm{g} / \mathrm{L}$. ${ }^{c}$ Duplicate measurements. Results presented in relative percent deviation (RPD). 

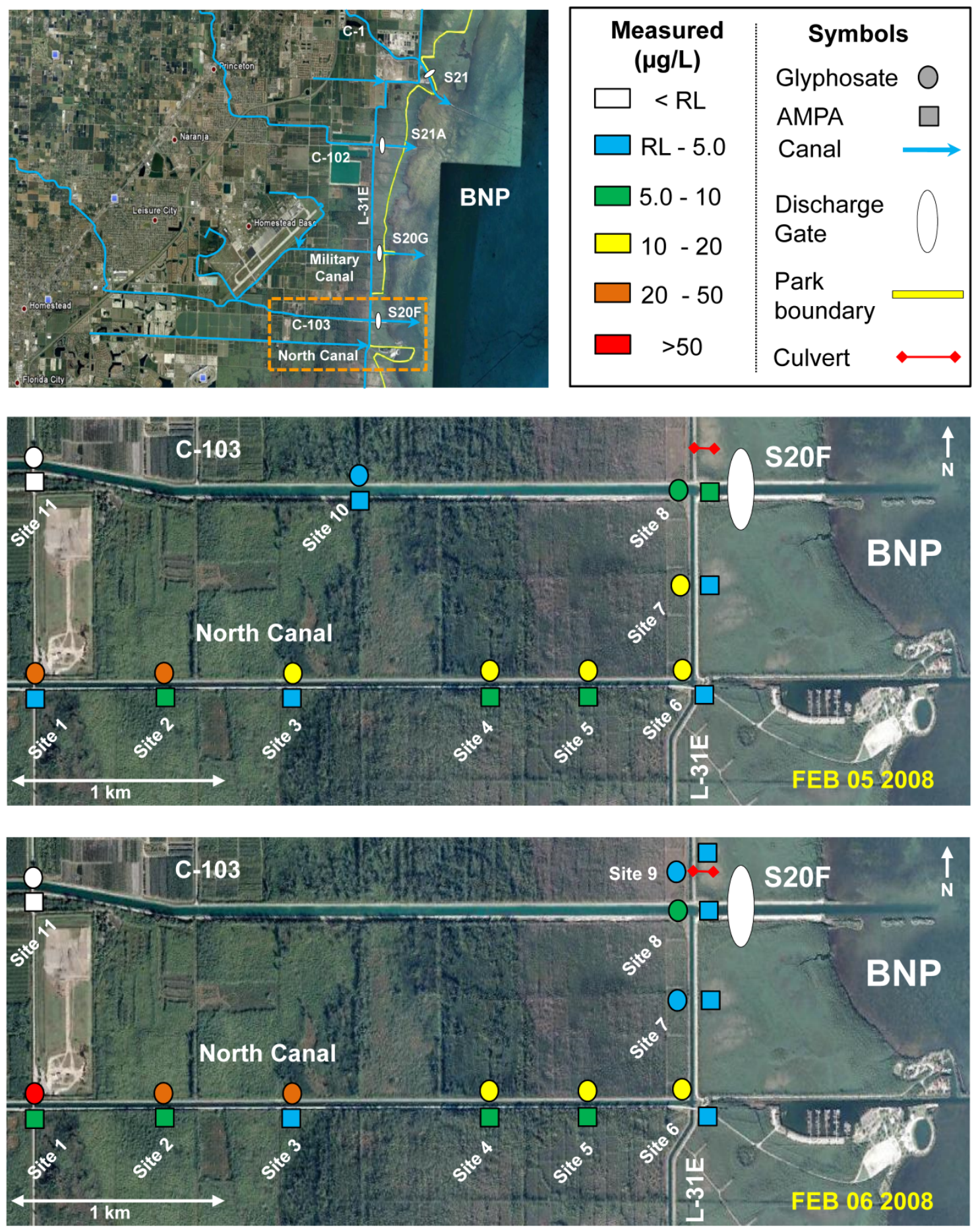

Figure 2.13 Sampling sites and results for collections in February 2008 at C-103 and North Canal. (RL: $0.174 \mu \mathrm{g} / \mathrm{L}$ for GLYP; $0.324 \mu \mathrm{g} / \mathrm{L}$ for AMPA). 
Table 2.6 Hydrological data from gate structures for the February, 2008 sample collection. Data obtained from DBHYDRO (SFWMD, 2013).

\begin{tabular}{c|c|c|c|c}
\hline $\begin{array}{c}\text { Gate } \\
\text { structure }\end{array}$ & Canal & $\begin{array}{c}\mathbf{0 2 / 0 1 / 2 0 0 8 ~ t o ~ 0 2 / 0 6 / 2 0 0 8 ~} \\
\text { Total rainfall }^{\mathbf{a}}(\mathbf{m m})\end{array}$ & $\begin{array}{c}\text { Discharge flow } \\
\mathbf{0 2 / 0 5 / 2 0 0 8}\left(\mathbf{m}^{\mathbf{3}} / \mathbf{s}\right)\end{array}$ & $\begin{array}{c}\text { Discharge flow }^{\mathbf{b}} \\
\mathbf{0 2 / 0 6 / 2 0 0 8}\left(\mathbf{m}^{\mathbf{3}} / \mathbf{s}\right)\end{array}$ \\
\hline S21 & C-1 & 0 & 0 & 0.01 \\
S21A & C-102 & 0 & 0 & 0 \\
S20G & Military & 0 & 0 & 0 \\
S20F & C-103 & 0 & 0.08 & 1.54 \\
\hline
\end{tabular}

${ }^{a}$ Period total. ${ }^{b}$ Day average.

The DBHYDRO data also showed that S20F gates were opened between 8:51 AM and 1:22 PM on February 6, before the second sample collection started (from 3:00 to 4:00 PM). Discharge from the other three gate structures in the area was negligible during both sampling days. The estimated amount of water discharged during the gate opening event was $(1.5 \pm 0.3) \times 10^{5} \mathrm{~m}^{3}$, calculated using the event duration and the average water discharge rate during the event. The latter was calculated using the discharge-rate coefficient of the S20F structure published by the U.S. Geological Survey (Swain et al., 1997), the S20F structural dimensions obtained from the SFWMD (2010) and data on gate height and water stages during the discharge event. Therefore, the discharge event caused a considerable increase of water movement in the sampled canals near the gate between sample collections, and this needs to be considered for discussing the observed concentrations.

No glyphosate or AMPA were detected in site 11 (C-103 upstream) before or after the water discharge event. Since this canal is the major contributor to the outflow in the S20F structure, the opening of the gate displaced a considerable amount of water from upstream. Therefore, these results suggest that this canal did not have a nearby source of glyphosate during the sampling period. The highest concentrations of 
glyphosate were measured in North Canal, which suggests that this canal was a target for herbicide application. Site 1 in North Canal contained the highest amount of glyphosate in both sampling days. At this particular site a considerable amount of terrestrial vegetation was observed (see figure 2.14), which could have made it a target for a direct glyphosate application.

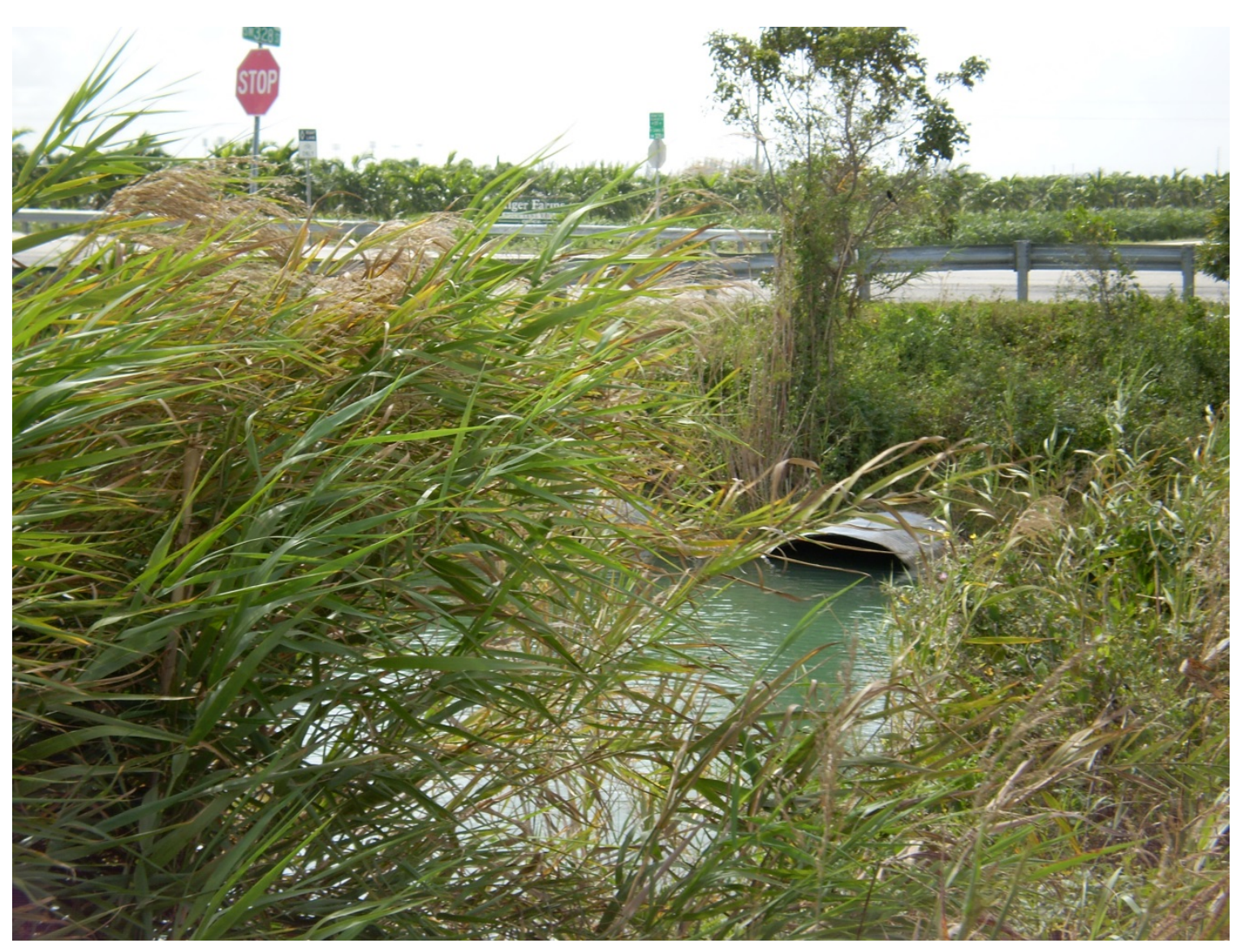

Figure 2.14 Terrestrial vegetation observed on the shoreline of North Canal at sampling site 1 , the most contaminated site with glyphosate in this study. (Picture taken at the moment of sample collection on February $6^{\text {th }}, 2008,2: 15$ PM) 
As presented in figure 2.15, a decrease trend was observed with increasing canal distance from site 1 . The decreasing trend and the concentrations observed were very similar during both days, thus the two-day average was used to create figure 2.15 . The concentrations of AMPA were constant in all sites during both days, which suggest that biodegradation was a limited removal pathway.

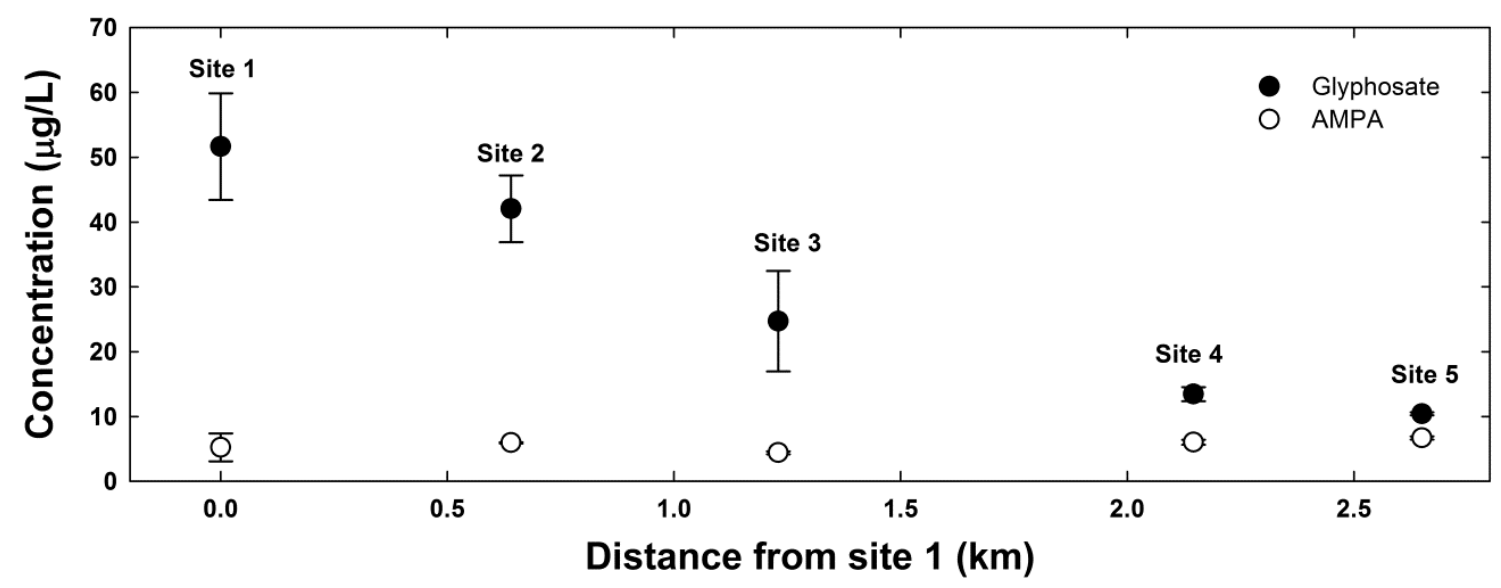

Figure 2.15 Two-day average concentrations measured in North Canal against distance from site 1, the point of highest concentrations of glyphosate detected, showing a fast decrease in concentration.

The results show that the discharge event at S20F caused a mild increase on the concentrations measured in site 1 and site 2 , which suggest that water flowing from upstream North Canal may have contained higher concentrations of glyphosate than site 1 and therefore the canal was subjected to herbicide applications upstream from that point. However, the concentrations in site 4 and site 5 were almost the same as in the previous day. Therefore, the decreasing trend may be a combination of a dilution effect from more concentrated sites upstream with a glyphosate removal pathway, and since no significant 
increases on the concentrations of AMPA were observed, adsorption to sediments and suspended particles may have played a dominant role in the concentration decrease.

The concentrations measured in L-31E during the first day were similar to sites in downstream North Canal but significantly lower during the second day, which could indicate that an important dilution with northbound L-31E water may have occurred at the North Canal/L-31E intersection during the water discharge event at S20F. Therefore, given the removal by adsorption and dilution effects, is possible that glyphosatecontaminated water from North Canal may have only contributed a small quantity of water to the total outflow in the discharge occurred at the S20F gate structure and quantities of glyphosate discharged with this event should have been negligible.

The maximum concentration of glyphosate detected in the study $(59.9 \mu \mathrm{g} / \mathrm{L}$, site 1) was lower than the chronic toxicity for green microalgae (NOEC $=200 \mu \mathrm{g} / \mathrm{L}$ ), the aquatic organism most sensitive to glyphosate according to available data (Giesy et al., 2000; WHO, 1994).

In a literature review for aquatic application risk assessment, Solomon found that marine diatoms had the lowest acute toxicity with an $\mathrm{EC}_{50}$ of $770 \mu \mathrm{g} / \mathrm{L}$, and considered that chronic toxicities of glyphosate have little value to establish risk to aquatic ecosystems because expositions to the herbicide are much shorter in the field than in laboratory toxicity tests, especially in estuarine systems where turbulence induced by 12 hour tidal cycles would cause a fast removal of glyphosate by adsorption onto sediments and suspended particles (Solomon \& Thompson, 2003). Therefore, even if the maximum observed concentration of glyphosate would have been near one of the culverts present in 
the L-31E levee for hydration of the coastal wetlands (for example, an herbicide application near site 9), dilution effects and removal by adsorption would have further reduced the environmental concentration of the herbicide upon discharge. Thus, the results obtained during the present investigation do not provide enough evidence that glyphosate used for canal maintenance may have been a significant threat to the protected areas in the vicinity of the sampled canals.

\subsubsection{Wide area collection on October 2009}

In order to assess background levels of glyphosate in all major canals in the area, a wide area sample collection trip was performed during October 22, 2009. Results are shown in table 2.8 and figure 2.16. Glyphosate was detected only in North and Goulds canals. Concentrations were always below $1 \mu \mathrm{g} / \mathrm{L}$, much lower than the concentrations observed in February 2008. The metabolite AMPA was ubiquitous, and concentrations were very similar than the previous sample collection trips in February, 2008. No apparent trends were observed in the concentrations of AMPA. Also, no significant increases of AMPA were observed in C-1 or L-31E at the vicinity of the South District WWTP, which is consistent with the fact that this particular WWTP uses deep well injection disposal of effluents (FDEP, 2013) and therefore should not discharge AMPA generated from biodegradation of household detergents directly into canals.

The presence of small quantities of glyphosate in two canals with adjacent agricultural farms suggests that these environments may represent an important source of the herbicide. The DBHYDRO data show that during the day previous to sampling, a mild rainfall event occurred in the area (see table 2.7). It is possible that runoff from 
farms could have been the main source of the measured concentrations of glyphosate in these canals.

It is also notable that glyphosate was found only in smaller canals that do not have a direct discharge gate. These canals are narrower, shallower and thus subjected to lower water flows than the larger C-103, North Canal, C-1 and Military Canal. The DBHYDRO data also show that three of the gate structures were opened during the sampling day, and therefore the considerable water movement could have contributed to the no detection of glyphosate in the major canals.

Table 2.7 Hydrological data from gate structures for the October 22, 2009 sample collection. Data obtained from DBHYDRO (SFWMD, 2013).

\begin{tabular}{c|c|c|c|c}
\hline Gate structure & Canal & $\begin{array}{c}\mathbf{1 0 / 2 1 / 2 0 0 9} \\
\text { Rainfall }^{\mathbf{~}}(\mathbf{m m})\end{array}$ & $\begin{array}{c}\mathbf{1 0} / \mathbf{2 2} / \mathbf{2 0 0 9} \\
\text { Rainfall }^{\mathbf{a}}(\mathbf{m m})\end{array}$ & $\begin{array}{c}\text { Discharge flow } \\
\mathbf{1 0 / 2 2} / \mathbf{2 0 0 9}\left(\mathbf{m}^{\mathbf{3}} / \mathbf{s}\right)\end{array}$ \\
\hline S21 & C-1 & 15.0 & 0.3 & 1.50 \\
S21A & C-102 & 3.6 & 0.3 & 3.12 \\
S20G & Military & 13.7 & 0 & 0 \\
S20F & C-103 & 8.6 & 0 & 15.2 \\
\hline
\end{tabular}

a Day total. ${ }^{\mathrm{b}}$ Day average.

Although very low background levels of glyphosate were detected in canals of the area of interest, these data along with the previous collections from 2008 show the capability of the developed methodology to discern between canals contaminated with direct applications of the herbicide and canals under the influence of minor local sources.

Although AMPA is also biodegradable, the metabolite has a higher environmental persistence than glyphosate (Giesy et al., 2000) and its widespread presence is consistent with a constant introduction of glyphosate into this aquatic environment. 

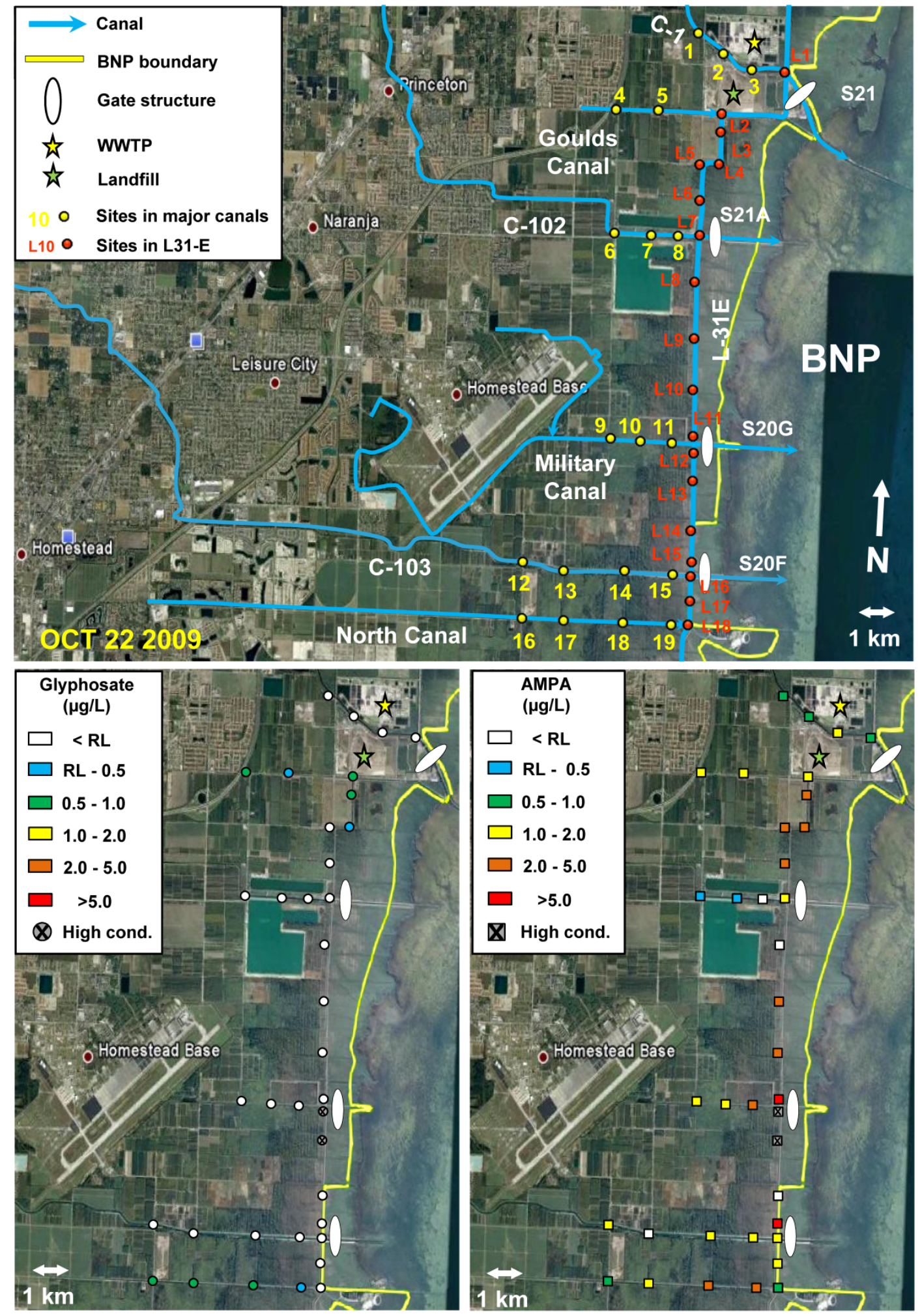

Figure 2.16 Sampling sites and results from the October $22^{\text {nd }}, 2009$ sample collection. Concentration color scale was reduced one order of magnitude from the 2008 sampling trips. (RL: $0.174 \mu \mathrm{g} / \mathrm{L}$ for glyphosate; $0.324 \mu \mathrm{g} / \mathrm{L}$ for AMPA). 
Table 2.8 Measured conductivities, measurements and QCs of glyphosate and AMPA in samples collected on October 22, 2009 from all canals in the area of interest. ${ }^{\text {a }}$

\begin{tabular}{|c|c|c|c|c|c|c|c|c|c|c|}
\hline \multirow[b]{2}{*}{ Site } & \multirow[b]{2}{*}{ Canal name } & \multirow[b]{2}{*}{ Lat. $\mathbf{N}$} & \multirow[b]{2}{*}{$\begin{array}{l}\text { Long. } \\
\text { W }\end{array}$} & \multirow[b]{2}{*}{$\begin{array}{c}\text { Cond. } \\
\text { (mS/cm) }\end{array}$} & \multicolumn{3}{|c|}{ Glyphosate } & \multicolumn{3}{|c|}{ AMPA } \\
\hline & & & & & Meas. & $\begin{array}{l}\mathrm{LFM}^{\mathrm{b}} \\
\text { or } \\
\boldsymbol{D} \boldsymbol{U P}^{c}\end{array}$ & $\begin{array}{c}\text { \%rec } \\
\text { or } \\
\boldsymbol{R P D}\end{array}$ & Meas. & $\begin{array}{c}\text { LFM }^{\mathrm{b}} \\
\text { or } \\
\boldsymbol{D} \boldsymbol{U P}^{c}\end{array}$ & $\begin{array}{c}\text { \%rec } \\
\text { or } \\
\boldsymbol{R P D}\end{array}$ \\
\hline 1 & $\mathrm{C}-1$ & 25.5486 & 80.3478 & 0.3 & - & 1.79 & 90 & 0.699 & 2.93 & 112 \\
\hline 2 & $\mathrm{C}-1$ & 25.5454 & 80.3427 & 0.3 & - & & & 0.659 & & \\
\hline 3 & $\mathrm{C}-1$ & 25.5437 & 80.3334 & 0.6 & - & & & 1.13 & & \\
\hline 4 & Goulds & 25.5370 & 80.3648 & 0.3 & 0.586 & 2.06 & 74 & 1.07 & 3.70 & 132 \\
\hline 5 & Goulds & 25.5370 & 80.3594 & 0.7 & 0.331 & & & 1.41 & & \\
\hline 6 & C-102 & 25.5194 & 80.3635 & 0.4 & - & & & 0.362 & & \\
\hline 7 & C-102 & 25.5193 & 80.3557 & 0.5 & - & - & n.a. & 0.643 & 0.616 & 4 \\
\hline 8 & C-102 & 25.5192 & 80.3507 & 0.5 & - & & & - & & \\
\hline 9 & Military & 25.4893 & 80.3634 & 1.0 & - & - & n.a. & 1.89 & 1.899 & 0.3 \\
\hline 10 & Military & 25.4893 & 80.3577 & 1.4 & - & & & 1.67 & & \\
\hline 11 & Military & 25.4894 & 80.3511 & 1.2 & - & & & 2.15 & & \\
\hline 12 & $\mathrm{C}-103$ & 25.4714 & 80.3794 & 3.7 & - & 1.65 & 83 & 1.31 & 4.12 & 140 \\
\hline 13 & C-103 & 25.4705 & 80.3713 & 1.9 & - & - & n.a. & - & - & n.a. \\
\hline 14 & C-103 & 25.4705 & 80.3609 & 2.5 & - & & & 1.21 & & \\
\hline 15 & C-103 & 25.4706 & 80.3497 & 3.4 & - & & & 1.73 & & \\
\hline 16 & North & 25.4629 & 80.3791 & 0.6 & 0.697 & 0.740 & 6 & 0.975 & 1.191 & 20 \\
\hline 17 & North & 25.4628 & 80.3734 & 0.6 & 0.598 & & & 1.25 & & \\
\hline 18 & North & 25.4629 & 80.3614 & 0.6 & 0.652 & & & 2.69 & & \\
\hline 19 & North & 25.4629 & 80.3478 & 2.7 & 0.424 & & & 3.21 & & \\
\hline L1 & C-1/L-31E & 25.5441 & 80.3311 & 0.3 & - & & & 0.964 & & \\
\hline $\mathrm{L} 2$ & Goulds/L-31E & 25.5371 & 80.3437 & 0.5 & 0.944 & & & 1.77 & & \\
\hline L3 & L-31E & 25.5344 & 80.3435 & 0.7 & 0.601 & & & 2.85 & & \\
\hline L4 & L-31E & 25.5299 & 80.3437 & 1.0 & 0.298 & 0.257 & 15 & 3.23 & 3.618 & 11 \\
\hline L5 & L-31E & 25.5298 & 80.3469 & 0.6 & - & & & 2.59 & & \\
\hline L6 & $\mathrm{L}-31 \mathrm{E}$ & 25.5251 & 80.3469 & 0.6 & - & & & 2.46 & & \\
\hline L7 & $\mathrm{C}-102 / \mathrm{L}-31 \mathrm{E}$ & 25.5196 & 80.3469 & 0.5 & - & & & 1.77 & & \\
\hline L8 & L-31E & 25.5118 & 80.3473 & 1.4 & - & & & - & & \\
\hline L9 & L-31E & 25.5029 & 80.3473 & 1.4 & - & & & 2.81 & & \\
\hline L10 & L-31E & 25.4948 & 80.3470 & 1.3 & - & & & 4.29 & & \\
\hline L11 & L-31E & 25.4899 & 80.3471 & 2.7 & - & & & 5.63 & & \\
\hline L12 & L-31E & 25.4890 & 80.3471 & $6.2 *$ & _* & - & n.a. & $4.42 *$ & 4.568 & 3 \\
\hline L13 & L-31E & 25.4833 & 80.3469 & $5.6^{*}$ & -* & & & -* & & \\
\hline L14 & $\mathrm{L}-31 \mathrm{E}$ & 25.4765 & 80.3469 & 3.6 & - & & & - & & \\
\hline L15 & L-31E & 25.4709 & 80.3468 & 4.5 & - & 2.06 & 103 & 6.65 & 9.12 & 123 \\
\hline L16 & C-103/L-31E & 25.4702 & 80.3468 & 2.4 & - & & & 1.74 & & \\
\hline L17 & L-31E & 25.4660 & 80.3468 & 1.1 & - & & & 1.08 & & \\
\hline L18 & North/L-31E & 25.4633 & 80.3469 & 2.0 & - & & & 0.965 & & \\
\hline
\end{tabular}

${ }^{a}$ All concentrations are listed in $\mu \mathrm{g} / \mathrm{L} .(-)$ : Below MDL; (*): Above conductivity safety threshold (4.5 mS/cm); (n.a.): not available. ${ }^{\mathrm{b}}$ Laboratory Fortified Matrix experiment, results measured in percent recovery. Fortification level was $2.0 \mu \mathrm{g} / \mathrm{L} .{ }^{\mathrm{c}}$ Duplicate measurements. Results presented in relative percent deviation (RPD). 


\subsubsection{Samples collected after a heavy rain event on April 2010}

A relatively heavy rain event occurred in the sampling area on April 27, 2010, with an approximate rainfall of $60 \mathrm{~mm}$ (see table 2.9), which was six times higher than the rainfall recorded during the day previous to the sampling in October, 2009.

Table 2.9 Hydrological data from gate structures for the April 28, 2010 sample collection. Data obtained from DBHYDRO (SFWMD, 2013).

\begin{tabular}{c|c|c|c|c}
\hline Gate structure & Canal & $\begin{array}{c}\mathbf{0 4} / \mathbf{2 7 / 2 0 1 0} \\
\text { Rainfall }^{\mathbf{a}}(\mathbf{m m})\end{array}$ & $\begin{array}{c}\mathbf{0 4} / \mathbf{2 8} / \mathbf{2 0 1 0} \\
\text { Rainfall }^{\mathbf{a}}(\mathbf{m m})\end{array}$ & $\begin{array}{c}\text { Discharge flow }^{\mathbf{b}} \\
\mathbf{0 4 / 2 8 / 2 0 1 0}\left(\mathbf{m}^{\mathbf{3}} / \mathbf{s}\right)\end{array}$ \\
\hline S21 & C-1 & 51.6 & 0 & 17.9 \\
S21A & C-102 & 55.1 & 0 & 6.23 \\
S20G & Military & 61.5 & 0 & 2.32 \\
S20F & C-103 & 67.1 & 0 & 9.14 \\
\hline
\end{tabular}

${ }^{a}$ Day total. ${ }^{b}$ Day average.

To assess if rainwater runoff was a source of glyphosate in the canal areas as the previous results suggested, a new sampling collection trip was organized on April 28, 2010. Samples were collected from the Goulds canal, C-1, C-103, a small tributary of C103 that was adjacent to a palm tree farm, and also from North Canal. Results are presented in table 2.10 and figure 2.17 . The highest concentrations of glyphosate were found in L-31E, north of the South District WWTP (sites 8 and 9), in an area adjacent to a large residential development, and L-31E may have had runoff input from maintenance activities in roads or other infrastructure. No glyphosate or AMPA were detected in site 7, which may be the result of dilution with water from $\mathrm{C}-1$ as the DBHYDRO data indicate that the S21 discharge gate was opened during all of the sampling day.

Only small quantities of glyphosate were found in the intersection of the Goulds canal and L-31E, and also in C-103 and North Canal. The sample from C-103 that 
contained glyphosate was collected directly from the opening of a culvert that connects that canal with a small canal under the influence of runoff from a palm tree farm, from which another sample was collected. As presented in figure 2.17, the small canal had a glyphosate concentration 10 times higher than $\mathrm{C}-103$ in the other side of the culvert, and also an important concentration of AMPA, which was not detected in C-103. The DBHYDRO data show that the S20F discharge gate was also opened when the samples were collected. The observation suggests that agricultural runoff is an important source of glyphosate and AMPA in the coastal canals with influence on the BNP protected areas, and also that fast flowing canals will dilute glyphosate and move it downstream from the input point.

Table 2.10 Measured conductivities and concentrations of glyphosate and AMPA in samples collected on April 27, 2010 from canals C-1, Goulds, C-103 and North Canal. ${ }^{\text {a }}$

\begin{tabular}{|c|c|c|c|c|c|c|c|c|c|c|}
\hline \multirow[b]{2}{*}{ Site } & \multirow[b]{2}{*}{ Canal name } & \multirow[b]{2}{*}{ Lat. $\mathbf{N}$} & \multirow[b]{2}{*}{$\begin{array}{c}\text { Long. } \\
\text { W }\end{array}$} & \multirow[b]{2}{*}{$\begin{array}{l}\text { Cond. } \\
(\mathrm{mS} / \mathrm{cm})\end{array}$} & \multicolumn{3}{|c|}{ Glyphosate } & \multicolumn{3}{|c|}{ AMPA } \\
\hline & & & & & Meas. & $\begin{array}{c}\mathrm{LFM}^{\mathrm{b}} \\
\text { or } \\
\boldsymbol{D} \boldsymbol{U} \boldsymbol{P}^{c}\end{array}$ & $\begin{array}{c}\% \text { rec } \\
\text { or } \\
\boldsymbol{R P D} \\
\end{array}$ & Meas. & $\begin{array}{c}\mathrm{LFM}^{\mathrm{b}} \\
\text { or } \\
\boldsymbol{D} \boldsymbol{U} \boldsymbol{P}^{c}\end{array}$ & $\begin{array}{c}\text { orec } \\
\text { or } \\
\boldsymbol{R P D} \\
\end{array}$ \\
\hline 1 & $\mathrm{C}-1$ & 25.5663 & 80.3619 & 0.7 & - & & & - & & \\
\hline 2 & $\mathrm{C}-1$ & 25.5594 & 80.3590 & 0.8 & - & 10.9 & 86 & - & 12.8 & 103 \\
\hline 3 & $\mathrm{C}-1$ & 25.5484 & 80.3474 & 0.7 & - & - & n.a. & - & - & n.a. \\
\hline 4 & $\mathrm{~L}-31 \mathrm{E}$ & 25.5372 & 80.3478 & 2.0 & $<\mathrm{RL}$ & & & - & & \\
\hline 5 & C-101/L-31E & 25.5375 & 80.3441 & 2.0 & 0.310 & & & $<\mathrm{RL}$ & & \\
\hline 6 & $\mathrm{~L}-31 \mathrm{E}$ & 25.5376 & 80.3337 & 2.0 & - & & & 4.69 & & \\
\hline 7 & C-1/L-31E & 25.5434 & 80.3314 & 1.1 & - & & & - & & \\
\hline 8 & L-31E & 25.5516 & 80.3314 & 0.7 & 2.01 & & & 1.36 & & \\
\hline 9 & L-31E & 25.5550 & 80.3313 & 1.2 & 2.02 & 13.3 & 89 & 1.25 & 14.1 & 103 \\
\hline 10 & C-103 & 25.4715 & 80.3794 & 1.6 & - & & & 1.34 & & \\
\hline 11 & C-103 & 25.4705 & 80.3715 & 1.0 & 0.859 & 12.6 & 93 & $<\mathrm{RL}$ & 14.5 & 114 \\
\hline $11 \mathrm{~A}$ & $\begin{array}{c}\text { C-103 } \\
\text { tributary }\end{array}$ & 25.4706 & 80.3716 & 1.3 & 7.40 & 6.73 & 10 & 4.37 & 3.96 & 10 \\
\hline 12 & North & 25.4628 & 80.3789 & 0.8 & - & & & 0.384 & & \\
\hline 13 & North & 25.4628 & 80.3711 & 0.9 & - & & & 1.22 & & \\
\hline 14 & North & 25.4629 & 80.3568 & 1.1 & 0.179 & 11.9 & 92 & 0.356 & 14.4 & 113 \\
\hline 15 & North/L-31E & 25.4633 & 80.3468 & 0.6 & - & - & n.a. & - & - & n.a. \\
\hline
\end{tabular}

${ }^{a}$ All concentrations are listed in $\mu \mathrm{g} / \mathrm{L} ;(-)$ : Below MDL; $(<\mathrm{RL})$ : Below reporting limit; (n.a.): not available. ${ }^{b}$ Laboratory Fortified Matrix experiment, results measured in percent recovery. Fortification level was $12.5 \mu \mathrm{g} / \mathrm{L} .{ }^{\mathrm{c}}$ Duplicate measurements. Results presented in relative percent deviation (RPD). 
During the April, 2010 trip, the frequency of detection and the measured concentrations of AMPA were significantly lower than on the previous collections, probably caused by dilution from the heavy rain event and the constant discharge flows at the gate structures throughout the sampling day and the day before.

The results from the April, 2010 and previous sampling collections suggest that glyphosate may have agricultural, urban and direct input sources in the coastal canal system. Although measured concentrations were always below the known chronic effect toxicity levels for the most sensitive organisms, glyphosate used in terrestrial applications contains surfactants that are more toxic to aquatic organisms than the herbicide itself (Relyea, 2005; Solomon \& Thompson, 2003). Thus, the occurrence of agriculture-related glyphosate may indicate that such surfactants may also be present in the canals, and the extent of the threat to the protected areas subjected to hydration with canal water should be investigated. Some surfactants used within glyphosate formulations are known to have a high toxicity to aquatic organisms, especially amphibians (such as polyethoxylated tallow amine (POEA) contained in Roundup ${ }^{\circledR}$ ) (Relyea, 2005). Other formulations that remain trade-mark secrets have proven to have the same high toxicity to aquatic organisms that POEA has (Relyea, 2012), and the identity and concentration of the surfactant in the formulation are unknown. Therefore, analyzing for unknown glyphosaterelated surfactants in these waters may be a challenging task, and detecting the biodegradable glyphosate and its main metabolite may be the simplest approach to assess this threat. 


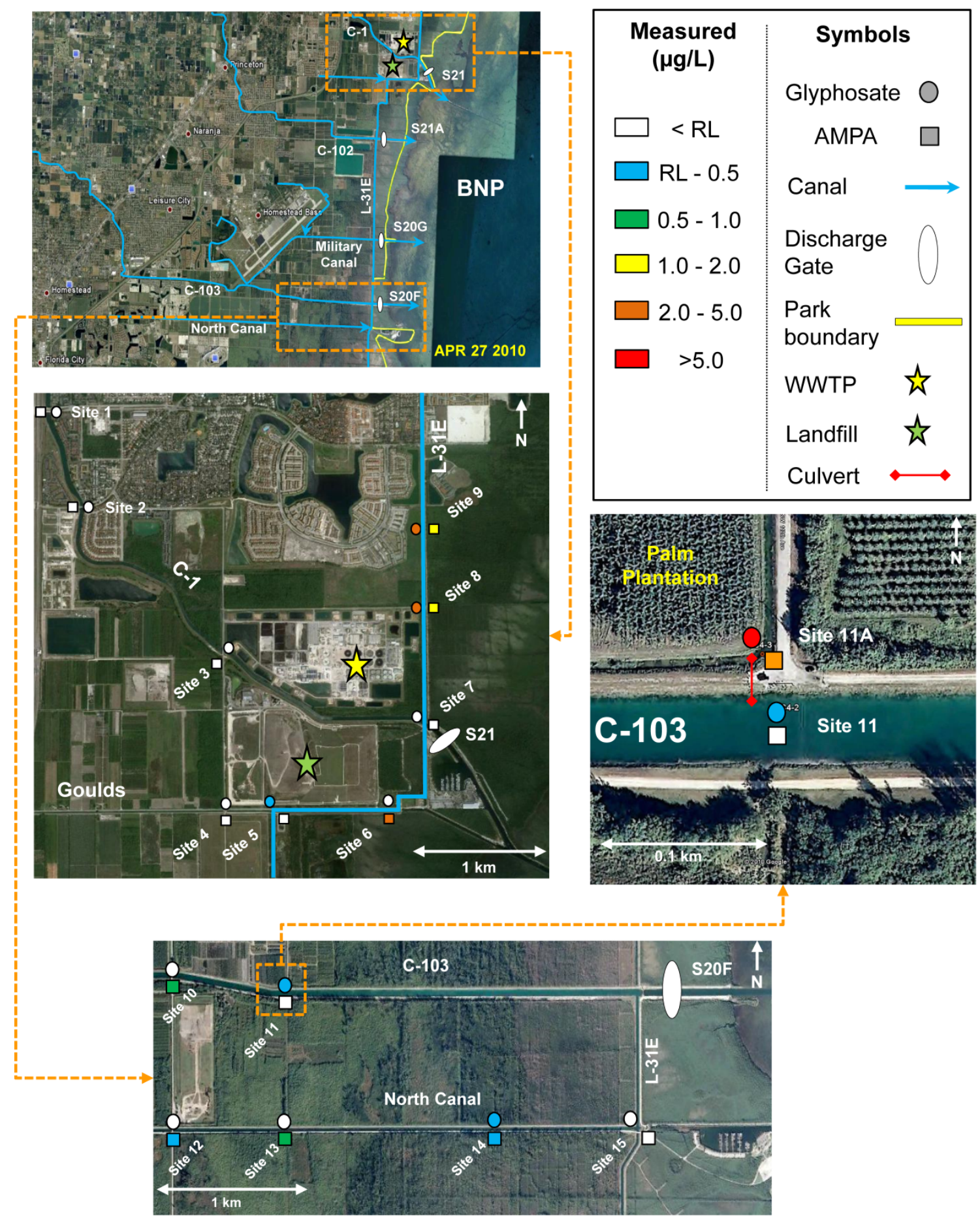

Figure 2.17 Sampling sites and results for the April 27, 2010 sample collection after a heavy rain event, from canals C-1, Goulds, C-103 and North Canal. (RL: $0.174 \mu \mathrm{g} / \mathrm{L}$ for glyphosate; $0.324 \mu \mathrm{g} / \mathrm{L}$ for AMPA). 


\subsection{Conclusions}

A simple, robust, inexpensive and sensitive method for the analysis of glyphosate and its main metabolites in surface waters has been developed. The methodology allows for preconcentration of 72 samples, calibrations and quality control samples in three to four days of unattended lyophilization. Simplicity is maintained throughout the analysis, as the only steps required are fortification with aspartic acid internal standard previous to water removal, and afterwards suspension of dried samples in borate buffer and EDTA, syringe filtration, introduction of the $\mathrm{FMOC}-\mathrm{Cl}$ reagent and injection into an $\mathrm{LC}$ system at least $30 \mathrm{~min}$ later.

Despite the simplicity of the developed methodology, method detection limits of 0.058 and $0.108 \mu \mathrm{g} / \mathrm{L}$ were obtained for glyphosate and AMPA using $20 \mathrm{~mL}$ of water samples. The most sensitive technique in the literature (Hanke et al., 2008) has a glyphosate MDL of $0.0007 \mu \mathrm{g} / \mathrm{L}$ for $80 \mathrm{~mL}$ samples, which is roughly 20 times more sensitive than this work when corrected for sample size. However, both the sample treatment steps and the instrumentation required in that technique are much more complicated and potentially expensive to implement, and the information gain on determining the herbicide in concentrations that are many orders of magnitude below any significant environmental effect may be of low utility for most routine monitoring efforts.

The method was developed with a dual FLD and MS/MS detection which allowed high sensitivity detection with unequivocal identification of glyphosate in contaminated sites. However, fluorescence chromatograms produced clean, interference-free peaks thanks to a high $\mathrm{pH}$ chromatographic separation using a specialized column for such 
application, which ensured selective elution of the anionic, derivatized analytes while neutral interferences were retained. The clean chromatograms obtained using the FLD could allow its standalone use, and therefore the minimum requirements to implement this method are a tray loading lyophilizer and a binary liquid chromatography pump with a fluorescence detector. These that can be easily met by many laboratories interested in monitoring glyphosate and its main metabolite in surface waters.

The method had a high dynamic range which allowed quantitation of background levels of the herbicide and also high amounts introduced by direct applications of the herbicide for canal maintenance. Environmental data collected using this method suggest that glyphosate has direct and indirect sources into the investigated coastal canal system, including agricultural runoff from local farms. Since waters from these canals will be used to hydrate coastal wetlands inside the protected area of the Biscayne National Park, a constant monitoring of glyphosate and its main metabolite may be needed to ensure that the herbicide is not a threat to these ecosystems. The occurrence of agricultural glyphosate in this canal system raises concerns that it may be associated with the introduction of large quantities of surfactants that are known to be more toxic to aquatic organisms that the herbicide itself.

Therefore, glyphosate and AMPA should be included in monitoring programs that will evaluate the quality of the water discharged into protected wetlands, and the methodology developed and successfully tested with field work during the course of this research may provide with a simple and robust tool to accomplish this goal. 


\subsection{Acknowledgment}

This project was partially funded by the U.S. Department of the Interior through the Biscayne National Park and by the Southeast Environmental Research Center at FIU (SERC) through the Cristina Menendez Fellowship, during the 2009-2010 funding cycle. 


\section{ANALYTICAL METHODS FOR THE ANALYSIS OF COREXIT ${ }^{\circledR}$ DISPERSANTS IN DIFFERENT STAGES OF AN OIL SPILL MONITORING EFFORT}

(Cesar E. Ramirez, Sudha Rani Batchu and Piero R. Gardinali. Analytical and Bioanalytical Chemistry, 2013, 405:4167-4175)

(Cesar E. Ramirez, Sudha Rani Batchu and Piero R. Gardinali. Thermo Scientific Application Note Number 586. 2013)

\subsection{Introduction}

On April 20th, 2010 the "Deepwater Horizon" (DWH) oil platform caught fire and sank in the Gulf of Mexico, creating a large release of oil and gas from the riser pipe and the uncapped well head. Efforts to contain and clean up the spill included the use of oil dispersants both above and below the surface. The dispersants Corexit ${ }^{\circledR}$ EC9500A and EC9527A (formerly Corexit ${ }^{\circledR} 9500$ and 9527) were authorized by the U.S. Environmental Protection Agency (USEPA) to be used in the Gulf of Mexico Oil Spill (USEPA, 2010c), and at least 1.8 million gallons were applied ("Official federal portal for the Deepwater BP oil spill response and recovery," 2010). Dispersants are a mixture of solvents and surfactants that reduce the interfacial tension between the water and oil, facilitating the breakup of the oil into small droplets that are easily dispersed by wind and wave action (Chapman et al., 2007). According to available MSDS, the components of Corexit ${ }^{\circledR}$ EC9500A include a proprietary blend of an organic sulfonic acid salt (10-30\% $\mathrm{w} / \mathrm{w})$, hydrotreated light petroleum distillates $(10-30 \% \mathrm{w} / \mathrm{w})$ and propylene glycol $(1-5 \%$ 
w/w) (NALCO, 2012a), whereas Corexit $^{\circledR}$ EC9527A contains mainly 2-butoxyethanol $(30-60 \% \mathrm{w} / \mathrm{w})$ and the same proprietary organic sulfonic acid salt $(10-30 \% \mathrm{w} / \mathrm{w})$ (NALCO, 2012b). Other known components include surfactant mixtures like Span 80, Tween 80 and Tween 85 (USEPA, 2010b).

The identity of the sulfonic salt common to both Corexit $^{\circledR}$ formulations was released by the USEPA (2010b) as the anionic surfactant dioctyl sulfosuccinate (DOSS, CAS number 577-11-7, figure 3.1). Kujawinski et al. (2011) reported that DOSS persisted up to $300 \mathrm{~km}$ from the well and remained in the water column up to 64 days after its application ceased, at concentrations ranging from 5 to $2100 \mathrm{ng} / \mathrm{L}$, implying that DOSS is not biodegradable or degrades at a very slow rate. Corexit ${ }^{\circledR}$ formulations were never applied in such a large scale before the DWH spill, hence its environmental fate after application is partially unknown. In absence of any other available criteria, the USEPA has listed an aquatic life benchmark $40000 \mathrm{ng} / \mathrm{L}$ for DOSS and suggested reporting limits for environmental analysis of $20000 \mathrm{ng} / \mathrm{L}$ (USEPA, 2010a).

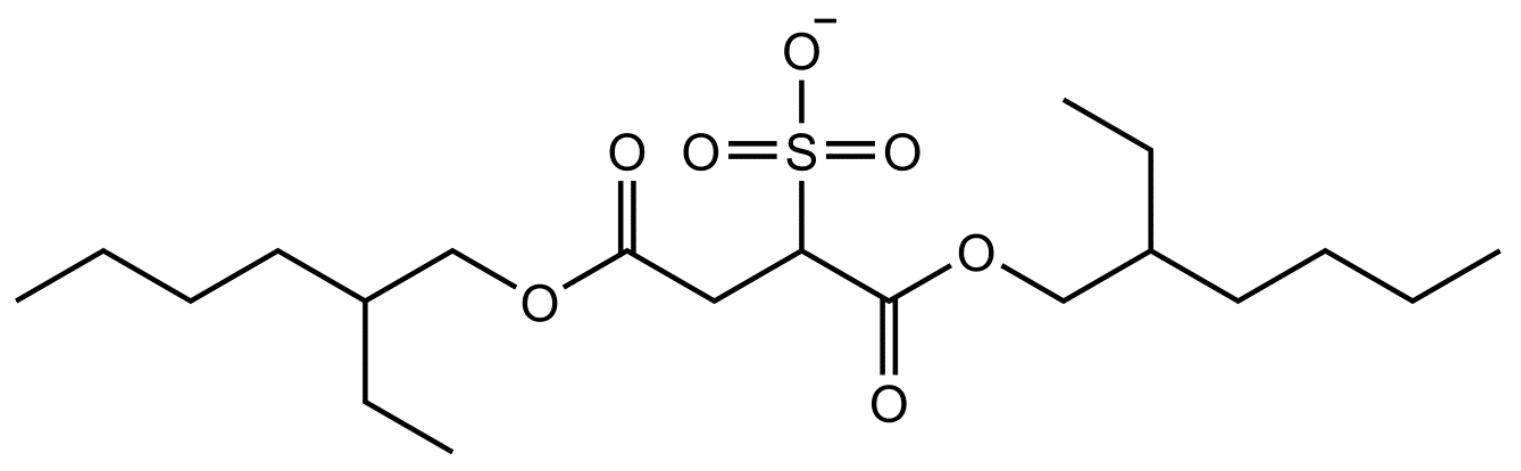

Figure 3.1 Structure of the dioctyl sulfosuccinate (DOSS) anion. 
In light of the above facts and given the large quantities of Corexit ${ }^{\circledR}$ that were applied into the Gulf of Mexico waters during the response efforts, there is a need for analytical methods capable of detecting its components in seawater, even when large dilution factors were expected to occur. DOSS was proposed as a marker to monitor the fate of dispersant based on its persistence in the environment (Kujawinski et al., 2011).

Place et al. (2010) confirmed the presence of DOSS in both Corexit ${ }^{\circledR}$ formulations and proved that it can be easily detected by ESI-MS/MS in the negative mode. Mathew et al. (2012) reported a direct injection method for DOSS in seawater amended with 50\% acetonitrile, with a reporting limit of $20000 \mathrm{ng} / \mathrm{L}$. They noticed a 20 -fold increase in the sensitivity of DOSS for samples amended with acetonitrile. Kujawinski et al. (2011) first reported the use of Solid Phase Extraction (SPE) to preconcentrate DOSS from high volumes of seawater, followed by LC-MS/MS, reporting a limit of quantification of 3 $\mathrm{ng} / \mathrm{L}$ using up to $7 \mathrm{~L}$ samples collected from the incident area. Their sample extraction includes separation of acidic components, basic and neutral components, water soluble components, treatment with resin and finally eluting the analyte from the resin with methanol. This procedure should be time consuming and requires a minimum of $1 \mathrm{~L}$ of sample. Therefore, a faster method with less sample consumption, such as online SPE, could represent a viable alternative that has not been investigated before.

This study presents two analytical methodologies for the analysis of DOSS in seawater. A simplified online SPE-LC-MS/MS method for ultra-trace determination of DOSS in seawater a complementary LC-MS/MS method as an alternative for samples 
that do not require such preconcentration, for example, in samples where Corexit $^{\circledR}$ has been recently applied.

Additionally, a third methodology was developed for the simultaneous analysis of DOSS and another Corexit ${ }^{\circledR}$ component in commercial formulations of dispersants and crude oil. The neutral dispersant 2-butoxyethanol (CAS number 111-76-2, figure 3.2) is the main component of Corexit ${ }^{\circledR}$ EC9527A accounting for 30-60\% w/w (NALCO, 2012b). It is also a common industrial product which can find its way into environmental samples from many other sources (Dartsch et al., 1999).

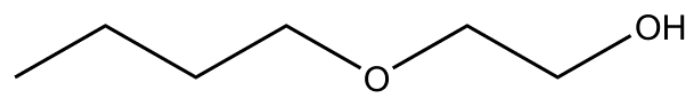

Figure 3.2 Structure of 2-butoxyethanol

Environmental concentrations of 2-butoxyethanol in seawater are expected to be low because of its fast biodegradation rate (half-life of 1 to 4 weeks) (Harris, 1998). Because of its multiple sources and biodegradability, 2-butoxyethanol may not be a suitable marker for Corexit ${ }^{\circledR}$ EC9527A in open ocean waters. However, applications of Corexit $^{\circledR}$ EC9527A in an oil spill response could potentially yield localized high concentrations of both 2-butoxyethanol and DOSS in floating crude oil and dispersed oilwater mixtures. A LC-MS/MS method capable to simultaneously detect and quantify the two main components of Corexit ${ }^{\circledR}$ EC9527A in dispersant formulations and crude oil from oil release sites could be extremely useful in identifying the Corexit ${ }^{\circledR}$ formulations employed and assessing the fate of its components. 


\subsection{Hypotheses}

- $\quad$ LC-MS/MS and online SPE-LC-MS/MS can be used to analyze DOSS at a wide dynamic range. The analyte can be stabilized in glass containers using acetonitrile.

- $\quad$ LC-MS/MS can be used to simultaneously detect DOSS and 2-butoxyethanol to identify Corexit ${ }^{\circledR}$ formulations before application.

- Crude oil from an accident site can be analyzed for Corexit ${ }^{\circledR}$ markers by LCMS/MS after Liquid-Liquid Extraction.

\subsection{Research Objectives}

The objectives of this project were as follows:

- To develop an ultra-sensitive, automated online SPE-LC-MS/MS method for the determination of DOSS in seawaters at low ng/L levels.

- To develop a complementary LC-MS/MS method for the very fast determination of DOSS in seawaters at low $\mu \mathrm{g} / \mathrm{L}$ levels.

- To address the sampling and sample storage techniques to minimize DOSS losses caused by adsorption to container surfaces.

- To develop an LLE+LC-MS/MS method for the simultaneous analysis of DOSS and 2-butoxyethanol in crude oil and commercial formulations. 


\subsection{Materials and reagents}

Certified DOSS and DOSS ${ }^{13} \mathrm{C}_{4}$ standards were purchased from Cambridge Isotopes Laboratories (Andover, MA., USA). Neat DOSS sodium salt was purchased from Acros Organics (Geel, Belgium) and used for initial calibration verification (ICV) purposes. 2-butoxyethanol was also purchased from Acros Organics. Deuterated standards sodium dodecyl- $\mathrm{D}_{25}$ sulfate $\left(\mathrm{SDS}-\mathrm{D}_{25}\right)$ and 2-butoxyethanol- $\mathrm{D}_{4}$ were purchased from CDN Isotope Laboratories (Quebec, Canada). Stock and working solutions of all compounds were prepared in acetonitrile. Artificial seawater $(3.5 \% \mathrm{w} / \mathrm{v})$ was prepared using commercially available Instant Ocean ${ }^{\circledR}$ salt. LC/MS grade acetonitrile, water, formic acid and ammonium formate were purchased from Fisher Scientific (Fairlawn, NJ., USA). Glass vials were cleaned by baking at $450{ }^{\circ} \mathrm{C}$ for at least $6 \mathrm{~h}$ before use. Fresh mobile phases were prepared every analysis day.

The online preconcentration was performed using an EQuan online SPE system (Thermo Scientific, Waltham, MA., USA), consisting of an HTC-PAL ${ }^{\mathrm{TM}}$ autosampler equipped with a $5 \mathrm{~mL}$ glass syringe and a $5 \mathrm{~mL}$ and a 0.030 in ID PEEK sample loop (model 1822) purchased from IDEX Health and Science (Oak Harbor, WA., USA); an Accela $^{\mathrm{TM}} 1000$ as analytical HPLC pump and an Accela ${ }^{\mathrm{TM}} 600$ as SPE loading pump. The online SPE column was a Hypersil Gold aQ ${ }^{\circledR}(20 \mathrm{~mm} \times 2.1 \mathrm{~mm}, 12 \mu \mathrm{m})$. All analytical separations were carried out using a Hypersil Gold aQ ${ }^{\circledR}$ column $(50 \mathrm{~mm} \times 2.1$ $\mathrm{mm}, 3 \mu \mathrm{m})$ protected by a Hypersil Gold aQ ${ }^{\circledR}$ pre-column $(10 \mathrm{~mm}$ x $2.1 \mathrm{~mm}$ x $3 \mu \mathrm{m})$. All columns were also obtained from Thermo Scientific. 
For the direct injection methods, the autosampler was equipped with a $100 \mu \mathrm{L}$ glass syringe and a $100 \mu \mathrm{L}$ stainless steel sample loop. Direct injection analytical separations were performed by using only the Accela ${ }^{\mathrm{TM}} 1000$ HPLC pump. Detection was performed by a TSQ Quantum Access ${ }^{\mathrm{TM}}$ QqQ Mass Spectrometer equipped with a Heated Electrospray Ionization (HESI) source. All devices were controlled using the Xcalibur 2.1 data acquisition software. The instrument and software were also obtained from Thermo Scientific.

\subsection{Seawater samples preservation procedure}

DOSS tends to bind to surfaces (Kujawinski et al., 2011; Mathew et al., 2012). Therefore, seawater analyzed in this study was preserved as soon as possible by placing $10.00 \mathrm{~mL}$ aliquots in $20 \mathrm{~mL}$ glass vials containing $5.000 \mathrm{~mL}$ of acetonitrile and storing the amended sample at or below $4{ }^{\circ} \mathrm{C}$ until analysis. The resulting acetonitrile concentration was $33 \% \mathrm{v} / \mathrm{v}$. All samples were processed and analyzed within 14 days of collection.

\subsection{DOSS MS/MS detection}

The HESI source was operated in negative mode and the mass spectrometer operated under the selective reaction monitoring (SRM) scan mode. The following optimized MS parameters were obtained by infusion of DOSS and DOSS $-{ }^{13} \mathrm{C}_{4}$ acetonitrile solutions: quantitative SRM transition: $\mathrm{m} / \mathrm{z} \quad 421 \rightarrow 81$, collision-induced dissociation (CID) energy: $27 \mathrm{eV}$; confirmation SRM transition: m/z 421 $\rightarrow 227$, CID: 24 $\mathrm{eV}$; DOSS- ${ }^{13} \mathrm{C}_{4}$ SRM transition: $\mathrm{m} / \mathrm{z} 425 \rightarrow 81$, CID: $27 \mathrm{eV}$; capillary voltage $4.0 \mathrm{kV}$; 
tube lens: $90 \mathrm{~V}$; skimmer offset: $8 \mathrm{~V}$; sheath gas $\left(\mathrm{N}_{2}\right)$ : 10 arbitrary units; auxiliary gas $\left(\mathrm{N}_{2}\right): 25$ arbitrary units; capillary temperature: $300{ }^{\circ} \mathrm{C}$; HESI heater temperature: $340{ }^{\circ} \mathrm{C}$; CID gas (Ar) pressure: 1.7 mTorr.

\subsection{Trace level determination of DOSS seawater by online SPE-LC-MS/MS}

\subsubsection{Sample preparation}

$5.600 \mathrm{~mL}$ of preserved seawater sample were transferred to a $10 \mathrm{~mL} \mathrm{LC} \mathrm{vial} \mathrm{and}$ fortified with DOSS ${ }^{13} \mathrm{C}_{4}$ internal standard (to $400 \mathrm{ng} / \mathrm{L}$ ), and a final volume of $6 \mathrm{~mL}$ was obtained using $33 \% \mathrm{v} / \mathrm{v}$ of acetonitrile in artificial seawater. The samples were thoroughly mixed and injected directly into the online SPE-LC-MS/MS system. Calibration solutions (0-500 $\mathrm{ng} / \mathrm{L})$ were prepared with artificial seawater, also maintaining the $33 \%$ acetonitrile/artificial seawater ratio. A 7-point set of calibration solutions was freshly prepared for each analysis batch.

\subsubsection{Online SPE-LC-MS/MS instrumental procedure}

A graphical representation of the online SPE system is shown in figure $3.3 .5 \mathrm{~mL}$ of samples, quality control samples or calibration solutions were loaded into the sample loop. The SPE column was placed in a rotary valve, allowing connection with either the loading pump (loading position) or the analytical pump (analysis position). The SPE column was maintained at the loading position for $8 \mathrm{~min}(5 \mathrm{~min}$ sample loading and 3 min washing), for $4 \mathrm{~min}$ at the analysis position and returned to the loading position for 2 min, for a total of 14 min run time. The mobile phase gradient programs for the loading 
and analytical pumps are shown in table 3.1, and the autosampler washing steps used to avoid carryover are listed in table 3.2 .

Table 3.1 Mobile phase delivery programs for pumps during the online SPE determination of DOSS in seawater. ${ }^{\mathrm{a}}$

\begin{tabular}{|c|c|c|c|c|c|c|c|c|c|c|c|}
\hline \multicolumn{6}{|c|}{ SPE LC pump } & \multicolumn{6}{|c|}{ Analytical LC pump } \\
\hline $\begin{array}{c}\mathrm{t} \\
(\mathrm{min})\end{array}$ & A & B & C & $\begin{array}{c}\text { Flow } \\
\text { (mL/min) }\end{array}$ & $\begin{array}{c}\text { Segment } \\
\text { description }\end{array}$ & $\begin{array}{c}\mathrm{t} \\
(\min )\end{array}$ & A & B & C & $\begin{array}{c}\text { Flow } \\
\text { (mL/min) }\end{array}$ & $\begin{array}{c}\text { Segment } \\
\text { description }\end{array}$ \\
\hline 0 & & & 100 & 1.0 & & 0 & & 98 & 2 & 0.325 & \\
\hline 2.0 & & & 100 & 1.0 & & & & & & & \\
\hline 3.0 & & 20 & 80 & 1.0 & Solid phase & & & & & & \\
\hline 3.5 & & 95 & 5 & 1.0 & extraction & $\begin{array}{l}3.2 \\
3.5\end{array}$ & & $\begin{array}{l}98 \\
20\end{array}$ & $\begin{array}{c}2 \\
80\end{array}$ & 0.325 & $\begin{array}{l}\text { Analysis } \\
\text { column }\end{array}$ \\
\hline 4.9 & & 95 & 5 & 1.0 & & & & & & & reset \\
\hline 5.0 & & 95 & 5 & 1.0 & Salt & & & & & & \\
\hline 7.9 & & 95 & 5 & 1.0 & removal & 7.9 & & 20 & 80 & 0.325 & \\
\hline 8.0 & & 95 & 5 & 1.0 & & 8.0 & & 20 & 80 & 0.325 & \\
\hline 8.5 & 100 & & & 1.0 & $\begin{array}{l}\text { loop water } \\
\text { flush }\end{array}$ & 10.8 & & 98 & 2 & 0.325 & \\
\hline 12.0 & 100 & & & 1.0 & $\begin{array}{l}\text { SPE } \\
\text { column } \\
\text { reset }\end{array}$ & & & & & & $\begin{array}{l}\text { Gradient } \\
\text { separation }\end{array}$ \\
\hline 14.0 & 100 & & & 1.0 & & 14.0 & & 98 & 2 & 0.325 & \\
\hline
\end{tabular}

Table 3.2 Washing program used to avoid carryover during the online SPE determination of DOSS in seawater. ${ }^{\text {a }}$

\begin{tabular}{ccc}
\hline Washing step & Solvent & Solvent path \\
\hline 1 & Water & syringe $\rightarrow$ waste \\
2 & $1: 1$ acetonitrile/methanol & syringe $\rightarrow$ waste \\
3 & Water & syringe $\rightarrow$ injector port $\rightarrow$ waste \\
4 & $1: 1$ acetonitrile/methanol & syringe $\rightarrow$ injector port $\rightarrow$ waste \\
\hline${ }^{\mathrm{a}}$ Volume for each step: $5 \mathrm{~mL}$ (syringe size).
\end{tabular}



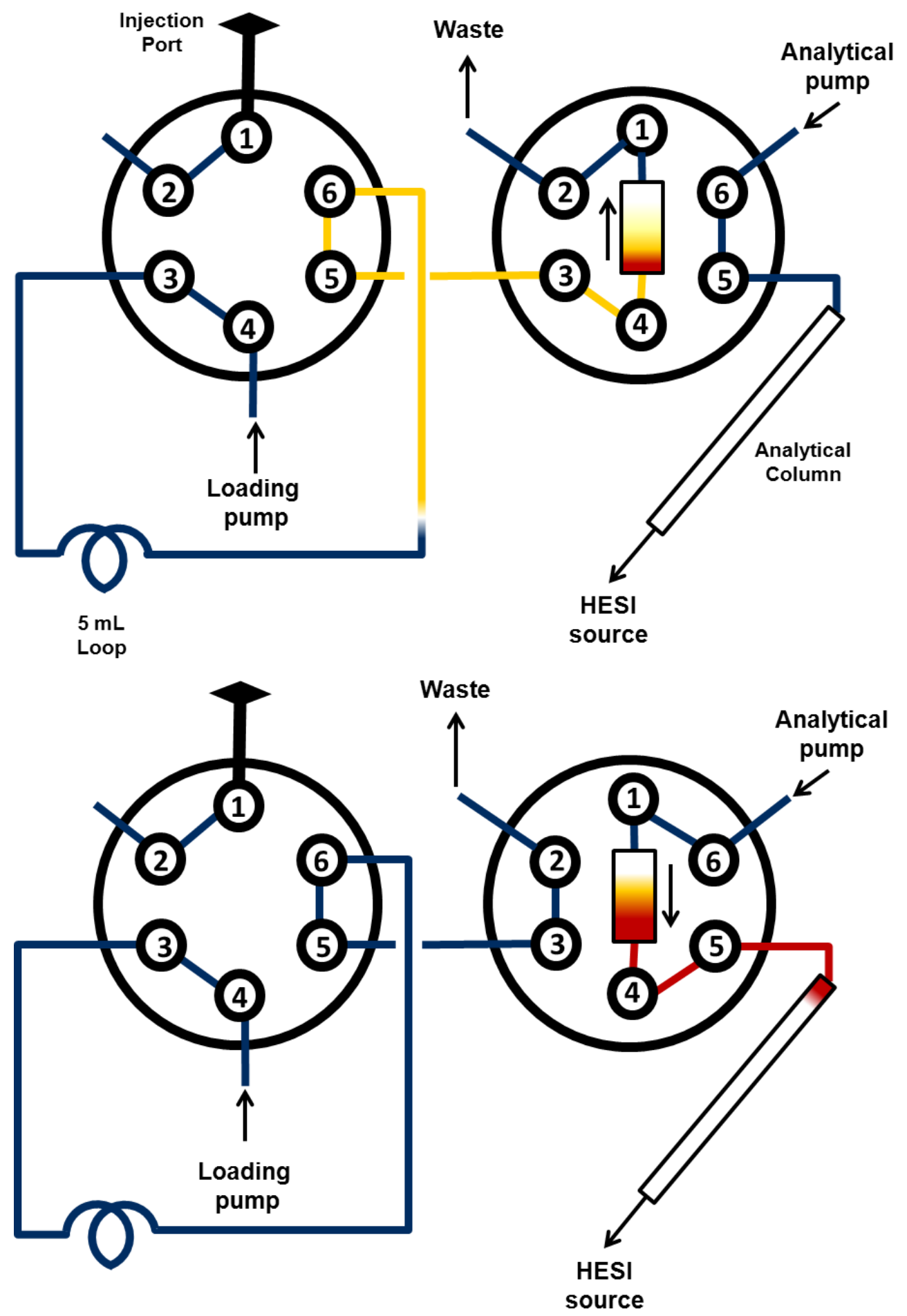

Figure 3.3 Online SPE system for the determination of DOSS in seawater. (TOP, loading position) $5 \mathrm{~mL}$ of sample are passed through the loading column followed with a washing program to remove inorganic species. (BOTTOM, analysis position) Analyte is backflushed into the analytical column for detection. 


\subsection{Fast determination of DOSS in seawater by direct injection LC-MS/MS}

This complementary method allows the determination of DOSS in seawater in the low $\mu \mathrm{g} / \mathrm{L}$ range within 7 minutes and with almost no sample manipulation. It can be readily adopted by laboratories without online SPE capabilities.

\subsubsection{Sample preparation}

$1.250 \mathrm{~mL}$ of the preserved samples were transferred to a $2 \mathrm{~mL} \mathrm{LC}$ amber vial, fortified with DOSS $-{ }^{13} \mathrm{C}_{4}$ internal standard (to $20 \mu \mathrm{g} / \mathrm{L}$ ) and a final volume of $1.500 \mathrm{~mL}$ was made with $33 \% \mathrm{v} / \mathrm{v}$ of acetonitrile in artificial seawater. Samples were thoroughly mixed and analyzed directly by LC-MS/MS. Calibration solutions $(0-20.0 \mu \mathrm{g} / \mathrm{L})$ were prepared with artificial seawater, also maintaining the $33 \%$ acetonitrile/artificial seawater ratio. A 7-point set of calibration solutions was freshly prepared for each analysis batch.

\subsubsection{LC-MS/MS instrumental procedure}

Samples, quality control samples and calibration solutions were injected using a $100 \mu \mathrm{L}$ stainless steel sample loop. The analysis was performed in 7 minutes according to the binary mobile phase program shown in table 3.3. In order to reduce peak broadening, the analytical run was started at $33 \%$ acetonitrile to match the proportion of that solvent in the injected solutions. This process focused the analyte in the column head providing good peak shape (typical chromatograms are shown in figure 3.10).

To prevent the transfer of non-volatile seawater salts into the ionization source, salts were flushed out of the column by increasing the aqueous mobile phase proportion 
to $98 \%$ while the column eluent was diverted to waste using a rotary valve. The autosampler washing steps used to avoid carryover are listed in table 3.4.

Table 3.3 Mobile phase delivery program for the fast determination of DOSS in seawater by LC-MS/MS. Column eluent is diverted to waste during the first $3 \mathrm{~min}$ and again from $5.5 \mathrm{~min}$ to the end of the analytical run.

\begin{tabular}{ccccc}
\hline Time (min) & Acetonitrile (\%) & $\mathbf{1 0} \mathbf{~ m M}$ NH4COO (\%) & Flow (mL/ min) & Segment description \\
\hline 0 & 33 & 67 & 0.325 & \multirow{2}{*}{ Analyte focusing } \\
0.1 & 33 & 67 & 0.325 & \\
\hline 0.2 & 2 & 98 & 0.325 & \multirow{2}{*}{ Salt removal } \\
0.6 & 2 & 98 & 0.325 & \\
\hline 0.9 & 33 & 67 & 0.325 & \multirow{2}{*}{ Analyte elution } \\
1.0 & 33 & 67 & 0.325 & \\
3.7 & 98 & 2 & 0.325 & \multirow{2}{*}{ Column reset } \\
5.6 & 98 & 2 & 0.325 & \\
\hline 5.9 & 33 & 67 & 0.325 & 0.325 \\
7.0 & 33 & 67 & &
\end{tabular}

Table 3.4 Washing program used to avoid carryover for the fast determination of DOSS in seawater by direct injection LC-MS/MS. ${ }^{a}$

\begin{tabular}{ccc}
\hline Washing step & Solvent & Solvent path \\
\hline 1 & Water & syringe $\rightarrow$ waste \\
2 & Water & syringe $\rightarrow$ waste \\
3 & $1: 1$ acetonitrile/methanol & syringe $\rightarrow$ waste \\
4 & $1: 1$ acetonitrile/methanol & syringe $\rightarrow$ waste \\
5 & Water & syringe $\rightarrow$ injector port $\rightarrow$ waste \\
6 & $1: 1$ acetonitrile/methanol & syringe $\rightarrow$ injector port $\rightarrow$ waste \\
\hline
\end{tabular}

${ }^{\mathrm{a}}$ Volume for each step: $100 \mu \mathrm{L}$ (syringe size). 


\subsection{Simultaneous analysis of DOSS and 2-butoxyethanol in dispersant formulations and crude oil}

\subsubsection{Crude oil sample preparation}

Approximately $5 \mu \mathrm{L}$ of crude oil samples were added to $2 \mathrm{~mL}$ amber LC vials, weighed and fortified with a mixture of 2-butoxyethanol- $\mathrm{D}_{4}$ and DOSS $-{ }^{13} \mathrm{C}_{4}$ surrogates.

Liquid-liquid extraction of each surrogate-fortified oil sample was performed by adding $1260 \mu \mathrm{L}$ of acetonitrile and mixing using a vortex for 2 min, resulting in a twophase system with undissolved oil on the vial walls. An aliquot of the acetonitrile phase was transferred to a second $2 \mathrm{~mL}$ amber $\mathrm{LC}$ vial containing $1000 \mu \mathrm{L}$ of artificial seawater, and was fortified with SDS- ${ }_{25}$ internal standard. A final volume of $1.500 \mathrm{~mL}$ was made up with acetonitrile. To ensure method uniformity, the injected sample was prepared to match the $66 \%$ seawater and $33 \%$ acetonitrile matrix used for seawater samples and commercial formulation. The method was tested with light crude oil from Wilcox Formation in Texas, USA and a crude oil sample collected during the DWH response effort (Enterprise sampling cruise on 5/22/2010, sample \# SOB-20100622-084).

\subsubsection{Commercial formulation sample preparation}

Corexit $^{\circledR}$ EC9500A and Corexit ${ }^{\circledR}$ EC9527A commercial formulations were weighed and serially diluted up to $10^{7}$ times, with the last dilution step made in artificial seawater. The resulting solutions were preserved with acetonitrile and prepared for analysis according to the procedure for the direct injection LC-MS/MS analysis of DOSS in seawater described before. 


\subsubsection{Preparation of calibration solutions}

The preparation of samples for the DOSS direct injection method for seawater analysis was modified to include 2-butoxyethanol- $\mathrm{D}_{4}, 2$-butoxyethanol and SDS- $\mathrm{D}_{25}$. Calibration ranges in this method varied from $0.5-20 \mu \mathrm{g} / \mathrm{L}$ for DOSS and $2.50-30.0 \mu \mathrm{g} / \mathrm{L}$ for 2-butoxyethanol in the injected solution. Calibration solutions contained $100 \mu \mathrm{g} / \mathrm{L}$ of 2-butoxyethanol- $\mathrm{D}_{4}$ and $20 \mu \mathrm{g} / \mathrm{L}$ of DOSS- ${ }^{13} \mathrm{C}_{4}$ used as surrogates, plus $100 \mu \mathrm{g} / \mathrm{L}$ of SDS- ${ }_{25}$ internal standard.

\subsubsection{LC-MS/MS instrumental procedure}

Direct infusion analysis suggested that 2-butoxyethanol could only be ionized in the presence of a proton donor modifier, thus $10 \mathrm{mM}$ ammonium formate was substituted by $0.1 \%$ formic acid in both the aqueous and organic mobile phases.

\subsubsection{Liquid chromatography}

Injection volume was $20 \mu \mathrm{L}$. Separation was performed in 10 min according to the binary gradient program between $0.1 \%$ formic acid in water (A) and $0.1 \%$ formic acid, $0.9 \%$ water and $99 \%$ acetonitrile (B) shown in table 3.5 .

Similarly to the direct injection method for the determination of DOSS in seawater, column effluent was also diverted to waste for the first 3 minutes with a rotary valve to prevent the transfer of seawater salts into the ionization source. The same autosampler washing steps were also used (listed in table 3.4). 
Table 3.5 Mobile phase delivery program for the simultaneous analysis of DOSS and 2butoxyethanol in dispersant formulations and crude oil by LC-MS/MS. ${ }^{\text {a }}$

\begin{tabular}{cccc}
\hline Time $(\mathbf{m i n})$ & A $(\mathbf{\%})$ & B $(\mathbf{\%})$ & Flow $(\mathbf{m L} / \mathbf{m i n})$ \\
\hline 0 & 98 & 2 & 0.325 \\
0.9 & 98 & 2 & 0.325 \\
3.7 & 2 & 98 & 0.325 \\
5.6 & 2 & 98 & 0.325 \\
5.9 & 98 & 2 & 0.325 \\
10.0 & 98 & 2 & 0.325 \\
\hline
\end{tabular}

${ }^{\mathrm{a}}$ Mobile phase A: $0.1 \% \mathrm{v} / \mathrm{v}$ formic acid in water; B: $0.1 \%$ formic acid, $0.9 \%$ water, $99 \% \mathrm{v} / \mathrm{v}$ acetonitrile.

\subsubsection{Mass spectrometry detection}

For this method the HESI source was operated as regular ESI (heater turned off) as the 2-butoxyethanol signal was observed to decrease rapidly with increasing heater temperature. The ionization source was operated in positive mode for the first 4 min of the chromatographic separation, detecting 2-butoxyethanol and 2-butoxyethanol- $\mathrm{D}_{4}$, and then switched to negative mode to detect DOSS, DOSS $-{ }^{13} \mathrm{C}_{4}$ and SDS-D 25 . The SRM scan mode was also used with this method. Optimized MS parameters for the positive mode segment were: 2-butoxyethanol quantitative SRM transition: m/z 119 $\rightarrow$ 63, CID: 5 $\mathrm{eV}$; confirmation SRM transition: $\mathrm{m} / \mathrm{z}$ 119 $\rightarrow 45$, CID: $9 \mathrm{eV} ;$ 2-butoxyethanol-D 4 transition: m/z 123 $\rightarrow 67$, CID: $6 \mathrm{eV}$; capillary voltage: $4.5 \mathrm{kV}$; tube lens: $50 \mathrm{~V}$; auxiliary gas $\left(\mathrm{N}_{2}\right)$ : 15 arbitrary units; capillary temperature: $325^{\circ} \mathrm{C}$; sheath gas $\left(\mathrm{N}_{2}\right)$ : 60 arbitrary units; CID gas (Ar) pressure: 1.0 mTorr.

Negative mode SRM detection parameters remained unchanged from the DOSS methods described before, except for the absence of HESI heating. This lower 
temperature causes a slight decrease in DOSS sensitivity but allows the simultaneous analysis of 2-butoxyethanol. SDS-D 25 SRM transition: m/z 290 $\rightarrow$ 98, CID: $42 \mathrm{eV}$.

\subsection{Results and discussion}

\subsubsection{Optimization of DOSS analytical signal and seawater sample preservation}

Direct infusion of DOSS acetonitrile solutions into the MS confirmed previous observations (Place et al., 2010) that showed a straightforward ionization of this analyte using electrospray ionization operating in the negative mode. This is expected as the DOSS anion is the conjugate base of the very strong dioctyl sulfosuccinic acid $\left(\mathrm{pK}_{\mathrm{a}}=\right.$ $0.08 \pm 0.5)^{2}$ thus has a weak basic character and does not protonate upon desolvation in the ESI interface. As shown in figure 3.4, DOSS produces two clear fragments upon collision-induced dissociation (CID), and these were used in this work as analytical and confirmation SRM transitions.

Previous publications have noted that DOSS tends to bind to many surfaces, resulting in decreased analytical signal (Kujawinski et al., 2011; Mathew et al., 2012). Initial observations during this work were in agreement with those results, as early attempts to analyze DOSS in fortified deionized water and seawater samples resulted in low, non-reproducible signals and recoveries.

${ }^{2}$ From Scifinder ${ }^{\circledR}$. (Substance search: dioctyl sulfosuccinic acid, CAS number 10041-19-7), (Calculated using Advanced Chemistry Development (ACD/Labs) Software V11.02 (C) 1994-2012 $\mathrm{ACD} / \mathrm{Labs}))$ 


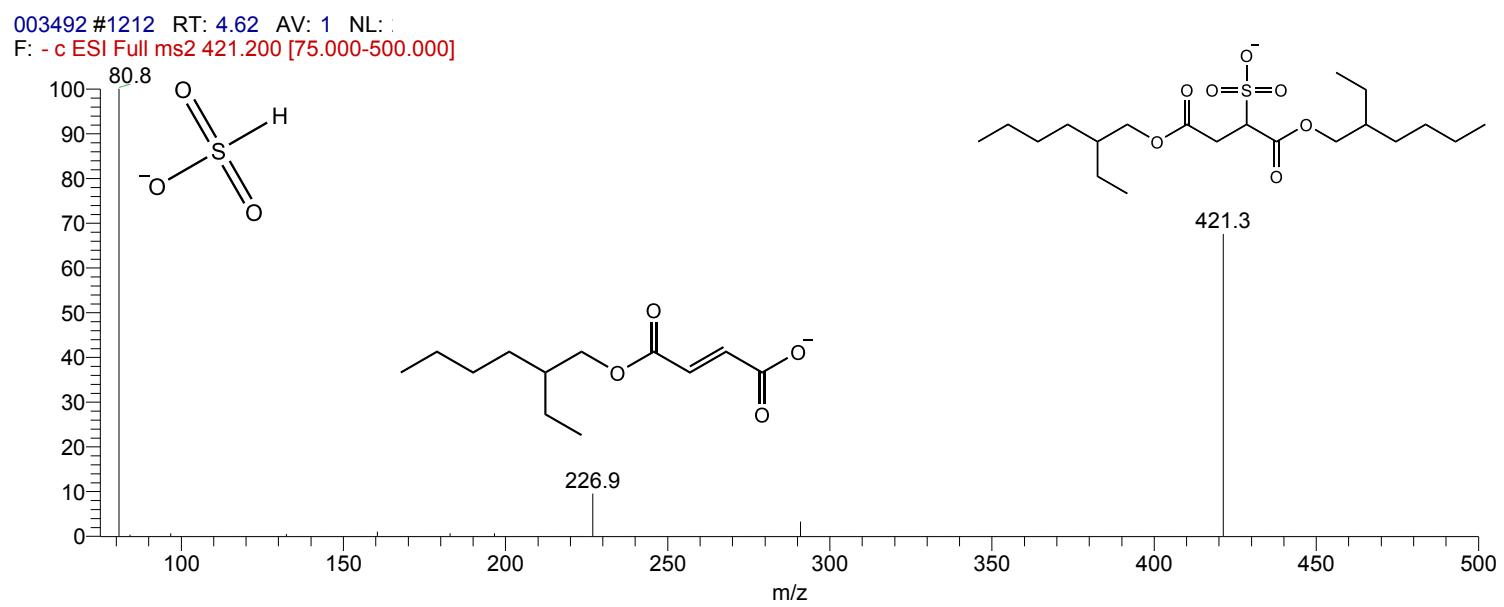

Figure 3.4 Product ion scan spectrum of DOSS obtained using negative mode electrospray ionization, showing the main and secondary collision-induced dissociation products and their probable structure. (Q1: m/z 421.2; Q3: 75-500 m/z, CID: $25 \mathrm{eV}$, scan time: $120 \mathrm{~ms}$ )

Mathew et al. (2012) proposed that 50\% dilution of seawater samples with acetonitrile produces good analytical signals. Two experiments were designed in order to verify the amount of acetonitrile required. In a first experiment, acetonitrile was compared to deionized water as dilution solvent. A $10 \mu \mathrm{g} / \mathrm{L}$ DOSS fortified seawater sample was diluted to $50 \%$, with the dilution solvent being progressively changed from deionized water to acetonitrile, keeping the dilution factor constant (figure 3.5). During this process, the DOSS peak area increased to a maximum as the percentage of acetonitrile increased, showing that acetonitrile is in fact responsible for the signal enhancement rather than a pure dilution effect. This enhancement or desorption effect was maximized around $25 \%$ acetonitrile. 


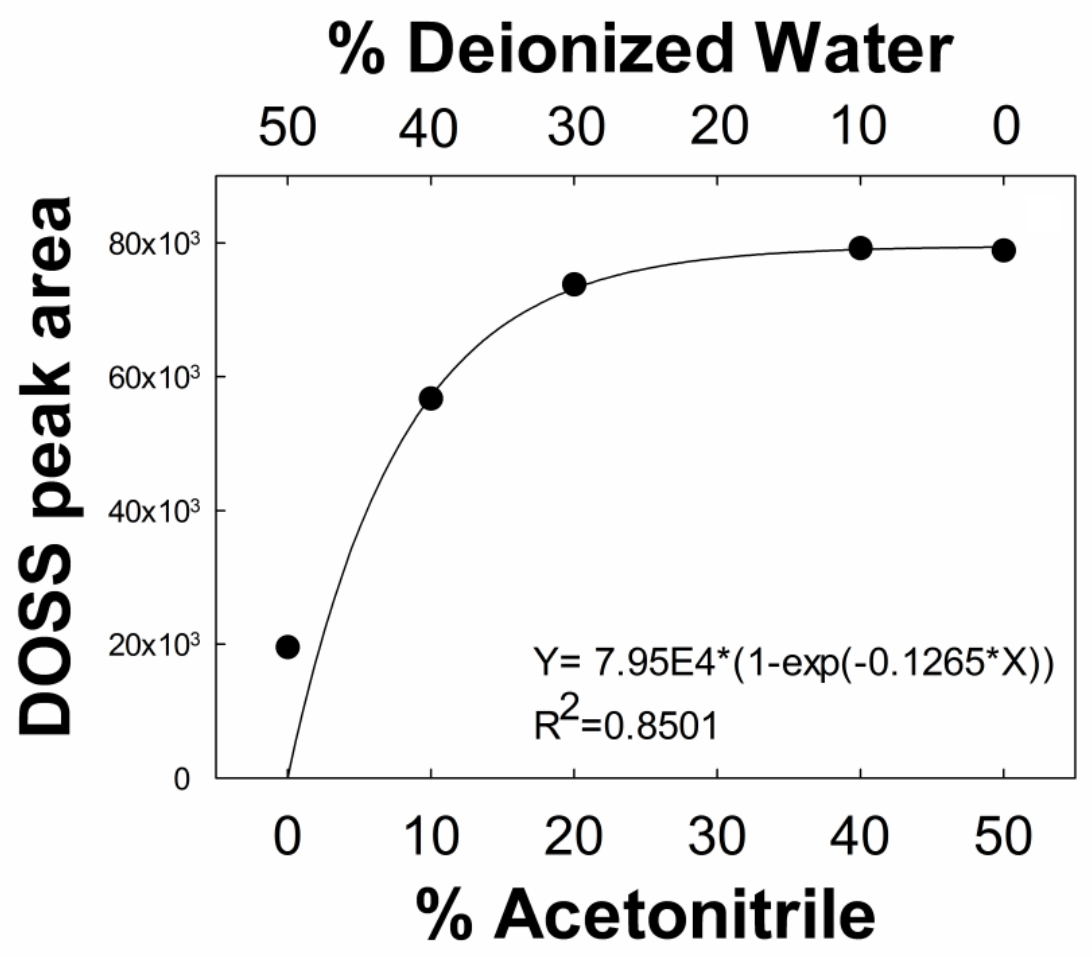

Figure 3.5 DOSS chromatographic signals are greater when acetonitrile is used as diluting solvent instead of deionized water at a fixed dilution factor.

In a second experiment, a fixed volume of seawater sample fortified with $5 \mu \mathrm{g} / \mathrm{L}$ of DOSS was sequentially diluted with acetonitrile, to obtain the optimal dilution factor. If a simple dilution was occurring a constantly decreasing signal would have been obtained. Instead, as shown in figure 3.6, DOSS signal increased to a maximum around $20 \% \mathrm{v} / \mathrm{v}$ acetonitrile and the expected dilution trend was observed after that. 


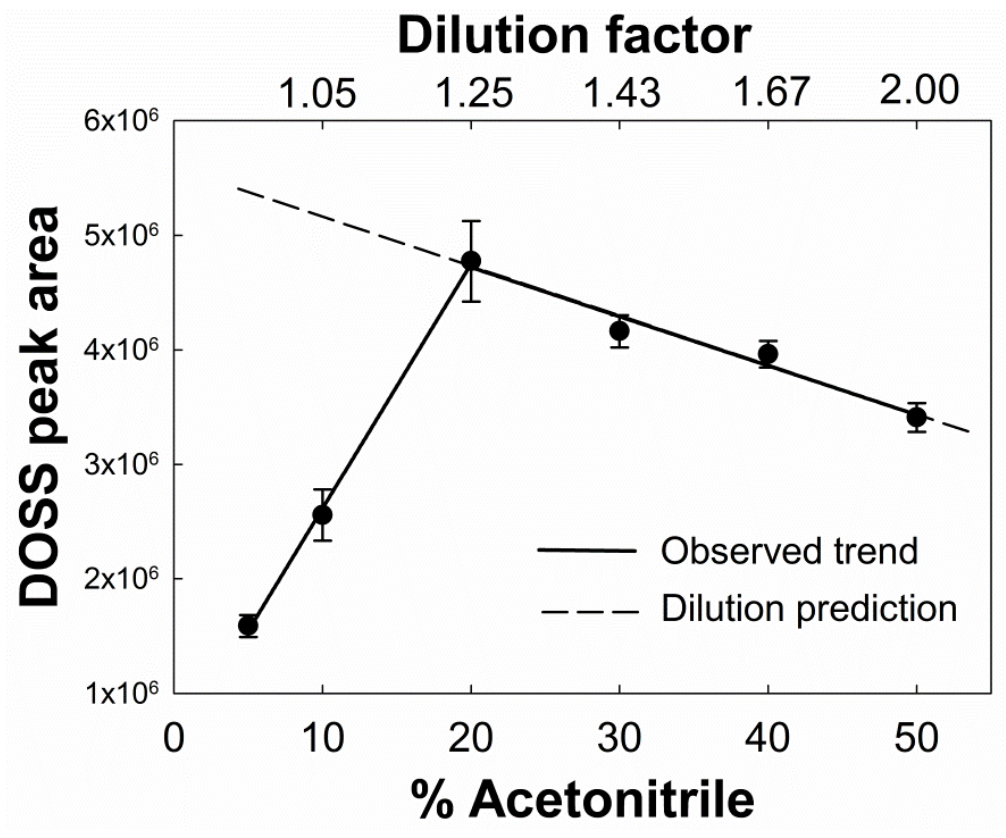

Figure 3.6 Determination of the optimum dilution factor using a seawater sample fortified with $5 \mu \mathrm{g} / \mathrm{L}$ DOSS. DOSS peak area increased until a 1.3 dilution factor was obtained (20 $\% \mathrm{v} / \mathrm{v}$ acetonitrile), and then decreased with further dilution.

These losses of DOSS from samples without acetonitrile preservation raised questions about the effectiveness of containers typically used to collect, transport and store seawater samples until analysis. In order to investigate storage effects, two sets of seawater samples were fortified with $5 \mu \mathrm{g} / \mathrm{L}$ of DOSS and immediately stored in three common types of bottles used for sample storage (glass, polytetrafluoroethylene (PTFE) and polyethylene $(\mathrm{PE})$ ) at or below $4^{\circ} \mathrm{C}$. One set was stored without acetonitrile preservation and the second set was preserved by adding acetonitrile to $33 \%$. Subsamples were taken at 0,1 and 3 and 25 hours and analyzed by direct injection LC-MS/MS. The results are shown in figure 3.7. In the absence of acetonitrile, the recoveries of DOSS were quickly reduced from the start of the experiment, whereas the samples preserved 
with $33 \% \mathrm{v} / \mathrm{v}$ acetonitrile produced stable DOSS signals with over $80 \%$ recovery up to 25 h storage time.

In order to test the stability of an acetonitrile-preserved sample over a longer period of time, $10.0 \mathrm{~mL}$ of artificial seawater were fortified with DOSS at a $4.70 \mu \mathrm{g} / \mathrm{L}$ level and placed in a $20 \mathrm{~mL}$ glass vial, diluted with $5.00 \mathrm{~mL}$ of acetonitrile $(33 \% \mathrm{v} / \mathrm{v})$ and stored at or below $4^{\circ} \mathrm{C}$. This sample was regularly analyzed for DOSS with the direct injection method for up to 250 days. As shown in figure 3.8, DOSS concentration was within two standard deviations from the mean during the entire study. Additionally, the measured DOSS concentration was within $\pm 20 \%$ of the assigned value for up to 150 days.

These results suggest that the proposed preservation method maintains DOSS in solution well beyond a typical laboratory holding time of 14 days. In addition, the two methods described by Kujawinski et al. (2011) and Mathew et al. (2012) require the rinsing of the container with acetonitrile, which in turn causes the sample to be totally depleted during analysis. The method described here provides a simpler approach, producing fast and reproducible results at low concentrations by preventing DOSS from interacting with vial walls at the moment of sample collection. The use of $33 \%$ acetonitrile (10:5 seawater: acetonitrile) is recommended for simplicity, allowing the use of volumetric material to deliver $10.0 \mathrm{~mL}$ seawater into glass sample vials containing 5.0 $\mathrm{mL}$ of acetonitrile, producing a $15.0 \mathrm{~mL}$ preserved sample that allows for different quality controls samples such as duplicates and matrix fortified samples to be created from the same container. 


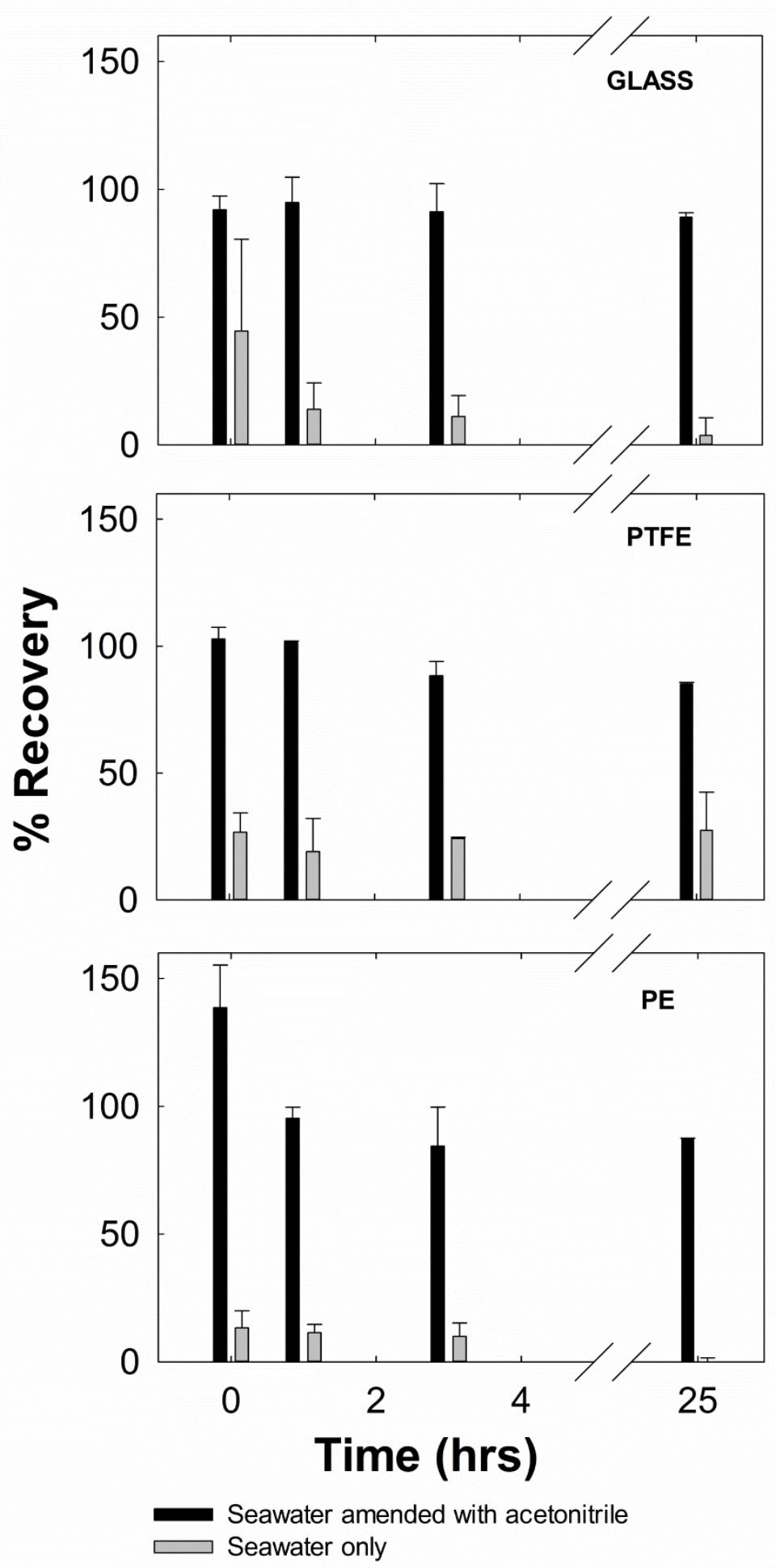

Figure 3.7 Effect of the sample preservation procedure observed in seawater samples fortified with $5 \mu \mathrm{g} / \mathrm{L}$ DOSS and stored in glass, polytetrafluoroethylene (PTFE), and polyethylene (PE) containers, measured in analyte recovery. 


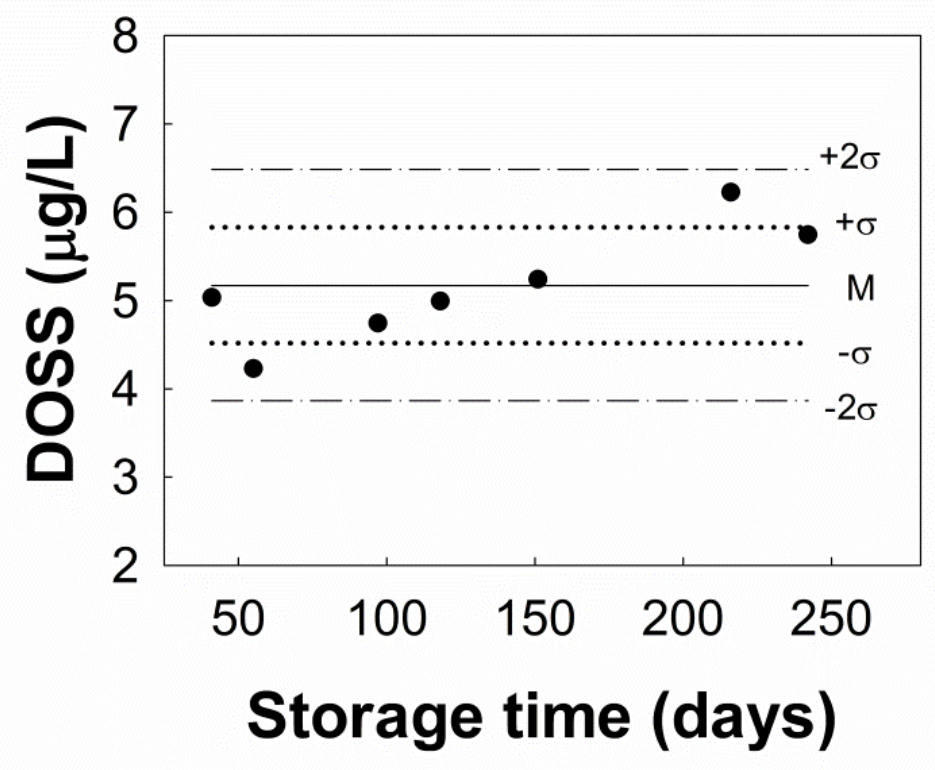

Figure 3.8 Validation of DOSS storage conditions. An artificial seawater sample was repeatedly analyzed for 250 days (fortification level $4.67 \mu \mathrm{g} / \mathrm{L}$, mean $5.17 \mu \mathrm{g} / \mathrm{L}$ ).

\subsubsection{Optimization of the online-SPE procedure}

SPE column loading, washing and reconditioning parameters were optimized for sensitivity and system stability under a repetitive cycle. The changes of acetonitrile concentration in the SPE column during the analysis cycle are graphically represented in figure 3.9. During step $1,3 \mathrm{~mL}$ of deionized water are passed while the autosampler operates to inject the $5 \mathrm{~mL}$ of sample, bringing the SPE column to highly aqueous conditions. At the start of the run $(0 \mathrm{~min})$ the injection port closes and $5 \mathrm{~mL}$ of the preserved seawater sample ( $33 \%$ in acetonitrile) are passed through the column to perform SPE (step 2). 
After extraction, the SPE column is washed with $2 \mathrm{~mL}$ of $10 \mathrm{mM}$ ammonium formate to remove inorganic species that could produce signal suppression and introduce salt build-up in the API source (step 3). DOSS chromatographic peak shape improved when the composition of the mobile phase in the SPE column matched the one in the analytical stream at the time of switching. Therefore, step 3 includes a $1 \mathrm{~mL}$ gradient to condition the SPE column to $20 \%$ acetonitrile before connection with the analytical pump. At $8 \mathrm{~min}$, the SPE and analytical columns are connected and the analyte is eluted (step 4). After a 4 min detection period, the SPE column is reconnected with the loading pump (step 5) and cleaned with $0.5 \mathrm{~mL} 95 \%$ acetonitrile. During this step column conditioning to highly aqueous conditions is initiated, resuming during step 1 of the following run in the queue.

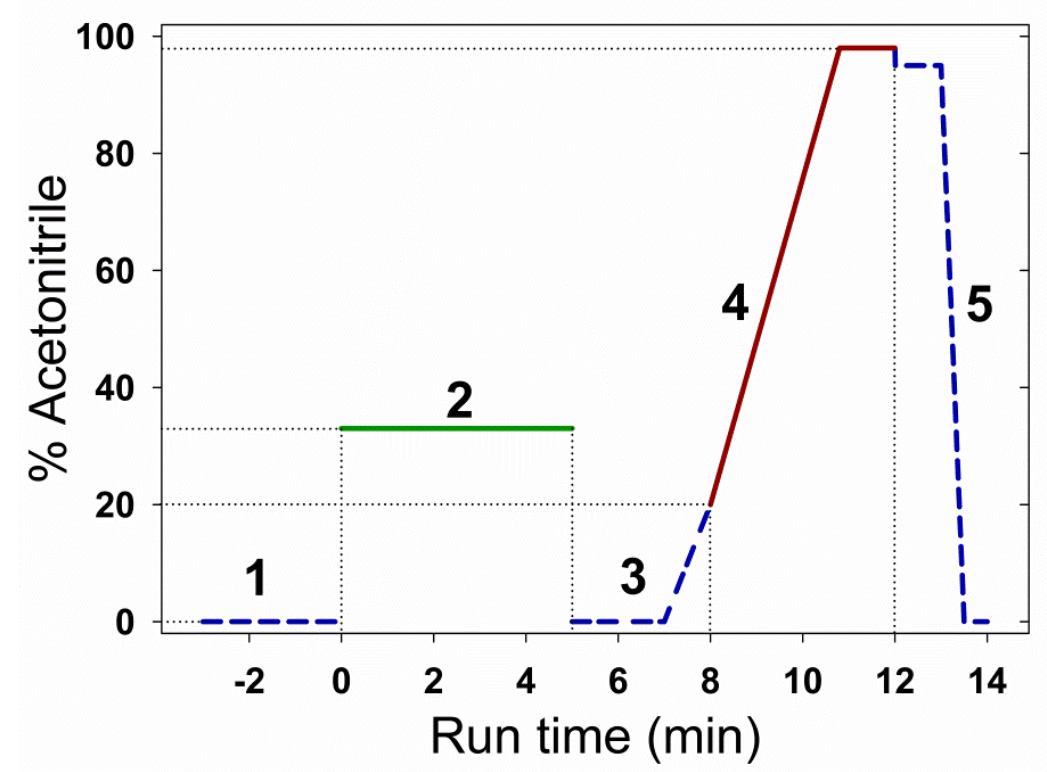

Figure 3.9 Evolution of the acetonitrile concentration in the SPE column during the SPELC-MS/MS analysis of DOSS in seawater showing the different analysis steps. 
In order to test the recovery of the developed online SPE procedure, the same amount ( $2 \mathrm{ng}$ ) of DOSS- ${ }^{13} \mathrm{C}_{4}$ was injected using both the online SPE and direct injection methods. The SPE-LC-MS/MS recovery relative to direct injection was $(113 \pm 14) \%$, calculated by using the DOSS $-{ }^{13} \mathrm{C}_{4}$ peak area from chromatograms obtained the same day using both methods $(\mathrm{n}=6)$. This result indicates that there is no analyte loss by breakthrough during the online SPE step, suggesting that DOSS is efficiently extracted by the SPE column in spite of the presence of $33 \%$ acetonitrile in the injected sample.

\subsubsection{Method validation - Online SPE \& Direct injection of DOSS in seawater}

\subsubsection{Calibration}

Calibration curves were obtained by plotting the peak area ratio of DOSS to its internal standard (DOSS/DOSS- ${ }^{13} \mathrm{C}_{4}$ ) against the DOSS concentration in $\mathrm{ng} / \mathrm{L}$, from the injection of seven calibration solutions. Linearity was observed in the range used $\left(\mathrm{R}^{2}>\right.$ 0.995) for both the SPE-LC-MS/MS and LC-MS/MS methods. Calibrations were verified using an ICV standard from a second source and the acceptable criteria was within $\pm 20 \%$ of known concentration.

\subsubsection{Blanks and carryover control}

A blank sample was prepared with every sample batch, by adding $10.0 \mathrm{~mL}$ of artificial seawater to $5.0 \mathrm{~mL}$ acetonitrile, using $20 \mathrm{~mL}$ glass vial from the same batch used for sample storage. Aliquots of these solutions were treated as seawater samples and analyzed with every sample batch. 
As discussed before, DOSS is a challenging analyte as it tends to bind to glass and other surfaces, raising concerns about carryover in the LC injection system. The combination of the sample preparation procedure (33\% acetonitrile in seawater) and using $50 \%$ acetonitrile/methanol as the organic washing solvent ensured a carryover-free operation in both the direct injection and the online SPE methods, verified by a carryover evaluation experiment. The later was carried out by consecutive injections of a blank and the calibration standard of highest concentration (direct injection method, 20,000 ng/L in $33 \%$ acetonitrile/seawater). As shown in table 3.6, the observed DOSS peak areas in the blanks represented less than $1 \%$ of the DOSS- ${ }^{13} \mathrm{C}_{4}$ peak areas, before and after the injection of the concentrated standard. These results are in agreement with an isotopic purity of $99 \%$ listed by the manufacturer of the certified DOSS- ${ }^{13} \mathrm{C}_{4}$ internal standard, and demonstrate that the developed washing cycle is capable of removing the analyte from the injection system up to $20000 \mathrm{ng} / \mathrm{L}$, the highest concentration of DOSS that was injected.

\subsubsection{Fortified blanks (FB) and fortified matrix (FM) experiments}

Two fortified blanks and one fortified matrix sample were prepared with every analytical batch. DOSS fortification levels were $200 \mathrm{ng} / \mathrm{L}$ (online SPE) and 3,660 ng/L (direct injection). Excellent recoveries were obtained upon analysis of laboratory fortified blanks $(100 \pm 9 \%, \mathrm{n}=54)$ and fortified matrix $(101 \pm 12 \%, \mathrm{n}=32)$ experiments, suggesting that matrix effects are under control by combining the use of DOSS $-{ }^{13} \mathrm{C}_{4}$ as internal standard with the use of seawater in matrix matched calibrations. 
Table 3.6 Results for the carryover evaluation experiment using the direct injection LC$\mathrm{MS} / \mathrm{MS}$ method for DOSS in seawater.

\begin{tabular}{|c|c|c|c|c|c|c|c|}
\hline $\begin{array}{c}\text { LC-MS/MS } \\
\text { FILE }\end{array}$ & NAME & $\begin{array}{l}\text { DOSS } \\
\text { AREA }\end{array}$ & $\begin{array}{c}{\text { DOSS- }-{ }^{13} \mathrm{C}_{4}}_{\text {AREA }} \\
\text { ARE }\end{array}$ & Ratio & $\begin{array}{c}\text { DOSS/ DOSS- }{ }^{13} \mathrm{C}_{4} \\
\% \text { in blanks }\end{array}$ & $\begin{array}{c}\text { Assigned } \\
(\mu \mathrm{g} / \mathrm{L})\end{array}$ & $\begin{array}{c}\text { Measured } \\
\mathrm{C}(\mu \mathrm{g} / \mathrm{L})\end{array}$ \\
\hline 12793 & Blank & $1.59 \mathrm{E}+05$ & $2.39 \mathrm{E}+07$ & $6.63 \mathrm{E}-03$ & 0.7 & 0 & -0.1 \\
\hline 12794 & Blank & $1.60 \mathrm{E}+05$ & $2.35 \mathrm{E}+07$ & $6.82 \mathrm{E}-03$ & 0.7 & 0 & -0.1 \\
\hline 12795 & CS6 & $1.93 \mathrm{E}+07$ & $2.19 \mathrm{E}+07$ & $8.83 \mathrm{E}-01$ & & 20.5 & 20.8 \\
\hline 12796 & Blank & $1.52 \mathrm{E}+05$ & $2.27 \mathrm{E}+07$ & $6.72 \mathrm{E}-03$ & 0.7 & 0 & -0.1 \\
\hline 12797 & Blank & $1.59 \mathrm{E}+05$ & $2.21 \mathrm{E}+07$ & $7.18 \mathrm{E}-03$ & 0.7 & 0 & -0.1 \\
\hline 12798 & CS6 & $1.77 \mathrm{E}+07$ & $2.24 \mathrm{E}+07$ & 7.91E-01 & & 20.5 & 18.7 \\
\hline 12799 & Blank & $1.76 \mathrm{E}+05$ & $2.19 \mathrm{E}+07$ & $8.04 \mathrm{E}-03$ & 0.8 & 0 & -0.1 \\
\hline 12800 & Blank & $1.80 \mathrm{E}+05$ & $2.35 \mathrm{E}+07$ & $7.65 \mathrm{E}-03$ & 0.8 & 0 & -0.1 \\
\hline 12801 & CS6 & $1.80 \mathrm{E}+07$ & $2.14 \mathrm{E}+07$ & $8.43 \mathrm{E}-01$ & & 20.5 & 19.9 \\
\hline 12802 & Blank & $1.75 \mathrm{E}+05$ & $2.43 \mathrm{E}+07$ & $7.21 \mathrm{E}-03$ & 0.7 & 0 & -0.1 \\
\hline 12803 & Blank & $1.80 \mathrm{E}+05$ & $2.35 \mathrm{E}+07$ & $7.65 \mathrm{E}-03$ & 0.8 & 0 & -0.1 \\
\hline 12804 & CS6 & $1.64 \mathrm{E}+07$ & $1.95 \mathrm{E}+07$ & 8.39E-01 & & 20.5 & 19.8 \\
\hline 12805 & Blank & $1.81 \mathrm{E}+05$ & $2.30 \mathrm{E}+07$ & $7.85 \mathrm{E}-03$ & 0.8 & 0 & -0.1 \\
\hline 12806 & Blank & $1.70 \mathrm{E}+05$ & $2.26 \mathrm{E}+07$ & $7.50 \mathrm{E}-03$ & 0.8 & 0 & -0.1 \\
\hline 12807 & CS6 & $1.82 \mathrm{E}+07$ & $2.19 \mathrm{E}+07$ & $8.33 \mathrm{E}-01$ & & 20.5 & 19.7 \\
\hline 12808 & Blank & $1.72 \mathrm{E}+05$ & $2.19 \mathrm{E}+07$ & $7.86 \mathrm{E}-03$ & 0.8 & 0 & -0.1 \\
\hline 12809 & Blank & $1.79 \mathrm{E}+05$ & $2.16 \mathrm{E}+07$ & 8.29E-03 & 0.8 & 0 & 0.0 \\
\hline 12810 & CS6 & $1.77 \mathrm{E}+07$ & $2.08 \mathrm{E}+07$ & $8.51 \mathrm{E}-01$ & & 20.5 & 20.1 \\
\hline 12811 & Blank & $1.93 \mathrm{E}+05$ & $2.39 \mathrm{E}+07$ & $8.06 \mathrm{E}-03$ & 0.8 & 0 & -0.1 \\
\hline 12812 & Blank & $1.85 \mathrm{E}+05$ & $2.11 \mathrm{E}+07$ & $8.77 \mathrm{E}-03$ & 0.9 & 0 & 0.0 \\
\hline 12813 & CS6 & $1.79 \mathrm{E}+07$ & $2.19 \mathrm{E}+07$ & $8.18 \mathrm{E}-01$ & & 20.5 & 19.3 \\
\hline 12814 & Blank & $1.70 \mathrm{E}+05$ & $2.37 \mathrm{E}+07$ & $7.16 \mathrm{E}-03$ & 0.7 & 0 & -0.1 \\
\hline 12815 & Blank & $1.72 \mathrm{E}+05$ & $2.22 \mathrm{E}+07$ & $7.72 \mathrm{E}-03$ & 0.8 & 0 & -0.1 \\
\hline \multicolumn{8}{|c|}{ Calibration Data } \\
\hline 12816 & CSO & $1.78 \mathrm{E}+05$ & $2.28 \mathrm{E}+07$ & $7.78 \mathrm{E}-03$ & & 0 & -0.1 \\
\hline 12817 & CS1 & $3.37 \mathrm{E}+05$ & $2.27 \mathrm{E}+07$ & $1.48 \mathrm{E}-02$ & & 0.19 & 0.11 \\
\hline 12818 & $\mathrm{CS} 2$ & $5.81 \mathrm{E}+05$ & $2.18 \mathrm{E}+07$ & $2.67 \mathrm{E}-02$ & & 0.50 & 0.39 \\
\hline 12819 & $\mathrm{CS} 3$ & $1.38 \mathrm{E}+06$ & $2.34 \mathrm{E}+07$ & $5.91 \mathrm{E}-02$ & & 1.25 & 1.17 \\
\hline 12820 & CS4 & $4.96 \mathrm{E}+06$ & $2.22 \mathrm{E}+07$ & $2.24 \mathrm{E}-01$ & & 4.98 & 5.10 \\
\hline 12821 & CS5 & $9.27 \mathrm{E}+06$ & $2.08 \mathrm{E}+07$ & $4.45 \mathrm{E}-01$ & & 9.96 & 10.4 \\
\hline 12822 & CS6 & $1.77 \mathrm{E}+07$ & $2.06 \mathrm{E}+07$ & $8.60 \mathrm{E}-01$ & & 20.5 & 20.3 \\
\hline
\end{tabular}

$Y=0.0103284+0.0418357 * X \quad R^{\wedge} 2=0.9992$ 


\subsubsection{Qualitative analysis}

Samples were considered to contain DOSS when peaks were present in both the DOSS main $(421 \rightarrow 81)$ and secondary $(421 \rightarrow 227)$ SRM transitions. Both signals were required to have a signal-to-noise ratio of 10 and a retention time within $2 \%$ of that of the DOSS- ${ }^{13} \mathrm{C}_{4}$ signal. Typical chromatograms for both methods are observed in figure 3.10.
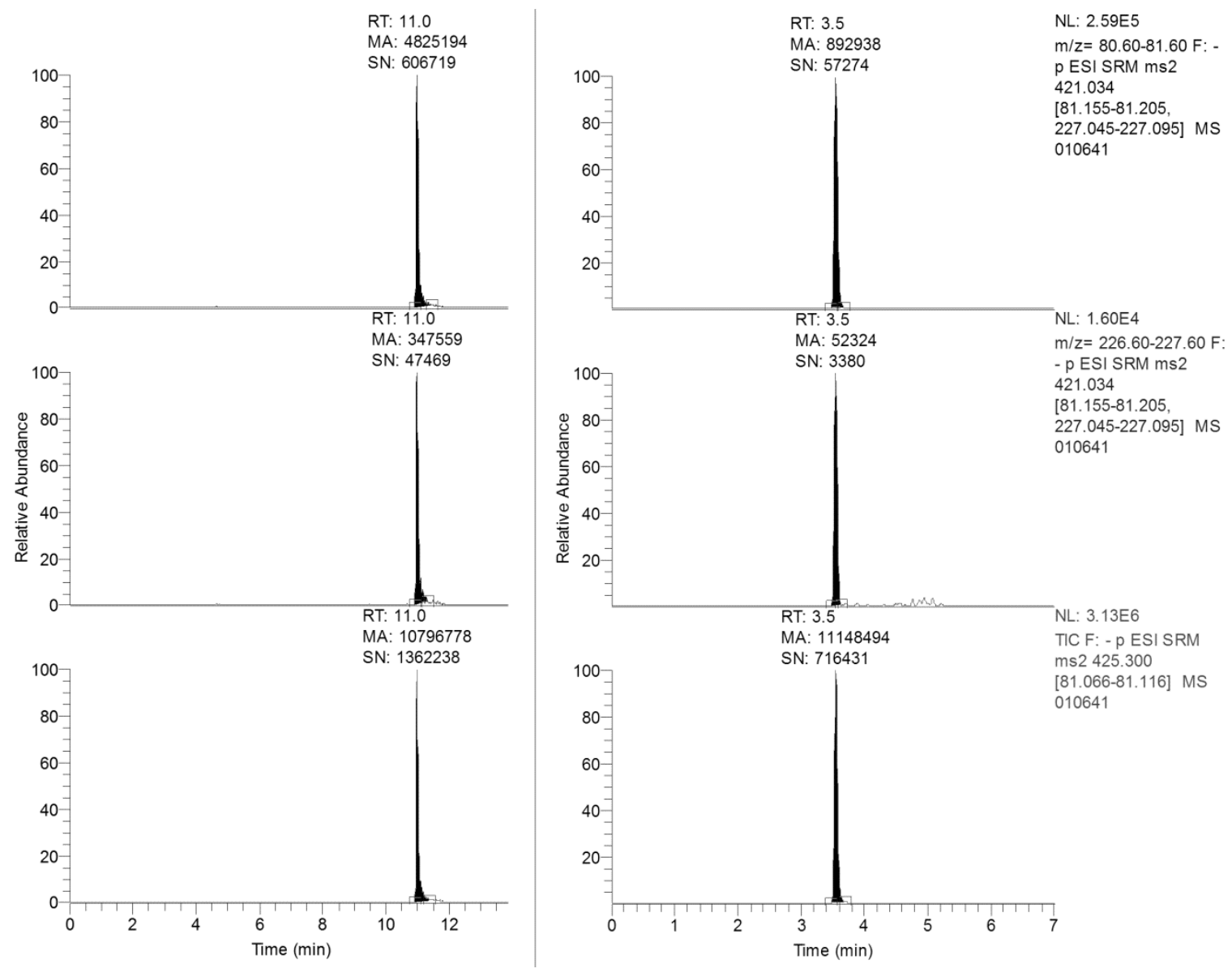

Figure 3.10 Typical DOSS chromatograms obtained by online SPE-LC-MS/MS (left) and direct injection (right) methods to quantify DOSS in seawater. From top to bottom: DOSS quantitative signal, DOSS qualitative signal, and DOSS- ${ }^{13} \mathrm{C}_{4}$ internal standard. The concentrations for online SPE were: $237 \mathrm{ng} / \mathrm{L}$ DOSS and $400 \mathrm{ng} / \mathrm{L}$ DOSS ${ }^{13} \mathrm{C}_{4}$. The concentrations for direct injection were as follows: $2,729 \mathrm{ng} / \mathrm{L}$ DOSS and 20,000 ng/L DOSS $-{ }^{13} \mathrm{C}_{4}$. 


\subsubsection{Detection limits}

Method detection limits (MDLs) were calculated by multiplying the standard deviation from seven measurements by the Student $t$ value $\left(t_{(7-1,99)}=3.143\right)$, according to procedures outlined by the USEPA (2010e), using aliquots of Biscayne Bay natural seawater. Fortification levels were $20 \mathrm{ng} / \mathrm{L}$ for online SPE and 1,000 ng/L for direct injection, obtaining MDLs of $7.0 \mathrm{ng} / \mathrm{L}$ and $440 \mathrm{ng} / \mathrm{L}$, respectively.

In comparison, Kujawinsky et al. (2011) reported the presence of DOSS in environmental samples to concentrations as low as $3 \mathrm{ng} / \mathrm{L}$, for 7 liters of sample using offline SPE and LC-MS. Although higher sensitivity is possible with that method, its complexity and the logistics required to collect large sample quantities makes it impractical for environmental monitoring.

Mathew et al. (2012) established a reporting limit of 20,000 ng/L for their direct injection method and therefore its ability to analyze open water samples is limited to areas of recent dispersant applications.

The USEPA has listed an aquatic life benchmark 40,000 ng/L for DOSS and suggested reporting limits for environmental analysis of 20,000 ng/L (USEPA, 2010a). The DOSS detection limits for both methods reported in this work (7.0 and $440 \mathrm{ng} / \mathrm{L})$ are well under the required reporting limits. 


\subsubsection{Analysis of DOSS and 2-butoxyethanol in crude oil and commercial formulations}

\subsubsection{Calibration}

Calibration plots for the crude oil analysis were produced by plotting the ratio of the peak areas of each analyte with the peak area of the internal standard $\left(\mathrm{SDS}-\mathrm{D}_{25}\right)$ against the standard concentration in the injected solutions. Linearity was observed for both analytes in the range used $\left(\mathrm{R}^{2}>0.995\right)$. Using these calibration curves the concentration of each analyte in the liquid extract was obtained. This concentration was corrected for the liquid-liquid extraction step using the percent recovery of the isotopically labeled surrogates, calculated with the relative response factors (adapted from (Denoux, Gardinali, \& Wade, 1998), see appendix 1 for details). The weight concentration was then back calculated using the corrected concentration and the weight of the crude oil sample.

As no extraction step is performed for the analysis of serially diluted commercial formulations, calibrations were performed similarly to the DOSS in seawater analyses described before. The weight percentage of DOSS and 2-butoxyethanol in commercial formulations were back calculated using the measured concentration and the total dilution factor applied.

\subsubsection{Analysis of crude oil samples}

The method was tested using two different oils: a sweet-light oil from Wilcox formation in Texas, USA and crude oil sample from the MC-252 well, collected on May 
$22^{\text {nd }} 2010$. None of the analytes were detected in the Wilcox formation oil whereas the oil originated at the MC-252 raiser contained $(4.0 \pm 0.2) \mathrm{mg} / \mathrm{Kg}$ of DOSS. However, 2butoxyethanol was not detected in the sample, which could indicate that Corexit ${ }^{\circledR}$ EC9527A was not employed during the response effort. Chromatograms from crude oil and commercial formulation analyses are presented in figure 3.11.

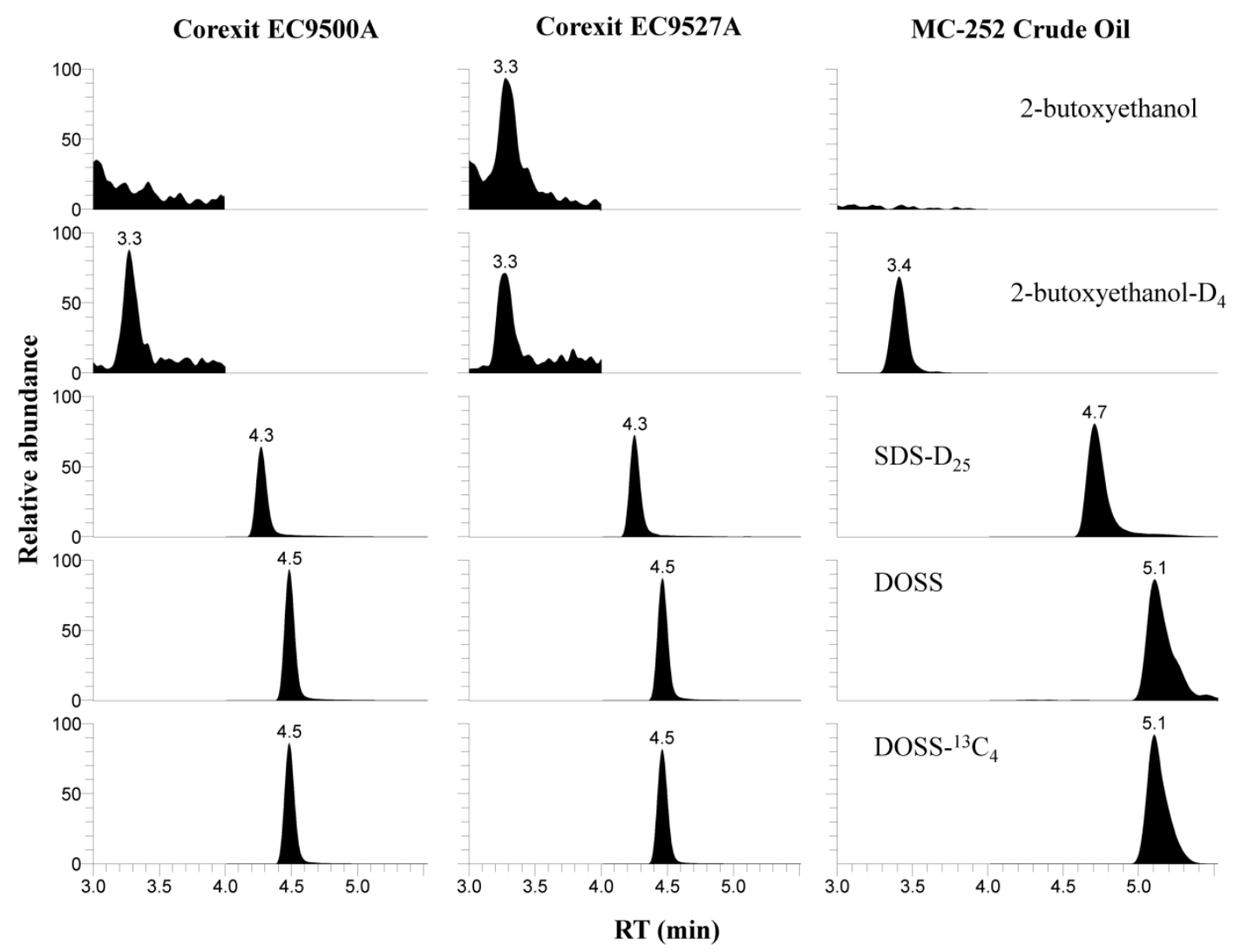

Figure 3.11 Chromatograms obtained using the direct injection LC-MS/MS method for serially diluted commercial formulations (dilution factor: $10^{7}$ ) and crude oil after liquidliquid extraction. The ESI source operated in positive mode from 0 to 4 min, and then switched to negative mode. The main SRM transition is shown for each compound, and chromatograms of both Corexit formulations are normalized to the same scale for comparison purposes. 


\subsubsection{Oil MDLs}

Because the MC-252 sample did contain DOSS, MDLs for crude oil analysis were determined by analyzing 7 replicates of the Wilcox formation crude oil, fortified to $2 \mathrm{mg} / \mathrm{Kg}$ of DOSS and $20 \mathrm{mg} / \mathrm{Kg}$ of 2-butoxyethanol. The calculated MDLs were 0.723

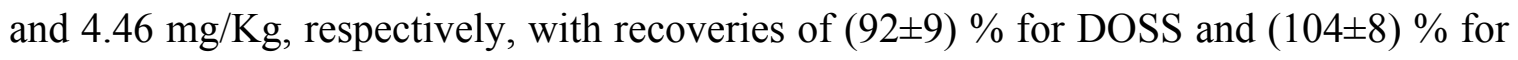
2-butoxyethanol $(\mathrm{n}=7)$.

\subsubsection{Analysis of DOSS and 2-butoxyethanol in commercial dispersant formulations}

Corexit $^{\circledR}$ EC9500A was found to contain $(21 \pm 2) \% \mathrm{w} / \mathrm{w}$ of DOSS. As expected, 2-butoxyethanol was not detected in that formulation. Corexit ${ }^{\circledR}$ EC9527A contained $(22 \pm 5) \% \mathrm{w} / \mathrm{w}$ of DOSS and $(37 \pm 2) \% \mathrm{w} / \mathrm{w}$ of 2-butoxyethanol. The obtained results were in good agreement with the numbers described in the MSDS of the commercial formulations (NALCO, 2012a, 2012b).

\subsection{Conclusions}

This report describes two robust analytical methods for the quantification of DOSS in seawater, that could be applied to monitor the fate and transport of the surfactant after Corexit ${ }^{\circledR}$ has been used in response efforts to counter oil spills. The combination of these two methods offers a rather large dynamic range with demonstrated high sensitivity and low matrix effects. Concerns about carryover and sample stability upon storage have also been addressed by means of acetonitrile preservation. The direct injection method can be quickly adopted by many laboratories with existing LC/MS 
capabilities. With a run time of 7 minutes, high quality data for a large number of samples can be quickly obtained. The direct injection MDL of $440 \mathrm{ng} / \mathrm{L}$ is lower than any previously available direct injection method for DOSS in seawater. However, the online SPE method also included in this study offers a 50 -fold sensitivity increase $(7.0 \mathrm{ng} / \mathrm{L}$ MDL), with a modest increase in analysis time of 10 minutes. The method sensitivity allows for routine monitoring of dispersant long after application. Additionally, a direct injection method for the simultaneous detection of two major components of Corexit ${ }^{\circledR}$ formulations (DOSS and 2-butoxyethanol) was developed and tested with a crude oil sample from the DHW accident site. Since DOSS was detected in this sample but 2butoxyethanol was not, results suggests that Corexit $^{\circledR}$ EC9527A probably was not employed during the response effort. The method was also successfully applied to analyze commercial dispersant formulations, quantifying their main components and clearly differentiating EC9500A from EC9527A.

All listed methods are fast, simple and require minimum sample preparation steps and sample quantities, allowing a variety of quality controls such as duplicates and matrix fortification experiments without the need of extensive sample volume collection. 


\section{FULLY AUTOMATED TRACE LEVEL DETERMINATION OF POLYCYCLIC AROMATIC HYDROCARBONS IN ENVIRONMENTAL WATERS BY ONLINE SPE-LC-APPI-MS/MS}

(Cesar E. Ramirez, Chengtao Wang and Piero R. Gardinali. Analytical and Bioanalytical Chemistry, 2013, in press)

\subsection{Introduction}

Polycyclic aromatic hydrocarbons (PAHs) are persistent organic pollutants produced by both human activities and natural phenomena. Polycyclic aromatic hydrocarbons enter surface waters mainly by atmospheric fallout, urban runoff, municipal and industrial effluents and the spill or leakage of petroleum and its derivates (Manoli \& Samara, 1999; Wolska et al., 2012). Petroleum-derived mixtures contain large amounts of PAHs (Wang et al., 2006) and these compounds are often used as markers to determine the source, fate and potential effects on natural resources after such substances are released to the environment (Boehm et al., 1997; Boehm et al., 2007).

Many PAHs have been found to have toxic, carcinogenic and mutagenic properties (ATSDR, 1990; Manzetti, 2012), which have prompted the imposition of strict regulations on their concentrations in effluents, environmental waters and drinking water supplies. The United States Environmental Protection Agency (USEPA) has considered 16 parent PAHs as priority pollutants for environmental monitoring purposes (Lerda, 2011). These priority PAHs and their structures are presented in table 4.1. 
Table 4.1 Polycyclic aromatic hydrocarbons listed as priority pollutants by the United States Environmental Protection Agency.

\begin{tabular}{|c|c|c|c|}
\hline PAH & $\begin{array}{c}\text { CAS } \\
\text { number }\end{array}$ & Structure & M.W. $\left(\mathrm{gmol}^{-1}\right)$ \\
\hline Naphthalene & $91-20-3$ & & 128.2 \\
\hline Acenaphtylene & $208-96-8$ & & 152.2 \\
\hline Acenaphthene & $83-32-9$ & & 154.2 \\
\hline Fluorene & $86-73-7$ & & 166.2 \\
\hline Anthracene & $120-12-7$ & & 178.2 \\
\hline Phenanthrene & $85-01-8$ & & 178.2 \\
\hline Fluoranthene & $206-44-0$ & & 202.3 \\
\hline Pyrene & $129-00-0$ & & 202.3 \\
\hline Benz[a]anthracene & $56-55-3$ & & 228.3 \\
\hline Chrysene & 218-01-9 & & 228.3 \\
\hline Benzo[a]pyrene & $50-32-8$ & & 252.3 \\
\hline Benzo[b]fluoranthene & $205-99-2$ & & 252.3 \\
\hline Benzo[k]fluoranthene & $207-08-9$ & & 252.3 \\
\hline Benzo[g,h,i]perylene & $191-24-2$ & & 276.3 \\
\hline Indeno $[1,2,3-c d]$ pyrene & $193-39-5$ & & 276.3 \\
\hline Dibenz $[a, h]$ anthracene & $53-70-3$ & & 278.3 \\
\hline
\end{tabular}


Well-established methodologies are available for the analysis of volatile and semi-volatile organic compounds in waste and surface waters, usually involving liquidliquid extraction (LLE) with methylene chloride followed by clean-up steps before analysis by gas chromatography coupled with mass spectrometry (GC-MS) (Denoux et al., 1998; Poster et al., 2006; USEPA, 1996b, 1996c, 2010d). These methodologies provide excellent chromatographic resolution because of the use of capillary GC columns, which allows the separation of isobaric PAHs that cannot be selectively detected by mass spectrometers. However, LLE requires a high volume of sample, is labor-intensive and also time consuming, thus sample throughput is severely limited. In addition, each sample analyzed by LLE + GC-MS uses a large amount of methylene chloride, which is then evaporated and released into the atmosphere.

A faster methodology than LLE+GC-MS with comparable sensitivity and chromatographic resolution, which also reduces the production of halogenated solvent waste, could be highly desirable to laboratories monitoring concentrations of PAHs in environmental waters and discharged effluents.

The use of solid phase extraction (SPE) has been reported as an alternative sample preparation procedure for $\mathrm{PAH}$ analysis. Sorbents, extraction and elution conditions have been previously documented (Marce \& Borrull, 2000). Although examples of offline SPE used as sample preparation step for LC analysis of PAHs are available in the literature, only three studies of online SPE analysis of PAHs from environmental waters have been reported. Renner et al. (1997) first reported the use of online SPE coupled with LC and fluorescence detection (SPE-LC-FLD) to analyze 16 
PAHs in $50 \mathrm{~mL}$ of freshwater samples, while Li et al. (2012) used the same SPE-LC-FLD technique for the analysis of 15 PAHs in $100 \mathrm{~mL}$ of seawater from the Japan Sea. These two studies were limited by the interferences caused by coeluting analytes and the nonselective nature of the FLD.

A third online SPE study for the detection of PAHs was published by Gimeno et al. (2002). The group analyzed 10 PAHs in $25 \mathrm{~mL}$ of seawater using online SPE with a single-quadrupole mass spectrometer (SPE-LC-MS) equipped with atmospheric pressure chemical ionization (APCI). Since PAHs have a planar structure formed by two or more fused aromatic rings (see table 4.1), the absence of any chemical groups capable of ionic exchange or electron capture causes low ionization efficiencies when traditional LC-MS interfaces such as APCI or electrospray ionization (ESI) are used.

The sensitivity of LC-MS detection of PAHs significantly increased with the introduction of atmospheric pressure photoionization (APPI), released independently by Robb et al. (2000) and Syage et al. (2000). In the APPI source, an electron is removed from molecules with lower ionization energies (IE) than that of a vacuum ultraviolet (VUV) radiation to which they are subjected to, obtaining single-charged, odd-electron molecular cations (Marchi et al., 2009; Robb et al., 2000), a process that is summarized in equation 1.

$$
\mathrm{M}+h v \rightarrow \mathrm{M}^{\cdot+}+\mathrm{e}^{-} \quad\left(\text { if } \mathrm{IE}_{\mathrm{M}}<h v\right)(\text { Equation 1, (Robb \& Blades, 2008)) }
$$

However, direct APPI has been shown as an inefficient way to generate ions from non-polar analytes (Robb \& Blades, 2008). Robb et al. (2000) proved the concept of 
dopant-assisted APPI, in which an intermediary compound is introduced at high concentrations into the APPI source producing large amounts of cations which in turn undergo a charge transfer with the eluting analytes (equation 2). With dopant-assisted APPI, a substantial sensitivity gain relative to direct, dopant-free photoionization of PAHs has been previously reported (Itoh et al., 2006).

$$
\begin{aligned}
& \mathrm{D}+h v \rightarrow \mathrm{D}^{{ }^{+}+\mathrm{e}^{-}} \quad\left(\text { if } \mathrm{IE}_{\mathrm{D}}<h v\right) \\
& \mathrm{D}^{\cdot+}+\mathrm{M} \rightarrow \mathrm{M}^{\cdot+}+\mathrm{D} \quad\left(\text { if } \mathrm{EA}_{\mathrm{D}}{ }^{\cdot+}>\mathrm{IE}_{\mathrm{M}}\right) \quad \text { (Equation 2, (Marchi et al., 2009)) }
\end{aligned}
$$

Although dopant-assisted APPI has been used before for the analysis of the USEPA 16 priority parent PAHs by direct injection LC-MS/MS (Cai, et al., 2009; Robb \& Blades, 2008), no previous reports are available on its use as detection for online SPELC applications to quantify a larger number of parent PAHs or alkylated PAHs.

The three previously published online SPE methods for the analysis of PAHs in waters shared the same approach: passing a large volume of water through a reverse phase column used for SPE purposes by means of a LC pump connected between the column and the sample. Such process requires sample filtration to avoid pump failure and large volumes of solvent for rinsing the pump mechanism in order to avoid carryover, is not amenable to automation and does not completely eliminate the time consumption disadvantage of the traditional LLE + GC-MS technique, with the added caveat of detecting fewer number of PAHs due to the lower chromatographic resolution offered by the employed LC separations. 
Passing samples through the SPE pump mechanism can be avoided by performing injections into large volume sample loops connected between the pump and the SPE column, an approach that is now well established for online SPE applications and allows for sample handling by robotic autosamplers (Busetti et al., 2012; Garcia-Ac et al., 2009; Wang \& Gardinali, 2012).

\subsection{Hypotheses}

- An online SPE-LC-MS/MS methodology can be developed for the automated analysis of PAHs in surface waters, avoiding lengthy sample preparation steps.

- A similar method performance to the traditional GC-MS methodology, in terms of chromatographic resolution and also in sensitivity, can be achieved by means of a liquid chromatography separation.

- Such methodology could be used to monitor the occurrence of PAHs in waters from the local urban environment of South Florida.

\subsection{Research objectives}

The objectives of the study were as follows:

- To optimize conditions for online SPE extraction, LC separation and dopantassisted atmospheric pressure photoionization tandem mass spectrometry (SPE-LC-APPI-MS/MS) detection, in order to develop a fully automated protocol for the determination of large numbers of both parents and alkylated PAHs in environmental waters. 
- To compare the performance of the developed methodology the traditional methodology for the analysis of a large number of PAHs in environmental waters (Liquid-liquid extraction followed by gas chromatography coupled with mass spectrometry (GC-MS).

- To analyze waters from different origins of the Miami Metropolitan Area in order to assess the applicability of the developed methodology for the monitoring of this type of pollution in urban environments.

\subsection{Materials and reagents}

Certified PAH and isotopically labeled PAH standard mixtures were purchased from Accustandard (New Haven, CT, USA). Additional single PAH certified standards or neat compounds were also obtained from Accustandard and from Sigma-Aldrich (St. Louis, MO, USA). Standard reference materials (2260a and 1491a) were obtained from NIST (Gaithersburg, MD, USA). Stock solutions were stored at $-20{ }^{\circ} \mathrm{C}$. Acetonitrile, water and methanol (LC-MS grade) were purchased from Fisher Scientific (Fairlawn, NJ, USA). Chlorobenzene dopant (extra dry, 99.8\% pure) was purchased from Acros Organics (Geel, Belgium) and used as received. Artificial seawater $(3.5 \% \mathrm{w} / \mathrm{v})$ was prepared using the commercially available Instant Ocean ${ }^{\circledR}$ salt.

Online preconcentration was performed using an EQuan online SPE system (Thermo Scientific, Waltham, MA, USA), consisting of an HTC-PAL ${ }^{\text {TM }}$ autosampler (equipped with a $5 \mathrm{~mL}$ glass syringe), an Accela ${ }^{\mathrm{TM}} 1000$ as analytical HPLC pump and an Accela ${ }^{\mathrm{TM}} 600$ as SPE loading pump. Stainless steel sample loops (models CSL5K and CSL10K, 5 and $10 \mathrm{~mL}$ respectively) were obtained from Valco Instruments (Houston, 
TX., USA). The online SPE column was a Hypersil Gold aQ ${ }^{\circledR}(20 \mathrm{~mm} \times 2.1 \mathrm{~mm}, 12$ $\mu \mathrm{m})$. Analytical separations were carried out using a Hypersil Green $\mathrm{PAH}^{\circledR}$ column (150 $\times 2.1 \mathrm{~mm}, 3 \mu \mathrm{m})$, protected by a Hypersil Green $\mathrm{PAH}^{\circledR}$ guard column $(10 \times 2.1 \mathrm{~mm}, 3$ $\mu \mathrm{m})$. All columns were also obtained from Thermo Scientific. Stainless steel tubing was used throughout the SPE-LC-MS/MS system.

Detection was performed on a TSQ Quantum Access ${ }^{\mathrm{TM}}$ triple-quadrupole mass spectrometer, equipped with an APPI source consisting in a Ion Max API source housing with a vaporizer probe (Thermo Scientific) and a Photomate ${ }^{\circledR}$ krypton lamp (Syagen, Santa Ana, CA, USA). The necessary parts to build the dopant sprayer described in this work were purchased from IDEX Health and Science (Oak Harbor, WA., USA). The EQuan system was controlled using the Xcalibur 2.1 data acquisition software (Thermo Scientific). Dopant was delivered using the combined output of two Fusion 200 programmable syringe pumps (Chemyx, Stafford, TX., USA), each equipped with two 10 mL Gastight ${ }^{\circledR}$ syringes (Hamilton, Reno, NV., USA).

Comparative GC-MS studies were performed using a TSQ Quantum XLSTM triple-quadrupole mass spectrometer (Thermo Scientific), using $70 \mathrm{eV}$ EI ionization and single ion monitoring (SIM) scan mode. GC separation was made by a Trace GC Ultra ${ }^{\mathrm{TM}}$ gas chromatograph, equipped with a Triplus ${ }^{\mathrm{TM}}$ autosampler (Thermo Scientific) and an Rtx $^{\circledR}$-5MS (30 m, 0.025 mm ID) capillary GC column (Restek, Bellefonte, PA, USA). 


\subsection{Environmental sampling}

All glassware used to collect and store samples was cleaned by heating to $450{ }^{\circ} \mathrm{C}$ for at least $6 \mathrm{~h}$ before use. Field samples were collected using $60 \mathrm{~mL}$ amber glass vials rinsed once with surface water, filled and capped with PTFE lined plastic caps without leaving air inside. Vials were then placed in plastic bags and transported to the laboratory on ice. A sampling blank, consisting of a $60 \mathrm{~mL}$ vial filled with artificial seawater, was placed on ice and transported during sampling and analyzed with the collected samples as negative blank.

Seawater samples were collected in a single trip during August 2012 around Northern Biscayne Bay, adjacent to the Miami metropolitan area. Two reclaimed water samples were collected from the North District Wastewater Treatment Plant in the Miami-Dade County during August and September 2012.

Rainwater and runoff samples were collected during a heavy rain event (tropical storm "Andrea", June 6 and 7, 2013; see figure 4.1) from the drainage openings at two parking lots from the Florida International University Biscayne Bay campus, and from the parking lot of a nearby residential complex. A reference rainwater sample was collected during the same event using a $1 \mathrm{~L}$ amber glass bottle and a glass funnel. All samples were stored at $4{ }^{\circ} \mathrm{C}$ and analyzed no more than 14 days after collection. 

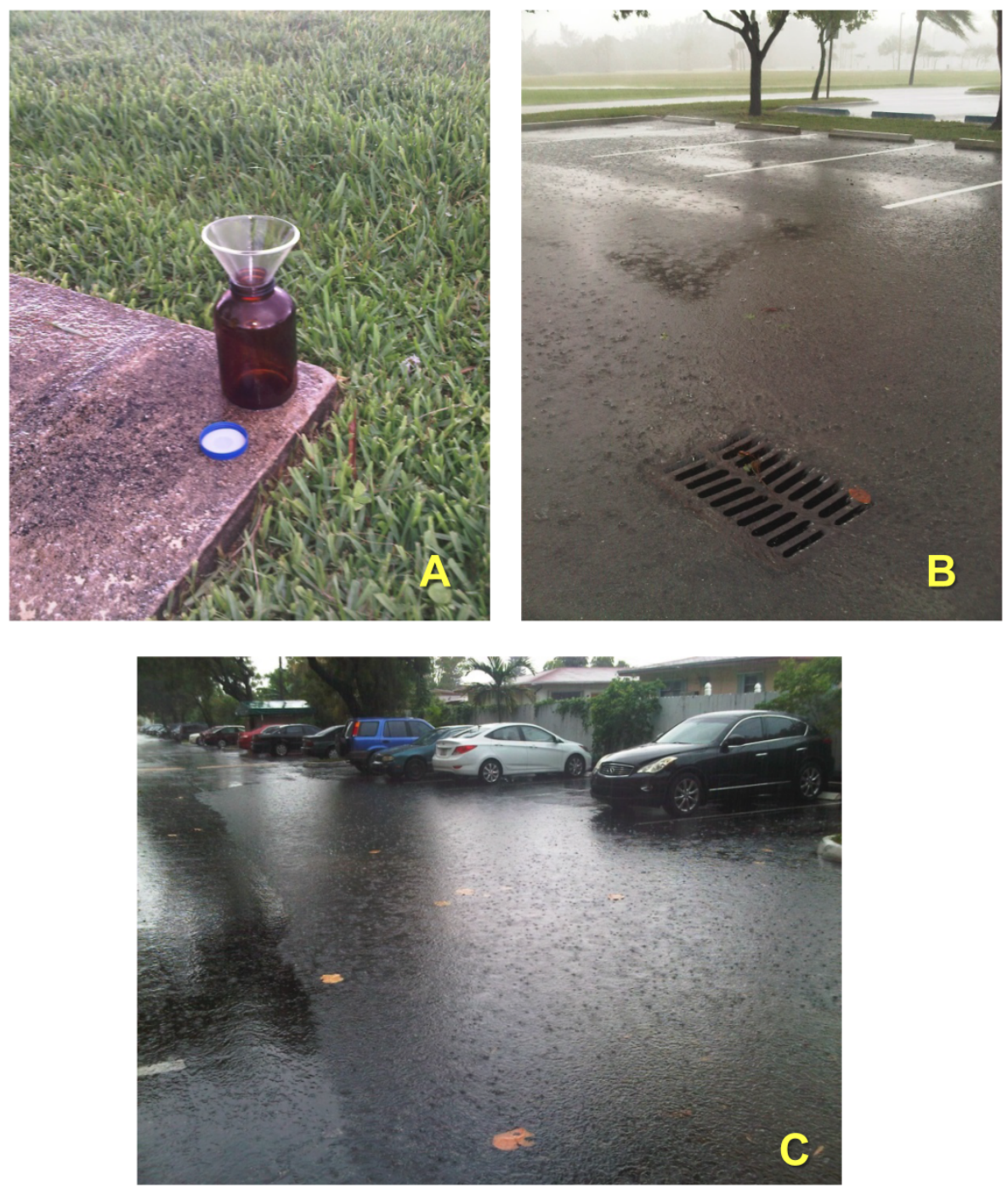

Figure 4.1 Rainwater and runoff sampling during tropical storm "Andrea". A: Glassware used for collection of reference rainwater. B: Sampling site at the drain of a parking lot at Florida International University, Biscayne Bay Campus. C: Sampling site at a flooded parking lot at a nearby apartment complex. 


\subsection{Analytical methodology}

\subsubsection{Sample preparation}

Working solutions of all PAHs were prepared each analysis day in methanol from stock solutions of certified standards. Refrigerated samples and standards were allowed to reach room temperature before preparation. Aliquots $(10 \mathrm{~mL})$ of waters were transferred directly from the sampling containers into a $10 \mathrm{~mL}$ LC vials containing $0.55 \mathrm{~mL}$ of a methanol solution of isotopically labeled PAHs and $0.45 \mathrm{~mL}$ of water. The resulting solutions contained $5 \%$ methanol and $95 \%$ water with $100 \mathrm{ng} / \mathrm{L}$ of each isotopically labeled PAH. Solutions were capped, thoroughly mixed and loaded to the online SPE system without further treatment. Matrix matched calibration solutions (5-500 ng/L) were prepared using the same procedure, using artificial seawater and working solutions containing analytes and internal standards in methanol. A 7-point set of calibration solutions was freshly prepared for each analysis batch.

\subsubsection{Online SPE-LC-MS/MS}

The samples, quality controls and calibration solutions were loaded onto the 10 $\mathrm{mL}$ stainless steel loop (rotary valve A, figure 4.2). The SPE column was placed in a second rotary valve (valve B, figure 4.2), allowing connection with either the loading pump or the analytical pump.

The steps of the analysis program, determined by valve turning events, are graphically presented in figure 4.2. During step 1, valve A turns and connects the filled sample loop with the SPE column, and a $5 \mathrm{mV}, 1000 \mathrm{~ms}$ electronic start signal is sent to 
all devices including the programmable dopant syringe pumps. $10 \mathrm{~mL}$ of sample are passed through the SPE column within $5 \mathrm{~min}$, followed by $2 \mathrm{~mL}$ of $1 \%$ methanol in water to remove inorganic species. Then, $0.5 \mathrm{~mL}$ of a short gradient to $60 \%$ methanol and 0.5 $\mathrm{mL}$ of $60 \%$ methanol are passed to prepare the SPE column for connection with the organic rich analytical stream. Additionally, during this step the analytical column is taken to initial gradient conditions.

Valve B turns at 8 min and step 2 begins. The SPE column is connected with the analytical column and gradient separation is started, while the sample loop is completely filled with methanol from the SPE LC pump. At 15 min, valve A turns (step 3) and the methanol filled sample loop is connected with the injection port. The autosampler sequentially injects $5 \mathrm{~mL}$ of methanol, $5 \mathrm{~mL}$ of water and two $5 \mathrm{~mL}$ portions of the next sample in the queue, while the chromatographic separation continues. Finally, at $24 \mathrm{~min}$ valve B turns again (step 4) and connects the SPE LC pump with the SPE column, which is then cleaned with $1 \mathrm{~mL}$ of acetonitrile and progressively taken to the highly aqueous initial conditions. The system is now ready to start the cycle for the next sample that is already pre-loaded in the sample loop.

These steps add to a total run time of 28 min per sample. The programs for all pumps are shown in table 4.2 and the complete autosampler settings and operation program is presented in appendix 2 . 


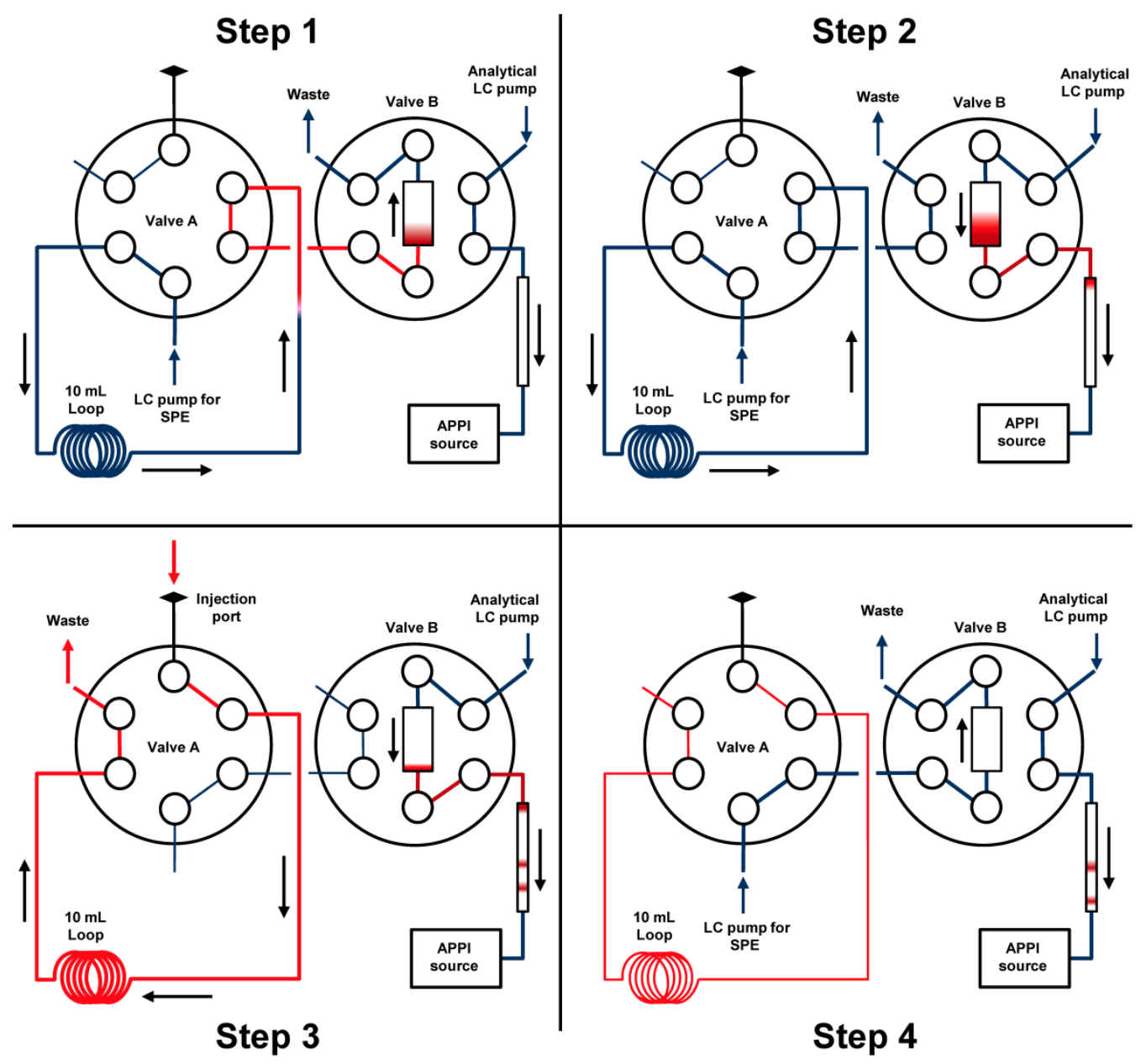

Figure 4.2 Online SPE system and automated analysis steps. Active flows are shown by arrows and thicker lines. Red: sample and PAHs. Blue: mobile phases.

\subsubsection{Dopant-assisted APPI-MS/MS detection}

The mass spectrometer was operated under APPI in the positive mode. The following parameters were used for all analytes: skimmer offset: $-10 \mathrm{~V}$; sheath gas $\left(\mathrm{N}_{2}\right)$ : 40 arbitrary units; auxiliary gas $\left(\mathrm{N}_{2}\right): 20$ arbitrary units; capillary temperature: $250{ }^{\circ} \mathrm{C}$; vaporizer temperature: $250^{\circ} \mathrm{C}$; collision-induced dissociation (CID) gas (Ar) pressure: 2.1 mTorr; scan time: $0.020 \mathrm{~s}$; scan width: $0.020 \mathrm{~m} / \mathrm{z}$. In order to reduce unnecessary 
instrument scans, two detection segments were used (segment 1: 8-18 minutes and segment 2: 18-28 min). Chlorobenzene dopant was introduced to the APPI source only during the detection period $(8-28 \mathrm{~min})$ through the nitrogen auxiliary gas line, delivered by two programmable syringe pumps operating simultaneously for total flow rate of $10 \%$ of that of the column eluent (see table 4.2). Selective reaction monitoring (SRM) scan events were obtained by direct infusion of individual PAHs solutions and are listed in table 4.3.

Table 4.2 Solvent delivery programs for all pumps used in the online SPE-LC-MS/MS analysis of PAHs. ${ }^{\mathrm{a}}$

\begin{tabular}{|c|c|c|c|c|c|c|c|c|c|c|c|c|}
\hline \multicolumn{6}{|c|}{ SPE LC pump } & \multicolumn{6}{|c|}{ Analytical LC pump } & \multirow{2}{*}{$\begin{array}{c}\begin{array}{c}\text { Dopant } \\
\text { pumps }\end{array} \\
\text { Flow }\end{array}$} \\
\hline $\begin{array}{c}\mathrm{t} \\
(\mathrm{min})\end{array}$ & $\mathbf{A}$ & B & $\mathbf{C}$ & Flow & $\begin{array}{c}\text { Segment } \\
\text { description }\end{array}$ & $\begin{array}{c}\mathrm{t} \\
(\mathrm{min})\end{array}$ & $\mathbf{A}$ & B & $\mathbf{C}$ & Flow & $\begin{array}{c}\text { Segment } \\
\text { description }\end{array}$ & \\
\hline 0 & 99 & 1 & & 2.0 & & 0 & & & 100 & 0.9 & & 0 \\
\hline 1.0 & 99 & 1 & & 2.0 & & & & & & & & \\
\hline 1.4 & 40 & 60 & & 2.0 & $\begin{array}{l}\text { Solld phase } \\
\text { extraction }\end{array}$ & 0 & & 100 & & 00 & Analysis & 0 \\
\hline 4.9 & 40 & 60 & & 2.0 & & 2.0 & & 100 & & 0.9 & $\begin{array}{c}\text { column } \\
\text { reset }\end{array}$ & 0 \\
\hline 5.0 & & 100 & & 1.0 & Salt & 6.0 & 30 & 70 & & 0.4 & & 0 \\
\hline 8.0 & & 100 & & 1.0 & & 8.0 & 30 & 70 & & 0.4 & & 0 \\
\hline 8.5 & & 100 & & 1.0 & $\begin{array}{l}\text { Sample } \\
\text { loop }\end{array}$ & $\begin{array}{c}8.5 \\
13.5\end{array}$ & $\begin{array}{l}30 \\
15\end{array}$ & $\begin{array}{l}70 \\
85\end{array}$ & & $\begin{array}{l}0.4 \\
0.6\end{array}$ & & $\begin{array}{l}0.04 \\
0.06\end{array}$ \\
\hline 15.0 & & 100 & & 1.0 & $\begin{array}{l}\mathrm{MeOH} \\
\text { flush }\end{array}$ & & & & & & & \\
\hline 15.1 & & 100 & & 0.1 & & & & & & & & \\
\hline 24.0 & & 100 & & 0.1 & Idle & 18.5 & & 100 & & 0.9 & Gradient & 0.09 \\
\hline 24.1 & & & 100 & 1.0 & $\begin{array}{c}\text { SPE } \\
\text { column }\end{array}$ & & & & & & separation & \\
\hline 25.0 & & & 100 & 1.0 & $\begin{array}{c}\mathrm{MeCN} \\
\text { wash }\end{array}$ & & & & & & & \\
\hline 26.0 & & 100 & & 1.0 & SPE & 26.0 & & & 100 & 0.9 & & 0.09 \\
\hline 27.0 & 99 & 1 & & 1.0 & column & & & & & & & \\
\hline 28.0 & 99 & 1 & & 1.0 & reset & 28.0 & & & 100 & 0.9 & & 0.09 \\
\hline
\end{tabular}


Table 4.3 Summary of SRM scan events for PAHs tested with this method (Bold: 16 USEPA priority PAHs; italic: isotopic labeled PAHs used as internal standards).

\begin{tabular}{|c|c|c|c|c|c|c|c|c|c|c|}
\hline РАH & $\begin{array}{c}\text { CAS } \\
\text { number }\end{array}$ & $\begin{array}{c}\mathbf{M}^{+\bullet} \\
\text { ion } \\
(\mathbf{m} / \mathbf{z})\end{array}$ & $\begin{array}{c}\text { Quant. } \\
\text { product } \\
(\mathrm{m} / \mathrm{z})\end{array}$ & $\begin{array}{l}C E^{a} \\
(e V)\end{array}$ & $\begin{array}{c}\text { Confirm. } \\
\text { product } \\
(\mathrm{m} / \mathrm{z})\end{array}$ & $\begin{array}{c}C E^{a} \\
(e V)\end{array}$ & $\begin{array}{c}\text { Confirm. } \\
\text { product } \\
\text { int. }(\%)^{b}\end{array}$ & $\begin{array}{c}\text { Tube } \\
\text { lens } \\
(V)\end{array}$ & $\begin{array}{c}\text { RT } \\
\text { (min) }\end{array}$ & $\begin{array}{l}\text { Scan } \\
\text { seg. }\end{array}$ \\
\hline Acenaphthene & $83-32-9$ & 154 & 153 & 16 & 152 & 29 & 72 & 82 & 13.1 & 1 \\
\hline Acenaphthene-D10 & $15067-26-2$ & 164 & 162 & 23 & 160 & 35 & 70 & 72 & 12.9 & 1 \\
\hline Acenaphtylene & $208-96-8$ & 152 & 151 & 16 & 150 & 23 & 50 & 69 & 12.1 & 1 \\
\hline Anthanthrene & $191-26-4$ & 276 & 274 & 43 & 272 & 69 & 99 & 108 & 24.2 & 2 \\
\hline Anthracene & $120-12-7$ & 178 & 176 & 29 & 152 & 22 & 54 & 82 & 14.9 & 1 \\
\hline Benz[a]anthracene & $56-55-3$ & 228 & 226 & 35 & 225 & 52 & 22 & 92 & 17.6 & $1+2$ \\
\hline Benzo[a]fluoranthene & $203-33-8$ & 252 & 250 & 73 & 248 & 41 & 38 & 120 & 18.5 & $1+2$ \\
\hline Benzo[a]pyrene & $50-32-8$ & 252 & 250 & 73 & 248 & 41 & 42 & 120 & 20.3 & $1+2$ \\
\hline Benzo[a]pyrene-D12 & $63466-71-7$ & 264 & 260 & 51 & 236 & 47 & 15 & 82 & 20.0 & 2 \\
\hline Benzo[b]fluoranthene, perylene ${ }^{\mathrm{d}}$ & $205-99-2,198-55-0$ & 252 & 250 & 73 & 248 & 41 & 38 & 120 & 19.1 & $1+2$ \\
\hline Benzo[b]fluorene & $243-17-4$ & 216 & 215 & 14 & 213 & 38 & 50 & 53 & 17.4 & $1+2$ \\
\hline Benzo[c]phenanthrene & $195-19-7$ & 228 & 226 & 35 & 225 & 52 & 24 & 92 & 16.3 & $1+2$ \\
\hline Benzo[e]pyrene, benzo[j]fluoranthene ${ }^{\mathrm{d}}$ & $192-97-2,205-82-3$ & 252 & 250 & 73 & 248 & 41 & 37 & 120 & 18.8 & $1+2$ \\
\hline Benzo[g,h,i]perylene & $191-24-2$ & 276 & 274 & 43 & 272 & 69 & 60 & 108 & 22.0 & 2 \\
\hline Benzo $[k]$ fluoranthene & $207-08-9$ & 252 & 250 & 73 & 248 & 41 & 35 & 120 & 19.9 & $1+2$ \\
\hline Biphenyl & $92-52-4$ & 154 & 152 & 29 & 153 & 16 & 90 & 82 & 12.4 & 1 \\
\hline C1-chrysenes & - & 242 & 239 & 42 & 241 & 22 & 65 & 80 & $18-20$ & $1+2$ \\
\hline C1-dibenzothiophenes & - & 198 & 197 & 10 & 165 & 25 & 49 & 68 & $14-16$ & $1+2$ \\
\hline C1-fluoranthenes/pyrenes & - & 216 & 215 & 14 & 213 & 38 & 50 & 53 & $15-17$ & $1+2$ \\
\hline C1-fluorenes & - & 180 & 165 & 19 & 164 & 35 & 21 & 53 & $14-16$ & 1 \\
\hline C1-naphthalenes & - & 142 & 141 & 21 & 115 & 32 & 71 & 57 & 12.5 & 1 \\
\hline C1-phenanthrenes/anthracenes & - & 192 & 191 & 22 & 189 & 40 & 90 & 67 & $15-18$ & $1+2$ \\
\hline C2-dibenzothiophenes & - & 212 & 211 & 20 & 152 & 39 & 30 & 83 & $15-19$ & $1+2$ \\
\hline C2-naphthalenes & - & 156 & 141 & 19 & 115 & 33 & 60 & 55 & $13-15$ & 1 \\
\hline C2-phenanthrenes/anthracenes & - & 206 & 189 & 39 & 191 & 22 & 58 & 137 & $17-19$ & $1+2$ \\
\hline C3-naphthalenes & - & 170 & 155 & 18 & 153 & 30 & 34 & 75 & $14-16$ & 1 \\
\hline C4-phenanthrenes/anthracenes & - & 234 & 219 & 11 & 204 & 22 & 75 & 10 & $17-19$ & $1+2$ \\
\hline Carbazole & 86-74-8 & 167 & 166 & 40 & 165 & 40 & 13 & 80 & 10.9 & 1 \\
\hline
\end{tabular}


Table 4.3 (continued) Summary of SRM scan events for PAHs tested with this method (Bold: 16 USEPA priority PAHs; italic: isotopic labeled PAHs used as internal standards).

\begin{tabular}{|c|c|c|c|c|c|c|c|c|c|c|}
\hline PAH & $\begin{array}{c}\text { CAS } \\
\text { number }\end{array}$ & $\begin{array}{c}\mathbf{M}^{+\bullet} \text { ion } \\
(\mathbf{m} / \mathbf{z})\end{array}$ & $\begin{array}{c}\text { Quant. } \\
\text { product } \\
(\mathbf{m} / \mathbf{z})\end{array}$ & $\begin{array}{l}\mathrm{CE}^{\mathrm{a}} \\
(\mathrm{eV})\end{array}$ & $\begin{array}{c}\text { Confirm. } \\
\text { product } \\
(\mathbf{m} / \mathbf{z})\end{array}$ & $\begin{array}{l}\mathrm{CE}^{\mathrm{a}} \\
(\mathrm{eV})\end{array}$ & $\begin{array}{l}\text { Confirm. } \\
\text { product } \\
\text { int. }(\%)^{b}\end{array}$ & $\begin{array}{c}\text { Tube } \\
\text { lens } \\
(V)\end{array}$ & $\begin{array}{c}\text { RT } \\
\text { (min) }\end{array}$ & $\begin{array}{l}\text { Scan } \\
\text { seg. }\end{array}$ \\
\hline Chrysene & $218-01-9$ & 228 & 226 & 35 & 225 & 52 & 22 & 92 & 18.0 & $1+2$ \\
\hline Chrysene-D12 & $1719-03-5$ & 240 & 236 & 37 & 212 & 34 & 14 & 108 & 17.8 & $1+2$ \\
\hline Dibenz[a,h]anthracene & $53-70-3$ & 278 & 276 & 42 & 274 & 65 & 62 & 105 & 21.9 & 2 \\
\hline Dibenzothiophene & $132-65-0$ & 184 & 152 & 30 & 139 & 39 & 90 & 85 & 14.0 & 1 \\
\hline Fluoranthene & $206-44-0$ & 202 & 200 & 40 & 199 & 57 & 16 & 73 & 15.6 & 1 \\
\hline Fluorene & $86-73-7$ & 166 & 165 & 21 & 164 & 33 & 23 & 101 & 13.6 & 1 \\
\hline Fluorene-D10 & $81103-79-9$ & 176 & 174 & 28 & 172 & 38 & 21 & 65 & 13.5 & 1 \\
\hline Indeno $[1,2,3-c d]$ pyrene & $193-39-5$ & 276 & 274 & 43 & 272 & 69 & 48 & 108 & 22.7 & 2 \\
\hline Naphthalene & $91-20-3$ & 128 & 127 & 25 & 102 & 20 & 90 & 48 & 11.5 & 1 \\
\hline Naphthalene-D8 & $1146-65-2$ & 136 & 134 & 30 & 108 & 30 & 59 & 80 & 11.4 & 1 \\
\hline Naphthobenzothiophene & $239-35-0$ & 234 & 202 & 25 & 189 & 33 & 90 & 100 & 18.2 & $1+2$ \\
\hline Perylene-D12 & $1520-96-3$ & 264 & 260 & 51 & 236 & 47 & 9 & 82 & 18.9 & 2 \\
\hline Phenanthrene & $85-01-8$ & 178 & 176 & 29 & 152 & 22 & 75 & 82 & 14.2 & 1 \\
\hline Phenanthrene-D10 & $1517-22-2$ & 188 & 184 & 40 & 160 & 32 & 98 & 82 & 14.0 & 1 \\
\hline Pyrene & $129-00-0$ & 202 & 200 & 40 & 199 & 57 & 20 & 73 & 16.0 & 1 \\
\hline Triphenylene & $217-59-4$ & 228 & 226 & 35 & 225 & 52 & 23 & 92 & 16.8 & $1+2$ \\
\hline
\end{tabular}




\subsection{Results and discussion}

\subsubsection{Optimization of dopant-assisted APPI detection}

The Photomate APPI source (figure 4.3) used in this study is supplied with a krypton VUV lamp. Krypton is selected because, as shown in table 4.4, the emission lines of this rare gas have enough energy to ionize all PAHs and the chlorobenzene dopant but not air components or common solvents used in reverse-phase LC, which translates into a low noise, selective ionization of compounds with lower ionization energy than that of the electron affinity of the ionized dopant molecule.

Smith et al. (2009) compared the performance of different dopants and dopant mixtures for PAH detection by APPI, concluding that pure chlorobenzene provides efficient charge transfer ionization for all PAHs in the presence of water, methanol and acetonitrile, thus commercially available high purity chlorobenzene was used as dopant in this study without any treatment. Under these conditions a strong positive molecular ion $\left(\mathrm{M}^{+\bullet}\right)$ for each analyte was always observed and isolated as the precursor ion for the SRM scan events, which is consistent with observations by other authors that have used chlorobenzene as dopant for APPI-LC-MS analysis of PAHs (Cai et al., 2009).

There are two types of commercially available APPI sources, the linear

Photospray $^{\circledR}$ (available only for AB SCIEX instruments) and the orthogonal Photomate ${ }^{\circledR}$ source used in this study (figure 4.3). Dopant delivery in almost every APPI application using the Photomate source has been performed by post column mixing of the dopant with the LC eluent, as this system is not equipped with an independent dopant delivery 
line which is standard for the Photospray source (Robb \& Blades, 2008). However, high backpressure and low miscibility of the dopant with reverse phase mobile phases can introduce background noise that affects source stability and can also cause peak shape degradation (Ehrenhauser et al., 2010; Robb \& Blades, 2008).

Table 4.4 Comparison of the first ionization energies of relevant chemical species present in the APPI source and selected PAHs with the energy of the VUV radiation produced by the krypton APPI lamp. ${ }^{\text {a }}$

\begin{tabular}{lcc}
\hline Compound & hv (eV) & IE (eV) \\
\hline Nitrogen & & 15.6 \\
Water & & 12.6 \\
Acetonitrile & & 12.2 \\
Oxygen & & 12.1 \\
Methanol & & 10.8 \\
& Kr secondary emission line & \\
Chlorobenzene (dopant) & 10.6 & \\
Naphthalene & 10.0 & 9.07 \\
Acenaphtylene & & 8.14 \\
Anthracene & & 8.12 \\
Fluorene & & 8.10 \\
Phenanthrene & & 7.91 \\
Fluoranthene & & 7.89 \\
Acenaphthene & & 7.90 \\
Chrysene & & 7.75 \\
Anthracene & & 7.60 \\
Pyrene & & 7.44 \\
Dibenz[a,h]anthracene & & 7.43 \\
Benzo[g,h,i]perylene & & 7.39 \\
Benzo[a]pyrene & & 7.17 \\
\hline
\end{tabular}

${ }^{a}$ Data from Marchi et al. (2009), Robb \& Blades (2008) and Smith et al. (2009).

The only report of gas-phase dopant delivery for the Photomate source was made by Ehrenhauser et al. (2010). These authors used an in-house made evaporation system located in line with the nitrogen supply, with a large dopant reservoir that enabled long term operation but requires custom made parts and is therefore difficult to implement. In the original Photospray publication, Robb et al. (2000) delivered the dopant directly into the vaporizer probe from a syringe pump by means of a fused silica capillary introduced 
with a tee connection at the nebulizer gas supply line. In the present study the latter approach was slightly modified by using two programmable syringe pumps and a spraying device placed in the auxiliary nitrogen gas stream (figure 4.3), which can be easily constructed from commercially available parts. With this system, little or no backpressure is applied to the syringe pumps which translate into stable dopant delivery. Also, since analytical signals maximized at a dopant flow rate of approximately $10 \%$ of the eluent flow rate, using a programmable dopant system has the advantage of maintaining this optimum ratio as the eluent flow rate changes during the chromatographic separation.

The spraying system was tested with two syringe pumps equipped with four 10 $\mathrm{mL}$ syringes ( $40 \mathrm{~mL}$ total), providing 26 runs (approx. 12 hours of continuous operation) before a syringe refill is required, which translates into a consumption of about $1.5 \mathrm{~mL}$ of chlorobenzene per sample. In comparison, the traditional LLE+GC-MS approach that may require up to $150 \mathrm{~mL}(3 \times 50 \mathrm{~mL}$ extractions $)$ of methylene chloride, which possesses an atmospheric half-life of approx. 150 days and is considered a human carcinogen (ATSDR, 2000; USEPA, 2011). In contrast, chlorobenzene has a much shorter atmospheric persistence (half-life of $20-40$ hours) and is not considered a carcinogen (ATSDR, 1990). Thus, both the lower quantity and the nature of the halogenated waste produced suggest that the online SPE-LC-MS/MS is a greener methodology than LLE+GC-MS. 

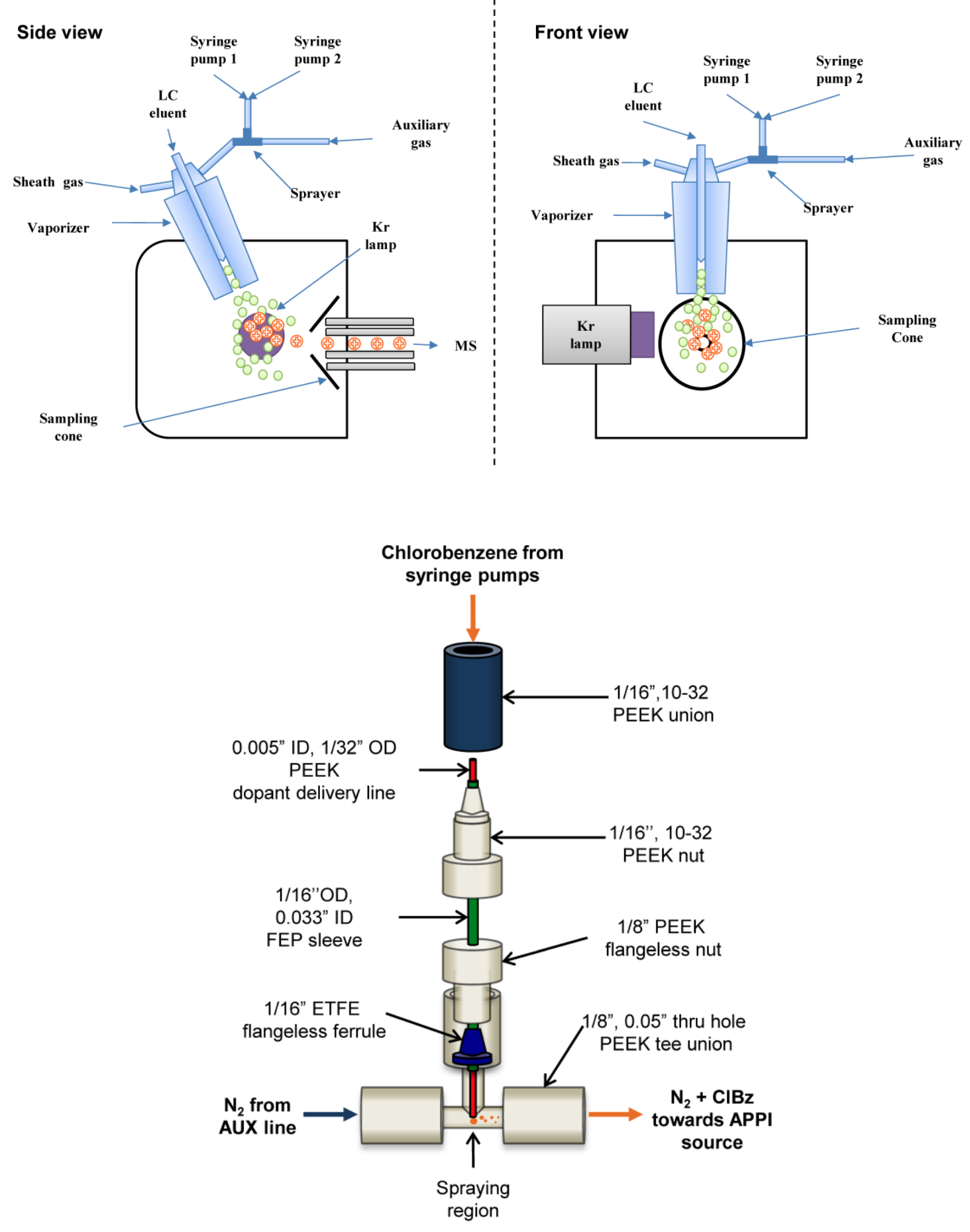

Figure 4.3 (Top) Graphical representation of the Photomate APPI source with the gasphase dopant delivery system used in this study (Modified from Ehrenhauser et al, 2010). (Bottom) Detail on the dopant sprayer device built from commercially available parts (Modification of the dopant introduction design from Robb et al., 2000). 


\subsection{Optimization of chromatographic separation}

During compound optimization for SRM detection, it was observed that PAHs with the same parent masses have similar behavior upon collision induced dissociation (same product ions, same collision energy, see table 4.3), eliminating the possibility of selective detection of isobaric PAHs. Because comprehensive PAH analysis requires quantitation beyond the 16 priority PAHs, a carefully controlled LC separation is required to solve most of these isobaric interferences. Since PAHs molecules have fixed planar conformations, chromatographic selectivity is governed solely by their molecular dimensions (Sander et al, 1999). Several authors have shown that polymeric C18 columns offer the highest shape selectivity for PAHs (Horak et al., 2004; Rimmer et al., 2005; Sander et al., 1999). Furthermore, complete chromatographic resolution of the 16 PAHs listed as priority by the EPA using the polymeric C18 Hypersil Green PAH stationary phase has been previously reported (Horak \& Lindner, 2008; Rimmer et al., 2005). Hypersil Green PAH was selected to explore the possibility of a liquid chromatography separation of most alkylated PAHs as these compounds are often used as markers to identify pollution sources and environmental transformations (Boehm et al., 1997; Wang et al., 1999).

Light PAHs (i.e., alkylnaphthalenes) could only be efficiently separated using a methanol/water gradient system, as the use of acetonitrile/water caused fast elution with no resolution control. On the other hand, methanol proved to be a weak solvent for heavy PAHs (m/z 228 and above), causing excessively high retention times and peak shape broadening even at $100 \%$ methanol isocratic elution. A second gradient between 
methanol and acetonitrile was then used after the water/methanol system. Still, retention times for heavier PAHs (m/z 252 and above) were also very high even at 100\% acetonitrile conditions. In order to perform an efficient, wide mass range separation, a flow rate gradient was also used in combination with solvent strength control, taking advantage of the steep backpressure drop observed as water is removed from the analytical column during the gradient.

Figure 4.4 compares the obtained resolution of alkylated PAHs contained in the standard reference material 1491a to that obtained by traditional GC-MS analysis. Although resolution for C1-naphthalenes was lower than GC, two marginally resolved peaks are observed in the SPE-LC-MS/MS separation of these compounds that differ only in the position of a single methyl group between adjacent carbon atoms, and since C1-naphthalenes are detected as a group the limited resolution does not affect quantitation. As analyte mass increased the observed resolution behavior tended to be similar than the obtained by GC-MS. Both techniques had the same difficulty separating C1-fluoranthenes and C1-pyrenes (4 peaks should be observed in the $\mathrm{m} / \mathrm{z} 216$ chromatogram), while complete resolution was observed for 3-methylchrysene and 6methylchrysene in both methods. All four methylphenanthrenes are visible and well separated from the 2-methylanthracene signal, in contrast to the GC-MS separation where a coelution of the two groups is observed.

These results indicate that isobaric alkylated PAHs can be partially resolved using single-column liquid chromatography separation, and the present study represents the first report of such finding. 


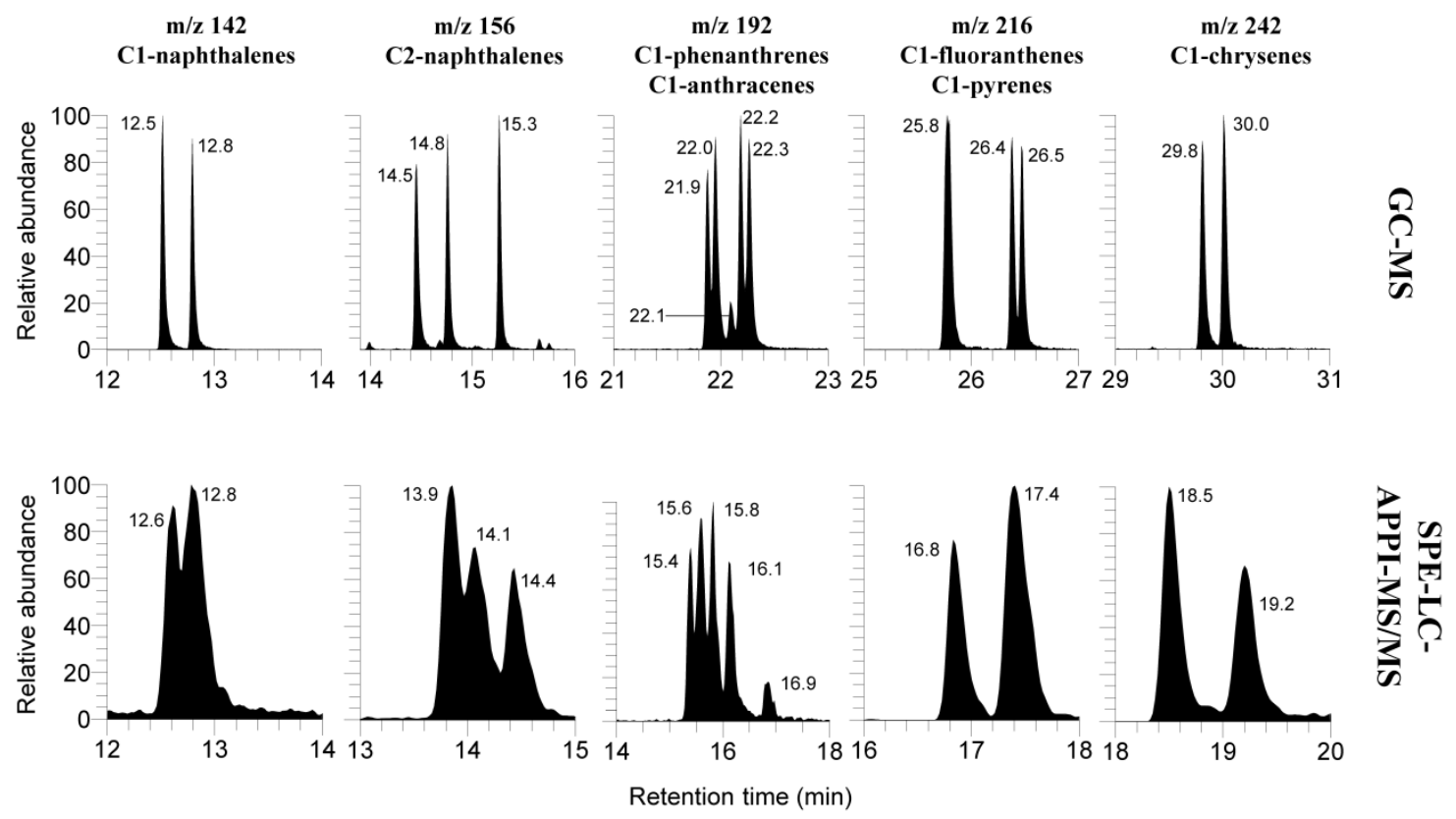

Figure 4.4 Comparison of peaks of PAHs contained in the Standard Reference Material 1491a, obtained by GC-MS analysis (1/10 dilution in hexane, top) and by SPE-LCMS/MS analysis (1/27500 serial dilution in seawater, bottom). A list of compounds contained in 1491a can be observed in table 4.5.

Although the observed resolution of alkylated PAHs may be not enough to replace capillary GC for PAH fingerprinting applications, the obtained resolution could be enough to be used as an screening tool to decide if a given sample should be analyzed using those time consuming techniques, taking advantage of the low sample consumption and the speed of this methodology. Additionally, the absence of sample preparation could provide the ability to track in almost real time the extent of a contamination by monitoring for the alkylated PAHs specific concentration patterns observed at the pollution source.

With the developed gradient separation, baseline resolution of the 16 priority PAHs from their isobaric interferences present in Standard Reference Material 2260a was 
obtained except for benzo[b]fluoranthene which coeluted with perylene. Attempts to separate these compounds without a significant increase of run time were unsuccessful and since method speed was a priority these two compounds were quantified together. Previously published LC methodologies reporting separation of the 16 priority PAHs by LC-MS/MS (Cai et al, 2012; Cai et al., 2009) did not evaluate chromatographic resolution of isobaric interferences with standards that contained a larger number of PAHs such as the Standard Reference Material 2260a used in this study. These results suggest that the occurrence of these types of interferences in LC-MS/MS methodologies should be evaluated in order to ensure a proper quantification of the priority PAHs.

\subsection{Optimization of the online SPE procedure}

The SPE sorbents and conditions for PAHs have been reviewed elsewhere (Marce \& Borrull, 2000). Regular C18 has been identified a good sorbent for PAH extraction. A highly-endcapped, commercially available C18 column especially designed for SPE was selected on the basis of its high stability towards aqueous samples.

The SPE column loading, washing and reconditioning parameters were optimized for extraction recovery, seawater salt elimination and prevention of carryover using isotopically labeled PAHs as testing compounds.

Same-day $10 \mathrm{~mL}$ injections of $100 \mathrm{ng} / \mathrm{L}$ (online SPE) and $100 \mu \mathrm{L}$ direct injections of $10,000 \mathrm{ng} / \mathrm{L}$ solutions in $70 \%$ methanol/water were made, accounting for $1.0 \mathrm{ng}$ on column for each compound (the $5 \mathrm{~mL}$ injection mode was tested against $50 \mu \mathrm{L}$ direct injection, $0.5 \mathrm{ng}$ on column). Percent recoveries were obtained using averaged peak 
areas, using at least 3 direct injection runs and 2 online SPE runs. The direct injection method had the same analytical gradient that the online SPE method, and the observed retention times were in agreement with an 8 min offset associated with the online SPE time, ensuring similar APPI source conditions at elution in both injection modes which enables the direct comparison of peak areas.

Passing at least $2 \mathrm{~mL}$ of aqueous mobile phase through the loading column after the SPE step was enough to prevent the transfer of salt residues to the APPI source. Peak shape degradation also occurred if the loading column was not conditioned with methanol before connecting with the organic-rich analytical stream at the start of the analytical gradient ( $70 \%$ methanol). Therefore, $1 \mathrm{~mL}$ of mobile phase was employed to increase the percentage of methanol before the columns were connected $(0.5 \mathrm{~mL}$ gradient increase and $0.5 \mathrm{~mL}$ hold). Recoveries of chrysene- $\mathrm{D}_{12}$, perylene- $\mathrm{D}_{12}$ and benzo[a]pyrene- $\mathrm{D}_{12}$ increased with the methanol proportion, and the SPE column could be washed with up to $60 \%$ methanol without significant losses of the light PAHs (figure 4.5). Additionally, online SPE signals for heavy PAHs proved erratic if the sample itself was not amended with organic solvents. A total of $5 \% \mathrm{v} / \mathrm{v}$ of methanol was required in the sample to obtain good signal reproducibility and recovery of naphthalene- $\mathrm{D}_{8}$, the only isotopically labeled PAH that showed significant recovery losses as a result of the addition of large amounts of methanol. 

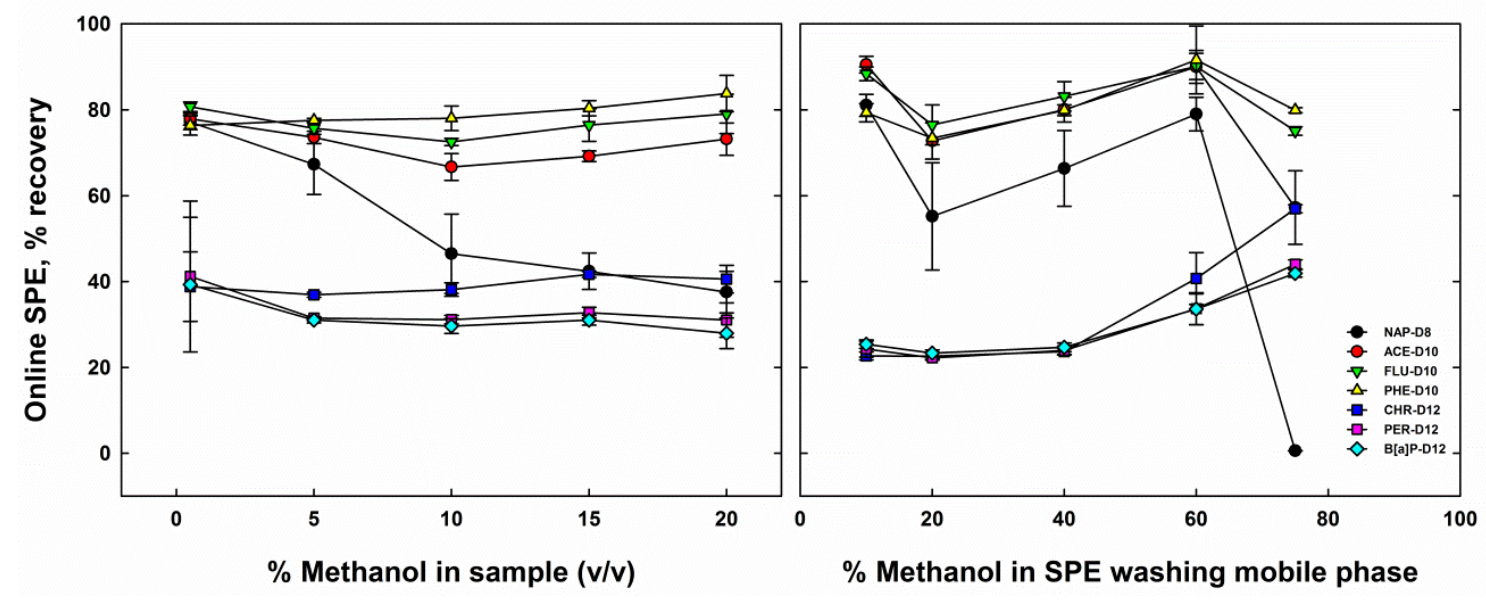

Figure 4.5 Effect of methanol on online SPE recovery of PAHs. (Left) Effect of the percentage of methanol dissolved in the sample. (Right) Effect of the percentage of methanol in the mobile phase used to wash the SPE column.

Analyte breakthrough was evaluated by performing injections using $5 \mathrm{~mL}$ and 10 $\mathrm{mL}$ stainless steel loops. Both sample loops used had the same specifications (stainless steel, 0.06 in ID with 0.03 in terminals), and the method program was adjusted to account for the lower injection volume. No significant difference in SPE recovery was observed, and $10 \mathrm{~mL}$ injections were adopted for enhanced sensitivity.

The sample loading flow rate during the SPE step was also evaluated at 1,2 and 3 $\mathrm{mL} / \mathrm{min}$ (SPE column backpressure increases steeply with flow rate, triggering the SPE pump high-pressure protection at $4 \mathrm{~mL} / \mathrm{min}$ ). As shown in figure 4.6 , no significant difference was observed at different flow rates and $2 \mathrm{~mL} / \mathrm{min}$ was chosen as a compromise between stable pump operation and minimized run time. Since samples were analyzed without filtration, SPE column backpressure slightly increased after every sequence (usually 40-50 injections). Flushing with acetonitrile at a flow rate of $5 \mathrm{~mL} / \mathrm{min}$ 
between sequences, in the opposite direction to sample loading, removed clogging particles and restored column performance.

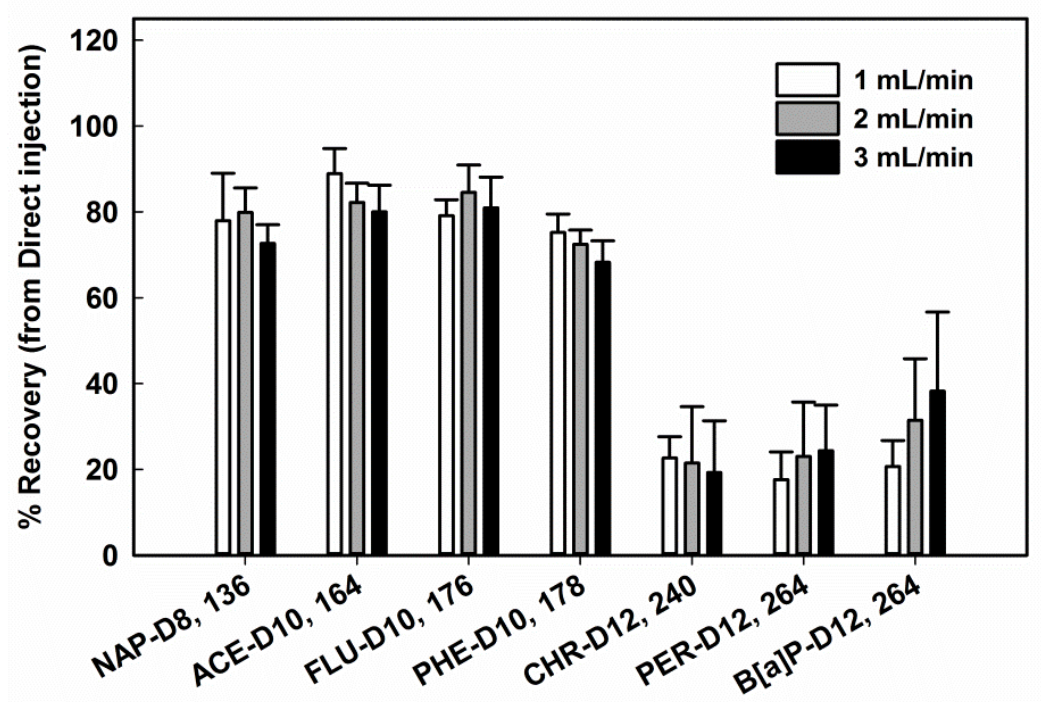

Figure 4.6 Effect of sample loading flow rate upon online SPE recovery of labeled PAHs.

\subsection{Method validation}

\subsubsection{Calibration and quality control}

Calibration curves were obtained by plotting the peak area ratio of each PAH to an isotopically labeled PAH internal standard against concentration in $\mathrm{ng} / \mathrm{L}$. Linearity was observed for all analytes in the range used $\left(\mathrm{R}^{2}>0.99 ; 5\right.$ to $\left.500 \mathrm{ng} / \mathrm{L}\right)$. Calibration stability was evaluated every 10 runs by injecting seawater fortified to $100 \mathrm{ng} / \mathrm{L}$. Calibration and method accuracy was verified by injecting artificial seawater fortified with serially diluted standard reference materials 1491a and 2260a (pooled recoveries are presented in table 4.5). 
Table 4.5 Pooled measurements of serially diluted Standard Reference Materials 2260a and 1491a in seawater. Total dilution factors used were 1/55000 for SRM 2260a and 1/18333 for 1491a. Three measurements were performed on different analysis days.

\begin{tabular}{|c|c|c|c|c|c|c|c|c|c|c|}
\hline \multirow{2}{*}{$\begin{array}{ll} & \text { PAH (listed compound) } \\
\text { Acenaphtene } & \end{array}$} & \multirow{2}{*}{$\frac{\text { SRM }}{2260 \mathrm{a}}$} & \multicolumn{3}{|c|}{$\begin{array}{c}\text { Certified } \\
\text { concentration }^{\mathrm{a}}\end{array}$} & \multicolumn{3}{|c|}{$\begin{array}{c}\text { Measured } \\
(\mathrm{n}=3)\end{array}$} & \multicolumn{3}{|c|}{$\%$ REC } \\
\hline & & 4.80 & \pm & 0.11 & 4.5 & \pm & 1.0 & 94 & \pm & 21 \\
\hline Acenaphtylene & $2260 \mathrm{a}$ & 5.41 & \pm & 0.17 & 4.8 & \pm & 0.9 & 89 & \pm & 17 \\
\hline Anthanthrene & $2260 \mathrm{a}$ & 1.91 & \pm & 0.03 & 1.7 & \pm & 0.3 & 89 & \pm & 16 \\
\hline Anthracene & $2260 a$ & 3.23 & \pm & 0.05 & 3.0 & \pm & 0.2 & 94 & \pm & 6 \\
\hline Benz[a]anthracene & $2260 \mathrm{a}$ & 3.82 & \pm & 0.07 & 4.0 & \pm & 0.4 & 106 & \pm & 11 \\
\hline Benzo[a]fluoranthene & $2260 a$ & 1.97 & \pm & 0.06 & 2.0 & \pm & 0.3 & 100 & \pm & 14 \\
\hline Benzo[a]pyrene & $2260 a$ & 4.07 & \pm & 0.02 & 4.6 & \pm & 0.2 & 113 & \pm & 6 \\
\hline Benzo[b]fluoranthene, perylene & $2260 \mathrm{a}$ & 10.6 & \pm & 0.1 & 9.8 & \pm & 0.6 & 92 & \pm & 6 \\
\hline Benzo[c]phenanthrene & $2260 \mathrm{a}$ & 3.99 & \pm & 0.03 & 4.3 & \pm & 1.4 & 109 & \pm & 34 \\
\hline Benzo[e]pyrene, benzo[j]fluoranthene & $2260 a$ & 10.6 & \pm & 0.1 & 8.0 & \pm & 0.4 & 76 & \pm & 4 \\
\hline Benzo[g,h,i]perylene & $2260 \mathrm{a}$ & 4.90 & \pm & 0.06 & 5.3 & \pm & 0.7 & 107 & \pm & 13 \\
\hline Benzo[k]fluoranthene & $2260 a$ & 2.98 & \pm & 0.03 & 3.0 & \pm & 0.3 & 101 & \pm & 11 \\
\hline Biphenyl & $2260 \mathrm{a}$ & 4.85 & \pm & 0.12 & 4.3 & \pm & 0.2 & 90 & \pm & 5 \\
\hline C1-anthracenes (2-methyl) & 1491a & 1.17 & \pm & 0.01 & 0.7 & \pm & 0.2 & 62 & \pm & 14 \\
\hline C1-chrysenes (3- and 6-methyl) & 1491a & 2.02 & \pm & 0.03 & 1.8 & \pm & 0.1 & 88 & \pm & 6 \\
\hline $\begin{array}{l}\text { C1-fluoranthenes/pyrenes (1- and 3-methylfluoranthene); } \\
\text { (1- and 4-methylpyrene) }\end{array}$ & $1491 \mathrm{a}$ & 3.82 & \pm & 0.13 & 3.3 & \pm & 0.9 & 86 & \pm & 23 \\
\hline C1-naphthalenes (1- and 2-methyl) & $1491 \mathrm{a}$ & 3.28 & \pm & 0.12 & 3.3 & \pm & 0.5 & 102 & \pm & 14 \\
\hline C1-phenanthrenes (1-, 2-, 3- and 9-methyl) & $1491 \mathrm{a}$ & 7.84 & \pm & 0.07 & 8.5 & \pm & 0.4 & 108 & \pm & 6 \\
\hline C2-naphthalenes (1,2-, 1,6- and 2,6-dimethyl) & $1491 \mathrm{a}$ & 4.46 & \pm & 0.14 & 4.2 & \pm & 1.8 & 94 & \pm & 41 \\
\hline C4-phenanthrenes/anthracenes (retene) & 1491a & 1.80 & \pm & 0.03 & 1.0 & \pm & 0.2 & 58 & \pm & 12 \\
\hline Chrysene & $2260 \mathrm{a}$ & 4.00 & \pm & 0.10 & 3.8 & \pm & 0.4 & 95 & \pm & 10 \\
\hline Dibenz $[a, h]$ anthrace & $2260 a$ & 3.94 & \pm & 0.05 & 4.4 & \pm & 0.2 & 113 & \pm & 5 \\
\hline Dibenzothiophene & $2260 \mathrm{a}$ & 3.80 & \pm & 0.15 & 3.5 & \pm & 0.7 & 93 & \pm & 18 \\
\hline Fluoranthene & $2260 \mathrm{a}$ & 7.20 & \pm & 0.08 & 6.4 & \pm & 1.2 & 89 & \pm & 17 \\
\hline Fluorene & $2260 \mathrm{a}$ & 4.07 & \pm & 0.10 & 3.5 & \pm & 0.3 & 85 & \pm & 8 \\
\hline Indeno[1,2,3-cd]pyrene & $2260 a$ & 3.83 & \pm & 0.03 & 4.1 & \pm & 0.4 & 106 & \pm & 11 \\
\hline Naphthalene & $2260 \mathrm{a}$ & 9.89 & \pm & 0.26 & 9.5 & \pm & 0.5 & 96 & \pm & 5 \\
\hline Phenanthrene & $2260 \mathrm{a}$ & 10.0 & \pm & 0.1 & 9.3 & \pm & 1.5 & 92 & \pm & 15 \\
\hline Pyrene & $2260 a$ & 7.74 & \pm & 0.07 & 7.0 & \pm & 0.9 & 91 & \pm & 12 \\
\hline Triphenylene & $2260 a$ & 3.56 & \pm & 0.14 & 4.5 & \pm & 0.3 & 126 & \pm & 11 \\
\hline
\end{tabular}

${ }^{\mathrm{a}}$ From certificate of analysis. (all concentrations are listed in $\mathrm{mg} / \mathrm{L}$ )

With every analysis batch, negative (reagent and sampling) and a positive (fortified to $100 \mathrm{ng} / \mathrm{L}$ ) blanks were also used. Additionally, one sample duplicate and one fortified matrix experiment was always analyzed per every 5 samples. The system was continuously tested for carryover by injecting a reagent blank after the highest calibration standard and after every calibration verification standard. 
Compound identification was considered positive when signals with a $\mathrm{S} / \mathrm{N}$ ratio above 3 were present in both the quantification and confirmation SRM transitions, with a maximum retention time difference of $0.2 \mathrm{~min}$ relative to calibration standards or standard reference materials. Calculated concentrations below method detection limits (MDLs) were considered non-detections. A reporting limit (RL) of 3 times the MDLs was set in order to reduce the risk of false positives and ensure data quality.

\subsubsection{Determination of method detection limits}

Method detection limits were calculated by multiplying the standard deviation from seven measurements by the Student $t$ value $\left(t_{(7-1,99)}=3.143\right)$, according to procedures outlined by the USEPA (2010e), using natural seawater (from the FIU Campus beach, see table 4.7), fortified to $50 \mathrm{ng} / \mathrm{L}$. For sensitivity comparison, MDLs for the traditional LLE+GC-MS methodology were determined using $1000 \mathrm{~mL}$ of the same seawater sample also fortified to $50 \mathrm{ng} / \mathrm{L}$ and extracted three times with $50 \mathrm{~mL}$ portions of methylene chloride. The extract was obtained, evaporated and cleaned according to established methods (EPA 3510C and 3630C) (USEPA, 1996b, 1996c) and analyzed by a GC-MS method available elsewhere (Denoux et al., 1998).

Results shown in table 4.6 shows that the average MDLs corrected for sample size obtained by LLE + GC-MS analysis are an order of magnitude higher than those obtained by SPE-LC-MS/MS. Although in practice lower MDL values can be obtained with LLE as a result of the possibility of using larger sample volumes, the higher per-volume sensitivity of the online SPE approach is more useful when limited amounts of sample are available. Also, the low sample volume required and high sample throughput of this 
method facilitates the analysis of multiple quality controls such as duplicates and fortified matrix experiments.

Table 4.6 Comparisons of MDL values obtained by SPE-LC-MS/MS and by LLE+GCMS. Fortification level were $50 \mathrm{ng} / \mathrm{L}$ in both experiments. (Concentrations are in $\mathrm{ng} / \mathrm{L}$ ).

\begin{tabular}{|c|c|c|c|}
\hline PAH (testing compound) & $\begin{array}{c}\text { SPE-LC- } \\
\text { MS/MS } \\
10 \mathrm{~mL}\end{array}$ & $\begin{array}{c}\text { LLE+ } \\
\text { GC-MS } \\
1000 \text { mL }\end{array}$ & $\begin{array}{c}\text { LLE+ } \\
\text { GC-MS } \\
10 \mathrm{~mL}^{*}\end{array}$ \\
\hline Acenaphthene & 15 & 1.5 & 150 \\
\hline Acenaphtylene & 16 & 1.2 & 120 \\
\hline Anthracene & 29 & 1.7 & 170 \\
\hline Benzo[a]anthracene & 12 & 2.5 & 250 \\
\hline Benzo[a]pyrene & 23 & 1.7 & 170 \\
\hline Benzo[b]fluoranthene & 34 & 3.1 & 310 \\
\hline Benzo[b]fluorene & 7.5 & 3.4 & 340 \\
\hline Benzo[e]pyrene & 16 & 1.2 & 120 \\
\hline Benzo[g,h,i]perylene & 19 & 1.5 & 150 \\
\hline Benzo[k]fluoranthene & 21 & 1.2 & 120 \\
\hline Biphenyl & 24 & 1.2 & 120 \\
\hline C1-anthracenes (2-methyl) & 8.7 & 2.2 & 220 \\
\hline C1-chrysenes, (6-methyl) & 23 & 1.5 & 150 \\
\hline C1-dibenzothiophenes (4-methyl) & 13 & 1.7 & 170 \\
\hline C1-fluorenes (1-methyl) & 12 & 1.5 & 150 \\
\hline C1-naphthalenes (2-methyl) & 13 & 1.8 & 180 \\
\hline C1-phenanthrenes (1-methyl) & 10 & 1.5 & 150 \\
\hline C2-dibenzothiophenes (4,6-dimethyl) & 12 & 1.5 & 150 \\
\hline C2-naphthalenes (2,6-dimethyl) & 15 & 1.7 & 170 \\
\hline C3-naphthalenes (2,3,5-trimethyl) & 17 & 1.5 & 150 \\
\hline C4-phenanthrenes (retene) & 18 & 2.6 & 260 \\
\hline Carbazole & 26 & 1.7 & 170 \\
\hline Chrysene & 12 & 2.4 & 240 \\
\hline Dibenzo[a,h]anthracene & 16 & 3.4 & 340 \\
\hline Dibenzothiophene & 11 & 1.7 & 170 \\
\hline Fluoranthene & 12 & 1.2 & 120 \\
\hline Fluorene & 7.9 & 1.5 & 150 \\
\hline Indeno[1,2,3-cd]pyrene & 26 & 4.8 & 480 \\
\hline Naphthalene & 20 & 1.2 & 120 \\
\hline Naphthobenzothiophene & 21 & 2.2 & 220 \\
\hline Phenanthrene & 19 & 2.2 & 220 \\
\hline Pyrene & 17 & 1.2 & 120 \\
\hline Average & 17 & 1.9 & 191 \\
\hline
\end{tabular}

* MDLs corrected for sample size 


\subsection{Environmental applications: Analysis of PAHs in environmentally relevant samples in the Miami-Dade County}

The developed methodology was tested by analyzing a group of multi-origin environmentally relevant water samples. Seawater collections were made from 7 sites in northern Biscayne Bay. Naphthalene and alkylnaphthalenes were detected in two of the sites in which activity of small vessels was observed (see table 4.7 for results).

The occurrence of alkylnaphthalenes in emissions by two stroke gas outboard engines and light-duty diesel vessels has been reported before (Chiang et al. 2012; Kelly et al., 2005). Additionally, the elevated water solubility of alkylnaphthalenes relative to other PAHs (Manoli \& Samara, 1999) may increase their permanence in the water long enough to be detected by the grab sampling performed. Although the method sensitivity was not enough to detect background concentrations in samples where no active boating was observed, a capability of fast detection of focalized emission of petroleum-derived products was demonstrated.

Suspended particles in rainwater runoff resulting from the erosion of impervious surfaces have been documented as an important source of PAHs into the environment (Mahler et al., 2012; Watts et al., 2010). To assess the performance of the developed methodology for the monitoring of PAHs in rainwater and runoff, samples from the drainage openings at three parking lots were collected during a heavy rain event in June 2013. 
Table 4.7 Results from the determination of PAHs in seawater from Northern Biscayne Bay by Online SPE-LC-MS/MS ${ }^{\text {a }}$ (in bold, USEPA priority PAHs).

\begin{tabular}{|c|c|c|c|c|c|c|c|c|}
\hline \multicolumn{3}{|l|}{ Site name } & \multirow{3}{*}{$\begin{array}{c}\begin{array}{c}\text { Haulover } \\
\text { Boat Ramp }\end{array} \\
25.91684 \\
80.12383\end{array}$} & \multirow{3}{*}{$\begin{array}{c}\begin{array}{c}\text { Haulover } \\
\text { Marina }\end{array} \\
25.90613 \\
80.12396\end{array}$} & \multicolumn{3}{|c|}{ Dinner Key Marina } & $\begin{array}{c}\text { Bayfront } \\
\text { Park }\end{array}$ \\
\hline \multirow{2}{*}{\multicolumn{3}{|c|}{$\begin{array}{c}\text { Latitude } \mathbf{N} \\
\text { Longitude W }\end{array}$}} & & & \multirow{2}{*}{\multicolumn{3}{|c|}{$\begin{array}{l}25.72720 \\
80.23767 \\
\end{array}$}} & 25.77274 \\
\hline & & & & & & & & 80.18491 \\
\hline PAH & MDL & $\mathbf{R L}$ & $\mathrm{C}$ & $\mathrm{C}$ & $\mathrm{C}$ & DUP & $\mathbf{R P D}^{\mathrm{d}}$ & $\mathrm{C}$ \\
\hline Acenaphthene & 15 & 45 & - & - & - & - & & - \\
\hline Acenaphtylene & 16 & 49 & - & - & - & - & & - \\
\hline Anthanthrene & 26 & 78 & - & - & - & - & & - \\
\hline Anthracene & 29 & 86 & - & - & - & - & & - \\
\hline Benz[a]anthracene & 12 & 36 & - & - & - & - & & - \\
\hline Benzo[a]fluoranthene & 16 & 48 & - & - & - & - & & - \\
\hline Benzo[a]pyrene & 23 & 69 & - & - & - & - & & - \\
\hline Benzo[b]fluoranthene, perylene & 34 & 102 & - & - & - & - & & - \\
\hline Benzo[b]fluorene & 7.5 & 23 & - & - & - & - & & - \\
\hline Benzo[c]phenanthrene & 12 & 36 & - & - & - & - & & - \\
\hline Benzo[e]pyrene, benzo[j]fluoranthene & 16 & 48 & - & - & - & - & & - \\
\hline Benzo[g,h,i]perylene & 19 & 57 & - & - & - & - & & - \\
\hline Benzo[k]fluoranthene & 21 & 63 & - & - & - & - & & - \\
\hline Biphenyl & 24 & 72 & - & - & - & - & & - \\
\hline C1-anthracenes & 8.7 & 26 & - & - & - & - & & - \\
\hline C1-chrysenes & 23 & 69 & - & - & - & - & & - \\
\hline C1-dibenzothiophenes & 13 & 39 & - & - & - & - & & - \\
\hline C1-fluor/pyrenes & 7.5 & 23 & - & - & - & - & & - \\
\hline C1-fluorenes & 12 & 35 & - & - & - & - & & - \\
\hline C1-naphthalenes & 13 & 40 & 129 & - & 74 & 76 & 3 & - \\
\hline C1-phenanthrenes & 10 & 30 & - & - & - & - & & - \\
\hline C2-dibenzothiophenes & 12 & 36 & - & - & - & - & & - \\
\hline C2-naphthalenes & 15 & 44 & $<\mathrm{RL}$ & - & 47 & 45 & 6 & - \\
\hline C2-phen/anthracenes & 18 & 54 & - & - & - & - & & - \\
\hline C3-naphthalenes & 17 & 51 & - & - & - & - & & - \\
\hline C4-phen/anthracenes & 18 & 54 & - & - & - & - & & - \\
\hline Carbazole & 26 & 77 & - & - & - & - & & - \\
\hline Chrysene & 11 & 33 & - & - & - & - & & - \\
\hline Dibenz[a,h]anthracene & 16 & 48 & - & - & - & - & & - \\
\hline Dibenzothiophene & 11 & 34 & - & - & - & - & & - \\
\hline Fluoranthene & 12 & 36 & - & - & - & - & & - \\
\hline Fluorene & 7.9 & 24 & - & - & - & - & & - \\
\hline Indeno $[1,2,3-c d]$ pyrene & 26 & 78 & - & - & - & - & & - \\
\hline Naphthalene & 20 & 60 & 101 & - & 104 & 100 & 5 & - \\
\hline Naphthobenzothiophene & 21 & 63 & - & - & - & - & & - \\
\hline Phenanthrene & 19 & 57 & - & - & - & - & & - \\
\hline Pyrene & 17 & 50 & - & - & - & - & & - \\
\hline Triphenylene & 12 & 36 & - & - & - & - & & - \\
\hline $\begin{array}{r}\text { TOTAL PAH } \\
\text { RPD and \% REC AVE }\end{array}$ & & & 230 & 0 & 226 & & $5 \pm 1$ & 0 \\
\hline
\end{tabular}

${ }^{\mathrm{a}} \mathrm{C}$ : Measured concentration (-): Below MDL. $(<\mathrm{RL})$ : Detection below reporting limit $(\mathrm{RL}=3 \times \mathrm{MDL})$. (n.a.): not available. ${ }^{\mathrm{b}} \mathrm{Measured}$ concentration in fortified matrix experiment. ${ }^{\mathrm{c}}$ Fortification level. ${ }^{\mathrm{d}}$ Relative percent difference between duplicates. All concentrations are listed in $\mathrm{ng} / \mathrm{L}$. 
Table 4.7. (continued) Results from the determination of PAHs in seawater from Northern Biscayne Bay by Online SPE-LC-MS/MS . (in bold, USEPA priority PAHs).

\begin{tabular}{|c|c|c|c|c|c|c|c|c|}
\hline \multicolumn{3}{|l|}{ Site name } & \multirow{2}{*}{$\begin{array}{c}\begin{array}{c}\text { Pelican } \\
\text { Harbor Park }\end{array} \\
25.84713\end{array}$} & \multirow{3}{*}{$\begin{array}{c}\begin{array}{c}\text { FIU Campus } \\
\text { Beach }\end{array} \\
25.90994 \\
80.13640 \\
\end{array}$} & \multicolumn{4}{|c|}{ Miami Beach Marina } \\
\hline \multicolumn{2}{|l|}{ Latitude N } & \multirow[b]{3}{*}{ RL } & & & \multirow{2}{*}{\multicolumn{4}{|c|}{$\begin{array}{l}25.77194 \\
80.14027\end{array}$}} \\
\hline \multicolumn{2}{|l|}{ Longitude W } & & 80.16782 & & & & & \\
\hline PAH & MDL & & $\mathrm{C}$ & $\mathrm{C}$ & $\mathrm{C}$ & $\mathrm{FM}^{\mathrm{b}}$ & $\mathrm{FL}^{\mathrm{c}}$ & \% REC \\
\hline Acenaphthene & 15 & 45 & - & - & - & 184 & 176 & 104 \\
\hline Acenaphtylene & 16 & 49 & - & - & - & 179 & 176 & 102 \\
\hline Anthanthrene & 26 & 78 & - & - & - & - & 0 & n.a. \\
\hline Anthracene & 29 & 86 & - & - & - & 179 & 176 & 101 \\
\hline Benz[a]anthracene & 12 & 36 & - & - & - & 160 & 176 & 91 \\
\hline Benzo[a]fluoranthene & 16 & 48 & - & - & - & - & 0 & n.a. \\
\hline Benzo[a]pyrene & 23 & 69 & - & - & - & 171 & 176 & 97 \\
\hline Benzo[b]fluoranthene, perylene & 34 & 102 & - & - & - & 370 & 373 & 99 \\
\hline Benzo[b]fluorene & 7.5 & 23 & - & - & - & 154 & 176 & 88 \\
\hline Benzo[c]phenanthrene & 12 & 36 & - & - & - & - & 0 & n.a. \\
\hline Benzo[e]pyrene, benzo[j]fluoranthene & 16 & 48 & - & - & - & 175 & 176 & 99 \\
\hline Benzo[g,h,i]perylene & 19 & 57 & - & - & - & 185 & 176 & 105 \\
\hline Benzo[k]fluoranthene & 21 & 63 & - & - & - & 189 & 176 & 108 \\
\hline Biphenyl & 24 & 72 & - & - & - & 208 & 176 & 118 \\
\hline C1-anthracenes & 8.7 & 26 & - & - & - & 168 & 176 & 95 \\
\hline C1-chrysenes & 23 & 69 & - & - & - & 172 & 176 & 97 \\
\hline C1-dibenzothiophenes & 13 & 39 & - & - & - & 171 & 176 & 97 \\
\hline C1-fluor/pyrenes & 7.5 & 23 & - & - & - & - & 0 & n.a. \\
\hline C1-fluorenes & 12 & 35 & - & - & - & 180 & 176 & 102 \\
\hline C1-naphthalenes & 13 & 40 & - & - & - & 419 & 353 & 119 \\
\hline C1-phenanthrenes & 10 & 30 & - & - & - & 182 & 176 & 103 \\
\hline C2-dibenzothiophenes & 12 & 36 & - & - & - & 166 & 176 & 94 \\
\hline C2-naphthalenes & 15 & 44 & - & - & - & 177 & 176 & 101 \\
\hline C2-phen/anthracenes & 18 & 54 & - & - & - & - & 0 & n.a. \\
\hline C3-naphthalenes & 17 & 51 & - & - & - & 163 & 176 & 93 \\
\hline C4-phen/anthracenes & 18 & 54 & - & - & - & 147 & 176 & 83 \\
\hline Carbazole & 26 & 77 & - & - & - & 176 & 176 & 100 \\
\hline Chrysene & 11 & 33 & - & - & - & 173 & 176 & 98 \\
\hline Dibenz $[\mathrm{a}, \mathrm{h}]$ anthracene & 16 & 48 & - & - & - & 188 & 176 & 107 \\
\hline Dibenzothiophene & 11 & 34 & - & - & - & 178 & 176 & 101 \\
\hline Fluoranthene & 12 & 36 & - & - & - & 180 & 176 & 101 \\
\hline Fluorene & 7.9 & 24 & - & - & - & 187 & 176 & 106 \\
\hline Indeno[1,2,3-cd]pyrene & 26 & 78 & - & - & - & 197 & 176 & 112 \\
\hline Naphthalene & 20 & 60 & - & - & - & 189 & 176 & 107 \\
\hline Naphthobenzothiophene & 21 & 63 & - & - & - & 158 & 176 & 90 \\
\hline Phenanthrene & 19 & 57 & - & - & - & 167 & 176 & 94 \\
\hline Pyrene & 17 & 50 & - & - & - & 166 & 176 & 94 \\
\hline Triphenylene & 12 & 36 & - & - & - & - & 0 & n.a. \\
\hline $\begin{array}{c}\text { TOTAL PAH } \\
\text { RPD and \% REC AVER }\end{array}$ & GE & & 0 & 0 & 0 & & & $100 \pm 8$ \\
\hline
\end{tabular}

${ }^{\mathrm{a}} \mathrm{C}$ : Measured concentration (-): Below MDL. $(<\mathrm{RL})$ : Detection below reporting limit (RL=3×MDL). (n.a.): not available. ${ }^{b}$ Measured concentration in fortified matrix experiment. ${ }^{c}$ Fortification level. ${ }^{d}$ Relative percent difference between duplicates. All concentrations are listed in $\mathrm{ng} / \mathrm{L}$.

As shown in table 4.8, PAHs were detected in runoff from only one of the three parking lots located in a residential complex. Chromatograms for the priority PAHs 
detected in that sample are compared with reference rainwater in figure 4.7, showing that an interference-free detection and positive identification was obtained for these analytes except for benzo[b]fluoranthene, which is not resolved from perylene by this methodology as discussed before. Also, since no PAHs were observed in the reference rainwater, this data set strongly suggests that the parking lot was the source of the contamination. The high number of parent PAHs detected, the predominance of heavy PAHs such as fluoranthene and pyrene and their relative concentrations are in agreement with previous reports of PAHs in rainwater runoff from coated parking lots (Mahler et al., 2005), suggesting that the presented methodology is applicable for this type of studies.

Although not enough data are available to explain the non-occurrence of PAHs in runoff from the campus parking lots, the residential parking lot had a much slower drainage capability and thus the sample was collected under moderate flooding conditions (see figure 4.1). The lower drainage rate may have enhanced the possibility of detections as PAH-containing suspended particles could not be washed out by the rain as fast as in the campus parking lots. It is also possible that the nature of the coatings are different, as it has been shown that asphalt-based coatings contain much less PAHs that coal-based coatings (Mahler et al., 2012). 
Table 4.8 Results from analysis of PAHs in rainwater and rainwater runoff from parking lots at the FIU Biscayne Bay Campus and a nearby apartment complex. ${ }^{\mathrm{a}}$ (in bold, USEPA priority PAHs).

\begin{tabular}{|c|c|c|c|c|c|c|c|c|c|c|c|}
\hline \multirow{2}{*}{\multicolumn{3}{|c|}{$\begin{array}{c}\text { Sample source } \\
\text { Sample description }\end{array}$}} & \multirow{3}{*}{$\begin{array}{c}\begin{array}{c}\text { Direct } \\
\text { collection }\end{array} \\
\begin{array}{c}\text { Ref. } \\
\text { rainwater }\end{array} \\
\mathrm{C}\end{array}$} & \multirow{2}{*}{\multicolumn{3}{|c|}{$\begin{array}{c}\begin{array}{c}\text { Apartment } \\
\text { complex }\end{array} \\
\begin{array}{c}\text { Partially flooded } \\
\text { parking lot }\end{array} \\
\end{array}$}} & \multicolumn{5}{|c|}{ FIU Biscayne Bay Campus } \\
\hline & & & & & & & \multirow{2}{*}{$\begin{array}{c}\begin{array}{c}\text { Parking } \\
\text { lot A }\end{array} \\
\mathrm{C}\end{array}$} & \multicolumn{4}{|c|}{ Parking lot B } \\
\hline PAH & MDL & $\mathbf{R L}$ & & $\mathrm{C}$ & DUP & $\mathbf{R P D}^{\mathrm{d}}$ & & $\mathrm{C}$ & $\mathrm{FM}^{\mathrm{b}}$ & $\mathrm{FL}^{\mathrm{c}}$ & $\begin{array}{c}\% \\
\text { REC }\end{array}$ \\
\hline Acenaphthene & 15 & 45 & - & - & - & & - & - & 105 & 110 & 95 \\
\hline Acenaphtylene & 16 & 49 & - & - & - & & - & - & 119 & 110 & 109 \\
\hline Anthanthrene & 26 & 78 & - & - & - & & - & - & - & 0 & n.a. \\
\hline Anthracene & 29 & 86 & - & - & - & & - & - & 118 & 110 & 107 \\
\hline Benz[a]anthracene & 12 & 36 & - & 190 & 202 & 6 & - & - & 105 & 110 & 96 \\
\hline Benzo[a]fluoranthene & 16 & 48 & - & - & - & & - & - & 111 & 0 & 101 \\
\hline Benzo[a]pyrene & 23 & 69 & - & $<\mathrm{RL}$ & $<\mathrm{RL}$ & & - & - & 100 & 110 & 91 \\
\hline Benzo[b]fluoranthene, perylene & 34 & 102 & - & 112 & 108 & 4 & - & - & 216 & 220 & 98 \\
\hline Benzo[b]fluorene & 7.5 & 23 & - & $<\mathrm{RL}$ & $<\mathrm{RL}$ & & - & - & 116 & 110 & 105 \\
\hline Benzo[c]phenanthrene & 12 & 36 & - & $<\mathrm{RL}$ & $<\mathrm{RL}$ & & - & - & 127 & 0 & n.a. \\
\hline $\begin{array}{l}\text { Benzo[e]pyrene, } \\
\text { benzo[j]fluoranthene }\end{array}$ & 16 & 48 & - & 117 & 116 & 1 & - & - & 111 & 110 & 101 \\
\hline Benzo[g,h,i]perylene & 19 & 57 & - & 60 & 61 & 2 & - & - & 124 & 110 & 113 \\
\hline Benzo[k]fluoranthene & 21 & 63 & - & $<\mathrm{RL}$ & $<\mathrm{RL}$ & & - & - & 105 & 110 & 96 \\
\hline Biphenyl & 24 & 72 & - & - & - & & - & - & 110 & 110 & 100 \\
\hline C1-anthracenes & 8.7 & 26 & - & - & - & & - & - & 99 & 110 & 90 \\
\hline C1-chrysenes & 23 & 69 & - & $<\mathrm{RL}$ & $<\mathrm{RL}$ & & - & - & - & 0 & n.a. \\
\hline C1-dibenzothiophenes & 13 & 39 & - & - & - & & - & - & 122 & 110 & 111 \\
\hline C1-fluor/pyrenes & 7.5 & 23 & - & $<\mathrm{RL}$ & $<\mathrm{RL}$ & & - & - & - & 0 & n.a. \\
\hline C1-fluorenes & 12 & 35 & - & - & - & & - & - & 109 & 110 & 99 \\
\hline C1-naphthalenes & 13 & 40 & - & - & - & & - & - & 209 & 220 & 95 \\
\hline C1-phenanthrenes & 10 & 30 & - & 48 & 51 & 6 & - & - & 358 & 330 & 108 \\
\hline C2-dibenzothiophenes & 12 & 36 & - & - & - & & - & - & 104 & 110 & 95 \\
\hline C2-naphthalenes & 15 & 44 & - & - & - & & - & - & 111 & 110 & 101 \\
\hline C2-phen/anthracenes & 18 & 54 & - & - & - & & - & - & - & 0 & n.a. \\
\hline C3-naphthalenes & 17 & 51 & - & - & - & & - & - & 105 & 110 & 95 \\
\hline C4-phen/anthracenes & 18 & 54 & - & - & - & & - & - & 112 & 110 & 102 \\
\hline Carbazole & 26 & 77 & - & 162 & 161 & 0.3 & - & - & 111 & 110 & 101 \\
\hline Chrysene & 11 & 33 & - & 153 & 169 & 10 & - & - & 112 & 110 & 101 \\
\hline Dibenz $[\mathbf{a}, \mathbf{h}]$ anthra & 16 & 48 & - & - & - & & - & - & 137 & 110 & 124 \\
\hline Dibenzothiophene & 11 & 34 & - & - & - & & - & - & 106 & 110 & 97 \\
\hline Fluoranthene & 12 & 36 & - & 410 & 387 & 6 & - & - & 104 & 110 & 95 \\
\hline Fluorene & 7.9 & 24 & - & $<\mathrm{RL}$ & $<\mathrm{RL}$ & & - & - & 100 & 110 & 91 \\
\hline Indeno[1,2,3-cd]pyrene & 26 & 78 & - & $<\mathrm{RL}$ & $<\mathrm{RL}$ & & - & - & 130 & 110 & 118 \\
\hline Naphthalene & 20 & 60 & - & - & - & & - & - & 91 & 110 & 83 \\
\hline Naphthobenzothiophene & 21 & 63 & - & $<\mathrm{RL}$ & $<\mathrm{RL}$ & & - & - & 86 & 110 & 78 \\
\hline Phenanthrene & 19 & 57 & - & 183 & 186 & 2 & - & - & 116 & 110 & 105 \\
\hline Pyrene & 17 & 50 & - & 293 & 315 & 7 & - & - & 117 & 110 & 107 \\
\hline Triphenylene & 12 & 36 & - & 48 & 45 & 6 & - & - & 117 & 110 & 106 \\
\hline $\begin{array}{c}\text { TOTAL PAH } \\
\text { RPD and \% REC AVEI }\end{array}$ & IGE & & 0 & 1777 & 1801 & $4 \pm 3$ & 0 & 0 & & & $100 \pm 9$ \\
\hline
\end{tabular}

${ }^{a}$ C: Measured concentration. (-): Below MDL. $(<\mathrm{RL})$ : Detection below reporting limit $(\mathrm{RL}=3 \times \mathrm{MDL})$. (n.a.): not available. ${ }^{b}$ Measured concentration in fortified matrix experiment. ${ }^{c}$ Fortification level. ${ }^{d}$ Relative percent difference between duplicates. All concentrations are listed in $\mathrm{ng} / \mathrm{L}$. 

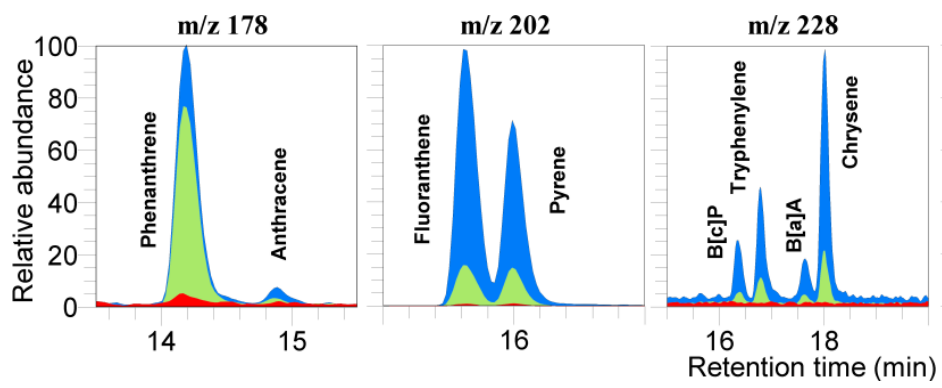

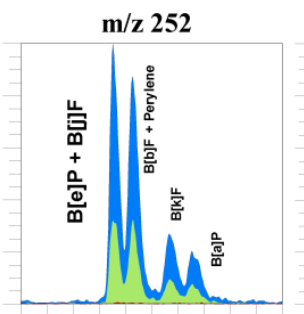

1820

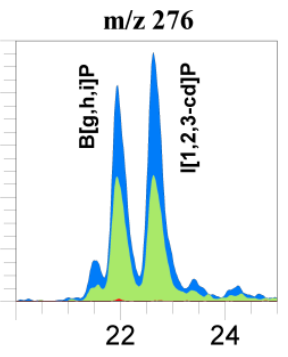

Figure 4.7 Chromatograms obtained upon analysis of a rainwater runoff sample from a residential parking lot showing the resolution obtained for priority PAHs. Blue trace: main (quantitative) SRM transition in runoff sample; green trace: secondary (confirmation) SRM transition in runoff sample; red trace: main SRM transition from injection of reference rainwater. The three traces of each chromatogram are normalized to the same scale.

The occurrence of PAHs in wastewater has been previously documented, and their removal by wastewater treatment plants (WWTPs) depends on the treatments applied. Vogelsang et al. (2006) observed that 2-3 ring PAHs accounted for $70 \%$ of the PAHs detected in the influents of 5 Norwegian WWTPs, with complete removal observed only in plants equipped with biodegradation steps. Bergqvist et al. (2006) observed that alkylnaphthalenes were the predominant PAHs in WWTPs influents in Sweden and Lithuania, observing incomplete removal with concentrations as high as 10$35 \mathrm{ng} / \mathrm{L}$ of C3-naphthalenes in the discharged effluents.

Therefore, WWTPs effluents are a potential source of light PAHs into the environment. Samples of reclaimed water used for irrigation at FIU Biscayne Bay campus were collected in two different dates and analyzed in order to assess the performance of the developed methodology to detect PAHs in discharged WWTP effluents. Alkylnaphthalenes were detected in one on the samples (table 4.9) but concentrations were lower than the reporting limit. Good recoveries were obtained in the 
fortified matrix experiment for reclaimed water, suggesting that method sensitivity rather than matrix effects prevented a positive quantification in these samples.

Table 4.9 Results from analysis of PAHs in reclaimed water obtained from the MiamiDade North District Wastewater Treatment plant. ${ }^{\text {a }}$ (in bold, USEPA priority PAHs).

\begin{tabular}{|c|c|c|c|c|c|c|c|}
\hline \multicolumn{3}{|l|}{ Collection Date } & \multirow{2}{*}{$\frac{09 / 11 / 2012}{\mathrm{C}}$} & \multicolumn{4}{|c|}{$8 / 16 / 2012$} \\
\hline РAH & MDL & RL & & $\mathrm{C}$ & $\mathrm{FM}^{\mathrm{b}}$ & $\mathrm{FL}^{\mathrm{c}}$ & $\begin{array}{c}\% \\
\text { REC }\end{array}$ \\
\hline Acenaphthene & 15 & 45 & - & - & 203 & 176 & 115 \\
\hline Acenaphtylene & 16 & 49 & - & - & 162 & 176 & 92 \\
\hline Anthanthrene & 26 & 78 & - & - & - & 0 & n.a. \\
\hline Anthracene & 29 & 86 & - & - & 185 & 176 & 105 \\
\hline Benz[a]anthracene & 12 & 36 & - & - & 164 & 176 & 93 \\
\hline Benzo[a]fluoranthene & 16 & 48 & - & - & - & 0 & n.a. \\
\hline Benzo[a]pyrene & 23 & 69 & - & - & 207 & 176 & 117 \\
\hline Benzo[b]fluoranthene, perylene & 34 & 102 & - & - & 363 & 373 & 97 \\
\hline Benzo[b]fluorene & 7.5 & 23 & - & - & 179 & 176 & 102 \\
\hline Benzo[c]phenanthrene & 12 & 36 & - & - & - & 0 & n.a. \\
\hline Benzo[e]pyrene, benzo[j]fluoranthene & 16 & 48 & - & - & 215 & 176 & 122 \\
\hline Benzo[g,h,i]perylene & 19 & 57 & - & - & 150 & 176 & 85 \\
\hline Benzo[k]fluoranthene & 21 & 63 & - & - & 219 & 176 & 124 \\
\hline Biphenyl & 24 & 72 & - & - & 163 & 176 & 93 \\
\hline $\mathrm{C} 1$-anthracenes & 8.7 & 26 & - & - & 175 & 176 & 99 \\
\hline C1-chrysenes & 23 & 69 & - & - & 167 & 176 & 95 \\
\hline C1-dibenzothiophenes & 13 & 39 & - & - & 195 & 176 & 111 \\
\hline C1-fluor/pyrenes & 7.5 & 23 & - & - & - & 0 & n.a. \\
\hline C1-fluorenes & 12 & 35 & - & - & 206 & 176 & 117 \\
\hline C1-naphthalenes & 13 & 40 & - & - & 364 & 353 & 103 \\
\hline C1-phenanthrenes & 10 & 30 & - & - & 180 & 176 & 102 \\
\hline C2-dibenzothiophenes & 12 & 36 & - & - & 153 & 176 & 81 \\
\hline C2-naphthalenes & 15 & 44 & - & $<\mathrm{RL}$ & 228 & 176 & 118 \\
\hline C2-phen/anthracenes & 18 & 54 & - & - & - & 0 & n.a. \\
\hline C3-naphthalenes & 17 & 51 & - & $<\mathrm{RL}$ & 197 & 176 & 97 \\
\hline C4-phen/anthracenes & 18 & 54 & - & - & 135 & 176 & 77 \\
\hline Carbazole & 26 & 77 & - & - & 157 & 176 & 89 \\
\hline Chrysene & 11 & 33 & - & - & 210 & 176 & 119 \\
\hline Dibenz[a,h]anthracene & 16 & 48 & - & - & 156 & 176 & 88 \\
\hline Dibenzothiophene & 11 & 34 & - & - & 188 & 176 & 106 \\
\hline Fluoranthene & 12 & 36 & - & - & 209 & 176 & 116 \\
\hline Fluorene & 7.9 & 24 & - & - & 168 & 176 & 95 \\
\hline Indeno[1,2,3-cd]pyrene & 26 & 78 & - & - & 174 & 176 & 99 \\
\hline Naphthalene & 20 & 60 & - & - & 161 & 176 & 91 \\
\hline Naphthobenzothiophene & 21 & 63 & - & - & 179 & 176 & 102 \\
\hline Phenanthrene & 19 & 57 & - & - & 175 & 176 & 99 \\
\hline Pyrene & 17 & 50 & - & - & 200 & 176 & 111 \\
\hline Triphenylene & 12 & 36 & - & - & - & 0 & n.a. \\
\hline $\begin{array}{c}\text { TOTAL PAH } \\
\% \text { REC AVERAGE }\end{array}$ & & & 0 & 0 & & & $102 \pm 12$ \\
\hline
\end{tabular}

${ }^{a}$ C: Measured concentration. (-): Below MDL. ( $<$ RL): Detection below reporting limit (RL=3×MDL). (n.a.): not available.

${ }^{\mathrm{b}}$ Measured concentration in fortified matrix experiment. ${ }^{\mathrm{c}}$ Fortification level. All concentrations are listed in $\mathrm{ng} / \mathrm{L}$. 
Excellent recoveries were also obtained in fortified matrices experiments with the other two types of environmental waters tested with this method, which may suggest that the use of a wide range of molecular sizes of isotopically labeled PAHs normalize analyte behavior during the automated preconcentration and analysis, keeping matrices effects under control in spite of the absence of sample clean up steps. In addition, method reproducibility was also demonstrated as low relative percent deviation (RPD) values were obtained from analysis of duplicates of seawater and runoff samples contained PAHs.

\subsection{Conclusions}

An automated protocol for the comprehensive analysis of 28 parent PAHs and their extended alkylated homologues by online SPE-LC-APPI-MS/MS has been successfully developed, with optimized parameters for extraction, separation and detection using dopant-assisted APPI. To date, this represents the largest number of PAHs analyzed simultaneously by liquid chromatography and the first report of a LC separation of alkylated PAHs.

A polymeric $\mathrm{C} 18$ column was used to develop a liquid chromatography separation of isobaric alkylated PAHs that resembles that of traditional capillary GC-MS for some compounds. The developed method is environmentally friendlier than the traditional approach, as only $1.5 \mathrm{~mL}$ of the chlorobenzene dopant is required versus the $150 \mathrm{~mL}$ of the carcinogen methylene chloride used for traditional GC-MS analysis. 
Factoring the costs of solvents, consumable materials, analyst time and the high sample throughput, the SPE-LC-MS/MS approach may also constitute a more economical alternative to analyze PAHs than GC-MS. Method performance and the control of matrix effects were demonstrated by obtaining good recoveries upon analysis of seawater, reclaimed water and rainwater runoff fortified with certified standards, showing the utility of this method to survey the occurrence of PAHs in different waters from the urban environment.

A survey of PAHs concentration in marinas located in the Miami area was conducted, and although background concentrations were below MDLs, localized PAH input events from boating activities were detected. Furthermore, the utility of the method to monitor PAHs inputs in WWTPs effluent and from parking lot rainwater runoff samples was proven. With lower run times, very simple sample preparation, lower generation of toxic solvent waste and higher sensitivity per volume of sample used, this method could represent a viable alternative to LLE+GC-MS for routine PAH monitoring, providing laboratories with a much higher sample throughput while reducing overall operation costs and the environmental impact of PAHs analysis. 


\section{IDENTIFICATION OF SOURCES OF AIRBORNE PARTICULATE MATTER COLLECTED AT A COASTAL SITE OF THE MIAMI METROPOLITAN AREA}

\subsection{Introduction}

Good air quality is a requirement for human health. Clean air is $99 \% \mathrm{O}_{2}$ and $\mathrm{N}_{2}$, with a $1 \%$ of other gases such as carbon dioxide, water vapor, argon and helium, and any substance that alters this natural composition causing measurable deleterious effects on living organisms, hindering normal human activities or degrading property and/or infrastructure is considered an air pollutant (Michulec et al., 2005; Seinfeld \& Pandis, 1998). Air pollutants exists in the form of gases (such as nitrogen oxides and sulfur dioxide) or in airborne particulate matter (APM, also called "aerosols"), defined as any liquid or solid suspended substance (other than water) formed by aggregation of two or more molecules (Brook et al., 2004).

APM contains both primary particles, which are suspended directly from an emission source, and secondary particles formed in the atmosphere from chemical reactions involving gaseous pollutants, i.e., the oxidation of $\mathrm{SO}_{2}$ to $\mathrm{H}_{2} \mathrm{SO}_{4}$ followed by nucleation of $\mathrm{H}_{2} \mathrm{SO}_{4}$ vapor (Seinfeld \& Pandis, 1998). Primary particles in the urban environment have a large number of anthropogenic sources such as emissions from internal combustion engines and fossil fuel-fired electricity plants; road, tire, and brake residues from vehicular traffic; industrial activities such as mining or metallurgy; agriculture activities; construction and demolition activities, etc. There are also natural 
sources of APM such as volcanic emissions, windblown mineral dust, pollen, mold, wildfires and marine spray (Brook et al., 2004).

It is known that airborne particles with a size below $10 \mu \mathrm{m}\left(\mathrm{PM}_{10}\right)$ are able to enter the lower respiratory track (termed "thoracic particles"), and are more likely than larger particles to become hazardous to humans. Furthermore, particles with sizes $<2.5$ $\mu \mathrm{m}\left(\mathrm{PM}_{2.5}\right.$, "breathable particles") have a considerable higher residence time in lungs and can reach alveoli (Brunekreef \& Holgate, 2002). Extensive epidemiological data compiled by the USEPA and other authors has shown that both short and long term exposure to $\mathrm{PM}_{2.5}$ causes increased hospital admissions and mortality from cardiovascular and respiratory problems (Brook et al., 2004; Brook et al., 2010; Brunekreef \& Holgate, 2002; USEPA, 2009). These facts have prompted the establishment of National Ambient Air Quality Standard (NAAQS) for airborne particulate matter by the USEPA, with maximum exposure concentrations of $12.0 \mu \mathrm{g} / \mathrm{m}^{3}$ (annual average) and $35 \mu \mathrm{g} / \mathrm{m}^{3}$ (24-h average) of $\mathrm{PM}_{2.5}$ in air and $150 \mu \mathrm{g} / \mathrm{m}^{3}(24-\mathrm{h}$ average) for $\mathrm{PM}_{10-2.5}$ (USEPA, 2012).

Bioaccessible metals (soluble in relevant bodily fluids) are believed to share responsibility for the toxicity of APM. Most of $\mathrm{PM}_{2.5-10}$ particles are deposited in the pharyngeal and tracheal regions from where they are transported by mucociliary clearance towards the mouth and are swallowed, coming into contact with gastric juice where a fraction may dissolve and become bioaccessible (Hamel et al., 1998). The smaller $\mathrm{PM}_{2.5}$ are able to reach alveoli from where, depending on particle solubility, elements can be absorbed into the bloodstream (Kappos, 2011). Anthropogenic activities 
are responsible for the ubiquitous occurrence of toxic metals such as $\mathrm{Cr}, \mathrm{Cu}, \mathrm{Mn}, \mathrm{Ni}, \mathrm{Pb}$, $\mathrm{V}$, As and $\mathrm{Zn}$ in urban APM, and their speciation and concentrations are highly dependent on the APM sources and local environmental conditions (Mukhtar \& Limbeck, 2013).

Because of their toxic effects, the European Union has set limits for the annual average concentration of $\mathrm{Pb}$ in $\mathrm{PM}_{10}\left(500 \mathrm{ng} / \mathrm{m}^{3}\right)$ and target values for $\mathrm{As}\left(6 \mathrm{ng} / \mathrm{m}^{3}\right), \mathrm{Ni}$ $\left(20 \mathrm{ng} / \mathrm{m}^{3}\right)$ and $\mathrm{Cd}\left(5 \mathrm{ng} / \mathrm{m}^{3}\right)(\mathrm{EU}, 2012)$. Lead is the only element individually listed by the USEPA in the NAAQS, with a three-month average exposure threshold of $150 \mathrm{ng} / \mathrm{m}^{3}$ in total suspended particles (TSP) (USEPA, 2012).

The tri-county metropolitan area in South Florida is home to 5.5 million residents (USDOC, 2010) and thus emissions of anthropogenic APM are expected. Based on inputs provided by State, Local and Tribal air agencies, the USEPA releases the National Emissions Inventory (NEI), with estimates on the extent of pollutant releases at national, regional or local levels (USEPA, 2013a). According to the 2008 NEI, construction dust, road dust, mining operations, industrial fuel combustion, internal combustion engines and prescribed fires are the main source of APM to the local air in South Florida (see table 5.1).

Since the atmosphere is a highly dynamic system capable of long range transportation of suspended particles, detailed chemical composition of APM not only depends on local sources, but also on long range transportation of APM by global-scale atmospheric movements. As has been documented in several reports by Prospero and coworkers at the University of Miami, mineral dust from the Saharan and Sahel deserts in 
Northern Africa is transported across the Atlantic by the trade winds, depositing large amounts of geological material on the Caribbean islands and the continental United States during the northern hemisphere summer, and on South America in the winter (Prospero, 1999) (see figure 5.1).

Table 5.1 Combined estimates of APM emissions $\left(\mathrm{PM}_{10}\right)$ from Miami-Dade, Broward and Palm Beach counties, according to the 2008 National Emissions Inventory (USEPA, 2013a).

\begin{tabular}{lcc}
\hline \multicolumn{1}{c}{ Source } & Emission (tons) & \% Emission \\
\hline Construction dust & 15208 & 26 \\
Paved road dust & 10285 & 17 \\
Unpaved road dust & 5162 & 9 \\
Diesel engines & 4845 & 9 \\
Mining (cement) & 4330 & 7 \\
Industrial fuel combustion & 4045 & 7 \\
Gasoline engines & 2482 & 5 \\
Prescribed fires & 2234 & 4 \\
Agricultural field burning & 2213 & 4 \\
Commercial marine vessels & 1295 & 2 \\
Commercial cooking & 1064 & 2 \\
Natural gas-fired power plants & 993 & 2 \\
Crops and livestock dust & 632 & 1 \\
Wildfires & 542 & 1 \\
Oil-fired power plants & 404 & 1 \\
Other sources combined & 3358 & 6 \\
\hline TOTAL & $\mathbf{5 9 0 9 0}$ & $\mathbf{1 0 0}$ \\
\hline
\end{tabular}

It has been estimated that between 130 and $1600 \mathrm{Tg} / \mathrm{yr}$ of mineral dust from Northern Africa is suspended by winds, making this region the main global source of airborne mineral dust (Engelstaedter et al., 2006). This long range transport is so significant that it is believed to play a major role in the formation of soil in the Caribbean islands and in the insertion of micronutrients such as iron, phosphate and nitrate for the 
fertilization of tropical rainforests (Muhs et al., 2007). However it also increases concentrations of APM in Florida and the Caribbean countries, where dust events have not only been correlated with public health problems such as surges in pediatric asthma (Prospero et al., 2008) but also with damage to local ecosystems. For example, coral reef death seems to correlate with periods of high concentration of mineral APM in air, with damage attributed to coral disease caused by viable mold spores in the African dust (Shinn et al., 2000).

With advancing desertification, the total arid land area in the planet is likely to increase along with mineral dust transportation to far away areas (Schlesinger et al., 1990), increasing awareness in the medical community on the health problems associated with far-traveled mineral APM (Kuehn, 2006). Adding to this, it is known that only the smallest fraction of particles $\left(\mathrm{PM}_{10}\right.$ and below) are able to remain airborne during long range atmospheric transportation, as deposition rates increase with particle weight (Muhs et al., 2007; Seinfeld \& Pandis, 1998). Thus the mineral dust reaching South Florida from Africa is most likely comprised of breathable particles, raising concerns of possible impacts on public health. 

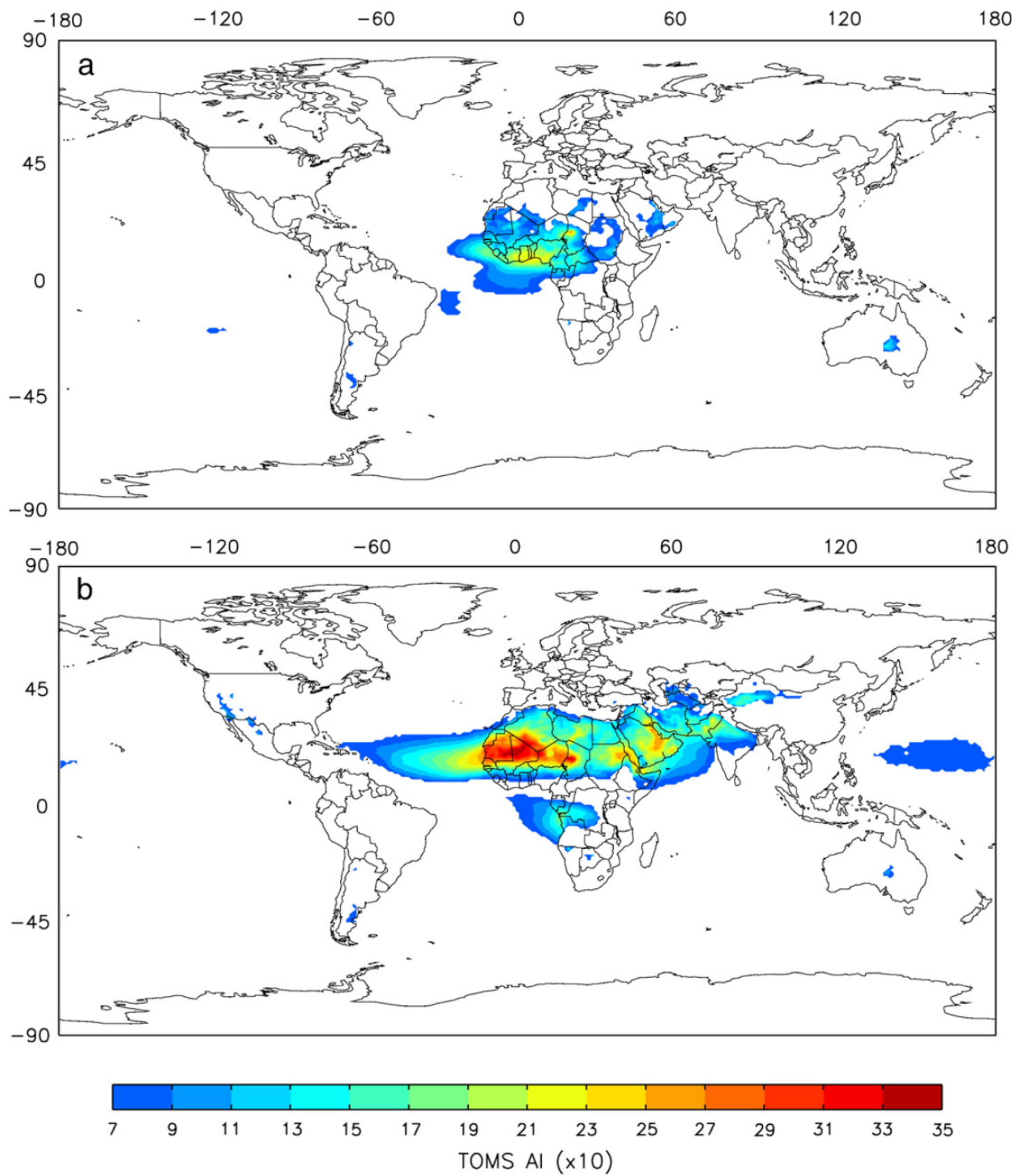

Figure 5.1 Seasonal averages of the Total Ozone Mapping Spectrometer absorbing Aerosol Index (TOMS AI) satellite product, between 1980 and 1992, showing the global movement of mineral dust in November-January (top) and May-July (bottom) (Engelstaedter et al., 2006). 
Because of these facts, there is a pressing need for the constant monitoring of APM pollution in the Miami Metropolitan area from both local and foreign origin. Such monitoring could potentially yield useful information on the trends of APM amounts in air and its provenance, to help governments in implementing policies aimed to mitigate risks associated with this threat.

The study of elemental composition of APM in urban air can yield information about the origin of airborne particles, the atmospheric processes involved in APM transportation and about the occurrence of elements known to have a high chronic and acute human toxicity (Ragosta et al., 2008).

The research group of Prospero and coworkers has collected APM samples from the late 1970s until at least 2010, performing elemental analysis along with other assays (Prospero, 1999; Trapp et al., 2010). That monitoring effort was focused on understanding the atmospheric phenomena involved in the long range transportation of mineral dust from Northern Africa and its implications on global climate and geochemical processes. In that sense, the air sampler located in Virginia Key was equipped with a wind direction sensor which activated the device only if the wind is blowing from the open sea, in order to eliminate APM inputs from local anthropogenic sources on their measurements. Thus, there are no studies available on the elemental composition and provenance of anthropogenic APM pollution in the Miami Metropolitan Area other than those involved with occurrence of mineral dust from Northern Africa.

Efforts to use elemental analysis to characterize APM from the Miami Area were initiated by our laboratory under the work of Arroyo-Mora, who collected APM samples 
regularly between the summer of 2005 and the winter of 2006 from a high volume sampler located in the vicinity of Port Everglades. The sampling site was in the middle of the Tri-county metropolitan area, and located near pollution emitters such as the Port Everglades Power Plant (oil-fired), the Fort Lauderdale International Airport and the shipping facilities at Port Everglades, which is the main port of Florida and ranks 32 in the United States in terms of annual tonnage (USDOT, 2013). Thus, APM collected at that site is potentially under the influence of anthropogenic sources and from airborne mineral dust arriving from the sea.

Arroyo-Mora performed a comparison between Laser Ablation Inductively Coupled Plasma Mass Spectrometry (LA-ICP-MS) with a direct ICP-MS analysis after acid digestion. The second technique was found to be more suitable for the analysis of APM in the collected filters since difficulties in obtaining a proper calibration hindered quantitation with LA-ICP-MS. Arroyo-Mora also demonstrated the occurrence of mineral dust in the summer months was by measuring signal increases of crustal elements such as Fe, Mn and Al (Arroyo-Mora, 2009). However, in that initial work no attempt was made on discussing the sources of the APM collected or applying statistical models that could help to interpret the observed elemental concentrations.

Multivariate receptor models (MRMs) are usually employed to help interpret air pollution data, including Enrichment Factors (EFs), Principal Component analysis (PCA), Positive Matrix Factorization (PMF), Chemical Mass Balance (CMB), UNMIX, among others. These have been reviewed extensively (Henry \& Christensen, 2010; Viana et al., 2008; Watson et al., 2002). PCA is very popular as it can be performed with widely 
available statistical software, is less complicated to use than others such as PMF and also does not require quantitative knowledge of the composition of emission sources which is the main limitation of CMB (Song et al., 2006). For example, Celo used principal PCA to identify sources of airborne particulate samples collected in different Canadian cities (Celo \& Dabek-Zlotorzynska, 2011). Furthermore, it has been proposed that to provide a higher degree of confidence to the data interpretation, is preferable to evaluate the similarities in the outputs of two MRMs. For example, PCA was used in combination with UNMIX in the works by Chen et al. (2007) in the San Joaquin Valley, California and by Song et al. (2006) in Beijing, China. Also known as N-dimensional Edge detection, UNMIX was first introduced by Henry (2003) and has gained popularity as is able to provide source apportionment based solely on the ambient data, and also because a peer-reviewed, free to use software package for its application is available from USEPA (Henry \& Christensen, 2010; USEPA, 2013b).

By increasing the number of samples available in the EARL-FIU library of APM filters, and by analyzing a large number of elements by Inductively Coupled Plasma Mass Spectrometry (ICP-MS), this work aimed to apply MRMs to identify the possible sources of airborne particulate samples collected by EARL-FIU in the vicinity of Port Everglades, FL. 


\subsection{Hypotheses}

Airborne Particulate Matter collected around the large installations of Port Everglades in Florida contain elements toxic to humans, such as $\mathrm{Cr}, \mathrm{Cu}, \mathrm{Mn}, \mathrm{Ni}, \mathrm{Pb}, \mathrm{V}$, As and $\mathrm{Zn}$, originating from both anthropogenic and natural sources.

Sources of APM can be identified by analyzing a large number of elements by ICP-MS and applying statistical analysis, differentiating between mineral dust and local anthropogenic APM sources.

\subsection{Study objectives}

- To continue the efforts started by previous researchers of our group to collect airborne particulate samples near Port Everglades, FL, in order to increment the number of airborne particulate matter samples.

- To perform elemental analysis by ICP-MS with a large number of elements, including Rare Earth Elements (REE), in order to perform statistical analysis to identify the different sources of APM to the local environment. 


\subsection{Materials and reagents}

Concentrated nitric acid and 30\% v/v hydrogen peroxide were Optima ${ }^{\mathrm{TM}}$ grade and purchased from Fisher Scientific (Fairlawn, NJ, USA). Multi-elemental certified calibration standards (Claritas PPT ${ }^{\mathrm{TM}}$ grade; $10,000 \mu \mathrm{g} / \mathrm{L}$ in $5 \% \mathrm{HNO}_{3}$ ) were purchased from Spex Certiprep (Metuchen, NJ, USA) for all element groups (cat. number CLMS-2 for regular elements and CLMS-1 for REE). The internal standard mixture for the analysis of regular elements was a 1/10 dilution of a solution containing $\mathrm{Ge}, \mathrm{Y}, \mathrm{In}, \mathrm{Bi}, \mathrm{Sc}$,

$\mathrm{Tb}$ and ${ }^{6} \mathrm{Li}$, also purchased from Spex Certiprep (Claritas PPT ${ }^{\mathrm{TM}}$ grade, cat. number CLISM1-100; $10,000 \mu \mathrm{g} / \mathrm{L} ; 3 \% \mathrm{HNO}_{3}$ ). For REE, the internal standard solution was prepared by combining $1 / 1000$ dilutions of single component, certified standards of $\mathrm{Bi}$, Ge and In $\left(1,000,000 \mu \mathrm{g} / \mathrm{L}\right.$ in $\left.3 \% \mathrm{HNO}_{3}\right)$ purchased from Environmental Express (Charleston, South Carolina, USA). Initial calibration verification was performed by using certified multi-elemental standards purchased from Accustandard (New Haven, CT, USA), Ultra Scientific (North Kingstown, RI, USA) and Environmental Express. The ICP-MS tuning solution $\left({ }^{6} \mathrm{Li}, \mathrm{Y}, \mathrm{Ce}, \mathrm{Tl}\right)$ was also purchased from Accustandard. Ultrahigh purity liquid argon was purchased from Airgas (Kennesaw, GA, USA).

Filters $(61 \times 61 \mathrm{~cm})$ were cut out from a roll of Versapor ${ }^{\circledR} 450 \mathrm{R}$ membrane (acrylic copolymer on a nonwoven nylon support, $0.45 \mu \mathrm{m}$ pore size), purchased from Pall (Port Washington, NY, USA). The filters were placed in a super-high air volume collector system, built by Pacific Sierra Research (Santa Monica, CA, USA) and property of the United States Geological Survey (USGS). The system is equipped with a digital air 
flowmeter to record the total air volume filtered, model GD-200 (Fluid Inventor AB, Stockholm, Sweden).

Filters sub-samples were digested using a $\mathrm{SC} 100$ HotBlock $^{\mathrm{TM}}$ digestion system, purchased also from Environmental Express. $50 \mathrm{~mL}$, metal-certified homopolymer polypropylene digestion vessels (model SC475) were used for sample digestion, in combination with the FilterMate ${ }^{\mathrm{TM}}$ metal-certified filtration system (model SC0409, 0.45 $\mu \mathrm{m}$ PTFE with a $2 \mu \mathrm{m}$ PTFE prefilter), also purchased from Environmental Express. A filtered air laminar flow hood was employed to minimize the introduction of impurities during sample preparations (Envirco, Albuquerque, NM, USA). Analysis of digestates was performed with an 4500 ICP-MS (Agilent Technologies, Santa Clara, CA, USA), equipped with an ASX-500 autosampler (Cetac Technologies, Omaha, NE, USA). Instrument operation and data analysis was performed with the Chemstation ${ }^{\mathrm{TM}}$ software, also obtained from Agilent Technologies.

Pictures for the determination of APM load percentage were taken with a 5.1 megapixel digital camera, model S5200, purchased from Fujifilm (Tokyo, Japan) mounted on a tripod equipped with a hydraulic level. Exact areas were determined from photographs using the CellSens ${ }^{\circledR}$ digital imaging software for research applications, purchased from Olympus (Tokyo, Japan). Filters were visually analyzed using a digital microscope, model VSX-200 (Keyence, Chicago, IL, USA) available at the International Forensic Research Institute at FIU. 
Statistical analysis software packages used were JMP version 10.0 (SAS, Cary, NC., USA), Sigmaplot version 12.5 (Systat Software Inc., San Jose, CA. USA) and UNMIX version 6.0 (USEPA, Washington, DC. USA).

\subsection{Sample collection}

A detailed description on the high volume air sampler and the sample location can be found on the work by Arroyo-Mora (2009). Briefly, an stainless steel sampler containing an airtight filter compartment is housed inside a trailer and the air is pulled onto the filter by a maintenance-free electric motor at a flow rate of approximately 100

$\mathrm{m}^{3} / \mathrm{h}$, entering trough an omnidirectional opening in a PVC pipe extending $4 \mathrm{~m}$ above the trailer rooftop (see figure 5.2).

The trailer was placed about 10 meters from the Port Everglades inlet (see figure 5.2). The collector operated $24 / 7$ and filters were replaced biweekly (when possible) between years 2005 and 2006. A second collection period was performed between 2008 and 2010 but collection was not as regular as the first period. With every filter installed, initial and final flow rates were recorded along with the total volume of air filtered. Exposed filters were carefully folded and stored in plastic bags at room temperature. 

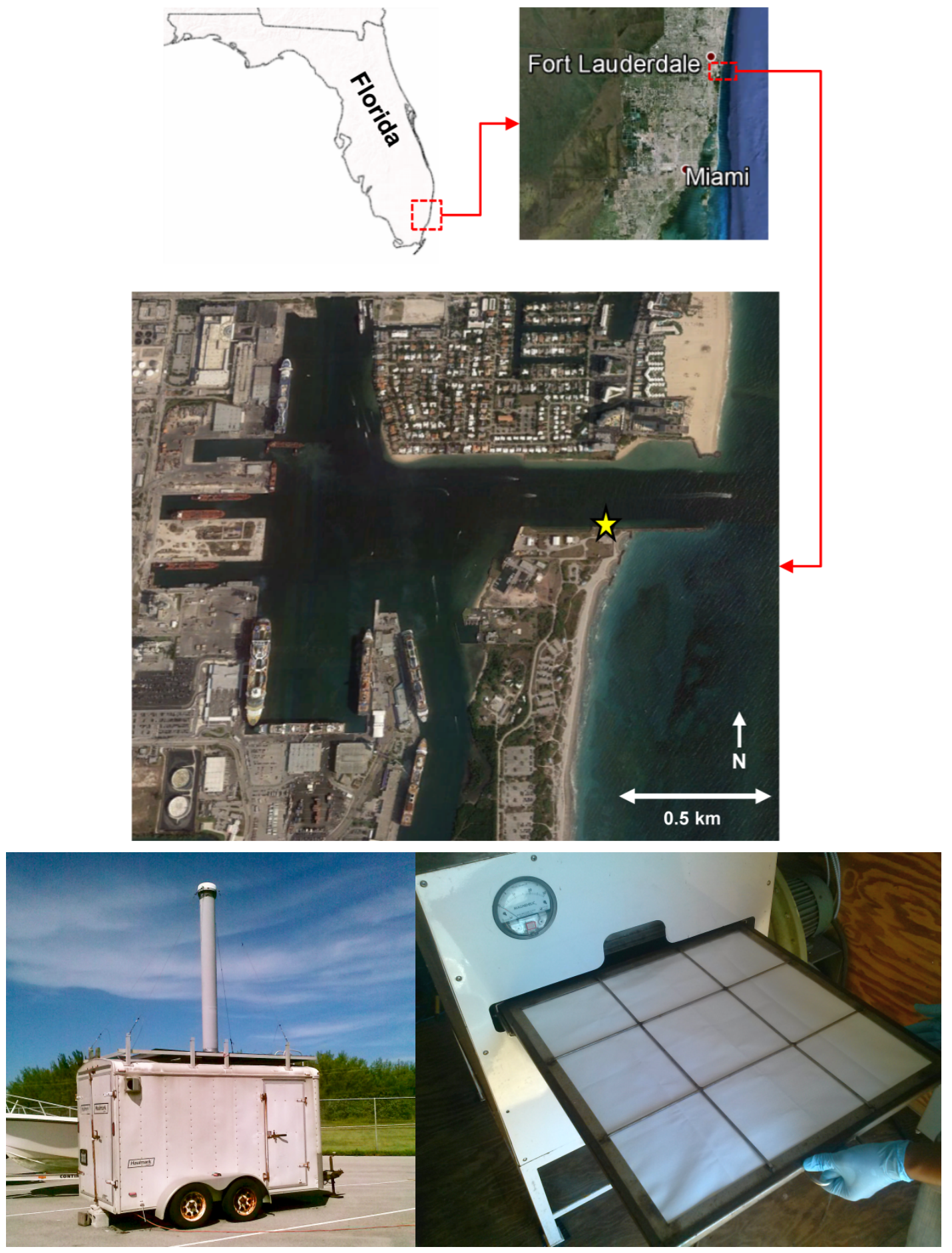

Figure 5.2 (Top) Location of airborne particulate matter collector at Port Everglades, Florida $\left(26.092542^{\circ} \mathrm{N}, 80.108415^{\circ} \mathrm{W}\right)$. (Bottom left) View of the trailer housing the air sampler and the omnidirectional air collection PVC pipe. (Bottom right) View of the air sampler machine with a new filter being loaded. 


\subsection{Analytical methodology}

\subsubsection{Determination of the concentration of APM in air}

A small piece was cut out from each filter and carefully weighed to the \pm 0.001 mg. Each weighed piece was then photographed with a tripod-mounted digital camera. The obtained picture was used to determine the area of the filter piece using a software originally designed to determine cellular areas from microscope observations. A distance reference included in the picture was used to calibrate the software (see figure 5.3). The total mass of APM in the exposed filter $\left(m_{A P M, e x}\right)$ results from subtracting the mass of an unexposed filter $\left(m_{v}\right)$ to that of the exposed filter $\left(m_{e x}\right)$. This quantity can be indirectly determined by subtracting the unexposed versapor area density $\left(\rho_{v}\right)$ from the obtained exposed filter area density $\left(\rho_{e x}\right)$ and multiplying by the total exposed area of the filters $\left(A_{\text {filter }}=(3151 \pm 48) \mathrm{cm}^{2}, \mathrm{n}=18\right)$.

$$
\boldsymbol{m}_{A P M, e x}=m_{e x}-m_{v}=\left(\rho_{\text {ex }}-\rho_{v}\right) * A_{\text {filter }}=\left(\frac{m_{\text {piece }}}{A_{\text {piece }}}-\rho_{v}\right) * A_{\text {filter }}
$$

Where $\left(m_{\text {piece }}\right)$ is the mass of the exposed filter piece and $\left(A_{\text {piece }}\right)$ is the output of the photographic area determination procedure. The unexposed filter area density was experimentally determined by weighing pieces of the unexposed material and measuring their area $\left(\rho_{v}=(7.6 \pm 0.2) \mathrm{mg} / \mathrm{cm}^{2}, \mathrm{n}=5\right)$.

The APM concentration in air $\left(C_{A P M, a i r}\right)$ was then calculated according to equation 2. 


$$
\boldsymbol{C}_{A P M, \boldsymbol{a i r}}=\frac{m_{A P M, e x}}{V_{\text {air }}}
$$

Where $\left(V_{\text {air }}\right)$ is the total volume of air that passed through the filter, obtained from the digital flowmeter at the air sampler.

The weight percentage of APM in each exposed filter was determined in order to enable the calculation of the amount of APM in each weighed portion of filters digested for ICP-MS analysis, according to equation 3.

$$
\% \boldsymbol{A P M}=\frac{m_{A P M, e x}}{m_{\text {ex }}} * 100=\frac{m_{A P M, \text { piece }}}{m_{\text {piece }}} * 100=\left(1-\frac{A_{\text {piece }} * \rho_{v}}{m_{\text {piece }}}\right) * 100
$$

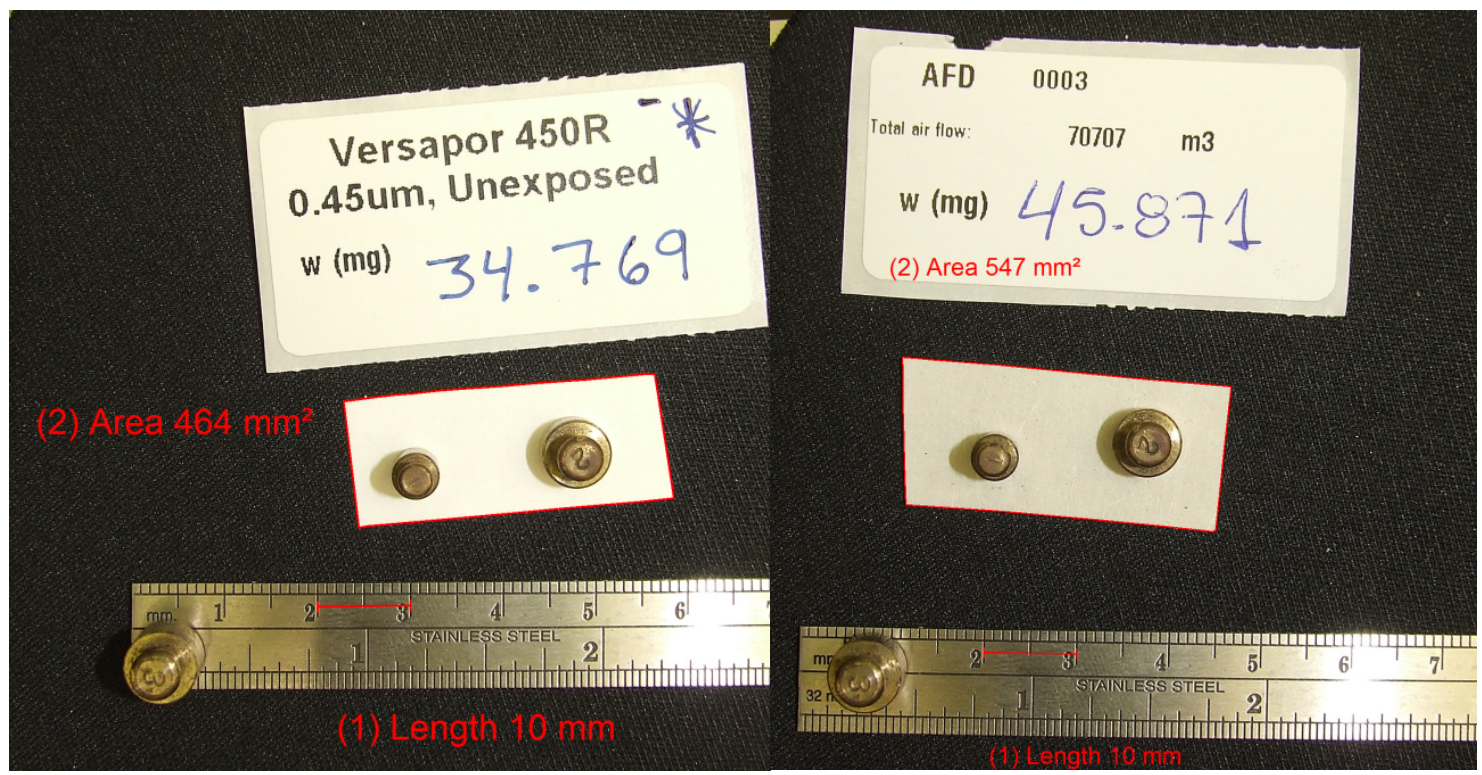

Figure 5.3 Output from the photographic procedure to determine areas of weighed filter pieces. (LEFT) Unexposed filter material. (RIGHT) Exposed filter subsample. This particular sample had an area density of $9.35 \mathrm{mg} / \mathrm{cm}^{2}$, equivalent to $18.6 \% \mathrm{w} / \mathrm{w}$ of APM and a concentration of APM in the filtered air of $34 \mu \mathrm{g} / \mathrm{m}^{3}$. 


\subsubsection{Sample preparation: acid digestion of filter sub-samples}

Filter sub-samples were treated with an acid reflux oxidative digestion procedure, derived from standard digestion procedures for sediments, soil and airborne particulate matter analysis by ICP-MS (methods EPA 3050B and EPA IO-3.1) (USEPA, 1996a, 1999a). This technique dissolves almost all elements in the sample and uses hydrogen peroxide to destroy organic matter that could protect metals from dissolution, including the polymeric filter. Each exposed filter was digested by duplicate.

A piece of approx. $4 \mathrm{~cm} \times 10 \mathrm{~cm}$ of each filter was cut out and shredded using acid-cleaned ceramic scissors. The shredded filter subsample was collected in a certified clean, disposable digestion vessel and weighed to the $\pm 0.1 \mathrm{mg}$. $5 \mathrm{~mL}$ of concentrated nitric acid were added to the samples in the digestion vessels, leaving the samples to react overnight.

The next day samples were subjected to acid reflux by heating at $95^{\circ} \mathrm{C}$ for 1 hour, covering the digestion vessels with a plastic cover. Then, a second $5 \mathrm{~mL}$ portion of concentrated nitric acid was added and heating continued for an additional hour, period after which samples were cooled to room temperature. A $0.5 \mathrm{~mL}$ volume of $30 \% \mathrm{v} / \mathrm{v}$ hydrogen peroxide was added, causing a highly exothermic reaction with effervescence, during which care was taken to prevent mechanical losses of digestates. After the effervescence receded, a second $0.5 \mathrm{~mL}$ volume of hydrogen peroxide was added, and heating resumed for another hour. This procedure was repeated two more times for a total of $3 \mathrm{~mL}$ of $30 \%$ hydrogen peroxide per sample. 
After the last heating period, digestates were cooled down to room temperature, taken to $25 \mathrm{~mL}$ with double deionized water and filtered directly in the digestion vessel with a push-down $0.45 \mu \mathrm{m}$ PTFE filter. The filtered digestates were then analyzed for elemental composition by ICP-MS.

\subsubsection{Analysis of digestates by ICP-MS}

Multi-elemental analysis of filter digestates was performed using three different instrumental methods for majors, trace and REE, which were minor modifications from the USEPA methodologies to analyze acid digestates of soils and filters for ambient particulate matter using ICP-MS (methods EPA 6020A and IO-3.5) (USEPA, 1999b, 2007b).

Acid digestates (or dilutions as needed) were fortified with internal standards and directly aspirated into a cooled nebulizing chamber. The nebulized droplets were carried into the plasma using argon, where a quick ionization of elements occurred. Ions thereby produced were introduced into a quadrupole mass spectrometer operating in scanning mode. Analytes and mass-to-charge rations used for quantification, calibration ranges and instrument detection limits are listed in table 5.2, along with the major spectroscopic interferences and the respective mathematical corrections employed. These corrective equations are listed in several EPA methods for environmental analysis by ICP-MS (USEPA, 1999b, 2007a, 2007b). 
Table 5.2 Elements, interferences, correction equations, calibration ranges and instrument detection limits for the determination of elemental composition of APM by ICP-MS.

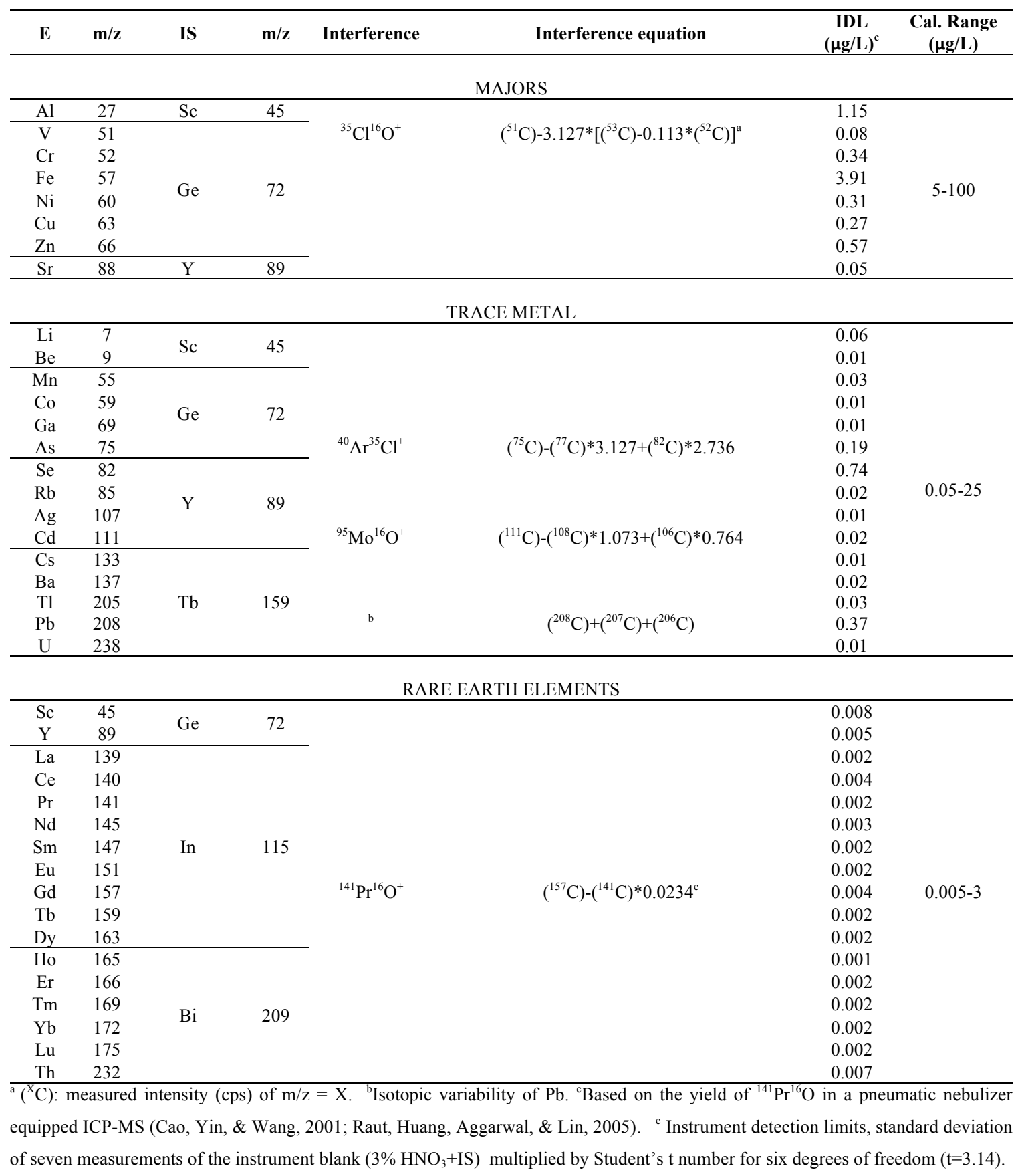




\subsubsection{ICP-MS instrumental parameters}

\section{Sample peristaltic pump}

Pre-analysis steps:

1.- Sample uptake (speed, uptake time): $\quad 0.5 \mathrm{rps}, 30 \mathrm{~s}$

2.- Signal stabilization (speed, stabilization time): $\quad 0.1 \mathrm{rps}, 30 \mathrm{~s}$

Analysis uptake speed: $\quad 0.1 \mathrm{rps}$

Post-analysis steps:

1.- AS probe rinse (speed, uptake time, solution): $\quad 0.5 \mathrm{rps}, 30 \mathrm{~s}, 2 \% \mathrm{HNO}_{3}$

2.- System rinse (speed, uptake time, solution): $\quad 0.5 \mathrm{rps}, 50 \mathrm{~s}, 3 \% \mathrm{HNO}_{3}$

\section{Nebulization}

Nebulizer type:

Nebulizing chamber type:

Nebulizing chamber temperature:

\section{Plasma parameters}

RF Power:

RF matching:

Carrier gas:

Blend gas:

\section{Integration}

Points per mass:

Time per integration point (total time per mass):

Majors:

Trace, REE:

Repetitions per mass:
$1200 \mathrm{~W}$

3

$100 \mathrm{~ms}(300 \mathrm{~ms})$

Babington

Quartz, Scott type

$2{ }^{\circ} \mathrm{C}$

$1.8 \mathrm{~V}$

$1.15 \mathrm{~L} / \mathrm{min}$

0

$200 \mathrm{~ms}(600 \mathrm{~ms})$

3 


\subsubsection{Calculations of elemental concentration in filtered air}

The final output concentration is calculated by considering the contribution of the unexposed filter to the measurement in the exposed filters.

The contribution of the filter (and other uncontrolled element inputs during digestion) can be estimated by digesting a portion of the unexposed filter along with the digested sample batch. A concentration of each element in the unexposed filter $\left(C_{E, v}\right)$ can be obtained by equation 4 :

$$
\boldsymbol{C}_{\boldsymbol{E}, \boldsymbol{v}}=\frac{o_{E, v} * D F * V_{\text {dig, }}}{m_{v^{*}} 1000},\left(\frac{m g_{E}}{k g_{\text {filter }}}\right)
$$

Where $\left(O_{E, v}\right)$ is the ICP-MS output measurement for element E (in $\left.\mu \mathrm{g} / \mathrm{L}\right)$ from the analysis of the unexposed filter digestate, $(D F)$ is the dilution factor applied to the digestate, $\left(V_{\text {dig, },}\right)$ is the total digestate volume (in $\left.\mathrm{mL}\right)$ and $\left(m_{v}\right)$ is the mass (in grams) of unexposed filter weighed to be digested. The mass of element $\mathrm{E}$ in the digestate of exposed filters contributed by the digestion of Versapor ${ }^{\circledR}$ material $\left(m_{E, v}\right)$ can then be calculated by equation 5 :

$$
\begin{gathered}
\boldsymbol{m}_{\boldsymbol{E}, \boldsymbol{v}}=\boldsymbol{C}_{\boldsymbol{E}, \boldsymbol{v}} * m_{v, e x}=\boldsymbol{C}_{\boldsymbol{E}, \boldsymbol{v}} *\left(m_{e x}-m_{A P M}\right) \\
=\boldsymbol{C}_{\boldsymbol{E}, \boldsymbol{v}} *\left[m_{e x}-m_{e x} * \frac{\% A P M}{100}\right]=\boldsymbol{C}_{\boldsymbol{E}, \boldsymbol{v}} * m_{e x}(1-0.01 * \% \mathrm{APM}),\left(m g_{E}\right)
\end{gathered}
$$

Where $\left(m_{v, e x}\right)$ is the mass of Versapor ${ }^{\circledR}$ in the exposed filter, $\left(m_{e x}\right)$ is the total mass of exposed filter weighed for digestion (in $\mathrm{kg}),\left(m_{A P M}\right)$ is the mass in $\mathrm{kg}$ of airborne particulate matter in the digested exposed filter sub-sample and (\%APM) is the percentage of APM in the exposed filter (see section 5.4.1). The concentration of element 
$\mathrm{E}$ in the $\mathrm{APM}\left(C_{E, A P M}\right)$ is equal to the ratio of the mass of $\mathrm{E}$ in the digestate produced by the digestion of APM $\left(m_{E, A P M}\right)$ and the mass of APM in the digested filter and can then be calculated by equation 6 :

$$
\boldsymbol{C}_{\boldsymbol{E}, \boldsymbol{A P M}}=\frac{m_{E, A P M}}{m_{A P M}}(6)
$$

The total mass of element $E$ dissolved in the digestate $\left(m_{E, \text { dig }}\right)$ can be directly obtained from the ICP-MS measurements and is equal to the sum of the mass contributed by the APM $\left(m_{E, A P M}\right)$ and the versapor filter $\left(m_{E, v}\right)$.

$$
\boldsymbol{m}_{\boldsymbol{E}, \boldsymbol{d i g}}=m_{E, A P M}+m_{E, v}
$$

Therefore, combining equations 5, 6 and 7 yields the concentration of element $\mathrm{E}$ in the airborne particulate matter (equation 8) with measurable variables:

$$
\begin{gathered}
\boldsymbol{C}_{\boldsymbol{E}, \boldsymbol{A P M}}=\frac{m_{E, \text { dig }}-m_{E, v}}{m_{A P M}} \\
=\left(\frac{100}{m_{e x} * \% A P M}\right) *\left[O_{E, e x} * D F * V_{d i g, e x} * 10^{-6}-\boldsymbol{C}_{E, v} * m_{e x}(1-0.01 * \% \mathrm{APM})\right],\left(\frac{m g_{E}}{k g_{A P M}}\right)
\end{gathered}
$$

Where $\left(O_{E, e x}\right)$ is the ICP-MS output measurement for element $\mathrm{E}($ in $\mu \mathrm{g} / \mathrm{L})$ from the analysis of the exposed filter digestate, $\left(V_{\text {dig,ex }}\right)$ is the final volume (in $\mathrm{mL}$ ) of the digestate of exposed filter and $\left(10^{-6}\right)$ is an unit conversion factor. The concentration of element $\mathrm{E}$ in the filtered air $\left(C_{E, \text { air }}\right)$ can be obtained by multiplying the concentration of element $\mathrm{E}$ in the APM by the concentration of APM in air $\left(C_{A P M, \text { air }}\right.$, in $\left.\mu \mathrm{g} / \mathrm{m}^{3}\right)$, obtained by the procedure outlined in section 5.4.1 (equation 8 ).

$$
\boldsymbol{C}_{E, \text { air }}=\boldsymbol{C}_{E, A P M} * \boldsymbol{C}_{A P M, a i r},\left(\frac{p g_{E}}{m_{\text {air }}^{3}}\right)
$$




\subsection{Results and discussion}

\subsubsection{Determination of filter APM load}

The determination of filter APM load is a critical step since concentrations of elements in air are calculated with this parameter. The APM load is usually determined with a gravimetric procedure, weighing the filters in reproducible conditions of temperature and relative humidity before and after APM collection (Rodriguez, Alastuey, \& Querol, 2012).

The procedure employed by Arroyo-Mora to determine the APM contents in the filter collected by FIU-EARL involved folding the filters into an open plastic container and weighing by difference to the $\pm 0.1 \mathrm{mg}$ (Arroyo-Mora, 2009). In the present work, it was observed that around $400 \mathrm{~min}$ (ca. 7 hours) were required to attain a constant weight of a whole filter, probably because trapped air inside the folded filter causes an increased apparent weight and is slowly released with time (see figure 5.4). This procedure is not practical and if the proper equilibration time is not allowed severe errors on the gravimetric analysis will occur yielding erroneous estimations on APM contents.

To overcome this challenge, an alternative approach was developed based on the photographic determination of the area of a small filter subsample after gravimetric analysis to the $\pm 0.001 \mathrm{mg}$, which required almost no balance equilibration time. This procedure is described in section 5.6.1 and the output of the photographic determination of filter APM load is presented in table 5.3. 
Table 5.3 Filter data and determination of APM load (see section 5.6.1).

\begin{tabular}{|c|c|c|c|c|c|c|c|c|}
\hline \multicolumn{3}{|c|}{ Filter Data } & \multicolumn{6}{|c|}{ Determination of APM load } \\
\hline Start & End & $\begin{array}{c}\text { Total } \\
\text { air }\left(\mathrm{m}^{3}\right)\end{array}$ & $\begin{array}{c}m_{\text {piece }} \\
(\mathrm{mg})\end{array}$ & $\begin{array}{c}A_{\text {piece }} \\
\left(\mathrm{mm}^{2}\right)\end{array}$ & $\begin{array}{c}\rho_{e x} \\
\left(\mathrm{mg} / \mathrm{cm}^{2}\right)\end{array}$ & $\begin{array}{c}m_{\text {APM,piece }} \\
(\mathrm{mg})\end{array}$ & $\begin{array}{c}\% \\
\text { APM } \\
\end{array}$ & $\begin{array}{l}C_{A M P, \text { air }} \\
\left(\mu \mathrm{g} / \mathrm{m}^{3}\right) \\
\end{array}$ \\
\hline $8 / 15 / 2005$ & $8 / 23 / 2005$ & 25887 & 32.949 & 327 & 10.08 & 8.03 & 24.4 & 299 \\
\hline $8 / 23 / 2005$ & $8 / 30 / 2005$ & 16068 & 34.552 & 370 & 9.34 & 6.36 & 18.4 & 337 \\
\hline $8 / 30 / 2005$ & $9 / 8 / 2005$ & 23967 & 45.130 & 503 & 8.97 & 6.80 & 15.1 & 178 \\
\hline 9/8/2005 & 9/19/2005 & 30616 & 44.985 & 467 & 9.63 & 9.40 & 20.9 & 207 \\
\hline $9 / 19 / 2005$ & $10 / 12 / 2005$ & 28496 & 42.423 & 412 & 10.30 & 11.03 & 26.0 & 296 \\
\hline $12 / 21 / 2005$ & $12 / 28 / 2005$ & 15496 & 53.604 & 551 & 9.73 & 11.62 & 21.7 & 429 \\
\hline $12 / 28 / 2005$ & $1 / 18 / 2006$ & 60769 & 41.965 & 499 & 8.41 & 3.94 & 9.4 & 41 \\
\hline $1 / 18 / 2006$ & $1 / 25 / 2006$ & 19432 & 30.578 & 308 & 9.93 & 7.11 & 23.2 & 374 \\
\hline $1 / 25 / 2006$ & $2 / 6 / 2006$ & 32784 & 33.236 & 359 & 9.26 & 5.88 & 17.7 & 157 \\
\hline $2 / 6 / 2006$ & $2 / 10 / 2006$ & 11030 & 54.279 & 572 & 9.49 & 10.69 & 19.7 & 534 \\
\hline $2 / 10 / 2006$ & $2 / 15 / 2006$ & 13878 & 41.387 & 489 & 8.46 & 4.13 & 10.0 & 192 \\
\hline $2 / 15 / 2006$ & $2 / 22 / 2006$ & 19435 & 56.959 & 608 & 9.37 & 10.63 & 18.7 & 283 \\
\hline $2 / 22 / 2006$ & $3 / 1 / 2006$ & 19833 & 39.565 & 412 & 9.60 & 8.17 & 20.7 & 315 \\
\hline $3 / 1 / 2006$ & $3 / 8 / 2006$ & 19458 & 58.520 & 568 & 10.30 & 15.24 & 26.0 & 434 \\
\hline $3 / 8 / 2006$ & $3 / 16 / 2006$ & 21852 & 60.952 & 668 & 9.12 & 10.05 & 16.5 & 217 \\
\hline $3 / 16 / 2006$ & $3 / 30 / 2006$ & 43820 & 54.431 & 552 & 9.86 & 12.37 & 22.7 & 161 \\
\hline $3 / 30 / 2006$ & $4 / 17 / 2006$ & 39789 & 81.684 & 735 & 11.11 & 25.68 & 31.4 & 277 \\
\hline $4 / 17 / 2006$ & $4 / 24 / 2006$ & 38204 & 48.877 & 546 & 8.95 & 7.27 & 14.9 & 110 \\
\hline $4 / 24 / 2006$ & $5 / 1 / 2006$ & 29857 & 57.010 & 611 & 9.33 & 10.45 & 18.3 & 181 \\
\hline $5 / 1 / 2006$ & $5 / 25 / 2006$ & 55889 & 46.226 & 440 & 10.51 & 12.70 & 27.5 & 163 \\
\hline $5 / 25 / 2006$ & $6 / 8 / 2006$ & 41633 & 57.999 & 607 & 9.56 & 11.75 & 20.3 & 146 \\
\hline $6 / 8 / 2006$ & $6 / 20 / 2006$ & 33818 & 48.647 & 472 & 10.31 & 12.68 & 26.1 & 250 \\
\hline $6 / 20 / 2006$ & $6 / 30 / 2006$ & 28147 & 64.541 & 627 & 10.29 & 16.76 & 26.0 & 299 \\
\hline $6 / 30 / 2006$ & $7 / 12 / 2006$ & 16136 & 62.878 & 670 & 9.38 & 11.82 & 18.8 & 345 \\
\hline $7 / 12 / 2006$ & $7 / 23 / 2006$ & 33479 & 41.797 & 463 & 9.03 & 6.52 & 15.6 & 132 \\
\hline $7 / 23 / 2006$ & $8 / 5 / 2006$ & 40182 & 66.833 & 746 & 8.96 & 9.99 & 14.9 & 105 \\
\hline $8 / 5 / 2006$ & $8 / 13 / 2006$ & 21801 & 47.747 & 489 & 9.76 & 10.49 & 22.0 & 310 \\
\hline $8 / 13 / 2006$ & $8 / 25 / 2006$ & 33186 & 60.639 & 600 & 10.11 & 14.92 & 24.6 & 236 \\
\hline $8 / 25 / 2006$ & $10 / 10 / 2006$ & 127080 & 65.138 & 634 & 10.27 & 16.83 & 25.8 & 66 \\
\hline $10 / 11 / 2006$ & $10 / 24 / 2006$ & 35967 & 63.327 & 691 & 9.16 & 10.67 & 16.9 & 135 \\
\hline $12 / 10 / 2007$ & $3 / 3 / 2008$ & 144450 & 57.878 & 576 & 10.05 & 13.99 & 24.2 & 53 \\
\hline $3 / 3 / 2008$ & $4 / 3 / 2008$ & 84079 & 44.436 & 549 & 8.09 & 2.60 & 5.9 & 18 \\
\hline $4 / 3 / 2008$ & $5 / 2 / 2008$ & 70707 & 45.871 & 547 & 8.39 & 4.19 & 9.1 & 34 \\
\hline $5 / 2 / 2008$ & $7 / 9 / 2008$ & 180397 & 59.229 & 647 & 9.15 & 9.93 & 16.8 & 27 \\
\hline 7/9/2008 & 8/18/2008 & 109247 & 45.649 & 517 & 8.83 & 6.25 & 13.7 & 35 \\
\hline 8/18/2008 & 11/7/2008 & 192848 & 47.772 & 578 & 8.27 & 3.73 & 7.8 & 11 \\
\hline $11 / 7 / 2008$ & $2 / 4 / 2009$ & 198915 & 43.162 & 509 & 8.48 & 4.38 & 10.1 & 14 \\
\hline $2 / 4 / 2009$ & $3 / 19 / 2009$ & 112023 & 39.891 & 503 & 7.93 & 1.56 & 3.9 & 9 \\
\hline 3/19/2009 & $4 / 22 / 2009$ & 79978 & 49.641 & 593 & 8.37 & 4.45 & 9.0 & 30 \\
\hline $4 / 22 / 2009$ & $8 / 28 / 2009$ & 275162 & 46.894 & 508 & 9.23 & 8.18 & 17.5 & 18 \\
\hline $8 / 28 / 2009$ & $5 / 10 / 2010$ & 508434 & 58.321 & 661 & 8.82 & 7.95 & 13.6 & 7 \\
\hline $6 / 2 / 2010$ & $6 / 22 / 2010$ & 99465 & 52.829 & 593 & 8.91 & 7.64 & 14.5 & 41 \\
\hline
\end{tabular}




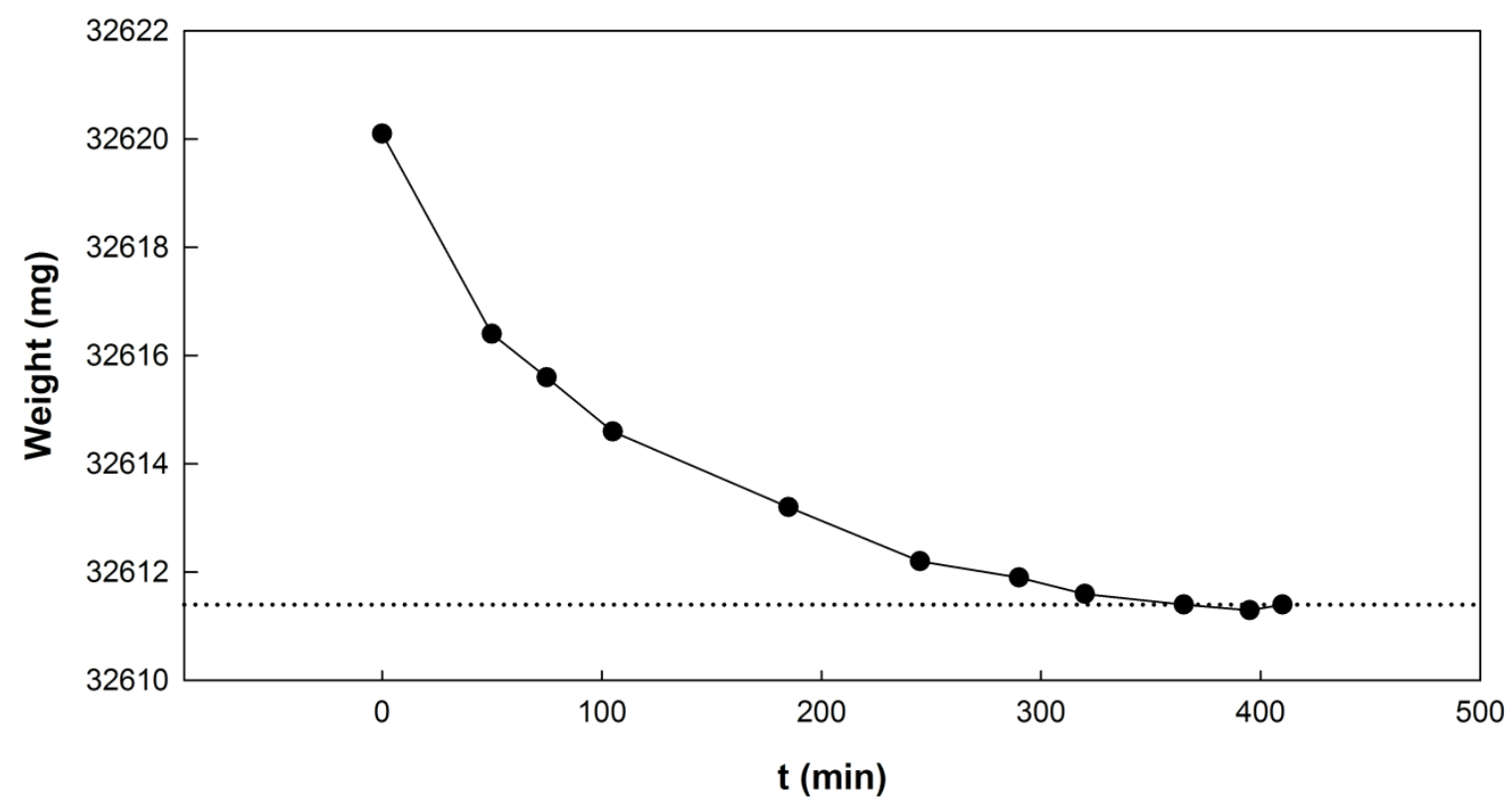

Figure 5.4 Equilibration time required for the weighting of a whole exposed filter (Final recorder weight: $32611.4 \mathrm{mg}$, dotted line).

\subsubsection{Estimation of method detection limits}

Method detection limits (MDLs) were determined by analyzing digestions of unexposed Versapor ${ }^{\circledR}$, subjected to the same analytical process as the exposed filter samples. This procedure accounts for all species introduced during the digestion process, including metallic content of the digestion vessels, filters and reagents. The standard deviation of five filter blank measurements was multiplied by the Student $t$ value $(\mathrm{t}=3.75)$. Method detection limits in terms of $\mathrm{mg}$ of element in $\mathrm{kg}$ of APM are listed in table 5.4. Elements that presented concentrations below the MDL (in term of $\mathrm{mg} / \mathrm{Kg}$ of APM) were considered as non-detected, and therefore do not contribute to the data analysis procedures discussed in the following sections. 
Table 5.4 Analyte concentrations measured in the Versapor filter media and estimated method detection limits. (All concentrations in $\mathrm{mg} / \mathrm{Kg}$ ).

\begin{tabular}{|c|c|c|c|c|}
\hline Element & $\mathbf{m} / \mathbf{z}$ & Filter & SD & MDL \\
\hline \multicolumn{5}{|c|}{ MAJORS } \\
\hline $\mathrm{Al}$ & 27 & 5.1 & 2.0 & 7.5 \\
\hline V & 51 & 0.8 & 0.3 & 1.6 \\
\hline $\mathrm{Cr}$ & 52 & 4.1 & 1.3 & 6.0 \\
\hline $\mathrm{Fe}$ & 57 & 15.9 & 5.8 & 21.8 \\
\hline $\mathrm{Ni}$ & 60 & 1.0 & 0.2 & 1.1 \\
\hline $\mathrm{Cu}$ & 63 & 16.5 & 2.7 & 10.2 \\
\hline $\mathrm{Zn}$ & 66 & 3.3 & 0.7 & 3.2 \\
\hline $\mathrm{Sr}$ & 88 & 0.07 & 0.01 & 0.1 \\
\hline \multicolumn{5}{|c|}{ TRACE METAL } \\
\hline $\mathrm{Li}$ & 7 & 0.024 & 0.018 & 0.12 \\
\hline $\mathrm{Be}$ & 9 & 0 & 0 & 0.01 \\
\hline $\mathrm{Mn}$ & 55 & 0.154 & 0.017 & 0.12 \\
\hline Co & 59 & 0.01 & 0.002 & 0.01 \\
\hline $\mathrm{Ga}$ & 69 & 0.03 & 0.038 & 0.26 \\
\hline As & 75 & 0.08 & 0.06 & 0.40 \\
\hline $\mathrm{Se}$ & 82 & 0.6 & 0.1 & 0.86 \\
\hline $\mathrm{Rb}$ & 85 & 0.05 & 0.06 & 0.40 \\
\hline $\mathrm{Ag}$ & 107 & 0.008 & 0.007 & 0.05 \\
\hline $\mathrm{Cd}$ & 111 & 0.002 & 0.001 & 0.02 \\
\hline Cs & 133 & 0 & 0 & 0.01 \\
\hline $\mathrm{Ba}$ & 137 & 0.08 & 0.01 & 0.09 \\
\hline $\mathrm{Tl}$ & 205 & 0 & 0 & 0.04 \\
\hline $\mathrm{Pb}$ & 208 & 0.076 & 0.003 & 0.39 \\
\hline Th & 232 & 0 & 0 & 0.0072 \\
\hline $\mathrm{U}$ & 238 & 0 & 0 & 0.01 \\
\hline \multicolumn{5}{|c|}{ RARE EARTH ELEMENTS } \\
\hline $\mathrm{Sc}$ & 45 & 0.06 & 0.02 & 0.1 \\
\hline Y & 89 & 0.007 & 0.004 & 0.03 \\
\hline $\mathrm{La}$ & 139 & 0.0018 & 0.0003 & 0.002 \\
\hline $\mathrm{Ce}$ & 140 & 0.0043 & 0.0005 & 0.005 \\
\hline $\operatorname{Pr}$ & 141 & 0.0002 & 0.0002 & 0.003 \\
\hline $\mathrm{Nd}$ & 143 & 0.0030 & 0.0002 & 0.003 \\
\hline $\mathrm{Sm}$ & 147 & 0.24 & 0.01 & 0.08 \\
\hline $\mathrm{Eu}$ & 151 & 0 & 0 & 0.0023 \\
\hline $\mathrm{Gd}$ & 157 & 0 & 0 & 0.004 \\
\hline $\mathrm{Tb}$ & 159 & 0 & 0 & 0.0020 \\
\hline Dy & 163 & 0 & 0 & 0.002 \\
\hline Ho & 165 & 0 & 0 & 0.0015 \\
\hline Er & 166 & 0 & 0 & 0.0021 \\
\hline Tm & 169 & 0 & 0 & 0.00175 \\
\hline $\mathrm{Yb}$ & 174 & 0 & 0 & 0.0019 \\
\hline $\mathrm{Lu}$ & 175 & 0 & 0 & 0.00221 \\
\hline
\end{tabular}




\subsubsection{Enrichment factors}

A simple receptor model to interpret airborne particulate matter data is the calculation of enrichment factor (EFs). Its use is well described in a recent review (Scheuvens et al., 2013). Briefly, the concentrations are compared with the average composition of the Earth Upper Continental Crust (UCC), and elements with large anthropogenic contributions will present high EFs while elements occurring from natural sources (crustal elements) will produce EFs closer to unity. Enrichment factors are calculated according to equation 9 , where $C_{S, E}$ and $C_{U C C, E}$ are the concentrations in the sample and in the UCC for element $\mathrm{E}$ while $C_{s, \text { ref }}$ and $C_{U C C, \text { ref }}$ are the concentrations in the sample and in the UCC of an element considered as crustal reference (usually aluminum is used). Based on this information, EFs were calculated using average upper crustal values found in the literature (Wedepohl, 1995). Results are presented in figure 5.5 .

$$
\boldsymbol{E} \boldsymbol{F}=\frac{C_{s, E} / C_{s, r e f}}{C_{U C C, E} / C_{U C C, \text { ref }}}
$$

The output shows that $\mathrm{Pb}, \mathrm{Zn}, \mathrm{V}, \mathrm{Ni}, \mathrm{Cd}, \mathrm{As}, \mathrm{Cr}$, and $\mathrm{Cu}$ presented the highest EFs, which suggests the presence of important local anthropogenic emissions of APM containing these elements. These results are in agreement with those from Trapp et al. (2010), who observed the highest EFs in these same elements in APM collected at Virginia Key. The EFs observed in that work were lower (maximum EF of $\sim 100$ for Cd), probably caused by the air sampler used, which was set to operate only when winds arrived from the open sea (north-northwest direction), to understand inputs of mineral 
dust arriving from northern Africa. That group attributed the enrichment of these elements to sources within the Miami area and in Virginia Key, also noting that anthropogenic sources in Northern Africa such as pollution from cities in the African Northern Atlantic coast could also contribute to anthropogenic elements in African Dust.

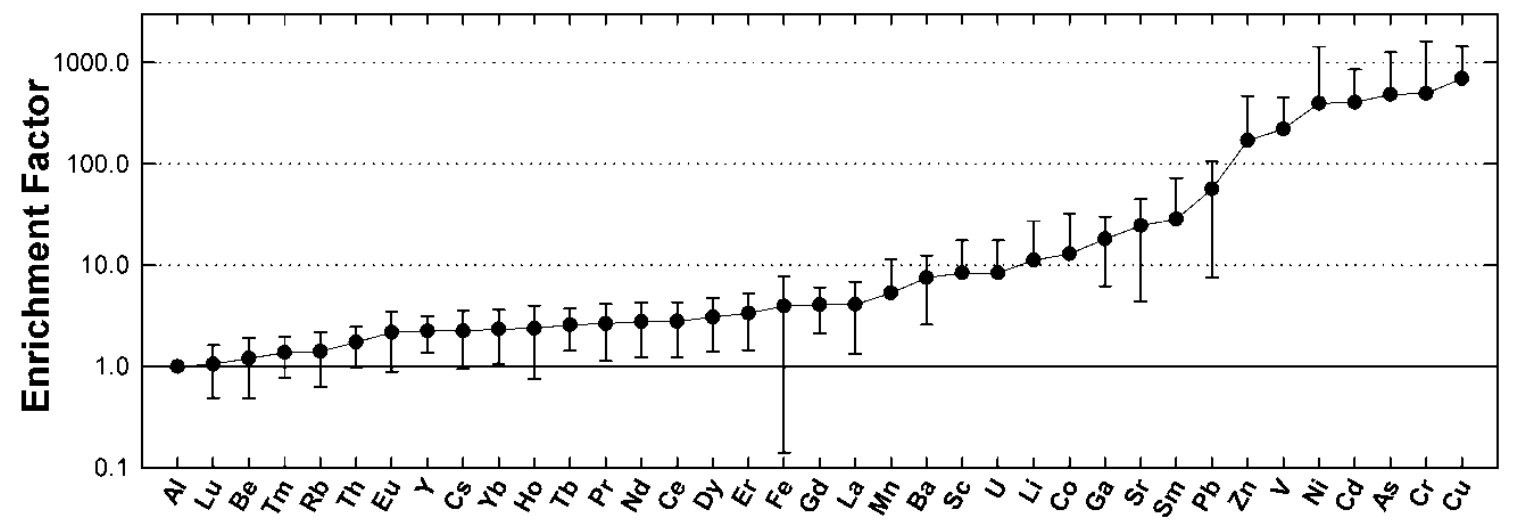

Figure 5.5 Enrichment factors used to identify elements of anthropogenic origin using aluminum as crustal reference.

The observed EFs are also in agreement with other works that collected total suspended particles in coastal urban environments. For example Xia and Gao (2010) reported that $\mathrm{Pb}, \mathrm{Cu}, \mathrm{Zn}$ and $\mathrm{Cd}$ were the most enriched elements (in that order) in APM collected in New Jersey, attributing this enrichments to heavy oil and coal combustion from power plants within the city. 


\subsubsection{Descriptive statistics}

The summary statistics on the collected dataset is presented in table 5.5 and in figure 5.6. The crustal elements $\mathrm{Fe}$ and $\mathrm{Al}$ were in average the most abundant elements, followed by $\mathrm{Cu}, \mathrm{V}, \mathrm{Zn}$ and $\mathrm{Cr}$, elements that presented a high anthropogenic character upon EF analysis (figure 5.5). Other crustal elements such as REEs follow in decreasing average abundance.

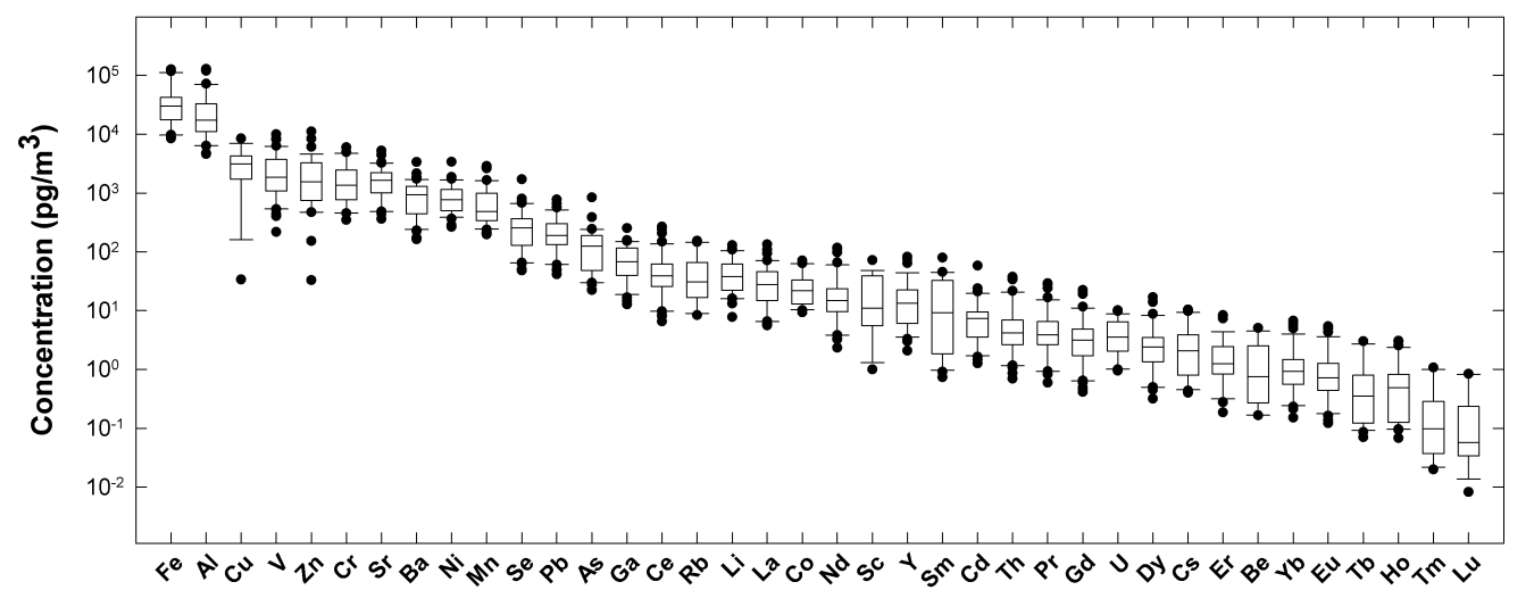

Figure 5.6 Box-plot diagrams of elements measured in the APM collected at Port Everglades, FL, ordered by decreasing mean concentrations.

Maximum concentrations guidelines for airborne metals listed as toxic by the European Union and the USEPA (As, $\mathrm{Ni}, \mathrm{Cd}$ and $\mathrm{Pb}$ ) were 1 to 3 orders of magnitude higher than the concentrations of those elements measured in the total suspended APM collected during the present work. However, the air quality standards are based on thoracic particles $\left(<10 \mu \mathrm{m}\right.$ diameter, or $\left.\mathrm{PM}_{10}\right)$ which are able to enter the respiratory track and become bioaccessible (Brunekreef \& Holgate, 2002), while the data presented in this work was produced from total suspended particles. 
Table 5.5 Summary statistics on the measured elemental concentrations ${ }^{\mathrm{a}}$ of APM collected at Port Everglades, FL, between 2005 and $2010(\mathrm{n}=42)$.

\begin{tabular}{|c|c|c|c|c|c|c|c|c|c|c|}
\hline Element & $\mathrm{AQS}^{\mathbf{b}}$ & MDL $^{\mathrm{e}}$ & $n^{f}$ & Mean & SD & Min. & 0.25 & Median & 0.75 & Max. \\
\hline $\mathrm{Fe}$ & & 3894 & 40 & 38222 & 32019 & 8428 & 17583 & 30234 & 42512 & 126735 \\
\hline $\mathrm{Al}$ & & 1332 & 42 & 28884 & 30873 & 4591 & 11221 & 17436 & 33110 & 128329 \\
\hline $\mathrm{Cu}$ & & 1825 & 18 & 4812 & 1704 & 3485 & 3527 & 4218 & 5774 & 8430 \\
\hline $\mathrm{Cr}$ & & 1066 & 20 & 3196 & 1451 & 1967 & 2233 & 2515 & 4468 & 5957 \\
\hline $\mathrm{Zn}$ & & 569 & 39 & 3036 & 2290 & 949 & 1480 & 2291 & 3827 & 11140 \\
\hline $\mathrm{V}$ & & 277 & 42 & 2916 & 2355 & 531 & 1208 & 1944 & 3767 & 9966 \\
\hline $\mathrm{Sr}$ & & 12 & 42 & 1812 & 1076 & 364 & 1008 & 1647 & 2237 & 5222 \\
\hline $\mathrm{Ba}$ & & 17 & 42 & 996 & 630 & 162 & 445 & 937 & 1302 & 3357 \\
\hline $\mathrm{Ni}$ & $20000^{d}$ & 193 & 34 & 965 & 615 & 364 & 511 & 817 & 1176 & 3392 \\
\hline $\mathrm{Mn}$ & & 21 & 42 & 764 & 663 & 197 & 340 & 487 & 1001 & 2871 \\
\hline $\mathrm{Se}$ & & 153 & 40 & 398 & 299 & 158 & 237 & 297 & 442 & 1709 \\
\hline $\mathrm{Pb}$ & $150000^{c}$ & 70 & 39 & 250 & 176 & 42 & 132 & 190 & 302 & 776 \\
\hline As & $6000^{d}$ & 72 & 30 & 212 & 167 & 86 & 143 & 168 & 214 & 843 \\
\hline $\mathrm{Rb}$ & & 72 & 20 & 132 & 32 & 85 & 99 & 145 & 152 & 153 \\
\hline $\mathrm{Ga}$ & & 47 & 38 & 104 & 43 & 58 & 67 & 101 & 131 & 251 \\
\hline $\mathrm{Ce}$ & & 0.9 & 42 & 57 & 59 & 6.5 & 26 & 39 & 63 & 266 \\
\hline $\mathrm{Li}$ & & 22 & 31 & 55 & 30 & 22.2 & 30 & 48 & 64 & 130 \\
\hline $\mathrm{Sc}$ & & 24 & 17 & 45 & 14 & 34.9 & 37 & 41 & 50 & 72 \\
\hline $\mathrm{Sm}$ & & 15 & 22 & 39 & 17 & 20.1 & 28 & 34 & 45 & 80 \\
\hline $\mathrm{La}$ & & 0.4 & 42 & 35 & 28 & 5.6 & 15 & 28 & 46 & 133 \\
\hline Co & & 2.6 & 18 & 26 & 17 & 9.3 & 13 & 22 & 33 & 71 \\
\hline $\mathrm{Nd}$ & & 0.5 & 42 & 24 & 27 & 2.3 & 9.6 & 15 & 24 & 117 \\
\hline $\mathrm{Y}$ & & 5.3 & 36 & 23 & 20 & 8.4 & 12.1 & 15 & 24 & 82 \\
\hline $\mathrm{Cd}$ & $5000^{\mathrm{d}}$ & 3.5 & 36 & 9.1 & 10 & 1.3 & 3.6 & 7.3 & 9.5 & 58 \\
\hline Th & & 1.3 & 40 & 7.3 & 9.1 & 0.7 & 2.6 & 4.2 & 7.0 & 37 \\
\hline $\operatorname{Pr}$ & & 0.5 & 42 & 6.1 & 6.7 & 0.6 & 2.7 & 3.9 & 6.5 & 29 \\
\hline $\mathrm{Gd}$ & & 0.8 & 41 & 4.8 & 5.3 & 0.6 & 1.8 & 3.2 & 5.0 & 22 \\
\hline $\mathrm{U}$ & & 2.5 & 34 & 4.4 & 2.7 & 0.9 & 2.1 & 3.6 & 6.4 & 10 \\
\hline Dy & & 0.4 & 41 & 3.5 & 3.9 & 0.3 & 1.4 & 2.4 & 3.5 & 17 \\
\hline Cs & & 2.6 & 24 & 3.0 & 2.9 & 0.4 & 0.8 & 2.1 & 3.9 & 10 \\
\hline Er & & 0.4 & 39 & 1.9 & 2.0 & 0.2 & 0.8 & 1.3 & 2.5 & 8.4 \\
\hline $\mathrm{Be}$ & & 2.3 & 18 & 1.5 & 1.7 & 0.2 & 0.3 & 0.8 & 2.5 & 5.0 \\
\hline $\mathrm{Yb}$ & & 0.3 & 34 & 1.4 & 1.6 & 0.2 & 0.6 & 0.9 & 1.5 & 6.7 \\
\hline $\mathrm{Eu}$ & & 0.4 & 34 & 1.2 & 1.3 & 0.14 & 0.5 & 0.7 & 1.3 & 5.4 \\
\hline $\mathrm{Tb}$ & & 0.4 & 27 & 0.9 & 0.9 & 0.15 & 0.3 & 0.5 & 1.1 & 3.0 \\
\hline Но & & 0.3 & 31 & 0.8 & 0.8 & 0.12 & 0.3 & 0.5 & 0.9 & 3.1 \\
\hline $\mathrm{Tm}$ & & 0.3 & 17 & 0.6 & 0.4 & 0.17 & 0.2 & 0.6 & 1.0 & 1.1 \\
\hline $\mathrm{Lu}$ & & 0.4 & 16 & 0.5 & 0.3 & 0.15 & 0.2 & 0.7 & 0.8 & 0.8 \\
\hline $\begin{array}{c}\text { Total APM } \\
\left(\times 10^{6}\right) \\
\end{array}$ & & - & & 180 & 135 & 7 & 40 & 171 & 299 & 434 \\
\hline
\end{tabular}

${ }^{\mathrm{a}}$ Concentration units are $\mathrm{pg} / \mathrm{m}^{3} .{ }^{\mathrm{b}}$ Current Air Quality Standards (PM 10 based). ${ }^{\mathrm{c}}$ USEPA (2012). ${ }^{\mathrm{d}} \mathrm{EU}(2012)$. ${ }^{\mathrm{e}}$ Conversion from mass MDLs listed in table 5.4, calculated using the average APM concentration in the whole dataset $\left(180 \mu \mathrm{g} / \mathrm{m}^{3}\right) .{ }^{\mathrm{f}}$ Number of samples above MDL. 
To gain information on the particle size distribution of the collected APM, a digital microscope was employed to view the exposed filter media surface, and representative examples are presented in figure 5.7. The change in filter coloration after exposure may suggest accumulation of fine particles. Since many particles were visually recognized and measured to sizes starting at $5 \mu \mathrm{m}$, it could be proposed that thoracic particles may be an important fraction of the collected APM. However, as discussed below, the low concentrations of toxic metals in the collected APM may not be an evidence of good air quality for public health.

The occurrence of coarse crystalline particles, possibly marine spray, was observed. Marine spray particles are produced at sizes ranging from a few nanometers to hundreds of micrometers when seawater waves break against the shoreline (de Leeuw et al., 2011). Since the air sampler was located very near the water it is possible that marine spray particles could have been continuously aspirated, and species such as sodium chloride and other marine salts that are not representative of APM depositions could be present in high quantities in the filters. A high amount of marine spray particles would increase the APM load of the filters which was determined gravimetrically (section 5.6.1) and thus would decrease the calculated concentrations of airborne toxic elements that deposited with fine particles on the sampling site.

Therefore, the concentrations of toxic elements in thoracic particles could be higher than reflected by this dataset, and further research is required to correctly establish the threat of toxic airborne metals to public health in the area. 

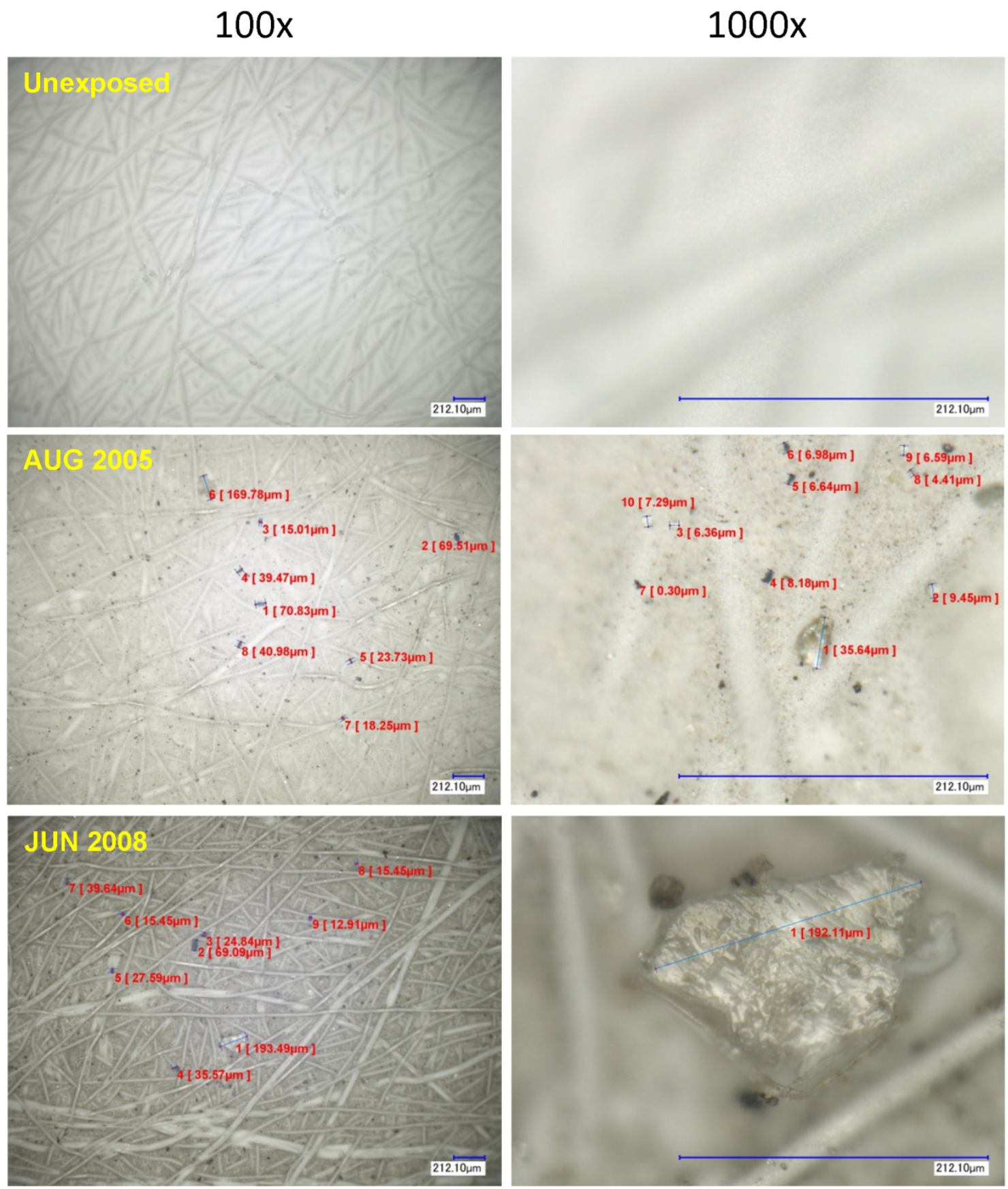

Figure 5.7 Digital microscope images of Versapor $^{\circledR}$ filters before and after APM collection at Port Everglades, FL. 


\subsubsection{Identification of APM sources}

The obtained data was analyzed using principal component analysis (PCA) and the UNMIX software provided by the USEPA, according to the methodology described by Song et al. (2006). PCA was performed on the correlation matrix (presented in appendix 3). Five factors were admitted based on the eigenvalue rule $(>1)$, which describe $89 \%$ of the variance observed in the dataset. Varimax rotation was applied on the obtained factors to simplify data interpretation. For the UNMIX model, the most abundant elements were selected according to the descriptive statistics output $(\mathrm{Fe}, \mathrm{Al}, \mathrm{V}$, $\mathrm{Zn}, \mathrm{Sr}$ ), along with the total APM concentration in air. The software was asked to identify initial species that would produce a solution. Then, additional species were added to the model in order of importance to compare with the PCA output, until the software could not identify a feasible solution.

Results are summarized in table 5.6 and the UNMIX output is graphically observed in figure 5.8. Results show that the UNMIX and the PCA outputs had a similar data structuration, except that UNMIX only identified four sources versus the five factors identified by PCA. Crustal elements such as Al, Fe and Mn presented strong loadings in factor number one (F1), along with all of the REEs. Source 1 (S1) from the UNMIX model strongly agrees with F1 in the PCA model. Therefore, this dataset suggests that F1 is probably the result of contributions by geological material such as mineral dust from North Africa and trace metal contributions from marine aerosol. 
Table 5.6 Comparison of factor loadings obtained using PCA and source contributions (\%) obtained using UNMIX. Similarities between both models are highlighted using colors. (Loadings $>0.5$ are bolded and $<0.2$ are faded. For UNMIX: $>50 \%$ contributions are bolded, $<10 \%$ faded).

\begin{tabular}{|c|c|c|c|c|c|c|c|c|c|c|}
\hline Element & F1 & F2 & F3 & F4 & F5 & Element & S1 & S2 & S3 & S4 \\
\hline $\mathrm{Th}$ & 0.98 & 0.10 & 0.04 & 0.09 & 0.00 & $\mathrm{Th}$ & 81 & 6 & 0 & 13 \\
\hline $\mathrm{Nd}$ & 0.98 & 0.14 & 0.10 & 0.08 & -0.04 & & & & & \\
\hline $\mathrm{Eu}$ & 0.98 & 0.03 & 0.04 & 0.17 & 0.04 & & & & & \\
\hline $\mathrm{Al}$ & 0.97 & 0.08 & 0.01 & -0.09 & 0.06 & $\mathrm{Al}$ & 63 & 14 & 0 & 23 \\
\hline $\mathrm{Gd}$ & 0.97 & 0.18 & 0.09 & 0.05 & -0.03 & & & & & \\
\hline $\mathrm{Yb}$ & 0.97 & 0.04 & -0.01 & 0.19 & 0.01 & & & & & \\
\hline Dy & 0.97 & 0.17 & 0.08 & 0.09 & -0.01 & & & & & \\
\hline $\operatorname{Pr}$ & 0.97 & 0.16 & 0.11 & 0.06 & -0.04 & & & & & \\
\hline $\mathrm{Er}$ & 0.97 & 0.14 & 0.06 & 0.13 & 0.00 & & & & & \\
\hline Ho & 0.97 & -0.03 & 0.00 & 0.20 & -0.02 & & & & & \\
\hline $\mathrm{Ce}$ & 0.96 & 0.21 & 0.13 & 0.02 & -0.04 & & & & & \\
\hline $\mathrm{Tb}$ & 0.95 & 0.00 & -0.03 & 0.19 & -0.12 & & & & & \\
\hline Y & 0.95 & 0.22 & -0.09 & -0.08 & -0.09 & $\mathrm{Y}$ & 68 & 23 & 0 & 9 \\
\hline $\mathrm{Mn}$ & 0.94 & 0.24 & 0.04 & 0.09 & 0.13 & $\mathrm{Mn}$ & 58 & 13 & 0 & 29 \\
\hline $\mathrm{Tm}$ & 0.91 & -0.04 & -0.22 & 0.09 & -0.08 & & & & & \\
\hline $\mathrm{Lu}$ & 0.90 & -0.01 & -0.24 & 0.08 & -0.10 & & & & & \\
\hline $\mathrm{Be}$ & 0.88 & -0.02 & -0.27 & -0.01 & -0.13 & & & & & \\
\hline $\mathrm{Fe}$ & 0.87 & 0.32 & -0.02 & -0.21 & 0.16 & $\mathrm{Fe}$ & 45 & 23 & 0 & 32 \\
\hline $\mathrm{La}$ & 0.85 & 0.42 & 0.17 & -0.07 & -0.07 & $\mathrm{La}$ & 52 & 39 & 0 & 9 \\
\hline $\mathrm{Co}$ & 0.85 & 0.29 & -0.01 & -0.03 & 0.29 & $\mathrm{Co}$ & 42 & 16 & 0 & 41 \\
\hline $\mathrm{Cs}$ & 0.83 & 0.09 & -0.30 & 0.22 & -0.13 & $\mathrm{Cs}$ & 94 & 0 & 0 & 6 \\
\hline $\mathrm{Rb}$ & 0.80 & 0.02 & -0.29 & 0.26 & -0.10 & & & & & \\
\hline $\mathrm{Sc}$ & 0.77 & -0.14 & -0.29 & -0.05 & -0.19 & & & & & \\
\hline $\mathrm{Li}$ & 0.72 & -0.05 & 0.02 & 0.46 & -0.07 & $\mathrm{Li}$ & 71 & 0 & 21 & 7 \\
\hline As & 0.52 & 0.08 & 0.03 & 0.71 & -0.04 & As & 46 & 0 & 54 & 0 \\
\hline $\mathrm{Pb}$ & -0.03 & 0.85 & 0.20 & 0.27 & 0.20 & $\mathrm{~Pb}$ & 1 & 49 & 14 & 36 \\
\hline $\mathrm{Ba}$ & 0.32 & 0.81 & 0.24 & -0.24 & 0.00 & $\mathrm{Ba}$ & 22 & 57 & 0 & 21 \\
\hline $\mathrm{U}$ & 0.42 & 0.81 & -0.20 & 0.19 & 0.14 & $\mathrm{U}$ & 30 & 30 & 0 & 40 \\
\hline $\mathrm{Sr}$ & 0.18 & 0.74 & 0.16 & 0.47 & -0.09 & $\mathrm{Sr}$ & 21 & 44 & 22 & 13 \\
\hline $\mathrm{Ga}$ & 0.40 & 0.73 & 0.25 & -0.38 & -0.09 & $\mathrm{Ga}$ & 26 & 62 & 0 & 12 \\
\hline $\mathrm{V}$ & -0.16 & 0.71 & 0.34 & -0.04 & 0.23 & V & 0 & 61 & 3 & 36 \\
\hline $\mathrm{Cd}$ & -0.11 & 0.28 & 0.78 & -0.07 & -0.11 & $\mathrm{Cd}$ & 0 & 55 & 45 & 0 \\
\hline $\mathrm{Zn}$ & -0.01 & 0.21 & 0.72 & 0.14 & 0.10 & $\mathrm{Zn}$ & 0 & 55 & 45 & 0 \\
\hline $\mathrm{Cu}$ & 0.06 & 0.15 & 0.61 & 0.66 & 0.21 & $\mathrm{Cu}$ & 0 & 0 & 100 & 0 \\
\hline $\mathrm{Cr}$ & -0.01 & 0.02 & 0.09 & 0.14 & 0.93 & $\mathrm{Cr}$ & 0 & 0 & 4 & 96 \\
\hline $\mathrm{Ni}$ & -0.15 & 0.48 & -0.05 & -0.20 & 0.79 & $\mathrm{Ni}$ & 0 & 16 & 0 & 84 \\
\hline Eigenvalue & 22 & 3 & 2 & 2 & 1 & APM & 7 & 62 & 29 & 2 \\
\hline$\%$ Var. & 58 & 13 & 7 & 6 & 5 & & & & & \\
\hline Cum. \% Var. & 58 & 71 & 78 & 84 & 89 & & & & & \\
\hline
\end{tabular}




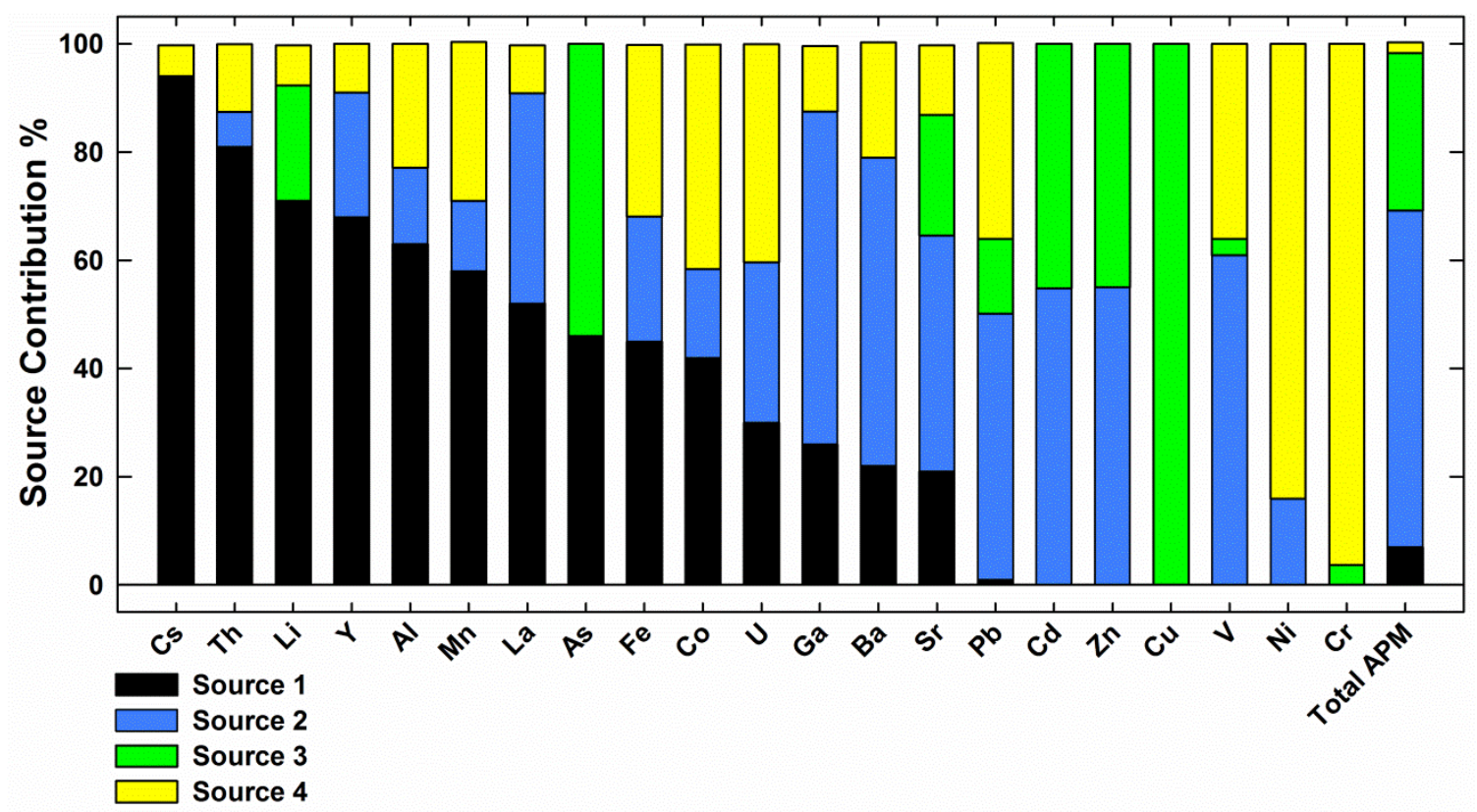

Figure 5.8 Contributions to individual elements in the APM collected at Port Everglades by each of the sources identified by the UNMIX statistical model.

Temporal analysis of elements selected from F1/S1 shows that this group in fact is influenced by African dust. As can be observed in figure 5.9, the concentrations of Fe, $\mathrm{Al}$ and the sum of REEs (except for Sm and La which were identified as slightly enriched in the EF analysis, section 5.7.3) were similar throughout 2006 except for the summer months of July-September. Those months are usually associated with the arrival of mineral dust from Northern Africa (Trapp et al., 2010), and dust events are clearly visible in figure 5.9 as sharp increases in the air concentration of those elements. 


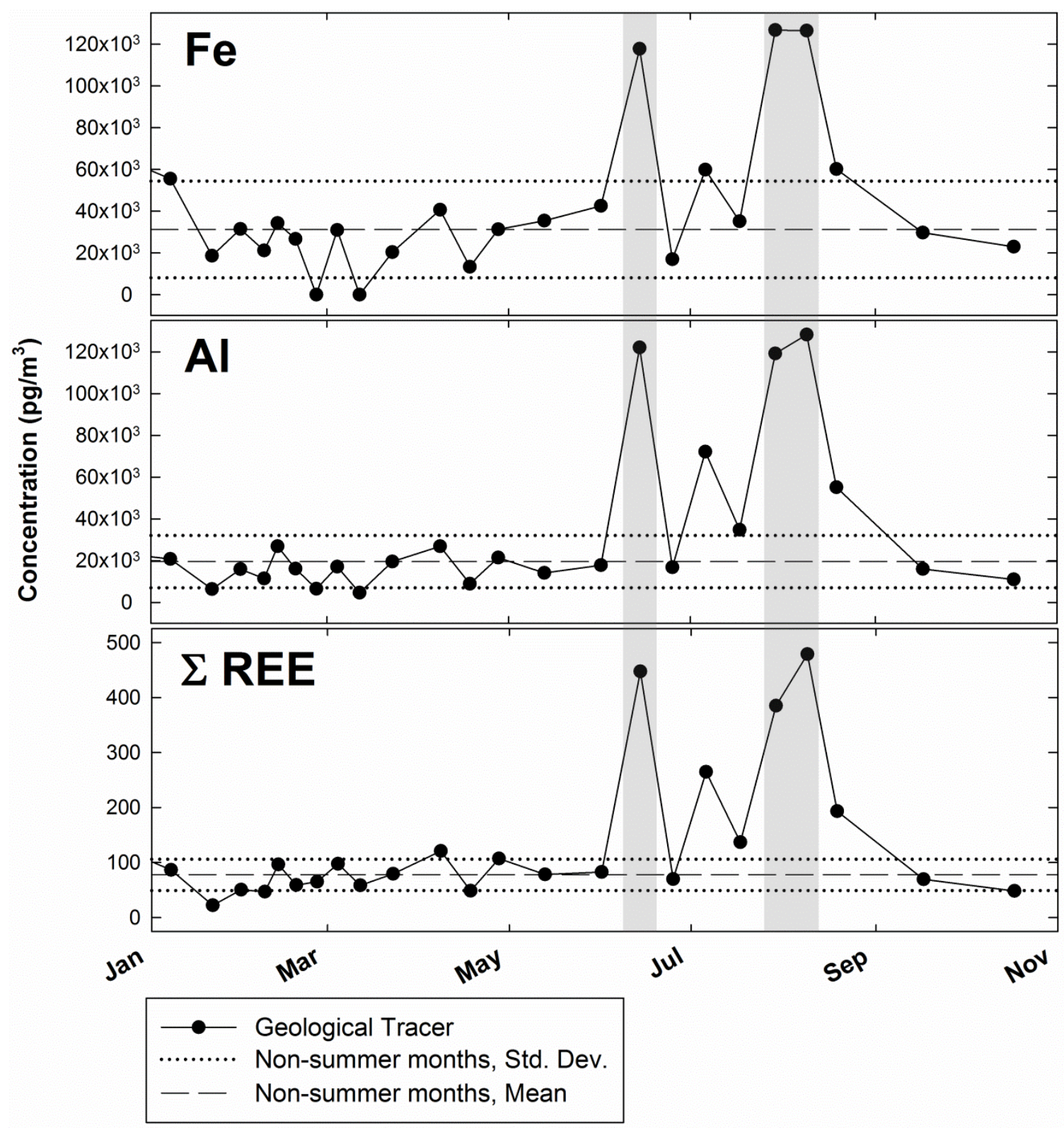

Figure 5.9 Concentrations of tracers of geological material measured in APM samples collected in 2006. African Dust events are highlighted with shaded areas. (Sm and La were excluded from the REEs as they present anthropogenic enrichment in the EF analysis, section 5.7.3).

These results suggest that the sum of REEs can also be employed as a proxy to detect events of airborne African Dust arriving to the local environment. The variability 
on the concentrations in non-summer months seems to be lower for REEs than for Fe or Al, which may be useful in order to identify African dust events more clearly. Additionally, these results demonstrate that African dust events can be readily identified using an omnidirectional sampler as the one used in this study, without interferences from local anthropogenic sources from the Miami area. Temporal analysis of REEs also confirms the observations by Arroyo-Mora, who used $\mathrm{Al}$ and $\mathrm{Fe}$ as mineral dust proxies for the same year (Arroyo-Mora, 2009).

Regarding other APM sources, Ni and V have been described before as indicators of fossil fuel combustion and petrochemical processes (Celo \& Dabek-Zlotorzynska, 2011; Querol et al., 2007). Ni and V presented loadings on F2 and F5, although not in the same proportion. Ni loaded strongly on F5 and UNMIX shows that S4 contributes to $84 \%$ of that element, while V load strongly on F2 and UNMIX presents a contribution of $61 \%$ by S2. This observation suggests that the collected APM has contributions from at least two distinct sources of fossil fuel-related emissions in the area.

Figure 5.10 presents the location of the air sampler relative to possible fossil fuel emission sources. Port Everglades has three main terminals for large, diesel-powered vessels (cargo ships, oil tankers and cruise ships) all within $3 \mathrm{~km}$ of the sampler. There is also the Oil-fired Port Everglades Electricity Plant $(2 \mathrm{~km})$ and the Fort Lauderdale International Airport (ca. $5 \mathrm{~km}$ ) surrounded by a large highway system. Thus, emissions from marine commercial vessels, the Port Everglades Power Plant, gasoline vehicles and aircrafts are potential fossil fuel related sources. 


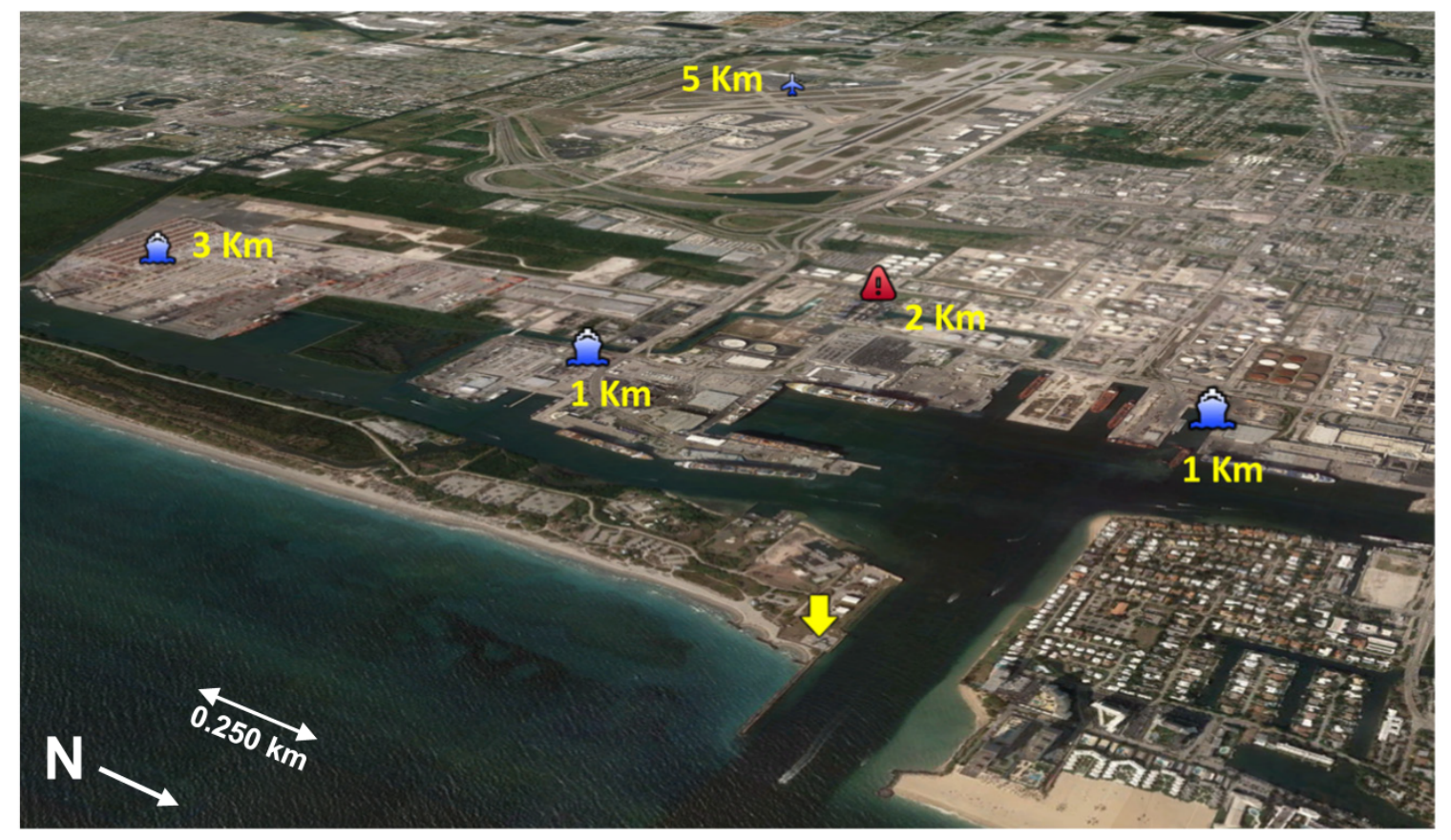

Figure 5.10 Location of the air sampler (yellow arrow) relative to the three docks of Port Everglades, FLL and the Port Everglades Power Station (red icon).

Table 5.7 summarizes the estimated Broward County emissions of selected airborne metals, obtained from the 2008 National Emissions Inventory (USEPA, 2013a). According to those figures, $97 \%$ of $\mathrm{Ni}$, the metal emitted in highest quantity, is originated from commercial marine vessels. Since Ni loadings are strong for F5 and also UNMIX shows an $84 \%$ contribution from S4, the combination of the measurements and the USEPA estimates suggests that F5/S4 is the contribution from shipping activities at Port Everglades. Further evidence is provided by $\mathrm{Cr}$, which has an even stronger loading on F5 and a $96 \%$ contribution from S4, which is also consistent with the USEPA estimates of $68 \%$ of emissions from commercial vessels. Since F5/S4 probably represents APM emissions from marine commercial vessels arriving or leaving Port Everglades, F2/S2 possibly represents the nearby Fort Lauderdale Electricity Plant which is oil-fired. The 
identification is reinforced by the relative large contribution of S2 to La and the loading of that element on F2 in the PCA model, as the occurrence of La in APM emitted from oil-fired electricity plants has been reported before (Olmez \& Gordon, 1985).

Table 5.7 Broward County emissions of airborne metals and percent contributions from different sources, according to USEPA National Emissions Inventory, 2008 (USEPA, 2013a).

\begin{tabular}{cccccccccc}
\hline $\mathbf{E}$ & $\begin{array}{c}\text { Total } \\
(\mathbf{k g})\end{array}$ & $\begin{array}{c}\text { Marine } \\
\text { vessels }\end{array}$ & $\begin{array}{c}\text { Oil } \\
\text { EG }^{\mathbf{a}}\end{array}$ & $\begin{array}{c}\text { Other } \\
\text { EG }\end{array}$ & $\begin{array}{c}\text { Natural } \\
\text { Gas EG }\end{array}$ & $\begin{array}{c}\text { Gasoline } \\
\text { engines }\end{array}$ & $\begin{array}{c}\text { Diesel } \\
\text { Engines }\end{array}$ & $\begin{array}{c}\text { Aircraft } \\
\text { emissions }\end{array}$ & Other \\
\hline $\mathrm{Ni}$ & 5282 & 97 & 1 & 0 & 1 & 1 & 0 & 0 & 0 \\
$\mathrm{~Pb}$ & 422 & 5 & 1 & 9 & 2 & 0 & 1 & 82 & 0 \\
$\mathrm{Cr}$ & 293 & 68 & 3 & 0 & 0 & 26 & 3 & 0 & 0 \\
$\mathrm{As}$ & 196 & 68 & 1 & 0 & 0 & 22 & 9 & 0 & 0 \\
$\mathrm{Co}$ & 110 & 89 & 11 & 0 & 0 & 0 & 0 & 0 & 0 \\
$\mathrm{Mn}$ & 72 & 30 & 12 & 0 & 10 & 36 & 12 & 0 & 0 \\
$\mathrm{Cd}$ & 9 & 38 & 10 & 39 & 2 & 0 & 1 & 0 & 10 \\
\hline
\end{tabular}

Cd presented a high enrichment factor in the collected APM (figure 5.5). This element loaded slightly on F2 and UNMIX shows that S2 contributes with 55\% of that element, suggesting that the electricity plant is an important source of airborne $\mathrm{Cd}$ in the Port Everglades area. The data does not relate $\mathrm{Cd}$ to F5/S4 (previously allocated to marine vessels) although the NEI estimates that $38 \%$ of $\mathrm{Cd}$ emissions are originated from that source. This could be result of a minimization of that source by the much more abundant contributions of the electricity plant to the total APM (as suggested by S2 in UNMIX) and by the presence of a third source, represented by F3. Table 5.7 shows that $39 \%$ of Broward County Cd emissions are estimated to originate from non-traditional electric generation, which include facilities such as the Wheelabrator North Broward Waste-to-Energy plant, located at approximately $10 \mathrm{~km}$ west from the air sampler. Another set of elements that presented a high loading on $\mathrm{F} 3$ are $\mathrm{Zn}$ and $\mathrm{Cu}$, suggesting a 
common provenance between the three elements. However airborne $\mathrm{Zn}$ and $\mathrm{Cu}$ are more commonly associated with suspended road dust from tire and brake wear (Celo \& DabekZlotorzynska, 2011; Querol et al., 2007). Copper also loads strongly on F4, along with As and $\mathrm{Pb}$. A similar association between $\mathrm{Cu}, \mathrm{As}$ and $\mathrm{Pb}$ was described by Celo and DabekZlotorzynska (2011) in Canadian cities, and those authors interpreted the observation as multiple industrial sources such as mining and also to construction dust. According to the 2008 NEI, aircrafts are an important source of $\mathrm{Pb}$ in Broward County, as lead tetraethyl is used as a fuel additive for piston aircrafts (Cho et al., 2011). On the basis of the output from both statistical models (table 5.6), it can be proposed that S3 in the UNMIX model corresponds to the sum of F3+F4 in the PCA model, which would explain the $100 \%$ contribution of $\mathrm{S} 3$ to airborne $\mathrm{Cu}$ from the mentioned industrial activities and road dust.

All these observations may suggest that F3 and F4 represent APM from inside the Metropolitan Area, and the common variability of the different sources described by $\mathrm{F} 3+\mathrm{F} 4$ and S3, such as road dust, incinerators, industrial sources, aircrafts, construction dust, mining activities, etc., could be a result of distance. Since these sources are far away from the air sampler, wind speeds and directions may have played a more significant role in the transport and deposition of APM from inside the city towards the coastal sampling site, than for nearby sources such as the power plant or the shipping vessels.

According to USEPA estimates, suspended road dust and construction dust are the main source of airborne pollution in the Tri-County Metropolitan Area (USEPA, 2013a), which could explain why S3 was assigned the second highest abundance in the 
contributions to APM by the UNMIX model following F2/S2 (identified as the electricity plant).

\subsection{Conclusions}

The elemental analysis of APM collected in the vicinity of Port Everglades, FL, suggests that certain toxic elements such as $\mathrm{Pb}, \mathrm{Cd}, \mathrm{Ni}, \mathrm{V}, \mathrm{As}, \mathrm{Cr}$ and $\mathrm{Cd}$ are heavily enriched relative to the Earth upper crustal concentrations, suggesting that anthropogenic activities are responsible for their introduction.

Visual analysis of the filters indicates a ubiquitous presence of coarse crystalline particles probably related to the aspiration of marine spray, which could have diluted the mass fractions of thoracic and breathable particles in the collected APM. Thus, concentrations of the toxic anthropogenic elements in fine particles that are relevant for human health could be significantly higher than what the obtained results reflect. The detection of toxic metals such as $\mathrm{Cd}$ from different sources in the collected APM suggest that the implementation of larger scale air quality monitoring programs in the Miami Metropolitan area is necessary, and such programs should perform size-dependent APM collections in order to assess the correct levels of toxic metals in air and the threat to public health.

According to the multivariable statistical methods, the Port Everglades Electricity Plant (demolished in July 2013) was the main source of airborne particles in the area and this plant was an important $\mathrm{Cd}$ emitter. The second source identified in order of abundance was suspended matter from within the city that contained signatures of road 
and construction dust, waste incineration and industrial activities. The association of $\mathrm{Cd}$ and As to these sources raises concerns over the overall air quality of the city, and further research is recommended in order to assess the levels of toxic elements in breathable particles.

The contributions from marine vessels and mineral dust from Africa were also detected but were less significant than the power plant emissions, probably because of their sporadic character. As expected, the data is consistent with previous reports that indicate that African dust contributions to the total APM are significant only in the summer months. The analysis of the mostly crustal rare earth elements was useful to allocate the source contributing with geological material using multivariate receptor models. Additionally, REEs were found to be a good proxy to detect events of high mineral dust concentrations in the local air. 


\section{GENERAL CONCLUSIONS}

A series of methodologies that focused on simplicity and automation or unattended operation were developed and applied to the local environment. Two research projects dealt with nontraditional pollutants such as the herbicide glyphosate as a possible threat to protected wetlands in Biscayne National Park, and the analytical chemistry of surfactants employed during the 2010 Gulf Oil Spill response effort. Other two projects involved more traditional environmental pollutants known to pose a threat to public health, such as polycyclic aromatic hydrocarbons and air particulate matter.

The concept of water removal by lyophilization followed by derivatization and analysis by LC-FLD+MS/MS was proven as a viable alternative for the analysis of glyphosate from canal waters. The developed methodology is simple to use, does not require expensive materials or reagents and also does not involve a high amount of analyst time. This technique was employed to assess the occurrence of the herbicide in canals that will be used to hydrate protected wetlands in BNP, and although data indicates that the aquatic use of glyphosate for canal maintenance does not seem to pose a threat to the protected environment, glyphosate was detected in runoff from agricultural farms which may pose a risk caused by the possible presence of toxic surfactants, and the investigation of this possibility is recommended.

The analysis of Corexit ${ }^{\circledR}$ surfactant components in seawater, crude oil and dispersant formulations was investigated, resulting in a family of LC-MS/MS and online SPE-LC-MS/MS methodologies that may be useful not only for tracking the extent and fate of these compounds in future oil spills involving dispersants, but also to identify the 
Corexit $^{\circledR}$ formulations involved. The automated online SPE methodology for the analysis of DOSS is able to detect this analyte in seawater at concentrations as low as $7 \mathrm{ng} / \mathrm{L}$, while the direct injection method can detect the compound in only 7 minutes. Seawater samples to be analyzed for DOSS should be stabilized with $15 \%$ acetonitrile in order to prevent analyte losses. The developed analytical protocols are being actively used to investigate the fate of Corexit ${ }^{\circledR}$ markers in the environment.

Regarding traditional pollutants, an alternative method for the analysis of PAHs that challenges the established LLE+GC-MS technique in terms of speed, simplicity and environmental friendliness was developed. This methodology employed online SPE-LCMS/MS in order to eliminate sample preparation which allows obtaining results in almost real time, with a much lower consumption of dangerous solvents such as methylene chloride. Additionally, this work reports the highest number of PAHs simultaneously analyzed by liquid chromatography to date and the first LC separation of alkylated PAHs. The analysis was tested with different waters from the Miami-Dade County, detecting the presence of alkylated PAHs in seawater from local marinas and regular heavy PAHs in runoff from residential parking lots. While no PAHs were detected in WWTPs effluents, good recoveries from fortified matrix experiments suggest that the analysis of PAHs in this type of water is possible. Thus, the highly automated methodology showed flexibility to analyze different types of water relevant to the urban environment.

Lastly, the elemental composition of atmospheric particulate matter collected from a coastal site of the Miami Metropolitan Area was analyzed. Receptor models were used to establish the anthropogenic character of toxic elements and their provenance, and 
results suggest that APM in that area was mainly originated by the oil-fired Port Everglades Power Plant, with a combination of possible suspended road dust and waste incineration emissions as the second source of importance. The exact concentrations of toxic elements in thoracic or breathable particles $\left(\mathrm{PM}_{10}, \mathrm{PM}_{2.5}\right)$ air could not be determined by the total suspended particles collection performed. However, toxic elements such as $\mathrm{Cd}$ and As presented high average enrichment factors, linked by two multivariate statistical models to the electricity plant and to suspended dust from inside the city. The possibility of high concentrations of $\mathrm{Cd}$, As and other toxic elements in breathable particles may be a justification for further research. Rare earth elements were used to identify contributions of geological material to the APM and to identify events of high concentration of mineral African dust arriving in Miami during in the summer months. 


\section{LIST OF REFERENCES}

Apple, D., \& Shaffer, J. (2010). Biscayne Bay Coastal Wetlands Phase 1. April 21, 2010 Public Workshop. United States Army Corps of Engineers, South Florida Water Management District. Retrieved on 08/07/2013 from: http://www.evergladesplan.org/pm/public_meetings/docs/042110_workshop_pres.pdf.

Arroyo-Mora, L. E. (2009). The Use of Hyphenated Spectrometric Techniques for the Environmental Forensic Assessment of Non-Traditional Pollutants and Degradates in the Greater Florida Everglades. (PhD. in Chemistry - Forensic Track), Florida International University, Miami, FL. USA. Retrieved on 09/12/2013 from: http://digitalcommons.fiu.edu/etd/144.

ATSDR. (1990). Toxicological profile for Chlorobenzene. Atlanta, GA. USA.: Agency for Toxic Substances and Disease Registry. U.S. Department of Health and Human Services.

ATSDR. (2000). Toxicological profile for Methylene Chloride. Atlanta, GA. USA.: Agency for Toxic Substances and Disease Registry. U.S. Department of Health and Human Services.

Bastug, A. S., Goz, S. E., Talman, Y., Gokturk, S., Asil, E., \& Caliskan, E. (2011). Formation constants and coordination thermodynamics for binary complexes of $\mathrm{Cu}(\mathrm{II})$ and some alpha-amino acids in aqueous solution. Journal of Coordination Chemistry, 64(2), 281-292. doi: 10.1080/00958972.2010.541454

Battaglin, W. A., Kolpin, D. W., Scribner, E. A., Kuivila, K. M., \& Sandstrom, M. W. (2005). Glyphosate, other herbicides, and transformation products in Midwestern streams, 2002. Journal of the American Water Resources Association, 41(2), 323-332. doi: 10.1111/j.1752-1688.2005.tb03738.x

Bellmund, S. (2008). [From National Park Service, personal communication].

Bergqvist, P. A., Augulyte, L., \& Jurjoniene, V. (2006). PAH and PCB removal efficiencies in Umea (Sweden) and Siauliai (Lithuania) municipal wastewater treatment plants. Water Air and Soil Pollution, 175(1-4), 291-303. doi: 10.1007/s11270-006-9139-5

Boehm, P. D., Douglas, G. S., Burns, W. A., Mankiewicz, P. J., Page, D. S., \& Bence, A. E. (1997). Application of petroleum hydrocarbon chemical fingerprinting and allocation techniques after the Exxon Valdez oil spill. Marine Pollution Bulletin, 34(8), 599-613. doi: $10.1016 / \mathrm{s} 0025-326 \times(97) 00051-9$

Boehm, P. D., Neff, J. M., \& Page, D. S. (2007). Assessment of polycyclic aromatic hydrocarbon exposure in the waters of Prince William Sound after the Exxon Valdez oil spill: 1989-2005. Marine Pollution Bulletin, 54(3), 339-356. doi: 10.1016/j.marpolbul.2006.11.025 
Borggaard, O. K., \& Gimsing, A. L. (2008). Fate of glyphosate in soil and the possibility of leaching to ground and surface waters: a review. Pest Management Science, 64(4), 441-456. doi: 10.1002/ps.1512

Botta, F., Lavison, G., Couturier, G., Alliot, F., Moreau-Guigon, E., Fauchon, N., Guery, B., Chevreuil, M., Blanchoud, H. (2009). Transfer of glyphosate and its degradate AMPA to surface waters through urban sewerage systems. Chemosphere, 77(1), 133-139. doi: 10.1016/j.chemosphere.2009.05.008

Brook, R. D., Franklin, B., Cascio, W., Hong, Y. L., Howard, G., Lipsett, M., Luepker, R., Mittleman, M., Samet, J., Smith, S. C., Tager, I. (2004). Air pollution and cardiovascular disease - A statement for healthcare professionals from the expert panel on population and prevention science of the American Heart Association. Circulation, 109(21), 2655-2671. doi: 10.1161/01.cir.0000128587.30041.c8

Brook, R. D., Rajagopalan, S., Pope, C. A., Brook, J. R., Bhatnagar, A., Diez-Roux, A. V., Holguin, F., Hong, Y. L., Luepker, R. V., Mittleman, M. A., Peters, A., Siscovick, D., Smith, S. C., Whitsel, L., Kaufman, J. D. (2010). Particulate Matter Air Pollution and Cardiovascular Disease An Update to the Scientific Statement From the American Heart Association. Circulation, 121(21), 2331-2378. doi: 10.1161/CIR.0b013e3181dbece1

Brunekreef, B., \& Holgate, S. T. (2002). Air pollution and health. Lancet, 360(9341), 1233-1242. doi: 10.1016/s0140-6736(02)11274-8

Busetti, F., Backe, W. J., Bendixen, N., Maier, U., Place, B., Giger, W., \& Field, J. A. (2012). Trace analysis of environmental matrices by large-volume injection and liquid chromatography-mass spectrometry. Analytical and Bioanalytical Chemistry, 402(1), 175-186. doi: 10.1007/s00216-011-5290-y

Cai, S. S., Stevens, J., \& Syage, J. A. (2012). Ultra high performance liquid chromatography-atmospheric pressure photoionization-mass spectrometry for highsensitivity analysis of US Environmental Protection Agency sixteen priority pollutant polynuclear aromatic hydrocarbons in oysters. Journal of Chromatography A, 1227, 138144. doi: 10.1016/j.chroma.2011.12.111

Cai, S. S., Syage, J. A., Hanold, K. A., \& Balogh, M. P. (2009). Ultra Performance Liquid Chromatography-Atmospheric Pressure Photoionization-Tandem Mass Spectrometry for High-Sensitivity and High-Throughput Analysis of US Environmental Protection Agency 16 Priority Pollutants Polynuclear Aromatic Hydrocarbons. Analytical Chemistry, 81(6), 2123-2128. doi: 10.1021/ac802275e

Cao, X. D., Yin, M., \& Wang, X. R. (2001). Elimination of the spectral interference from polyatomic ions with rare earth elements in inductively coupled plasma mass spectrometry by combining algebraic correction with chromatographic separation. Spectrochimica Acta Part B-Atomic Spectroscopy, 56(4), 431-441. doi: 10.1016/s05848547(01)00170-7 
Celo, V., \& Dabek-Zlotorzynska, E. (2011). Concentration and Source Origin of Trace Metals in PM2.5 Collected at Selected Canadian Sites within the Canadian National Air Pollution Surveillance Program. In F. Zereini \& C. L. S. Wiseman (Eds.), Urban Airborne Particulate Matter (pp. 19-38): Springer Berlin Heidelberg.

Chapman, H., Purnell, K., Law, R. J., \& Kirby, M. F. (2007). The use of chemical dispersants to combat oil spills at sea: A review of practice and research needs in Europe. Marine Pollution Bulletin, 54(7), 827-838. doi: 10.1016/j.marpolbul.2007.03.012

Chen, L. W. A., Watson, J. G., Chow, J. C., \& Magliano, K. L. (2007). Quantifying PM2.5 source contributions for the San Joaquin Valley with multivariate receptor models. Environmental Science \& Technology, 41(8), 2818-2826. doi: $10.1021 / \mathrm{es} 0225105$

Chiang, H.-L., Lai, Y.-M., \& Chang, S.-Y. (2012). Pollutant constituents of exhaust emitted from light-duty diesel vehicles. Atmospheric Environment, 47, 399-406. doi: 10.1016/j.atmosenv.2011.10.045

Cho, S. H., Richmond-Bryant, J., Thornburg, J., Portzer, J., Vanderpool, R., Cavender, K., \& Rice, J. (2011). A literature review of concentrations and size distributions of ambient airborne $\mathrm{Pb}$-containing particulate matter. Atmospheric Environment, 45(28), 5005-5015. doi: 10.1016/j.atmosenv.2011.05.009

Corbera, M., Hidalgo, M., \& Salvado, V. (2006). Extraction and preconcentration of the herbicide glyphosate and its metabolite AMPA using anion-exchange solid phases. Microchimica Acta, 153(3-4), 203-209. doi: 10.1007/s00604-005-0462-0

Coupe, R. H., Kalkhoff, S. J., Capel, P. D., \& Gregoire, C. (2012). Fate and transport of glyphosate and aminomethylphosphonic acid in surface waters of agricultural basins. Pest Management Science, 68(1), 16-30. doi: 10.1002/ps.2212

Coutinho, C. F. B., Coutinho, L. F. M., Mazo, L. H., Nixdorf, S. L., \& Camara, C. A. P. (2008). Rapid and direct determination of glyphosate and aminomethylphosphonic acid in water using anion-exchange chromatography with coulometric detection. Journal of Chromatography A, 1208(1-2), 246-249. doi: 10.1016/j.chroma.2008.09.009

Dartsch, P. C., Hildenbrand, S., Gfrorer, W., Kimmel, R., \& Schmahl, F. W. (1999). Cytotoxicity of 2-butoxyethanol and its oxidation products in vitro. International Archives of Occupational and Environmental Health, 72, M57-M61. doi: $10.1007 / \mathrm{p} 100014203$

de Leeuw, G., Andreas, E. L., Anguelova, M. D., Fairall, C. W., Lewis, E. R., O'Dowd, C., Schulz, M., Schwartz, S. E. (2011). Production Flux of Sea Spray Aerosol. Reviews of Geophysics, 49. doi: 10.1029/2010rg000349 
Denoux, G. J., Gardinali, P., \& Wade, T. L. (1998). Quantitative Determination of Polynuclear Aromatic Hydrocarbons by Gas Chromatography/Mass Spectrometry (GC/MS) - Selected Ion Monitoring (SIM) Mode. In G. G. Lauenstein \& A. Y. Cantillo (Eds.), Sampling and Analytical Methods of the National Status and Trends Program Mussel Watch Project:1993-1996 Update (pp. 129-139). Silver Spring, Maryland.: National Oceanic and Atmospheric Administration.

Duke, S. O., \& Powles, S. B. (2008). Glyphosate: a once-in-a-century herbicide. Pest Management Science, 64(4), 319-325. doi: 10.1002/ps.1518

Ehrenhauser, F. S., Wornat, M. J., Valsaraj, K. T., \& Rodriguez, P. (2010). Design and evaluation of a dopant-delivery system for an orthogonal atmospheric-pressure photoionization source and its performance in the analysis of polycyclic aromatic hydrocarbons. Rapid Communications in Mass Spectrometry, 24(9), 1351-1357. doi: $10.1002 / \mathrm{rcm} .4518$

Engelstaedter, S., Tegen, I., \& Washington, R. (2006). North African dust emissions and transport. Earth-Science Reviews, 79(1-2), 73-100. doi: 10.1016/j.earscirev.2006.06.004

EU. (2012). Air quality in Europe. Copenhagen, Denmark.: Retrieved on 09/18/2013 from http://www.eea.europa.eu/publications/air-quality-in-europe-2012.

FDACS. (2010). Summary of Agricultural Pesticide Use in Florida 2007-2009. Tallahassee, Fl.: $\quad$ Retrieved on $07 / 26 / 2013$ from: http://www.flaes.org/pdf/PUI_narrative_2010.pdf.

FDEP. (2013). Florida Department of Environmental Protection. 2012 Reuse Inventory. Appendix E. Tallahassee, FL. USA. Retrieved on 08/14/2013 from: http://www.dep.state.fl.us/water/reuse/docs/inventory/Appendix_E.pdf

Ferriter, A., Doren, B., Goodyear, C., Thayer, D., Burch, J., Toth, L., Bodle, M., Lane, J., Schmitz, D., Pratt, P., Snow, S., Langeland, K. (2006). South Florida Environmental Report Chapter 9: The Status of Nonindigenous Species in the South Florida Environment. West Palm Beach, FL.: South Florida Water Management District. Retrieved on 07/30/2013 from: http://www.sfwmd.gov/portal/page/portal/pg_grp_sfwmd_sfer/portlet_prevreport/2006_s fer/volume1/chapters/v1_ch_9.pdf.

Freuze, I., Jadas-Hecart, A., Royer, A., \& Communal, P. Y. (2007). Influence of complexation phenomena with multivalent cations on the analysis of glyphosate and aminomethyl phosphonic acid in water. Journal of Chromatography A, 1175(2), 197-206. doi: 10.1016/j.chroma.2007.10.092

Galloway, J. (2009). South Florida Environmental Report Appendix 5-10: STA Herbicide Application Summary for Water Year 2008. West Palm Beach, FL.: South Florida Water Management District. Retrieved on 07/30/2013 from: 
http://www.sfwmd.gov/portal/page/portal/pg_grp_sfwmd_sfer/portlet_sfer/tab2236041/2 009report/report/v1/appendices/v1_app5-10.pdf.

Garcia-Ac, A., Segura, P. A., Viglino, L., Furtos, A., Gagnon, C., Prevost, M., \& Sauve, S. (2009). On-line solid-phase extraction of large-volume injections coupled to liquid chromatography-tandem mass spectrometry for the quantitation and confirmation of 14 selected trace organic contaminants in drinking and surface water. Journal of Chromatography A, 1216(48), 8518-8527. doi: 10.1016/j.chroma.2009.10.015

Gianessi, L. P. (2008). Economic impacts of glyphosate-resistant crops. Pest Management Science, 64(4), 346-352. doi: 10.1002/ps.1490

Giesy, J. P., Dobson, S., \& Solomon, K. R. (2000). Ecotoxicological risk assessment for Roundup (R) Herbicide. Reviews of Environmental Contamination and Toxicology, Vol $167,167,35-120$.

Gimeno, R. A., Altelaar, A. F. M., Marce, R. M., \& Borrull, F. (2002). Determination of polycyclic aromatic hydrocarbons and polycylic aromatic sulfur heterocycles by highperformance liquid chromatography with fluorescence and atmospheric pressure chemical ionization mass spectrometry detection in seawater and sediment samples. Journal of Chromatography A, 958(1-2), 141-148. doi: 10.1016/s0021-9673(02)00386-2

Glass, R. L. (1987). Adsorption of Glyphosate by Soils and Clay Minerals. Journal of Agricultural and Food Chemistry, 35(4), 497-500. doi: 10.1021/jf00076a013

Grey, L., Nguyen, B., \& Yang, P. (2001). Liquid chromatography/electrospray ionization/isotopic dilution mass spectrometry analysis of $n$-(phosphonomethyl) glycine and mass spectrometry analysis of aminomethyl phosphonic acid in environmental water and vegetation matrixes. Journal of Aoac International, 84(6), 1770-1780.

Guo, Z. X., Cai, Q. T., \& Yang, Z. G. (2005). Determination of glyphosate and phosphate in water by ion chromatography - inductively coupled plasma mass spectrometry detection. Journal of Chromatography A, 1100(2), 160-167. doi: 10.1016/j.chroma.2005.09.034

Hamel, S. C., Buckley, B., \& Lioy, P. J. (1998). Bioaccessibility of metals in soils for different liquid to solid ratios in synthetic gastric fluid. Environmental Science \& Technology, 32(3), 358-362. doi: 10.1021/es9701422

Hanke, I., Singer, H., \& Hollender, J. (2008). Ultratrace-level determination of glyphosate, aminomethylphosphonic acid and glufosinate in natural waters by solid-phase extraction followed by liquid chromatography-tandem mass spectrometry: performance tuning of derivatization, enrichment and detection. Analytical and Bioanalytical Chemistry, 391(6). doi: 10.1007/s00216-008-2134-5 
Hao, C., Morse, D., Morra, F., Zhao, X., Yang, P., \& Nunn, B. (2011). Direct aqueous determination of glyphosate and related compounds by liquid chromatography/tandem mass spectrometry using reversed-phase and weak anion-exchange mixed-mode column. Journal of Chromatography A, 1218(33). doi: 10.1016/j.chroma.2011.06.070

Harris, O., Wilbur, S., George, J., Eisenmann, C. (1998). Toxicological Profile for 2butoxyethanol and 2-butoxyethanol acetate. Atlanta, GA. USA.: U.S. Department of Health and Human Services, Agency for Toxic Substances and Disease Registry Retrieved from http://www.atsdr.cdc.gov/toxprofiles/tp.asp?id=347\&tid=61.

Henry, R. C. (2003). Multivariate receptor modeling by N-dimensional edge detection. Chemometrics and Intelligent Laboratory Systems, 65(2), 179-189. doi: 10.1016/s01697439(02)00108-9

Henry, R. C., \& Christensen, E. R. (2010). Selecting an Appropriate Multivariate Source Apportionment Model Result. Environmental Science \& Technology, 44(7), 2474-2481. doi: $10.1021 /$ es9018095

Hidalgo, C., Rios, C., Hidalgo, M., Salvado, V., Sancho, J. V., \& Hernandez, F. (2004). Improved coupled-column liquid chromatographic method for the determination of glyphosate and aminomethylphosphonic acid residues in environmental waters. Journal of Chromatography A, 1035(1), 153-157. doi: 10.1016/j.chroma.2004.02.044

Horak, J., \& Lindner, W. (2008). Contribution of sulfonyl-aromatic and sulfonic acidaromatic interactions in novel sulfonyl/sulfonic acid-embedded reversed phase materials. Journal of Chromatography A, 1191(1-2), 141-156. doi: 10.1016/j.chroma.2007.12.059

Horak, J., Maier, N. M., \& Lindner, W. (2004). Investigations on the chromatographic behavior of hybrid reversed-phase materials containing electron donor-acceptor systems II. Contribution of pi-pi aromatic interactions. Journal of Chromatography A, 1045(1-2), 43-58. doi: 10.1016/j.chroma.2004.05.096

Ibanez, M., Pozo, O. J., Sancho, J. V., Lopez, F. J., \& Hernandez, F. (2005). Residue determination of glyphosate, glufosinate and aminomethylphosphonic acid in water and soil samples by liquid chromatography coupled to electrospray tandem mass spectrometry. Journal of Chromatography A, 1081(2), 145-155. doi: 10.1016/j.chroma.2005.05.041

Ibanez, M., Pozo, O. J., Sancho, J. V., Lopez, F. J., \& Hernandez, F. (2006). Reevaluation of glyphosate determination in water by liquid chromatography coupled to electrospray tandem mass spectrometry. Journal of Chromatography A, 1134(1-2), 5155. doi: 10.1016/j.chroma.2006.07.093

Imfeld, G., Lefrancq, M., Maillard, E., \& Payraudeau, S. (2013). Transport and attenuation of dissolved glyphosate and AMPA in a stormwater wetland. Chemosphere, 90(4), 1333-1339. doi: 10.1016/j.chemosphere.2012.04.054 
Itoh, N., Aoyagi, Y., \& Yarita, T. (2006). Optimization of the do pant for the trace determination of polycyclic aromatic hydrocarbons by liquid chromatography/dopantassisted atmospheric-pressure photoionization/mass spectrometry. Journal of Chromatography A, 1131(1-2), 285-288. doi: 10.1016/j.chroma.2006.08.091

James, R. T., \& Zhang, J. (2011). South Florida Environmental Report Chapter 10: Lake Okeechobee Protection Program - State of the Lake and Watershed. West Palm Beach, FL.: South Florida Water Management District Retrieved from http://www.sfwmd.gov/portal/page/portal/pg_grp_sfwmd_sfer/portlet_prevreport/2011_s fer/v1/chapters/v1_ch10.pdf.

Jaworska, J., Van Genderen-Takken, H., Hanstveit, A., van de Plassehe, E., \& Feijtel, T. (2002). Environmental risk assessment of phosphonates, used in domestic laundry and cleaning agents in the Netherlands. Chemosphere, 47(6), 655-665. doi: 10.1016/s00456535(01)00328-9

Kappos, A. (2011). Health Risks of Urban Airborne Particles. In F. Zereini \& C. L. S. Wiseman (Eds.), Urban Airborne Particulate Matter (pp. 527-551): Springer Berlin Heidelberg.

Kelly, C. A., Ayoko, G. A., Brown, R. J., \& Swaroop, C. R. (2005). Underwater emissions from a two-stroke outboard engine: a comparison between an EAL and an equivalent mineral lubricant. Materials \& Design, 26(7), 609-617. doi: 10.1016/j.matdes.2004.08.013

Kolpin, D. W., Thurman, E. M., Lee, E. A., Meyer, M. T., Furlong, E. T., \& Glassmeyer, S. T. (2006). Urban contributions of glyphosate and its degradate AMPA to streams in the United States. Science of the Total Environment, 354(2-3), 191-197. doi: 10.1016/j.scitotenv.2005.01.028

Kuehn, B. M. (2006). Desertification called global health threat. Jama-Journal of the American Medical Association, 295(21), 2463-2465. doi: 10.1001/jama.295.21.2463

Kujawinski, E. B., Soule, M. C. K., Valentine, D. L., Boysen, A. K., Longnecker, K., \& Redmond, M. C. (2011). Fate of Dispersants Associated with the Deepwater Horizon Oil Spill. Environmental Science \& Technology, 45(4), 1298-1306. doi: 10.1021/es103838p

Kusters, M., \& Gerhartz, M. (2010). Enrichment and low-level determination of glyphosate, aminomethylphosphonic acid and glufosinate in drinking water after cleanup by cation exchange resin. Journal of Separation Science, 33(8), 1139-1146. doi: $10.1002 /$ jssc. 200900556

Le Bot, B., Colliaux, K., Pelle, D., Briens, C., Seux, R., \& Clement, M. (2002). Optimization and performance evaluation of the analysis of glyphosate and AMPA in water by HPLC with fluorescence detection. Chromatographia, 56(3-4), 161-164. 
Le Fur, E., Colin, R., Charreteur, C., Dufau, C., \& Peron, J. J. (2000). Determination of glyphosate herbicide and aminomethylphosphonic acid in natural waters by liquid chromatography using pre-column fluorogenic labeling. Part I: Direct determination at the $0.1 \mathrm{mu} \mathrm{g} / \mathrm{L}$ level using FMOC. Analusis, 28(9), 813-818. doi: 10.1051/analusis:2000148

Lee, E. A., Strahan, A. P., \& Thurman, E. M. (2002). Methods of Analysis by the U.S. Geological Survey Organic Geochemistry Research Group-Determination of Glyphosate, Aminomethylphosphonic Acid, and Glufosinate in Water Using Online SolidPhase Extraction and High-Performance Liquid Chromatography/Mass Spectrometry. Lawrence, Kansas: United States Geological Survey. Retrieved from http://ks.water.usgs.gov/pubs/reports/ofr.01-454.pdf.

Lerda, D. (2011). Polycyclic Aromatic Hydrocarbons (PAHs) Factsheet. 4th Edition. European Commission, Joint Research Centre, Institute for Reference Materials and Measurements. Geel, Belgium. Retrieved on 04/24/2013 from: http://irmm.jrc.ec.europa.eu/EURLs/EURL_PAHs/about_pahs/Documents/Factsheet $\% 20$ PAH.pdf

Li, Y., Yoshida, S., Chondo, Y., Nassar, H., Tang, N., Araki, Y., Toriba, A., Kameda, T., Hayakawa, K. (2012). On-Line Concentration and Fluorescence Determination HPLC for Polycyclic Aromatic Hydrocarbons in Seawater Samples and Its Application to Japan Sea. Chemical \& Pharmaceutical Bulletin, 60(4), 531-535.

Mahler, B. J., Van Metre, P. C., Bashara, T. J., Wilson, J. T., \& Johns, D. A. (2005). Parking lot sealcoat: An unrecognized source of urban polycyclic aromatic hydrocarbons. Environmental Science \& Technology, 39(15), 5560-5566. doi: 10.1021/es0501565

Mahler, B. J., Van Metre, P. C., Crane, J. L., Watts, A. W., Scoggins, M., \& Williams, E. S. (2012). Coal-Tar-Based Pavement Sealcoat and PAHs: Implications for the Environment, Human Health, and Stormwater Management. Environmental Science \& Technology, 46(6), 3039-3045. doi: 10.1021/es203699x

Mallat, E., \& Barcelo, D. (1998). Analysis and degradation study of glyphosate and of aminomethylphosphonic acid in natural waters by means of polymeric and ion-exchange solid-phase extraction columns followed by ion chromatography post-column derivatization with fluorescence detection. Journal of Chromatography A, 823(1-2), 129136. doi: 10.1016/s0021-9673(98)00362-8

Manoli, E., \& Samara, C. (1999). Polycyclic aromatic hydrocarbons in natural waters: sources, occurrence and analysis. Trac-Trends in Analytical Chemistry, 18(6), 417-428. doi: 10.1016/s0165-9936(99)00111-9

Manzetti, S. (2012). Ecotoxicity of polycyclic aromatic hydrocarbons, aromatic amines, and nitroarenes through molecular properties. Environmental Chemistry Letters, 10(4), 349-361. doi: 10.1007/s10311-012-0368-0 
Marce, R. M., \& Borrull, F. (2000). Solid-phase extraction of polycyclic aromatic compounds. Journal of Chromatography A, 885(1-2), 273-290. doi: 10.1016/s00219673(00)00428-3

Marchi, I., Rudaz, S., \& Veuthey, J. L. (2009). Atmospheric pressure photoionization for coupling liquid-chromatography to mass spectrometry: A review. Talanta, 78(1), 1-18. doi: $10.1016 /$ j.talanta.2008.11.031

Mathew, J., Schroeder, D. L., Zintek, L. B., Schupp, C. R., Kosempa, M. G., Zachary, A. M., Schupp, G. C., Wesolowski, D. J. (2012). Dioctyl sulfosuccinate analysis in nearshore Gulf of Mexico water by direct-injection liquid chromatography-tandem mass spectrometry. Journal of Chromatography A, 1231(0), 46-51. doi: 10.1016/j.chroma.2012.01.088

Michulec, M., Wardencki, W., Partyka, M., \& Namiesnik, J. (2005). Analytical techniques used in monitoring of atmospheric air pollutants. Critical Reviews in Analytical Chemistry, 35(2), 117-133. doi: 10.1080/10408340500207482

Miles, C. J., Wallace, L. R., \& Moye, H. A. (1986). Determination of Glyphosate Herbicide and (aminomethyl)phosphonic acid in Natural Waters by Liquid Chromatography using precolumn Fluorogenic Labeling with 9-fluorenylmethyl chloroformate. Journal of the Association of Official Analytical Chemists, 69(3), 458461.

Mossler, M. A., \& Nesheim, O. N. (2011). Tropical Fruit Pest Management Strategic Plan (PMSP). Gainesville, FL. USA.: University of Florida, Institute of Food and Agricultural Sciences (IFAS) Retrieved on 08/09/2013 from: http://edis.ifas.ufl.edu/pdffiles/PI/PI06200.pdf.

Moye, H. A., \& Boning, A. J. (1978). Flourogenic Labeling of Glyphosate and its metabolite with 9-fluorenylmethyl chloroformate for analysis by HPLC. Abstracts of Papers of the American Chemical Society, 176(SEP), 47-47.

Moye, H. A., Miles, C. J., \& Scherer, S. J. (1983). A simplified High-Performance Liquid-Chromatographic Residue Procedure for the Determination of Glyphosate Herbicide and (aminomethyl)phosphonic acid in Fruits and Vegetables employing Postcolumn Fluorogenic Labeling. Journal of Agricultural and Food Chemistry, 31(1), 69-72. doi: $10.1021 / \mathrm{jf00115a018}$

Muhs, D. R., Budahn, J. R., Prospero, J. M., \& Carey, S. N. (2007). Geochemical evidence for African dust inputs to soils of western Atlantic islands: Barbados, the Bahamas, and Florida. Journal of Geophysical Research-Earth Surface, 112(F2), 26. doi: $10.1029 / 2005 j \mathrm{jf000445}$ 
Mukhtar, A., \& Limbeck, A. (2013). Recent developments in assessment of bioaccessible trace metal fractions in airborne particulate matter: A review. Analytica Chimica Acta, 774, 11-25. doi: 10.1016/j.aca.2013.02.008

NALCO. (2012a). Safety Data Sheet Product Corexit ® EC9500A. Retrieved on 02/05/2013 from: http://www.nalcoesllc.com/nes/documents/MSDS/NESLLCCOREXIT-EC9500A-March_2012.pdf.

NALCO. (2012b). Safety Data Sheet Product Corexit ${ }^{\circledR}$ EC9527A. Retrieved on 02/05/2013 from: http://www.nalcoesllc.com/nes/documents/MSDS/NESLLCCOREXIT-_EC9527A-March_2012.pdf.

Nedelkoska, T. V., \& Low, G. K. C. (2004). High-performance liquid chromatographic determination of glyphosate in water and plant material after pre-column derivatisation with 9-fluorenylmethyl chloroformate. Analytica Chimica Acta, 511(1), 145-153. doi: 10.1016/j.aca.2004.01.027

Official Federal Portal for the Deepwater BP Oil Spill Response and Recovery. (2010). Retrieved on 10/12/2010 from: http://www.restorethegulf.gov/release/2010/08/28/operations-and-ongoing-responseaugust-28-2010.

Olmez, I., \& Gordon, G. E. (1985). Rare-Earths - Atmospheric Signatures for Oil-Fired Power-Plants and Refineries. Science, 229(4717), 966-968. doi: 10.1126/science.229.4717.966.

Oppenhuizen, M. E., \& Cowell, J. E. (1991). Liquid-Chromatographic Determination of Glyphosate and Aminomethylphosphonic Acid (AMPA) in Environmental Water Collaborative Study. Journal of the Association of Official Analytical Chemists, 74(2), 317-323.

Patsias, J., Papadopoulou, A., \& Papadopoulou-Mourkidou, E. (2001). Automated trace level determination of glyphosate and aminomethyl phosphonic acid in water by on-line anion-exchange solid-phase extraction followed by cation-exchange liquid chromatography and post-column derivatization. Journal of Chromatography A, 932(12), 83-90. doi: 10.1016/s0021-9673(01)01253-5

Pfeuffer, R. J. (2011). South Florida Water Management District ambient pesticide monitoring network: 1992 to 2007. Environmental Monitoring and Assessment, 182(1-4), 485-508. doi: 10.1007/s 10661-011-1892-2

Place, B., Anderson, B., Mekebri, A., Furlong, E. T., Gray, J. L., Tjeerdema, R., \& Field, J. (2010). A Role for Analytical Chemistry in Advancing our Understanding of the Occurrence, Fate, and Effects of Corexit Oil Dispersants. Environmental Science \& Technology, 44(16), 6016-6018. doi: 10.1021/es102319w 
Pollegioni, L., Schonbrunn, E., \& Siehl, D. (2011). Molecular basis of glyphosate resistance - different approaches through protein engineering. Febs Journal, 278(16), 2753-2766. doi: 10.1111/j.1742-4658.2011.08214.x

Poster, D. L., Schantz, M. M., Sander, L. C., \& Wise, S. A. (2006). Analysis of polycyclic aromatic hydrocarbons (PAHs) in environmental samples: a critical review of gas chromatographic (GC) methods. Analytical and Bioanalytical Chemistry, 386(4), 859-881. doi: 10.1007/s00216-006-0771-0

Prospero, J. M. (1999). Long-term measurements of the transport of African mineral dust to the southeastern United States: Implications for regional air quality. Journal of Geophysical Research-Atmospheres, 104(D13), 15917-15927. doi: $10.1029 / 1999 j \mathrm{j} 900072$

Prospero, J. M., Blades, E., Naidu, R., Mathison, G., Thani, H., \& Lavoie, M. C. (2008). Relationship between African dust carried in the Atlantic trade winds and surges in pediatric asthma attendances in the Caribbean. International Journal of Biometeorology, 52(8), 823-832. doi: 10.1007/s00484-008-0176-1

Qian, K., Tang, T., Shi, T. Y., Wang, F., Li, J. Q., \& Cao, Y. S. (2009). Residue determination of glyphosate in environmental water samples with high-performance liquid chromatography and UV detection after derivatization with 4-chloro-3,5dinitrobenzotrifluoride. Analytica Chimica Acta, 635(2), 222-226. doi: 10.1016/j.aca.2009.01.022

Querol, X., Viana, M., Alastuey, A., Amato, F., Moreno, T., Castillo, S., Pey, J., de la Rosa, J., de la Campa, A. S., Artinano, B., Salvador, P., Dos Santos, S. G., FernandezPatier, R., Moreno-Grau, S., Negral, L., Minguillon, M. C., Monfort, E., Gil, J. I., Inza, A., Ortega, L. A., Santamaria, J. M., Zabalza, J. (2007). Source origin of trace elements in PM from regional background, urban and industrial sites of Spain. Atmospheric Environment, 41(34), 7219-7231. doi: 10.1016/j.atmosenv.2007.05.022

Ragosta, M., Caggiano, R., Macchiato, M., Sabia, S., \& Trippetta, S. (2008). Trace elements in daily collected aerosol: Level characterization and source identification in a four-year study. Atmospheric Research, 89(1-2), 206-217. doi: 10.1016/j.atmosres.2008.01.009

Ramstedt, M., Norgren, C., Sheals, J., Shchukarev, A., \& Sjoberg, S. (2004). Chemical speciation of $\mathrm{N}$-(phosphonomethyl)glycine in solution and at mineral interfaces. Surface and Interface Analysis, 36(8), 1074-1077. doi: 10.1002/sia.1844

Raut, N. M., Huang, L. S., Aggarwal, S. K., \& Lin, K. C. (2005). Mathematical correction for polyatomic isobaric spectral interferences in determination of lanthanides by inductively coupled plasma mass spectrometry. Journal of the Chinese Chemical Society, 52(4), 589-597. 
Relyea, R. A. (2005). The lethal impact of roundup on aquatic and terrestrial amphibians. Ecological Applications, 15(4), 1118-1124. doi: 10.1890/04-1291

Relyea, R. A. (2012). New effects of Roundup on amphibians: Predators reduce herbicide mortality; herbicides induce antipredator morphology. Ecological Applications, 22(2), 634-647.

Renner, T., Baumgarten, D., \& Unger, K. K. (1997). Analysis of organic pollutants in water at trace levels using fully automated solid-phase extraction coupled to highperformance liquid chromatography. Chromatographia, 45, 199-205. doi: $10.1007 / \mathrm{bf02505561}$

Rimmer, C., Sander, L., \& Wise, S. (2005). Selectivity of long chain stationary phases in reversed phase liquid chromatography. Analytical and Bioanalytical Chemistry, 382(3), 698-707. doi: 10.1007/s00216-004-2858-9

Robb, D. B., \& Blades, M. W. (2008). State-of-the-art in atmospheric pressure photoionization for LC/MS. Analytica Chimica Acta, 627(1), 34-49. doi: 10.1016/j.aca.2008.05.077

Robb, D. B., Covey, T. R., \& Bruins, A. P. (2000). Atmospheric pressure photoionisation: An ionization method for liquid chromatography-mass spectrometry. Analytical Chemistry, 72(15), 3653-3659. doi: 10.1021/ac0001636

Rodriguez, S., Alastuey, A., \& Querol, X. (2012). A review of methods for long term in situ characterization of aerosol dust. Aeolian Research, 6, 55-74. doi: 10.1016/j.aeolia.2012.07.004

Rueppel, M. L., Brightwell, B. B., Schaefer, J., \& Marvel, J. T. (1977). Metabolism and Degradation of Glyphosate in Soil and Water. Journal of Agricultural and Food Chemistry, 25(3), 517-528. doi: 10.1021/jf60211a018

Sancho, J. V., Hernandez, F., Lopez, F. J., Hogendoorn, E. A., Dijkman, E., \& vanZoonen, P. (1996). Rapid determination of glufosinate, glyphosate and aminomethylphosphonic acid in environmental water samples using precolumn fluorogenic labeling and coupled-column liquid chromatography. Journal of Chromatography A, 737(1), 75-83. doi: 10.1016/0021-9673(96)00071-4

Sander, L. C., Pursch, M., \& Wise, S. A. (1999). Shape selectivity for constrained solutes in reversed-phase liquid chromatography. Analytical Chemistry, 71(21), 4821-4830. doi: $10.1021 /$ ac9908187

Scheuvens, D., Schutz, L., Kandler, K., Ebert, M., \& Weinbruch, S. (2013). Bulk composition of northern African dust and its source sediments - A compilation. EarthScience Reviews, 116, 170-194. doi: 10.1016/j.earscirev.2012.08.005 
Schlesinger, W. H., Reynolds, J. F., Cunningham, G. L., Huenneke, L. F., Jarrell, W. M., Virginia, R. A., \& Whitford, W. G. (1990). Biological Feedbacks in Global Desertification. Science, 247(4946), 1043-1048. doi: 10.1126/science.247.4946.1043

Schuler, L. J., \& Rand, G. M. (2008). Aquatic risk assessment of herbicides in freshwater ecosystems of south Florida. Archives of Environmental Contamination and Toxicology, 54(4), 571-583. doi: 10.1007/s00244-007-9085-2

Seinfeld, J. H., \& Pandis, S. N. (1998). Atmospheric Chemistry and Physics: From Air Pollution to Climate Change. New York, NY. USA: John Wiley \& Sons.

SFWMD. (2010). Canals in South Florida: A Technical Support Document. West Palm Beach, Florida: South Florida Water Management District.

SFWMD. (2013). DBHYDRO Browser. Retrieved on 06/01/2013 from: http://www.sfwmd.gov/dbhydro

SFWMD, \& USACE. (2011). Final Integrated Project Implementation Report and Environmental Impact Statement. Jacksonville, FL. USA.: Retrieved on 08/07/2013 from:

http://www.evergladesplan.org/pm/projects/project_docs/pdp_28_biscayne/010612_fpir/ 010612_bbcw_vol_1_main_report_rev_mar_2012.pdf.

Shinn, E. A., Smith, G. W., Prospero, J. M., Betzer, P., Hayes, M. L., Garrison, V., \& Barber, R. T. (2000). African dust and the demise of Caribbean coral reefs. Geophysical Research Letters, 27(19), 3029-3032. doi: 10.1029/2000g1011599

Sinha, S. N., Vasudev, K., Rao, M. V. V., \& Odetokun, M. (2011). Quantification of organophosphate insecticides in drinking water in urban areas using lyophilization and high-performance liquid chromatography-electrospray ionization-mass spectrometry techniques. International Journal of Mass Spectrometry, 300(1), 12-20. doi: 10.1016/j.ijms.2010.11.006

Skark, C., Zullei-Seibert, N., Schottler, U., \& Schlett, C. (1998). The occurrence of glyphosate in surface water. International Journal of Environmental Analytical Chemistry, 70(1-4), 93-104. doi: 10.1080/03067319808032607

Smith, D. R., Robb, D. B., \& Blades, M. W. (2009). Comparison of Dopants for Charge Exchange Ionization of Nonpolar Polycyclic Aromatic Hydrocarbons with ReversedPhase LC-APPI-MS. Journal of the American Society for Mass Spectrometry, 20(1), 7379. doi: 10.1016/j.jasms.2008.09.012

Solomon, K. R., \& Thompson, D. G. (2003). Ecological risk assessment for aquatic organisms from over-water uses of glyphosate. Journal of Toxicology and Environmental Health-Part B-Critical Reviews, 6(3), 289-324. doi: 10.1080/15287390390155571 
Song, Y., Xie, S. D., Zhang, Y. H., Zeng, L. M., Salmon, L. G., \& Zheng, M. (2006). Source apportionment of PM2.5 in Beijing using principal component analysis/absolute principal component scores and UNMIX. Science of the Total Environment, 372(1), 278286. doi: $10.1016 /$ j.scitotenv.2006.08.041

Stalikas, C. D., \& Konidari, C. N. (2001). Analytical methods to determine phosphonic and amino acid group-containing pesticides. Journal of Chromatography A, 907(1-2), 119. doi: $10.1016 / \mathrm{s} 0021-9673(00) 01009-8$

Steinrucken, H. C., \& Amrhein, N. (1980). The Herbicide Glyphosate is a Potent Inhibitor Of 5-enolpyruvyl-shikimic-acid 3-phosphate synthase. Biochemical and Biophysical Research Communications, 94(4), 1207-1212. doi: 10.1016/0006291x(80)90547-1

Sun, Y. J., Wang, C. Y., Wen, Q. Y., Wang, G. X., Wang, H. H., Qu, Q. S., \& Hu, X. Y. (2010). Determination of Glyphosate and Aminomethylphosphonic Acid in Water by LC Using a New Labeling Reagent, 4-Methoxybenzenesulfonyl Fluoride. Chromatographia, 72(7-8), 679-686. doi: 10.1365/s10337-010-1705-8

Swain, E. D., Kapadia, A., Kone, S., Damisse, E., Mtundu, D., \& Tillis, G. M. (1997). Determining Discharge-Coefficient Ratings for Coastal Structures in Dade County, Florida. Tallahassee, Florida: U.S. Department of the Interior, U.S. Geological Survey.

Syage, J. A., Evans, M. D., \& Hanold, K. A. (2000). Photoionization mass spectrometry. American Laboratory, 32(24), 24-+.

TOXNET. (2007). (L)-Aspartic Acid. Bethesda, MD., USA.: National Institutes of Health, United Stated National Library of Medicine, Toxicology Data Network (TOXNET). Retrieved on 08/18/2013 from: http://toxnet.nlm.nih.gov/cgibin/sis/search/a?dbs+hsdb:@term+@DOCNO+1430.

Trapp, J. M., Millero, F. J., \& Prospero, J. M. (2010). Temporal variability of the elemental composition of African dust measured in trade wind aerosols at Barbados and Miami. Marine Chemistry, 120(1-4), 71-82. doi: 10.1016/j.marchem.2008.10.004

USDOC. (2010). U.S. Census Bureau. Florida Quickfacts. Retrieved on 09/18/2013, from http://quickfacts.census.gov/qfd/states/12000.html

USDOT. (2013). Tonnage of Top 50 U.S. Water Ports, Ranked by Total Tons. Retrieved on 09/22/2013 from:

http://www.rita.dot.gov/bts/sites/rita.dot.gov.bts/files/publications/national_transportation _statistics/html/table_01_57.html

USEPA. (1990). Method 547: Determination of Glyphosate in Drinking Water by DirectAqueous Injection HPLC, Post-Column Derivatization, and Fluorescence Detection. Cincinnati, OH. USA: Environmental Monitoring Systems Laboratory, Office of 
Research and Development. Retrieved on 08/04/2013 from http://water.epa.gov/scitech/methods/cwa/bioindicators/upload/2007_11_06_methods_me thod_547.pdf.

USEPA. (1996a). Method 3050B: Acid digestion of sediments, sludges and soils.

Washington, DC., USA: Retrieved on 09/06/2013 from:

http://www.epa.gov/osw/hazard/testmethods/sw846/pdfs/3050b.pdf.

USEPA. (1996b). Method 3510C. Separatory Funnel Liquid-Liquid Extraction.

Washington, D.C., USA.: Retrieved on 07/06/2013 from:

http://www.epa.gov/osw/hazard/testmethods/sw846/pdfs/3510c.pdf.

USEPA. (1996c). Method 3630C. Silica Gel Cleaunp Online Test Methods for Evaluating Solid Waste, Physical/Chemical Methods (SW-846) (Revision 3). Washington, D.C.

USA. Retrieved on 04/12/2013 from:

http://www.epa.gov/osw/hazard/testmethods/sw846/pdfs/3630c.pdf

USEPA. (1999a). Method IO-3.1: Selection, preparation and extraction of filter material. Cincinnati, OH, USA: Retrieved on 09/07/2013 from:

http://www.epa.gov/ttnamti1/files/ambient/inorganic/mthd-3-1.pdf.

USEPA. (1999b). Method IO-3.5: Determination of metals in ambient particulate matter using inductively coupled plasma mass spectrometry (ICP/MS). Cincinnati, OH, USA.

Retrieved on 09/07/2013 from:

http://www.epa.gov/ttnamti1/files/ambient/inorganic/mthd-3-5.pdf.

USEPA. (2007a). Method 200.8: Determination of trace elements in waters and wastes by Inductively Coupled Plasma - Mass Spectrometry. Cincinnati, OH, USA. Retrieved on 09/07/2013 from:

http://water.epa.gov/scitech/methods/cwa/bioindicators/upload/2007_07_10_methods_me thod_200_8.pdf.

USEPA. (2007b). Method 6020A: Inductively Coupled Plasma Mass Spectrometry. Washington, DC. USA. Retrieved on 09/06/2013 from: http://www.epa.gov/osw/hazard/testmethods/sw846/pdfs/6020a.pdf.

USEPA. (2009). Integrated Science Assessment for Particulate Matter (Final Report). EPA/600/R-08/139F. Washington, DC. USA: U.S. Environmental Protection Agency. Retrieved on $\quad 09 / 14 / 2013$ from: http://cfpub.epa.gov/ncea/cfm/recordisplay.cfm?deid=216546.

USEPA. (2010a). Retrieved on 10/22/2010 from: http://www.epa.gov/bpspill/dispersantmethods.html

USEPA. (2010b). Retrieved on 02/05/2013 from: http://www.epa.gov/bpspill/dispersants-qanda.html\#general 
USEPA. (2010c). National Contingency Plan Product Schedule. Retrieved on 10/12/2010 from: http://www.epa.gov/emergencies/content/ncp/product_schedule.htm

USEPA. (2010d). U.S. Code of Federal Regulations, Title 40. Part 136, Appendix A: Methods for Organic Chemical Analysis of Municipal and Industrial Wastewater. Method 610 - Polynuclear Aromatic Hydrocarbons. Washington, D.C. USA.: Office of the Federal Register.

USEPA. (2010e). U.S. Code of Federal Regulations, Title 40. Part 136, Appendix B: Definition and procedures for the determination of the method detection limit-Revision 1.11. Washington, DC. USA.: Office of the Federal Register.

USEPA. (2011). Toxicological Review of Dichloromethane (Methylene Chloride). EPA/635/R-10/003F. Retrieved on 06/22/13 from http://www.epa.gov/iris/toxreviews/0070tr.pdf. Washington, D.C. USA.

USEPA. (2012). National Ambient Air Quality Standards (NAAQS). Retrieved on 09/14/2013 from: http://www.epa.gov/air/criteria.html.

USEPA. (2013a). 2008 National Emissions Inventory Data \& Documentation. Washington. DC. USA. Retrieved on 09/18/2013 from: http://www.epa.gov/ttn/chief/net/2008inventory.html.

USEPA. (2013b). EPA Unmix 6.0 Model. Retrieved on 09/18/2013 from: http://www.epa.gov/heasd/research/unmix.html.

Viana, M., Pandolfi, M., Minguillón, M. C., Querol, X., Alastuey, A., Monfort, E., \& Celades, I. (2008). Inter-comparison of receptor models for PM source apportionment: Case study in an industrial area. Atmospheric Environment, 42(16), 3820-3832. doi: http://dx.doi.org/10.1016/j.atmosenv.2007.12.056

Vogelsang, C., Grung, M., Jantsch, T. G., Tollefsen, K. E., \& Liltved, H. (2006). Occurrence and removal of selected organic micropollutants at mechanical, chemical and advanced wastewater treatment plants in Norway. Water Research, 40(19), 3559-3570. doi: 10.1016/j.watres.2006.07.022

Vreeken, R. J., Speksnijder, P., Bobeldijk-Pastorova, I., \& Noij, T. H. M. (1998). Selective analysis of the herbicides glyphosate and aminomethylphosphonic acid in water by on-line solid-phase extraction high-performance liquid chromatography electrospray ionization mass spectrometry. Journal of Chromatography A, 794(1-2), 187-199. doi: 10.1016/s0021-9673(97)01129-1

Wang, C. T., \& Gardinali, P. R. (2012). Comparison of multiple API techniques for the simultaneous detection of microconstituents in water by on-line SPE-LC-MS/MS. Journal of Mass Spectrometry, 47(10), 1255-1268. doi: 10.1002/jms.3051 
Wang, Z. D., Fingas, M., \& Page, D. S. (1999). Oil spill identification. Journal of Chromatography A, 843(1-2), 369-411. doi: 10.1016/s0021-9673(99)00120-x

Wang, Z. D., Stout, S. A., \& Fingas, M. (2006). Forensic fingerprinting of biomarkers for oil spill characterization and source identification. Environmental Forensics, 7(2), 105146. doi: $10.1080 / 15275920600667104$

Watson, J. G., Zhu, T., Chow, J. C., Engelbrecht, J., Fujita, E. M., \& Wilson, W. E. (2002). Receptor modeling application framework for particle source apportionment. Chemosphere, 49(9), 1093-1136. doi: 10.1016/s0045-6535(02)00243-6

Watts, A. W., Ballestero, T. P., Roseen, R. M., \& Houle, J. P. (2010). Polycyclic Aromatic Hydrocarbons in Stormwater Runoff from Sealcoated Pavements. Environmental Science \& Technology, 44(23), 8849-8854. doi: 10.1021/es102059r

Wedepohl, K. H. (1995). The Composition of the Continental Crust. Geochimica Et Cosmochimica Acta, 59(7), 1217-1232.

Wells, D. E. (1998). Development of reference and test materials for organic contaminants in water. Analyst, 123(5), 983-989. doi: 10.1039/a705043g

WHO. (1994). Environmental Health Criteria 159. Geneva, Swittzerland: World Health Organization. Retrieved on 08/07/2013 from: http://www.inchem.org/documents/ehc/ehc/ehc159.htm\#SectionNumber:4.1.

Wolska, L., Mechlinska, A., Rogowska, J., \& Namiesnik, J. (2012). Sources and Fate of PAHs and PCBs in the Marine Environment. Critical Reviews in Environmental Science and Technology, 42(11), 1172-1189. doi: 10.1080/10643389.2011.556546

Xia, L. L., \& Gao, Y. (2010). Chemical composition and size distributions of coastal aerosols observed on the US East Coast. Marine Chemistry, 119(1-4), 77-90. doi: 10.1016/j.marchem.2010.01.002

You, J., \& Koropchak, J. A. (2003). Condensation nucleation light scattering detection with ion chromatography for direct determination of glyphosate and its metabolite in water. Journal of Chromatography A, 989(2), 231-238. doi: 10.1016/s00219673(03)00084-0 


\section{APPENDICES}

\section{Appendix 1 Determination of the recovery of surrogates used to correct for the} liquid-liquid extraction step to quantify DOSS and 2-butoxyethanol in crude oil

The following equation is used to calculate the relative response factors (RRF) of the surrogates relative to the internal standard in each calibration solution:

$$
R R F_{S U}=\frac{\left(A_{S U}\right) *\left(C_{I S}\right)}{\left(C_{S U}\right) *\left(A_{I S}\right)}
$$

Where:

$\mathrm{A}_{\mathrm{SU}}=$ Peak area of the surrogate (isotopically labeled analytes).

$\mathrm{A}_{\mathrm{IS}}=$ Peak area of the internal standard $\left(\mathrm{SDS}-\mathrm{D}_{25}\right)$.

$\mathrm{C}_{\mathrm{SU}}=$ Concentration of the surrogate in the calibration solution.

$\mathrm{C}_{\mathrm{IS}}=$ Concentration of the internal standard in the calibration solution.

The following equation is used to calculate the average relative response factor of the surrogate from all the calibration runs $(n=$ number of calibration runs):

$$
\overline{R R F}_{S U}=\frac{\sum_{1}^{n} R R F_{n}}{n}
$$


Finally, the following equation is used to calculate the percent recovery for the surrogate relative to the internal standard in each sample.

$$
\% R_{S U}=\frac{\left(A_{S U}\right) *\left(C_{I S}\right)}{\left(A_{I S}\right) *\left(\frac{C_{S U}}{D F}\right)\left(\overline{R R F_{S U}}\right)} * 100
$$

Where:

$\mathrm{A}_{\mathrm{IS}}=$ Peak area of the internal standard.

$\mathrm{A}_{\mathrm{SU}}=\quad$ Peak area of the surrogate.

$\mathrm{C}_{\mathrm{IS}}=$ Concentration of the internal standard in the injected solution.

$\mathrm{C}_{\mathrm{SU}}=$ Concentration of the surrogate in the sample extract.

$\mathrm{DF}=$ Dilution factor applied to the sample extract for analysis 
Appendix 2 Autosampler settings and injection program for the determination of PAHs by online SPE-LC/MS/MS

\section{Autosampler settings}

Syringe size:

$5000 \mu \mathrm{L}$

Air volume:

0

Pre-clean with solvents: $\quad 0$

Pre-clean with sample: $\quad 0$

Filling speed:

$100 \mu \mathrm{L} / \mathrm{s}$

Filling strokes:

0

Injection speed:

$100 \mu \mathrm{L} / \mathrm{s}$

Pre-inject delay:

$500 \mathrm{~ms}$

Post-injection delay:

$500 \mathrm{~ms}$

Rinsing solvent 1:

Deionized water

Rinsing solvent 2:

Methanol

Post-clean with solvent 1:

1

Post-clean with solvent 2: $\quad 1$

Valve clean solvent 1:

Valve clean solvent 2: 1

Number of Injections: $\quad 2$

Number of Injections 2: $\quad 0$

Look ahead delay time: $\quad 5 \mathrm{~min}$ 


\section{Macro program: "MH_MultiSampling_LookAhead_PAH_CR_v2.1"}

List of commands in macro:

Commands: 26

MOVETO_OBJECT(Home,,,)

LOCK_TERMINAL(On,)

SWITCH_INJ(Inject to,Active,,)

CLEAN_INJ(Wash2,Inject to,ValveCleanSolvent2,,,,,,,,,)

CLEAN_INJ(Wash1,Inject to,ValveCleanSolvent1,,,,,,,,)

REPEAT(NumberOfInjections,)

GET_SAMPLE(SL.tray,SL.index,SL.volume,,,,PullUpSpeed,,Filling Strokes,Off,,,)

PUT_SAMPLE(Inject to,1,,SL.volume,PushOutSpeed,,)

$\operatorname{END}()$

INC_INDEX()

REPEAT(Number of Injections 2,)

GET_SAMPLE(SL.tray,SL.index,SL.volume,,,,PullUpSpeed,,Filling Strokes,Off,,,)

PUT_SAMPLE(Inject to,1,,SL.volume,PushOutSpeed,,)

END()

WAIT_FOR_DS()

SWITCH_INJ(Inject to,Standby,,)

SET_OUT_SIG(Injected,On,1000,)

SET_OUT_SIG(Injected,Off,,)

SET_OUT_SIG(Injected,On,1000,)

SET_OUT_SIG(Injected,Off,,)

SWITCH_EVENT(SW-Out1,On,1,)

SWITCH_EVENT(SW-Out1,Off,,)

CLEAN_SYR(Wash1,PostCleanSolvent1,,,,,,) 
CLEAN_SYR(Wash2,PostCleanSolvent2,,,,,,)

LOCK_TERMINAL(Off,)

CLEANUP(Wash1,Off,Off,Off,Off,Off,Off,Off,)

The aforementioned list of commands in combination with the autosampler settings will order the Thermo HTC PAL autosampler to perform the following sequential actions:

- $\quad$ Switch injection port to "LOAD" position

- $\quad$ Inject $5 \mathrm{ml}$ methanol through injection port and into sample loop

- $\quad$ Inject $5 \mathrm{ml}$ deionized water through injection port and into sample loop

- $\quad$ Aspirate and inject $5 \mathrm{~mL}$ sample

- $\quad$ Repeat (reads from "Number of injections" at Settings)

- $\quad$ Switch injection port to "INJECT" position

- $\quad$ Send a $1000 \mathrm{~ms}$ start signal (used to wake up dopant delivery pumps)

- $\quad$ Send a second $1000 \mathrm{~ms}$ start signal (used to start dopant delivery program)

- $\quad$ Send start event to LC pumps and mass spectrometer

- $\quad$ Cleans syringe with $5 \mathrm{~mL}$ deionized water to remove salts

- $\quad$ Cleans syringe with methanol to remove organics 
Appendix 3 Correlation coefficients matrix between concentrations of elements ${ }^{\mathrm{a}}$ measured in airborne particulate matter collected at Port Everglades, FL. $\left(n=42, R^{2}>0.6\right.$ highlighted $)$.

\begin{tabular}{|c|c|c|c|c|c|c|c|c|c|c|c|c|c|c|c|c|c|c|c|c|c|c|c|c|}
\hline & Al & $\mathbf{V}$ & $\mathrm{Cr}$ & $\mathbf{F e}$ & $\mathbf{N i}$ & $\mathbf{C u}$ & $\mathrm{Zn}$ & $\mathrm{Sr}$ & $\mathbf{L i}$ & $\mathbf{B e}$ & Mn & Co & $\mathbf{G a}$ & As & Se & $\mathbf{R b}$ & $\mathbf{C d}$ & Cs & Ba & $\mathbf{P b}$ & $\mathbf{U}$ & Sc & $Y$ & Th \\
\hline Al & 1 & -0.1 & 0.0 & 0.9 & 0.0 & 0.0 & 0.0 & 0.2 & 0.6 & 0.8 & 0.9 & 0.9 & 0.5 & 0.5 & -0.1 & 0.7 & -0.1 & 0.8 & 0.4 & 0.0 & 0.5 & 0.7 & 0.9 & 1.0 \\
\hline $\mathbf{V}$ & -0.1 & 1 & 0.2 & 0.1 & 0.6 & 0.3 & 0.4 & 0.5 & -0.2 & -0.2 & 0.0 & 0.1 & 0.4 & -0.1 & 0.2 & -0.3 & 0.4 & -0.2 & 0.5 & 0.7 & 0.5 & -0.3 & 0.0 & -0.1 \\
\hline $\mathrm{Cr}$ & 0.0 & 0.2 & 1 & 0.1 & 0.7 & 0.4 & 0.1 & 0.0 & 0.0 & -0.1 & 0.1 & 0.2 & 0.0 & 0.0 & 0.0 & -0.1 & 0.0 & -0.1 & 0.0 & 0.2 & 0.2 & -0.2 & -0.1 & 0.0 \\
\hline $\mathrm{Fe}$ & 0.9 & 0.1 & 0.1 & 1 & 0.2 & 0.0 & 0.0 & 0.3 & 0.5 & 0.7 & 0.9 & 0.9 & 0.6 & 0.4 & 0.0 & 0.7 & 0.0 & 0.7 & 0.6 & 0.2 & 0.6 & 0.6 & 0.9 & 0.9 \\
\hline $\mathbf{N i}$ & 0.0 & 0.6 & 0.7 & 0.2 & 1 & 0.0 & 0.2 & 0.2 & -0.3 & -0.2 & 0.0 & 0.3 & 0.3 & -0.2 & -0.1 & -0.2 & 0.1 & -0.2 & 0.4 & 0.5 & 0.4 & -0.3 & -0.1 & -0.1 \\
\hline $\mathbf{C u}$ & 0.0 & 0.3 & 0.4 & 0.0 & 0.0 & 1 & 0.4 & 0.5 & 0.3 & -0.1 & 0.2 & 0.1 & 0.1 & 0.5 & 0.4 & 0.0 & 0.6 & 0.0 & 0.2 & 0.4 & 0.2 & -0.2 & -0.1 & 0.1 \\
\hline$Z_{n}$ & 0.0 & 0.4 & 0.1 & 0.0 & 0.2 & 0.4 & 1 & 0.3 & 0.0 & -0.3 & 0.1 & 0.1 & 0.2 & 0.1 & 0.1 & -0.1 & 0.4 & -0.1 & 0.3 & 0.5 & 0.0 & -0.3 & 0.0 & 0.1 \\
\hline $\mathrm{Sr}$ & 0.2 & 0.5 & 0.0 & 0.3 & 0.2 & 0.5 & 0.3 & 1 & 0.3 & 0.1 & 0.4 & 0.3 & 0.5 & 0.5 & 0.3 & 0.2 & 0.3 & 0.2 & 0.6 & 0.6 & 0.7 & -0.1 & 0.3 & 0.3 \\
\hline $\mathbf{L i}$ & 0.6 & -0.2 & 0.0 & 0.5 & -0.3 & 0.3 & 0.0 & 0.3 & 1 & 0.6 & 0.7 & 0.6 & 0.1 & 0.6 & 0.2 & 0.6 & -0.1 & 0.7 & 0.1 & 0.1 & 0.4 & 0.6 & 0.6 & 0.7 \\
\hline Be & 0.8 & -0.2 & -0.1 & 0.7 & -0.2 & -0.1 & -0.3 & 0.1 & 0.6 & 1 & 0.8 & 0.7 & 0.3 & 0.5 & -0.1 & 0.8 & -0.2 & 0.9 & 0.2 & -0.1 & 0.4 & 0.9 & 0.8 & 0.8 \\
\hline Mn & 0.9 & 0.0 & 0.1 & 0.9 & 0.0 & 0.2 & 0.1 & 0.4 & 0.7 & 0.8 & 1 & 0.9 & 0.5 & 0.6 & 0.0 & 0.8 & 0.0 & 0.8 & 0.5 & 0.3 & 0.6 & 0.6 & 0.9 & 1.0 \\
\hline Co & 0.9 & 0.1 & 0.2 & 0.9 & 0.3 & 0.1 & 0.1 & 0.3 & 0.6 & 0.7 & 0.9 & 1 & 0.5 & 0.5 & -0.1 & 0.6 & -0.1 & 0.7 & 0.5 & 0.3 & 0.6 & 0.6 & 0.8 & 0.9 \\
\hline $\mathbf{G a}$ & 0.5 & 0.4 & 0.0 & 0.6 & 0.3 & 0.1 & 0.2 & 0.5 & 0.1 & 0.3 & 0.5 & 0.5 & 1 & 0.0 & 0.2 & 0.2 & 0.5 & 0.3 & 0.9 & 0.5 & 0.6 & 0.2 & 0.5 & 0.4 \\
\hline As & 0.5 & -0.1 & 0.0 & 0.4 & -0.2 & 0.5 & 0.1 & 0.5 & 0.6 & 0.5 & 0.6 & 0.5 & 0.0 & 1 & 0.3 & 0.5 & 0.0 & 0.5 & 0.1 & 0.2 & 0.4 & 0.3 & 0.5 & 0.6 \\
\hline Se & -0.1 & 0.2 & 0.0 & 0.0 & -0.1 & 0.4 & 0.1 & 0.3 & 0.2 & -0.1 & 0.0 & -0.1 & 0.2 & 0.3 & 1 & -0.1 & 0.4 & -0.1 & 0.2 & 0.2 & 0.0 & -0.1 & -0.1 & 0.0 \\
\hline $\mathbf{R b}$ & 0.7 & -0.3 & -0.1 & 0.7 & -0.2 & 0.0 & -0.1 & 0.2 & 0.6 & 0.8 & 0.8 & 0.6 & 0.2 & 0.5 & -0.1 & 1 & -0.3 & 0.9 & 0.1 & 0.0 & 0.4 & 0.7 & 0.7 & 0.8 \\
\hline Cd & -0.1 & 0.4 & 0.0 & 0.0 & 0.1 & 0.6 & 0.4 & 0.3 & -0.1 & -0.2 & 0.0 & -0.1 & 0.5 & 0.0 & 0.4 & -0.3 & 1 & -0.2 & 0.4 & 0.4 & 0.0 & -0.3 & -0.1 & -0.1 \\
\hline Cs & 0.8 & -0.2 & -0.1 & 0.7 & -0.2 & 0.0 & -0.1 & 0.2 & 0.7 & 0.9 & 0.8 & 0.7 & 0.3 & 0.5 & -0.1 & 0.9 & -0.2 & 1 & 0.2 & 0.1 & 0.5 & 0.7 & 0.8 & 0.8 \\
\hline $\mathbf{B a}$ & 0.4 & 0.5 & 0.0 & 0.6 & 0.4 & 0.2 & 0.3 & 0.6 & 0.1 & 0.2 & 0.5 & 0.5 & 0.9 & 0.1 & 0.2 & 0.1 & 0.4 & 0.2 & 1 & 0.7 & 0.6 & 0.1 & 0.5 & 0.4 \\
\hline $\mathbf{P b}$ & 0.0 & 0.7 & 0.2 & 0.2 & 0.5 & 0.4 & 0.5 & 0.6 & 0.1 & -0.1 & 0.3 & 0.3 & 0.5 & 0.2 & 0.2 & 0.0 & 0.4 & 0.1 & 0.7 & 1 & 0.7 & -0.2 & 0.1 & 0.1 \\
\hline $\mathbf{U}$ & 0.5 & 0.5 & 0.2 & 0.6 & 0.4 & 0.2 & 0.0 & 0.7 & 0.4 & 0.4 & 0.6 & 0.6 & 0.6 & 0.4 & 0.0 & 0.4 & 0.0 & 0.5 & 0.6 & 0.7 & 1 & 0.3 & 0.6 & 0.5 \\
\hline Sc & 0.7 & -0.3 & -0.2 & 0.6 & -0.3 & -0.2 & -0.3 & $\begin{array}{l}0.1 \\
-0.1\end{array}$ & 0.6 & 0.9 & 0.6 & 0.6 & 0.2 & 0.3 & -0.1 & 0.7 & -0.3 & 0.7 & 0.1 & -0.2 & 0.3 & 1 & 0.7 & 0.7 \\
\hline$Y$ & 0.9 & 0.0 & -0.1 & 0.9 & -0.1 & -0.1 & 0.0 & 0.3 & 0.6 & 0.8 & 0.9 & 0.8 & 0.5 & 0.5 & -0.1 & 0.7 & -0.1 & 0.8 & 0.5 & 0.1 & 0.6 & 0.7 & 1 & 1.0 \\
\hline Th & 1.0 & -0.1 & 0.0 & 0.9 & -0.1 & 0.1 & 0.1 & 0.3 & 0.7 & 0.8 & 1.0 & 0.9 & 0.4 & 0.6 & 0.0 & 0.8 & -0.1 & 0.8 & 0.4 & 0.1 & 0.5 & 0.7 & 1.0 & 1 \\
\hline
\end{tabular}


VITA

CESAR E. RAMIREZ

2006 B.Sc. in Chemistry.

Universidad Simón Bolívar.

Caracas, Venezuela.

PROFESSIONAL EXPERIENCE

2010-2013 Research Assistant.

Florida International University.

Miami, Florida.

2007-2010 Teaching Assistant.

Florida International University.

Miami, Florida.

2006-2007 Chemical Analyst.

Universidad Simón Bolívar.

Caracas, Venezuela.

FELLOWSHIPS

2009-2010 Cristina Menendez Fellowship.

Southeast Environmental Research Center.

Miami, Florida.

PUBLICATIONS

HIGH SENSITIVITY LIQUID CHROMATOGRAPHY TANDEM MASS SPECTROMETRIC METHODS FOR THE ANALYSIS OF DIOCTYL SULFOSUCCINATE IN DIFFERENT STAGES OF AN OIL SPILL RESPONSE MONITORING EFFORT. Cesar E. Ramirez, Sudha Rani Batchu, Piero R. Gardinali. Analytical and Bioanalytical Chemistry, 2013, 405:4167-4175.

FULLY AUTOMATED TRACE LEVEL DETERMINATION OF PARENT AND ALKYLATED PAHS IN ENVIRONMENTAL WATERS BY ONLINE SPE-LC-APPIMS/MS. Cesar E. Ramirez, Chengtao Wang, Piero R. Gardinali. Analytical and Bioanalytical Chemistry, 2013. (In press). 


\section{CONFERENCES (Oral Presentations)}

NOVEL METHOD FOR THE DETERMINATION OF GLYPHOSATE AND AMINOMETHYLPHOSPHONIC ACID (AMPA) IN ENVIRONMENTAL WATERS. Cesar E. Ramirez and Piero R. Gardinali. SETAC North America 30th Annual Meeting. New Orleans, LA. November 30th, 2009

FAST, ULTRA-TRACE LEVEL ANALYSIS OF AN OIL DISPERSANT IN SEAWATER USING THE THERMO EQUAN SYSTEM. Cesar E. Ramirez and Piero R. Gardinali. Thermo Scientific Productivity Series 2012. Ft. Lauderdale, Fl. March 27, 2012

FULLY AUTOMATED, TRACE LEVEL DETECTION OF PAHS IN SALTWATER BU ONLINE-PRECONCENTRATION LIQUID CHROMATOGRAPHY TANDEM MASS SPECTROMETRY (LC-MSMS): THE QUEST TO ELIMINATE SAMPLE PREPARATION. Cesar E. Ramirez, Chengtao Wang and Piero R. Gardinali. SETAC North America 33rd Annual Meeting in Long Beach, California. November 15th, 2012.

CONFERENCES (Posters)

TRACE-LEVEL DETERMINATION OF GLYPHOSATE AND AMINOMETHYLPHOSPHONIC ACID (AMPA) IN AQUEOUS SAMPLES WITH MINIMUM PRETREATMENT, FOLLOWED BY LIQUID CHROMATOGRAPHY WITH SIMULTANEOUS FLUORESCENCE AND MASS SPECTROMETRY DETECTION. Cesar E. Ramirez and Piero R. Gardinali. 238th ACS National Meeting. Washington, D.C. August, 16-20 2009.

SIMULTANEOUS DETERMINATION OF COREXIT EC9500A \& EC9527A COMPONENTS IN SEAWATER AND CRUDE OIL BY LIQUID CHROMATOGRAPHY/TANDEM MASS SPECTROMETRY. Cesar E. Ramirez, Sudha Rani Batchu and Piero R. Gardinali. 59th American Society for Mass Spectrometry. Conference on Mass Spectrometry and Allied Topics. Denver, CO. June 05-09, 2011

DETECTION OF PARENT AND ALKYLATED POLYCYCLIC AROMATIC HYDROCARBONS IN OPEN OCEAN SURFACE WATERS BY ONLINE - SPE UPLC-APPI/MSMS. Cesar E. Ramirez and Piero R. Gardinali. 7th Annual LC/MS/MS International Workshop on Environmental Applications and Food Safety. Buffalo, NY. June 13-14, 2011

ELEMENTAL COMPOSITION OF AIRBORNE PARTICULATE MATTER COLLECTED AT PORT EVERGLADES IN SOUTH FLORIDA. Cesar E. Ramirez, Luisa Rojas de Astudillo, Luis E. Arroyo-Mora, Douglas Seba and Piero R. Gardinali. First International Workshop on the Long-Range Transport and Impacts of African Dust on the Americas. San Juan, Puerto Rico. October 6-7, 2011 